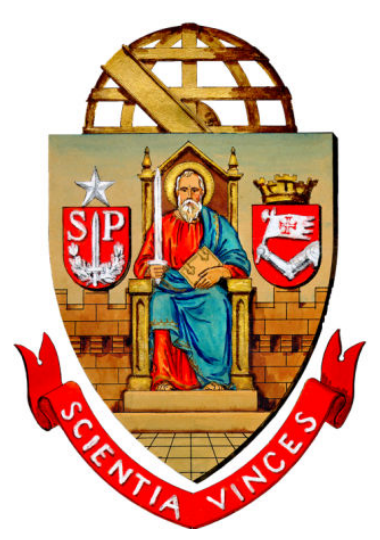

UNIVERSIDADE DE SÃO PAULO

FACULDADE DE ODONTOLOGIA DE RIBEIRÃO PRETO

PROGRAMA DE PÓS-GRADUAÇÃO EM REABILITAÇÃO ORAL

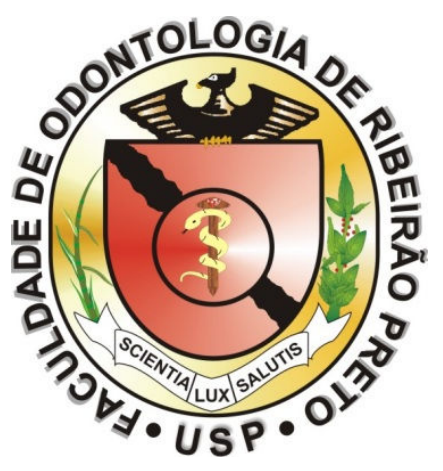

CONRADO INGRACI DE LUCIA

ANÁLISE QUANTITATIVA DOS NÍVEIS DE CÁLCIO, COLAGENASE A E B DURANTE O REPARO ÓSSEO EM CALVÁRIAS DE RATOS SOB MODELO EXPERIMENTAL DE DEFEITO ÓSSEO

Ribeirão Preto 
Conrado Ingraci De Lucia

\section{ANÁLISE QUANTITATIVA DOS NIIVEIS DE CÁLCIO, COLAGENASE A E B DURANTE O REPARO ÓSSEO EM CALVÁRIAS DE RATOS SOB MODELO EXPERIMENTAL DE DEFEITO ÓSSEO}

Dissertação apresentada como requisito parcial para obtenção do grau de Mestre em Odontologia, no Curso de Pós-Graduação em Reabilitação Oral em Odontologia, Área de Concentração: Biologia Oral, Universidade de São Paulo.

Orientador: João Paulo Mardegan Issa

VERSÃO ORIGINAL

Ribeirão Preto 
AUTORIZO A REPRODUÇÃO E DIVULGAÇÃO DO TEOR TOTAL OU PARCIAL DESTE

TRABALHO POR QUALQUER MEIO CONVENCIONAL OU ELETRÔNICO, PARA FINS DE ESTUDO E PESQUISA, DESDE QUE CITADA A FONTE.

Ficha catalográfica elaborada pela Biblioteca Central do Campus USP - Ribeirão Preto

Conrado Ingraci de Lucia

Análise quantitativas dos níveis de cálcio, Colagenase $A$ e $B$ durante o reparo ósseo em calvárias de ratos sob o modelo experimental de defeito ósseo. Ribeirão Preto, 2013.

158 p. : il. ; $30 \mathrm{~cm}$.

Versão Original da Dissertação de Mestrado, apresentada à Faculdade de Odontologia de Ribeirão Preto/USP. Área de concentração: Biologia Oral.

1. Tecido ósseo. 2. Defeito ósseo. 3. rhBMP-2. 4. MMP-2. 5. MMP-9 
FOLHA DE APROVAÇÃO

Conrado Ingraci De Lucia

Dissertação apresentada como requisito parcial para obtenção do grau de Mestre em Odontologia, no Curso de Pós-Graduação em Reabilitação Oral em Odontologia, Área de Concentração: Biologia Oral, Universidade de São Paulo.

Aprovado em:

1

Banca Examinadora:

1) Prof.(a). Dr.(a).:

Instituição:

Julgamento: Assinatura:

2) Prof.(a). Dr.(a).:

Instituição:

Julgamento:

Assinatura:

3) Prof.(a). Dr.(a).:

Instituição:

Julgamento:

Assinatura: 
Dedico esse trabalho à minha família que me amparou em todos os momentos dessa incrível jornada e à minha amada noiva Juliana por todo apoio e incentivo enchendo de alegria os meus dias. 


\section{AGRADECIMENTOS}

Ao meu orientador, Prof. Dr. João Paulo Mardegan Issa, pelo apoio, orientação e principalmente pela amizade e incentivo.

À minha orientadora, Profa. Dra . Raquel Fernanda Gerlach, que ensinou muito nos vários anos que a acompanhei e me deu todo o apoio para a realização desse projeto.

Ao meu grande amigo Fellipe, que esteve comigo desde a época de faculdade e elaborou vários projetos em parceria, muito obrigado.

Aos meus colegas de laboratório que hoje são todos grandes amigos, muitíssimo obrigado por tudo que vocês fizeram por mim, principalmente nos momentos mais difíceis.

Ao curso de pós-graduação e meus professores, sem eles hoje eu nada seria. Muito obrigado.

Agradeço também à FAPESP n. 2011/01512-0 (auxilio regular), que providenciou os recursos necessários para a realização do projeto. 


\section{RESUMO}

O osso é um tipo especializado de tecido com alto teor mineral e desempenha variadas funções no organismo, como a reserva de cálcio, proteção de estruturas vitais e alavanca para a movimentação dos músculos. Constantemente o osso passa por processos de remodelação, o que mantém sua estrutura funcional e repara pequenas fraturas que ocorrem normalmente devido ao estresse do uso contínuo. O sistema de reparo funciona em perfeita sincronia mediante células que produzem os componentes ósseos e células que os reabsorvem permitindo a organização do tecido. Esse sistema de manutenção depende da interação entre estas células bem como dos sinais enviados por mediadores e moduladores. Várias proteínas funcionam como indutores de formação óssea, mas também no sentido de facilitar essa reconstrução. Dentre estas proteínas se encontram as BMPs, que possuem grande potencial osteoindutor, e MMPs, que atuam em diversas fases da construção e manutenção deste tecido. Particularmente a BMP-2 tem mostrado um potencial significativo em termos de indução e sua forma recombinante a rhBMP-2, produzida por engenharia recombinante, foi liberada para comercialização e utilização clínica. Quanto às MMPs, há importante função das MMP-2 e MMP-9 neste tecido. A primeira estruturando a matriz e modulando o processo de reabsorção nos processos inflamatórios inerentes ao reparo; a segunda atuando desde fases iniciais às tardias, produzida principalmente por osteoclastos e utilizada na remodelação do osso novo. Porém, esta capacidade de reparo do osso é limitada e defeitos ósseos de grande extensão exigem muito do organismo, podendo levar a um reparo que não se estrutura devidamente. Assim, várias técnicas foram propostas para estimular o desenvolvimento ósseo e a utilização de enxertos se mostrou eficaz para fornecer um arcabouço de crescimento, facilitando a implantação do osso neofomado e protegendo o leito do defeito durante todo o extenso período de recuperação. O presente estudo enfocou três diferentes tipos de enxerto ósseo (autólogo, homólogo e heterólogo) e suas associações com a proteína rhBMP-2, verificando sob o aspecto bioquímico a relação de cada um com a quantidade de MMP-2 e MMP-9 em dois tempos de reparo diferentes. De maneira geral, verificou-se que no primeiro momento há maior produção de MMP-2 e os níveis de MMP-9 se mantém de forma relativamente constante nos dois tempos cirúrgicos. O enxerto autólogo apresenta melhores resultados, seguido dos obtidos no enxerto homólogo e heterólogo respectivamente, entretanto a adição de rhBMP-2 a estes enxertos não parece influenciar nos níveis de MMP-2 e MMP-9 nos dois períodos. A dosagem de cálcio revelou que se apresentavam mais mineralizados os grupos de enxerto autólogo e homólogo, os demais grupos além de apresentar menores níveis de cálcio, ainda decresceram nestes níveis no segundo período do experimento.

Palavras-chave: tecido ósseo; enxerto ósseo; rhBMP-2; MMP-2; MMP-9; dosagem de cálcio 


\begin{abstract}
Bone is a special tissue with a high mineral content and performs various functions in the body, such as calcium reserves, protection of vital structures and muscles lever during the movement. Bone constantly undergoes remodeling processes, which keeps its functional structure and repair small fractures that commonly occur due to the stress of continuous use. The repair system works perfectly synchronized by the cells that produce bone components and resorbing cells, allowing the perfect tissue organization. This maintenance system depends on the interaction between these cells and the signals sent by mediators and modulators. Several proteins operate to induce bone formation, but also to facilitate the reconstruction. Among these proteins are the BMPs, which have great osteoinductive potential, and MMPs that act at different stages of construction and maintenance of this tissue. Particularly BMP-2 has shown significant potential in terms of induction and its recombinant form, rhBMP-2, produced by recombinant engineering, has been released for clinical use and commercialization. In relation to MMPs, there are important functions of MMP-2 and MMP-9 in this tissue. First, structuring the matrix and modulating the resorption during inflammatory processes inherent to repair; second, acting at early to later stages, produced mainly by osteoclasts and used during bone remodeling. However, this repair capacity is limited and large bone defects require a lot of strength of the body, may leading to a bone repair not well structured. Thus, several proposed techniques to stimulate the development and use of bone grafts were effective to provide a framework for growth, facilitating the implementation of new bone and protecting the defect bed throughout the extended recovery period. This study focused on three different types of bone graft (autologous, homologous and heterologous) and their association with rhBMP-2 protein, evaluating the biochemical aspects according to the amount of MMP-2 and MMP-9 in two different periods of time. In general, it was found that firstly, there is an increased production of MMP-2, and MMP-9 levels remain relatively constant in both considered periods of time. The autologous graft presented the best results followed by homologous and heterologous, respectively; however the addition of rhBMP-2 in these grafts did not seem to influence the MMP-2 and MMP-9 levels, in both periods of time. The calcium dosage revealed more mineralization at the autologous and homologous groups, the other groups, besides having lower calcium levels, decreased these levels at the second period of this experiment.
\end{abstract}

Keywords: bone, bone graft, rhBMP-2, MMP-2, MMP-9; calcium dosage 


\section{LISTA DE SIGLAS}

AGEs - produtos de glicação avançada

ANG - angiopoetina

BMP - proteína morfogenética do osso

BSA - soroalbumina bovina

CTx - telopeptídeo-C do colágeno tipo 1

FGF - fator de crescimento de fibroblasto

HGF - fator de crescimento de hepatócito

IGF - fator de crescimento semelhante à insulina

IL - interleucina

M-CSF - fator estimulante de colônia de fagócito mononuclear

MMP - metaloprotease de matriz

OPG - osteoprotegerina

PDGF - fator de crescimento derivado de plaqueta

PGE - prostaglandina

PTH - paratormônio

PTHR1 - receptor para paratormônio

PTH-rp - proteína relacionada ao paratormônio

RANKL - receptor ativador do ligante kappaB fator nuclear

rhBMP-2 - BMP recombinante humana 2

Runx2 - fator transcripcional relacionado a Runt2

TGF- $\beta$ - fator de crescimento transformador $\beta$

TIMP - inibidor tecidual de metaloprotease de matriz

TNF- $\alpha$ - fator de necrose tumoral $\alpha$

VEGF - fator de crescimento endotélio vascular 


\section{SUMÁRIO}

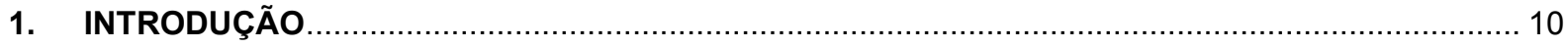

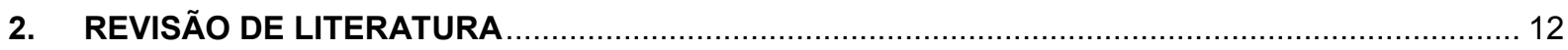

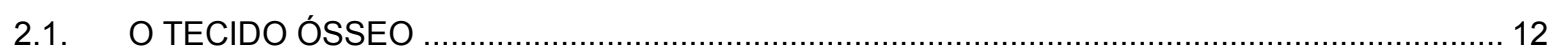

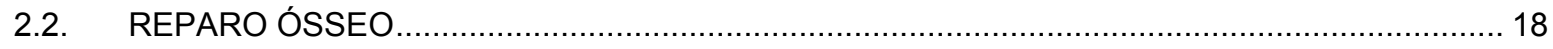

2.3. MMP …

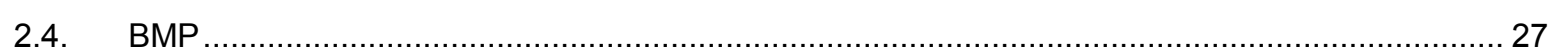

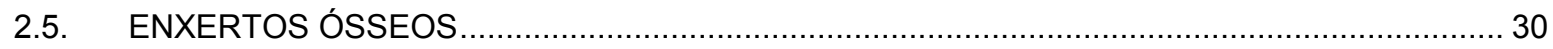

3. JUSTIFICATIVA

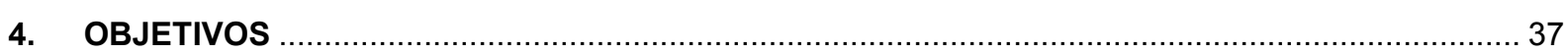

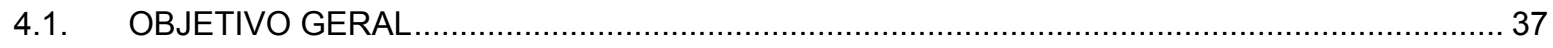

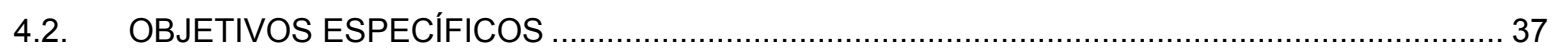

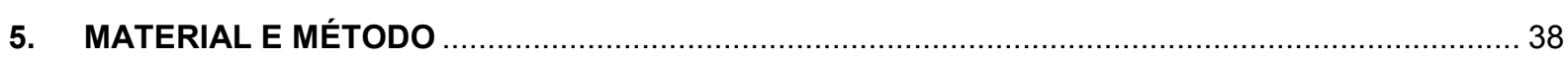

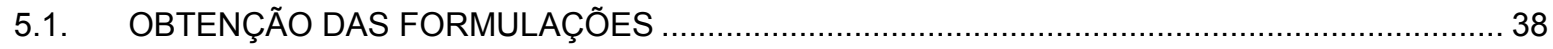

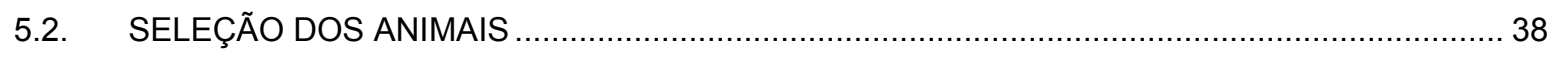

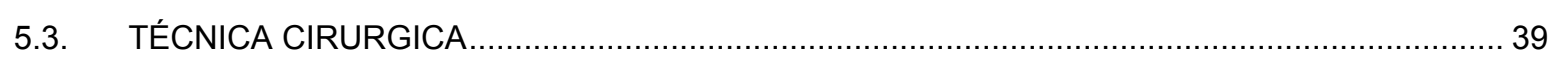

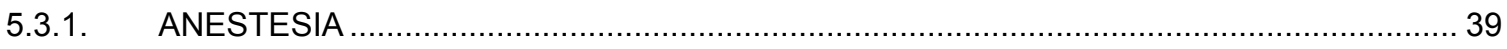

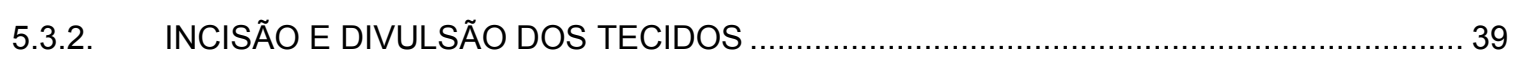

5.3.3. CRIAÇÃO DO DEFEITO ÓSSEO CIRÚRGICO E INSERÇÃO DOS MATERIAIS ............... 40

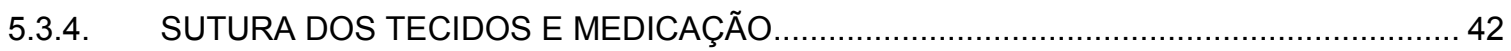

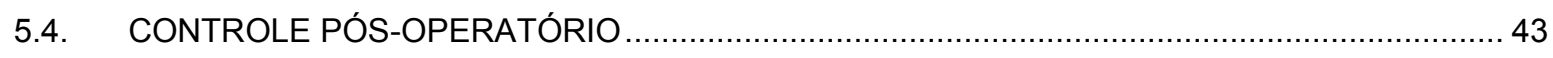

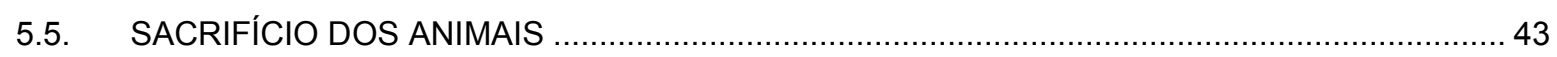

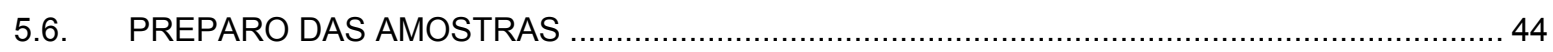

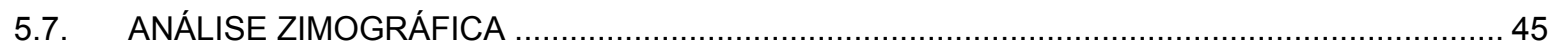

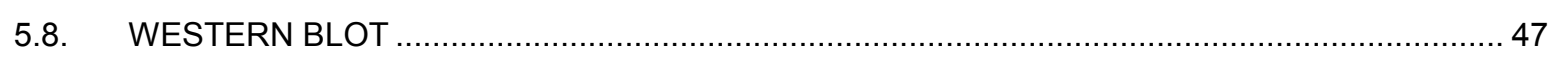

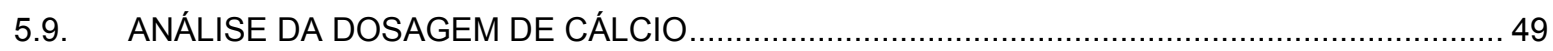

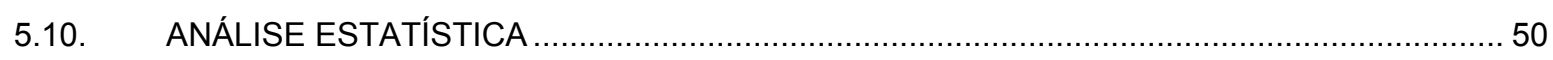

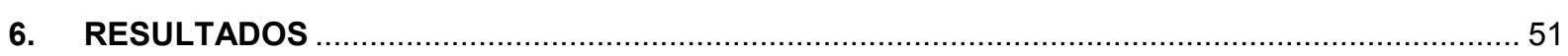

6.1. PESO DOS ANIMAIS - ANÁLISE COMPARATIVA DOS GRUPOS ……............................... 51

6.2. MMP-2 e proMMP-2 - ANÁLISE COMPARATIVA DOS GRUPOS ……...................................... 53

6.3. MMP-9 e proMMP-9 - ANÁLISE COMPARATIVA DOS GRUPOS …........................................ 59

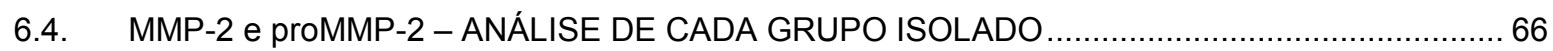

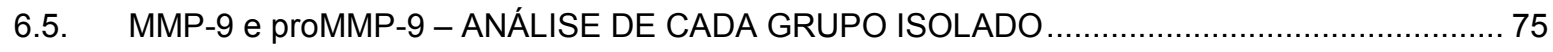

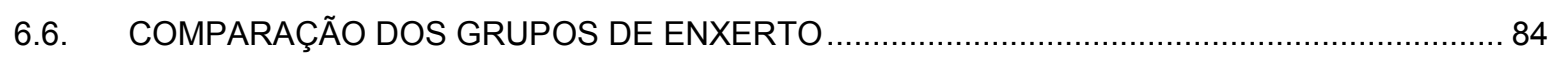

7. DISCUSSÃO

8. CONCLUSÃO

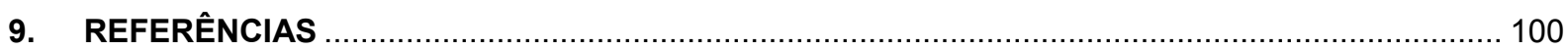




\section{INTRODUÇÃO}

O tecido ósseo é composto basicamente por três elementos de diferentes naturezas: matriz orgânica, minerais e células ósseas. A maior parte da matriz é composta de fibras colágenas. Os minerais ósseos são constituídos de fosfato de cálcio, sob a forma de cristais de hidroxiapatita, com halos hidratados, nos quais se encontram íons fosfato e cálcio em grande proporção e numerosos outros íons magnésio, sódio, potássio, bicarbonatos e citratos (ROBERTSON, 1976). A dureza do osso depende de seus constituintes inorgânicos; a resistência e a elasticidade dependem de sua matriz orgânica, com grande abundância de fibras colágenas. Além disso, todos os ossos são recobertos, tanto na superfície interna como externa, por camadas de tecido contendo células osteogênicas (osteoblastos, osteócitos e osteoclastos) (JUNQUEIRA \& CARNEIRO, 2008). Este tecido representa um órgão complexo de múltiplas funções. Ele fornece integridade estrutural ao corpo, é um local de hematopoiese e armazenamento de cálcio e fósforo (LORENZO ET AL., 2008).

A regeneração óssea é um processo fisiológico que ocorre durante o reparo normal de uma fratura e na remodelação contínua durante toda a vida do indivíduo. Entretanto em várias situações esta regeneração toma amplas proporções, como na reconstrução de grandes defeitos ósseos, decorrentes de traumas, infecções ou ressecções cirúrgicas. Atualmente há uma gama de alternativas para beneficiar este processo de regeneração, como a enxertia de tecidos ósseos de diferentes fontes ou mesmo biomateriais que simulam o tecido ósseo e/ou favorecem o processo reparatório, estimulando a multiplicação celular, sendo quimiotáxicos para células que atuam no reparo e ativando vias de proliferação vascular para a correta nutrição 
do tecido. As terapias de engenharia óssea, locais ou sistêmicas, têm sido amplamente estudadas visando debelar as limitações das técnicas atuais e produzir, cada vez mais, substitutos viáveis aos enxertos de osso natural, buscando baratear e facilitar a obtenção dos materiais e também fornecer opções que engrandeçam o reparo causando os menores danos possíveis ao hospedeiro.

Hoje disponibilizamos, em termos de enxerto ósseo, materiais classificados como autógeno, homógeno e xenógeno. Tanto o autógeno quanto o homógeno têm sido amplamente utilizados na prática cirúrgica; já o xenógeno, por apresentar grande resposta antigênica, é menos empregado (DUARTE DA SILVA ET AL., 2000).

Um substituto ósseo com características ideais deveria ter propriedades físico-químicas parecidas com as do osso, para facilitar a regeneração óssea; ter a capacidade de associar propriedades osteoindutoras e osteocondutoras; ser biocompatível e reabsorvível, sendo completamente substituído por osso no final do processo (GIANNOUDIS ET AL., 2005). Além disso, deve beneficiar a revascularização do local da lesão e mesmo fornecer nutrição para a peça enxertada. No que diz respeito à vascularização, um passo fundamental para a angiogênese consiste na habilidade das células endoteliais adentrarem o espaço mantido pela matriz extracelular. A degradação da matriz é um passo inicial de extrema importância cuja figura central são as MMPs, enzimas que atuam nessa degradação. Além de atuarem degradando a membrana basal do endotélio capilar e a matriz circundante, as MMPs facilitam outras funções necessárias para a morfogênese capilar (GHAJAR ET AL., 2008).

Outros fatores de crescimento são amplamente estudados quanto sua característica de beneficiar o reparo. Desses, moléculas como as BMPs se 
destacaram devido a seu potencial osteoindutivo. Elas induzem a proliferação de células mesenquimais e outros osteoprogenitores, além de estimular sua diferenciação em osteoblastos. Com a utilização de tecnologia de DNA recombinante, a BMP-2 está licenciada para uso clínico desde 2002. E, nos últimos dez anos, muitos avanços seguiram no entendimento de suas funções (DIMITRIOU ET AL., 2011).

Assim, este trabalho visa identificar parte desse universo complexo do reparo ósseo de defeitos cirúrgicos, disponibilizando materiais osteoindutores diversos e analisando, sob o ponto de vista bioquímico a remodelação e a remineralização, evidenciadas pela produção de proteases específicas para a substituição dos tecidos de reparo e pelos níveis de cálcio presente nos ossos neoformados.

\section{REVISÃO DE LITERATURA}

\subsection{O TECIDO ÓSSEO}

O tecido ósseo é um tecido conjuntivo especializado formado por células e material extracelular calcificado (matriz óssea). Esta tem essencialmente dois constituintes principais: minerais e colágeno (JUNQUEIRA \& CARNEIRO, 2008). A parte mineral é responsável pela rigidez e força do osso, enquanto o colágeno atua na habilidade de reduzir os impactos recebidos por esse tecido (MARTIN \& CORREA, 2010). O colágeno ósseo é constantemente renovado e suas fibras são estabilizadas por proteínas, produtos de glicação avançada (AGEs) e proteoglicanas. Os ossos in natura contêm colágeno tipo 1 contendo proteoglicanas de baixa massa molecular e proteínas não colágenas que correspondem a $25 \%$ do 
seu peso; além disso, uma parte mineral que corresponde a $65 \%$ do peso total e 10\% de sua constituição em água (JUNQUEIRA \& CARNEIRO, 2008).

A mineralização da matriz óssea acontece em duas etapas sucessivas. A mineralização primária ocorre quando a nova matriz colágena começa a mineralizar rapidamente e representa de 50 a $60 \%$ da mineralização máxima. Logo após, a taxa de mineralização desacelera e começa a mineralização secundária que continua ao longo dos anos. Geralmente a mineralização se estabiliza em 90 a $95 \%$ da mineralização máxima. O grau de mineralização secundária é dependente da remodelação óssea; quando a remodelação se apresenta diminuída, é mais longo o tempo de mineralização secundária. Quando a remodelação acontece de forma rápida, o osso recentemente formado é removido antes do tempo ideal de mineralização secundária (MARTIN \& CORREA, 2010).

Enquanto aumenta o grau de mineralização, o tecido começa a se tornar mais quebradiço (friável) e requer menos energia menor força atuante para fraturar. Assim, um osso hipermineralizado pode se tornar até mais frágil que um osso com menor grau de mineralização. Mas, também, quando a reabsorção óssea começa antes da mineralização ideal, um déficit de minerais leva à diminuição da rigidez e força do osso (RIGGS ET AL., 1994). O tempo de desmineralização óssea está relacionado com a quantidade de cálcio presente no osso e varia de acordo com o tipo de osso e animal em experimento (GUO ET AL., 1991).

Muitos fatores de crescimento estão envolvidos na osteogênese. Proteínas morfogenéticas do osso, fatores de crescimento transformadores- $\beta$ (TGF- $\beta$ ), fatores de crescimento semelhantes à insulina (IGF I e II), fatores de crescimento derivados de plaquetas (PDGF), fatores de crescimento de fibroblastos (FGFs) e fatores de 
crescimento endotélio vasculares (VEGF), que, inclusive são propostos para utilização na engenharia óssea (HERFORD ET AL., 2011).

A qualidade óssea é determinada pelas propriedades estruturais e pela taxa de remodelação óssea. A remodelação é um processo contínuo de renovação óssea onde um tecido ósseo velho ou danificado é reabsorvido e um novo tecido ósseo é formado para sua reposição, mantendo assim a integridade mecânica do osso e a homeostase do cálcio no organismo. As propriedades estruturais dos ossos incluem sua geometria (tamanho e forma) e sua microarquitetura (trabecular ou cortical), enquanto suas propriedades materiais incluem sua composição mineral e concentração de colágeno (JUNQUEIRA \& CARNEIRO, 2008; MARTIN \& CORREA, 2010).

A integridade do esqueleto requer um balanço dinâmico entre formação óssea e reabsorção óssea, que é controlado por hormônios calcitrópicos e citocinas. Essa remodelação é baseada na ação combinada de células formativas e reabsortivas que atuam substituindo o osso antigo com novo osso, assegurando a integridade do esqueleto. Essa sequência tem que ser precisamente regulada por fatores locais e sistêmicos, pois desvios entre o balanço normal de formação e reabsorção podem significar severa aceleração na perda óssea ou na formação óssea, com consequências desastrosas de aumento de risco de fraturas ou síndromes compressivas (ERIKSEN, 2010).

A remodelação inicia com reabsorção osteoclástica, uma atividade erosiva que delimita lacunas de reabsorção cuja profundidade varia de $60 \mu \mathrm{m}$ em indivíduos jovens e $40 \mu \mathrm{m}$ em indivíduos mais velhos. Esse período de reabsorção tem uma duração média de 30-40 dias e é seguido de formação óssea por um período de 150 
dias (ERIKSEN ET AL., 1984 a e b). No osso normal, o resultado do ciclo de remodelação se completa quando a lacuna de reabsorção é reposta com novo osso.

Esta remodelação é coordenada por diversos fatores que contribuem para a qualidade do osso. O balanço entre a reabsorção e a formação é crucial na preservação desta qualidade, no reparo de fraturas microarquiteturais, na manutenção da densidade mineral óssea e na redução do risco de fraturas (MARTIN \& CORREA, 2010). Uma remodelação acelerada leva a uma redução irreversível da estrutura trabecular, resultando em um osso mais frágil e aumentando o risco de fraturas. Os marcadores da remodelação são passíveis de identificação na urina e no sangue. São subprodutos de osteoblastos/osteócitos e osteoclastos, como por exemplo, fragmentos de quebras de colágeno tipo 1 (CTx - telopeptídeo-C do colágeno tipo 1 ósseo), decorrentes da degradação do colágeno. Níveis elevados de CTx geralmente indicam remodelação acelerada (MARTIN \& CORREA, 2010).

Osteoclastos são células gigantes multinucleadas originadas pela fusão de células precursoras mononucleares. São especializados na reabsorção óssea e possuem grande variedade de estruturas celulares que auxiliam neste processo (RAISZ ET AL., 2002). Quanto à origem, os osteoclastos apresentam várias semelhanças a macrófagos, expressando inclusive diversos antígenos em comum. Porém é clara a distinção das duas células em outros antígenos de superfície de membrana específicos. Suas células precursoras mononucleares aparecem na matriz óssea e sangue circulante (LORENZO ET AL., 2008; TSURUKAI ET AL., 1998). A principal citocina que regula a formação do osteoclasto é o receptor ativador do ligante kappaB fator nuclear (RANKL) (SUDA ET AL., 1999). A formação e ativação dos osteoclastos são processos regulados pelas células osteoblásticas, que contribuem com pelo menos dois fatores essenciais à osteoclastogênese: o 
RANKL e o M-CSF (fator estimulante de colônia de fagócito mononuclear) (LORENZO ET AL., 2008).

Osteoblastos são células mesenquimais derivadas de células progenitoras do mesoderma e crista neural e, sua formação implica a diferenciação das progenitoras em pré-osteoblastos proliferativos, osteoblastos produtores de matriz óssea e eventualmente em osteócitos. O primeiro marcador osteoblástico, fator transcripcional relacionado a Runt2 (Runx2), é necessário para a diferenciação das células progenitoras na linhagem osteoblástica (KOMORI, 1997). Durante essa sequência de proliferação celular, o Runx2 regula a expressão de genes que codificam a produção de osteocalcina, VEGF, RANKL e esclerostina (LIAN, 2006).

Além disso, um grande número de fatores parácrinos, autócrinos e endócrinos afetam o desenvolvimento e maturação dos osteoblastos, como: proteínas morfogenéticas do osso (BMPs), fatores de crescimento como FGF e IGF, fatores angiogênicos como endotelina-1, hormônios como o paratormônio (PTH) e agonistas de protaglandinas (QIN, 2003). O osteoblasto completamente diferenciado se caracteriza pela co-expressão de fosfatase alcalina e colágeno do tipo 1, ambos importantes para a síntese da matriz óssea e sua subsequente mineralização (MURSHED, 2005).

Osteoblastos maduros também produzem reguladores de mineralização de matriz como osteocalcina, osteopontina e ostenectina, além de RANKL que é necessário para a diferenciação osteoclástica assim como o receptor para PTH (PTHR1). Quando a matriz óssea calcifica sobre influencia dos osteoblastos, uma parte destas células fica aprisionada no interior da matriz e persiste no osso maduro, sendo agora denominadas osteócitos. Estas são as células encontradas no interior da matriz óssea, ocupando as lacunas das quais partem canalículos. Cada lacuna 
contém apenas um osteócito (JUNQUEIRA \& CARNEIRO, 2008). Os osteócitos são responsáveis pela manutenção do tecido ósseo e da sua remodelação, comunicando-se com as células da periferia do osso. Eles se interconectam e se comunicam com as células superficiais mediante projeções no interior de canalículos, fornecendo uma via de transporte de nutrientes e metabólitos entre os vasos sanguíneos e as várias células (KLEIN-NULEND ET AL., 2003; KNOTHE ET AL., 2004).

Já a diferenciação osteoclástica é regulada pela interação RANKL/RANK/OPG. Essa via se baseia nos osteoblastos promovendo a diferenciação dos osteoclastos por meio da apresentação de RANKL em sua membrana e a ligação com o receptor RANK na membrana do precursor mononuclear de osteoclastos. Essa diferenciação RANKL/RANK é inibida pela ativação do receptor osteoprotegerina (OPG), que também é produzido pelos osteoblastos (KHOSLA, 2001). Estrógenos aumentam a expressão de OPG e diminuem a de RANKL, favorecendo a formação óssea. A perda óssea pósmenopausa está ligada à redução dos níveis de estrógeno, favorecendo a reabsorção.

A formação de vasos sanguíneos necessita de dois importantes processos: vasculogênese e angiogênese. A vasculogênese se refere ao processo onde uma vascularização nascente, chamada de plexo capilar primário, é montada por angioblastos e célula-tronco durante o desenvolvimento embrionário. Por outro lado, a angiogênese diz respeito à formação de novos capilares que se desenvolvem a partir do sistema vascular pré-existente, em um processo de geração de novos vasos sanguíneos em estágios avançados de desenvolvimento ou no reparo de tecidos (GHAJAR ET AL., 2008). No caso da angiogênese, uma cascada complexa 
de eventos define o processo morfogenético, incluindo a degradação das membranas basais, proliferação e migração de células, organização da vascularização madura e sua estabilização por células da musculatura lisa e reposição das membranas basais (JAIN, 2003).

\subsection{REPARO ÓSSEO}

Uma fratura óssea normalmente se cura pela combinação de ossificação intramembranosa e endocondral. A ossificação endocondral começa externamente ao periósteo, adjacente ao local de fratura, em regiões que são mecanicamente menos estáveis. Internamente ao periósteo, a ossificação intramembranosa forma o calo duro (DIMITRIOU ET AL., 2005). São as pontes entre as regiões de calo duro através da fratura que promovem a estabilização inicial e a recuperação da função biomecânica (GERSTENFELD ET AL., 2006).

Três componentes são vitais na engenharia de tecido ósseo. O primeiro se refere às células formadoras de osso, o segundo, fatores de crescimento osteoindutores e o terceiro, um arcabouço osteocondutivo. Estes arcabouços osteocondutivos proporcionam um suporte mecânico imediato, mimetizam a matriz óssea extracelular e guiam a formação do osso em local e formato desejado (HERFORD ET AL., 2011).

Para que se inicie o processo de reparo de uma fratura os restos celulares e restos de matriz que foram rompidos devem ser removidos por meio da ação de macrófagos. Simultaneamente, periósteo e endósteo respondem com intensa proliferação, originando um tecido muito rico em células osteoprogenitoras que formam um colar em torno da fratura e que penetra entre as extremidades ósseas 
fraturadas. Este processo evolui de modo a aparecer, após algum tempo, um calo ósseo e finalmente sua completa substituição por osso secundário (ROSSI JUNIOR ET AL., 2010).

As fases do processo de reparo se iniciam com uma resposta inflamatória imediata, que leva ao recrutamento de células-tronco mesenquimais e subsequente diferenciação em condrócitos (que produzem cartilagem) e osteoblastos (que formam osso). Depois de produzida a matriz cartilaginosa é transformada de cartilagem mineralizada até osso. Essa formação óssea primária é seguida de remodelação, onde o calo ósseo inicial é reestruturado por reabsorção e formação secundária de osso, restaurando a estrutura anatômica funcional. O processo biológico que guia esses estágios é regulado por moléculas sinalizadoras celulares que podem ser divididas em três grupos: citocinas pró-inflamatórias, membros da superfamília dos TGF- $\beta$ e fatores angiogênicos (GERSTENFELD ET AL., 2003).

A fase inflamatória está associada com a ruptura vascular e formação de um hematoma, recrutamento de células-tronco mesenquimais, proliferação celular e início da condrogênese, seguida de crescimento vascular e neo-angiogênese. Interleucinas -1 e -6 (IL-1 e -6) e fator de necrose tumoral (TNF- $\alpha$ ) atuam principiando a cascata de reparo. TGF- $\beta$, PDGF e BMP-2 aumentam a formação do calo inicial. Angiopoetinas e VEGF são induzidos para estimular o crescimento vascular de vasos do periósteo, essencial para o progresso do processo de reparo da fratura (JUNQUEIRA \& CARNEIRO, 2008; MARTIN \& CORREA, 2010).

A fase de formação óssea primária mostra uma osteogênese mais rápida, envolvendo recrutamento de células ósseas e formação de tecido ósseo, assim como apoptose de condrócitos, recrutamento de osteoclastos e reabsorção da cartilagem mineralizada e neo-angiogênese continuada. BMPs aumentam sua 
expressão na reabsorção da cartilagem calcificada e promovem o recrutamento de células da linhagem osteoblástica. VEGFs são expressos para estimular a neoangiogênese (AI-AQL ET AL., 2008). A fase de formação óssea secundária e remodelação óssea estão associadas com a reconstituição da medula óssea normal (FAZZALARI, 2011).

O VEGF é produzido pelos osteoblastos e está envolvido com o estímulo direto da angiogênese (proliferação de células endoteliais, aumento da permeabilidade vascular, vasodilatação dependente do óxido nítrico) e osteogênese (migração e ativação de osteoblastos e células derivadas de monócitos). Pertence à família de múltiplos genes que são responsáveis pela formação de vasos sanguíneos e recrutamento hematopoiético de células-tronco (VEGF-A, -B e fator de crescimento placentário), e também pelo desenvolvimento do sistema linfático (VEGF-C e -D) (TOWLER ET AL., 2003).

A maioria dos fatores de crescimento do tecido ósseo - prostaglandina E2 (PGE-2), BMP-2, IGF-1, FGF-2, PTH, e proteína relacionada ao paratormônio (PTHrp), funcionam como secretagogos para o estímulo angiogênico do VEGF no osso. O PTH-rp é expresso pelas células endoteliais e promove interação parácrina da produção osteoblástica de VEGF. A IGF-1 regula positivamente a produção de VEGF e parece estar relacionada à sinalização durante fenômenos de isquemia e hipóxia. BMP-2 e -4 são potentes estimuladores da angiogênese, aumentando a secreção de VEGF pelos osteoblastos. A ação parácrina e autócrina do VEGF e lipídios angiogênicos aumentam a massa e resistência óssea, assim como agentes osteo-anabólicos incrementam a angiogênese (TOWLER ET AL., 2003).

A angiogênese está intimamente relacionada com a reabsorção óssea e fatores angiogênicos como VEGF e endotelina regulam a atividade de osteoblastos 
e osteoclastos (BRANDI ET AL., 2006). Além disso, vasos sanguíneos servem como via de transporte para precursores de osteoblastos e osteoclastos para sítios de remodelação ativa. Células endoteliais comandam a diferenciação de células da medula óssea para o fenótipo osteoblástico. VEGF também é expresso durante a osteogênese intramembranosa. Osteoblastos e osteoclastos possuem receptores para VEGF e também produzem VEGF (TOMBRAN-TINK ET AL., 2004). A expressão de VEGF está associada com fases precoces de remodelação óssea e induz quimiotaxia para osteoblastos e sua diferenciação (LI ET AL., 2005).

Nos ossos a rede vascular é essencial para a formação, metabolismo, cura e remodelação. Na ossificação intramembranosa há uma invasão de capilares que transportam células da medula óssea que se diferenciam em osteoblastos e começam a depositar matriz óssea. $\mathrm{Na}$ ossificação endocondral, a base cartilaginosa avascular é substituída por tecido ósseo altamente vascularizado. Condrócitos hipertróficos produzem estimuladores angiogênicos, como o VEGF, FGF-1 e -2, permitindo a invasão capilar e angiogênese. Os condrócitos hipertróficos e células migratórias da recém formada medula óssea secretam metaloproteases de matriz (MMPs), que degradam a matriz extracelular permitindo ainda maior invasão vascular.

A MMP-9 regula também a liberação de VEGF-A que se encontra ligada à matriz cartilaginosa hipertrófica. Uma vez liberado, o VEGF-A se liga a seus receptores nas células endoteliais, osteoclastos e osteoblastos (CENNI ET AL., 2011). A angiogênese é fundamental para o reparo de fraturas. Um dos eventos mais precoces da reparação óssea é a reconstrução da circulação intra-óssea (SCHINDELER ET AL., 2008). Em situações patológicas e reparo de lesões as MMPs desenvolvem papel importante no gatilho que quebra a quiescência dos 
processos angiogênicos permitindo a formação de novas redes capilares (GHAJAR ET AL., 2008).

Seguindo o trauma, a ruptura de vasos leva a uma hipóxia aguda do tecido adjacente bem como à ativação do sistema de coagulação. A resposta inflamatória ativa citocinas e fatores de crescimento que recrutam células da medula óssea e células endoteliais para o local da fratura. O VEGF significantemente aumenta a quantidade de pro-MMP-2 e -9 contidas em vesículas de células endoteliais, além disso, também aumenta expressão do fator transcriptivo ETS-1, que resulta em um aumento nos níveis de MMPs-1, -3 e -9. A formação de novo osso durante a cura da fratura está primariamente associada à ossificação endocondral precedida por formação de calo mole, um processo que requer remodelação enzimática extensiva de matriz extracelular, em sua maior parte realizado por proteases da família das MMPs (ODA ET AL., 1999; TARABOLETTI ET AL., 2002).

$\mathrm{Na}$ recuperação dos tecidos ósseos, particularmente de defeitos de continuidade ou de volume, células (idealmente células-tronco mesenquimais pluripotentes) se apresentam para diferenciação e formação dos diferentes tipos teciduais. Os pontos de questionamento giram em torno da identificação e utilização criteriosa de fatores de diferenciação (que facilitariam os processos de proliferação e diferenciação celular na direção do tipo tecidual desejado) apropriados para a regeneração óssea e do desenvolvimento de arcabouços que possibilitem a organização da matriz extracelular óssea (OLIVEIRA ET AL., 2011).

De tal modo, o tecido ósseo possui capacidade de regeneração, uma recuperação fisiológica espontânea, entretanto, limitada em diversos aspectos. O reparo de defeitos ósseos amplos ainda necessita de intervenção mediante a aplicação de enxertos ósseos, procedimento que facilita essa recuperação 
fisiológica. O sucesso na incorporação desse enxerto depende do contato do mesmo com as margens do defeito, da proliferação das células osteoprogenitoras do osso sadio circundante e sequencialmente da diferenciação de osteoblastos, da osteocondução e das propriedades mecânicas do tecido que está em remodelação (PETERSON ET AL., 2000).

\subsection{MMP}

MMPs são endopeptidases dependentes de zinco reconhecidas por sua habilidade em clivar constituintes da matriz extracelular. Elas pertencem a uma família de aproximadamente 20 membros que dividem características comuns em estrutura e elementos funcionais e são produzidas por diferentes genes. Estas enzimas são primordialmente distinguidas de outras classes de proteinases devido a sua dependência de íons metálicos e a necessidade de um meio com $\mathrm{pH}$ neutro para a ativação e correto funcionamento. Dependendo de sua especificidade pelo substrato e particularidades estruturais, podem ser categorizadas como: colagenases (MMP-1, MMP-8 e MMP-13), gelatinases (MMP-2 e MMP-9), estromelisinas (MMP-3, MMP-10 e MMP-11), matrilisina (MMP-7), elastase (MMP12) e tipo membrana (MT1-MMP, MT2-MMP, MT3-MMP, MT4-MMP) (CORBEL ET AL., 2000).

As MMPs são secretadas na forma de proenzimas (forma latente), denominadas proMMP, e necessitam de ativação para ser completamente funcionais. Elas possuem um domínio propeptidico (80 aminoácidos) que contém uma sequência altamente conservada. Um resíduo de cisteína nessa sequência faz a manutenção do zimógeno com coordenação direta do sítio de ligação do átomo de 
zinco no domínio catalítico, o que bloqueia o acesso desse sítio catalítico ao substrato (VAN WART \& BIRKEDAL-HANSEN, 1990).

A sequência sinal, localizada no sítio $\mathrm{N}$-terminal da proteína, direciona a proteinase ainda não processada ao retículo endoplasmático. $O$ domínio propeptídeo é um dos dois fatores que mantém a protease em sua forma inativa. A clivagem proteolítica deste sinal se faz necessária para a ativação do precursor de MMP (zimógeno). O domínio catalítico liga dois íons zinco, um estrutural e outro catalítico e, além disso, ainda liga íons cálcio (GHAJAR ET AL., 2008).

Os maiores inibidores fisiológicos das MMPs são a-2-macroglobulinas e a família de inibidores específicos inibidores teciduais de MMPs (TIMPs), produzidos por vários tipos celulares (MURPHY \& DOCHERTY, 1992). Os TIMP-1 e -2 são secretados em forma solúvel, enquanto o TIMP-3 está associado à matriz extracelular, normalmente possuem alta afinidade às MMPs, ligando-se numa relação 1:1 molar ao sítio catalítico ativo, fazendo com que essa MMP perca sua atividade proteolítica. Além disso, os TIMP-1 e -2 podem formar complexos específicos com os zimógenos das MMP-9 e -2 respectivamente (CORBEL ET AL., 2000). O TIMP-2 forma um complexo trimolecular na superfície de células com MT1MMP e a forma zimógena da MMP-2 e regula a formação e os níveis de concentração da MMP-2 ativa (STRONGIN ET AL., 1995).

As MMPs são consideradas as principais responsáveis pela degradação da matriz extracelular. Elas são expressas em processos fisiológicos durante o desenvolvimento e pequenos reparos do organismo, mas também em situações patológicas. No tecido adulto, uma pequena concentração de MMPs condiz com a remodelação natural da matriz extracelular, enquanto que em situações inflamatórias 
e lesões há grande quantidade de MMPs sendo produzidas no intuito de reparar a matriz danificada (BIRKEDAL-HANSEN ET AL., 1993).

MMPs estão integradas à resposta inflamatória e diferenciação celular no local de fratura. Elas atuam na remodelação de cartilagem, osso e angiogênese durante as fases de calo mole e remodelação no reparo (BEHONICK ET AL., 2007). Também são expressas em estágios precoces do reparo em vários tipos celulares, incluindo células inflamatórias.

A MMP-2 (gelatinase A, colagenase tipo IV de 72kDa, gene 16q13-q21) é uma metaloprotease de matriz inicialmente descrita e purificada de tumores metastáticos presentes em roedores e cultura de células de melanoma humano (HOYHTYA ET AL., 1990; SALO ET AL., 1983). A enzima é altamente expressada por fibroblastos, células endoteliais e epiteliais (VARTIO ET AL., 1982). É secretada na forma de proMMP-2 e ativada na superfície celular mediante interação com MT1MMP. Esta colagenase participa na degradação da matriz extracelular clivando colágenos dos tipos I, IV, V, VII e X, laminina, elastina, fibronectina e proteoglicanas (GALASSO ET AL., 2012; STERNLICHT \& WERB, 2001).

A MMP-9 (gelatinase B, colagenase tipo IV de 92kDa, gene 20q11.2-q13.1) foi inicialmente purificada de macrófagos humanos. Sua expressão se limita a osteoclastos, macrófagos, trofoblastos e queratinócitos (GALASSO ET AL., 2012). É considerada a protease mais abundante em osteoclastos (LOGAR ET AL., 2007). Inicialmente, é secretada na forma de proMMP-9, inativa, e posteriormente é ativada por uma cascata de eventos que envolve diversas substâncias como os inibidores TIMP-1 e TIMP-3 e o complexo plasminogênio/MMP-3 (RAMOS-DE SIMONE ET AL., 1999). Esta enzima degrada a matriz extracelular, iniciando e promovendo a neoformação vascular (MAZZIERI ET AL., 1997). A MMP-9 é altamente expressada 
em monócitos (precursores de osteoclastos) e em osteoclastos multinucleados que reabsorvem o osso (REPONEN ET AL., 1994). Embora se saiba que macrófagos produzem MMP-2 e -9, o aumento no número de macrófagos não parece estar correlacionado ao aumento na concentração de MMP-9 (CORBEL ET AL., 2000).

Em resposta ao estímulo angiogênico, células endoteliais degradam a membrana basal de microvasos mediante a secreção de enzimas proteolíticas, inclusive MMP-2 e -9 (NGUYEN ET AL., 2001). Então, estas células migram através da membrana, degradam e continuam clivando a matriz extracelular em seu caminho. O endotélio se alinha de maneira bipolar para formar o lúmen e a nova via capilar por onde o sangue flui (VAN HINSBERGH ET AL., 2006).

Não é por coincidência que estes fatores pro-angiogênicos aumentam a expressão de diversas variedades de MMPs. Dada sua habilidade de degradação da matriz extracelular e facilitar a cascata angiogênica, essas proteases são grandes efetoras do processo de angiogênese. Duas das mais potentes quimiocinas angiogênicas, VEGF e FGF, aumentam muito a produção de pro-MMP-2 e -9 contidas em vesículas e liberadas por células endoteliais (TARABOLETTI ET AL., 2002). Além disso, esses dois fatores também regulam a transcrição do fator ETS-1, que resulta no aumento dos níveis de MMP-1, -3 e -9 (ODA ET AL., 1999). Outro fator angiogênico, o fator de crescimento de hepatócito (HGF), estimula o aumento de MT1-MMP e formas latentes e ativas de MMP-2 (WANG \& KEISER, 2000). Angiopoetina2 (Ang-2) aumenta a expressão de MMP-1 e -9 na presença do VEGF (ETOH ET AL., 2001). IL-1, -6 e -8 aumentam a expressão de MMP-9 (HANEMAAIJER ET AL., 1993; YAO ET AL., 2006), enquanto a IL-8 também estimula a produção de MMP-2 (LI ET AL, 2003). TGF- $\beta 1$ aumenta a expressão de MMP-2 e -9 por células endoteliais (PUYRAIMOND ET AL., 1999). 


\subsection{BMP}

Para a formação do tecido ósseo, basicamente necessita-se da diferenciação de células pluripotentes em osteoblastos, células com potencial osteoindutor. Assim, surgiram pesquisas cujo objetivo visa identificar no osso desmineralizado as possíveis substâncias que atuariam na diferenciação destas células. Uma glicoproteína de baixo peso molecular precocemente identificada no processo recebeu a denominação de polipeptídio da morfogênese do osso. Esta promovia a formação óssea ectópica (OLIVEIRA ET AL., 2011).

Posteriormente estas proteínas foram classificadas como proteínas ósseas morfogenéticas e reconhecidas como BMPs (do inglês bone morphogenetic proteins). Seu estudo revelou que elas pertencem a uma subfamília do grupo de fatores de crescimento transformadores- $\beta$. No osso são produzidas por células osteoprogenitoras, osteoblastos, condrócitos e plaquetas (SHEN ET AL., 2009). São reguladas por fatores específicos, como o tipo de células-alvo onde vão atuar, o estágio de diferenciação destas células, a concentração da proteína no local de ação e a interação com outras proteínas que podem induzir ou diminuir sua expressão. As BMPs induzem uma cascata sequencial de eventos que leva à condrogênese, osteogênese, angiogênese e a síntese controlada de matriz extracelular (DIMITRIOU ET AL., 2005; TSIRIDIS ET AL., 2007).

A principal ação da BMP na produção do osso no organismo é servir como fator de diferenciação de células-tronco mesenquimais, convertendo estas células em condrócitos e osteoblastos, ambos imprescindíveis na construção do arcabouço ósseo (LIEBERMAN ET AL., 2002). 
Células-tronco multipotentes expressam marcadores de múltiplas linhagens celulares. Estes mantém a célula no estado indiferenciado por mecanismos de "feedback" negativo. Para estimular as células na diferenciação de tipos específicos faz-se necessário a indução por diferentes fatores (TREMAIN ET AL., 2001). Na diferenciação em linhagens osteogênicas, o fator inicial e mais específico é o Runx2. Ele ativa e regula a diferenciação mediante duas vias de sinalização independentes, uma utilizando TGF- $\beta$ e a outra BMP-2 (LEE ET AL., 2000). Os osteoblastos, advindos das células-tronco mesenquimais mostram como é importante a interação entre as proteínas no local de produção de tecido ósseo, pois são induzidos pelas BMPs e também regulados por TGF, IGF-1 e VEGF (RILEY, 1996).

As várias formas da BMP foram inicialmente descritas como indutoras da formação óssea. Sabe-se existir aproximadamente 25 tipos de BMPs e estas mostraram ser capazes de muitos outros papéis além da construção do osso. Elas guiam diversos processos durante o desenvolvimento do organismo e auxiliam na homeostase e reparo de diferentes tecidos (SIEBER ET AL., 2009). As BMP-2, -4, -7 e -9, em particular, exercem importante função na morfogênese óssea (BESSA ET AL., 2008).

Tsumaki e Yoshikawa (2005) descreveram em seu estudo os eventos envolvidos na formação de tecido ósseo facilitados pelas BMPs, entre eles: quimiotaxia e proliferação de células mesenquimais, diferenciação em condroblastos e osteoblastos, calcificação da matriz cartilaginosa, angiogênese e invasão vascular, diferenciação, mineralização e remodelação ósseas, seguida de formação de medula óssea. Afirmaram que esses eventos são semelhantes aos que ocorrem num processo normal de ossificação endocondral. O estímulo devido à aplicação da proteína indutora apenas tornaria mais precoce o processo. Wang e colaboradores 
(1990) verificaram que o aumento da concentração de BMP-2 na matriz óssea implantada diminui o tempo para que ocorra nova formação óssea.

Procurando aprofundar o conhecimento dos fatores de indução óssea e aperfeiçoar sua utilização clínica, se tornou necessária a produção de BMPs recombinantes. A primeira molécula estudada detalhadamente para a aplicação clínica foi a BMP-2 recombinante humana (rhBMP-2), produzida inicialmente em células ovarianas de hamster chinês. A purificação e caracterização bioquímica dessas moléculas mostrou que elas são similares às moléculas de BMP encontradas nos ossos, mostrando que o vetor eucarionte foi fidedigno na estruturação quaternária da proteína. A implantação ectópica de rhBMP-2 mostrou que esta molécula é osteoindutora, provando mediante exames histológicos que a implantação de diferentes dosagens em diferentes períodos de tempo levava a neoformação óssea, inicialmente com osso cartilaginoso, fato desencadeado pelas moléculas BMP in vivo (ISRAEL ET AL., 1992; INODA ET AL., 2004; KAMAKURA ET AL., 2004).

A rhBMP-2 atua de maneira diversa sobre os diferentes tipos celulares e biomateriais. Um estudo de Kim e colaboradores (KIM ET AL., 1997) mostrou que a rhBMP-2 estimula a produção de fosfatase alcalina pelas células da medula óssea fresca e colônias formadoras de fibroblastos. E o tratamento com rhBMP-2 mostra um aumento da atividade osteoblásticas in vitro (ONG ET AL., 1997). Participa da diferenciação de células mesenquimais em células com fenótipo de osteoblastos, aumentando a atividade da fosfatase alcalina, do AMPc (em resposta ao hormônio da paratireóide) e de osteocalcina (THIES ET AL., 1992; WANG ET AL., 1990; YAMAGUCHI ET AL., 1991). 
Outros estudos evidenciam que estas proteínas apresentam ação local, devendo ser depositadas diretamente no sítio onde se busca desenvolver o processo de reparo, e preferencialmente devem ser carreadas por agente que permita sua difusão por entre as células, facilitando a osteoindução (MARUKAWA ET AL., 2001; CIANI ET AL., 2006).

No início, as BMPs eram extraídas da matriz óssea e compunham uma mistura de não apenas fatores de osteoindução, mas também diversos fatores imunógenos provenientes da matriz extracelular do vetor. Desde os primeiros clones moleculares de BMP utilizados pela biotecnologia, a produção por técnica de DNA recombinante levou à produção em larga escala e altamente purificada, pois era obtida unicamente a proteína de interesse. Mas, apesar do fato de as proteínas recombinantes humanas se mostrarem muito menos imunógenas em comparação àquelas obtidas pela purificação em tecidos animais, muitas apresentaram uma alta indução de anticorpos no local da infusão (SCHELLEKENS, 2002). Mesmo assim, a aplicação local de rhBMP-2 não parece demonstrar qualquer efeito tóxico sistêmico (ROSS ET AL., 2000; SCHELLEKENS, 2003).

\subsection{ENXERTOS ÓSSEOS}

Vários tipos de biomateriais e suas associações experimentais são estudados no processo de reparação do tecido ósseo, considerando sua capacidade inata de reconstituir a estrutura lesada em sua forma original com restauração da estrutura histológica e propriedades mecânicas (SASSIOTO ET AL., 2004).

Porém, como defeitos ósseos de grande extensão necessitam de um tempo maior de reparo, a engenharia tecidual se mostra eficiente para promover uma 
recuperação controlada, favorecida e muitas vezes guiada. Dentro das técnicas de engenharia tecidual um importante auxiliador do reparo ósseo extenso é a enxertia óssea, provinda de variadas fontes que atrelada ou não a materiais indutores, facilita a reconstrução do defeito. Diante dessa variedade de opções para as enxertias, alguns parâmetros devem ser seguidos para a adequada seleção do material, como: potencial de osteogênese, osteocondução e osteoindução; capacidade de estabilização do material no leito; não promover ou facilitar processos infecciosos, ser de fácil acesso, baixo custo e não promover morbidade ao doador (YILDIRIM ET AL., 2000).

Quanto à origem, os enxertos são denominados: autólogos ou autógenos, tipo de enxertia óssea em que o material ósseo é transplantado de uma área doadora para outra área receptora em um mesmo indivíduo (WEIGEL \& BOJRAB, 1996); homólogos ou homógenos, onde a relação entre tecido ósseo doador e receptor, envolvem dois indivíduos da mesma espécie, mas não o mesmo indivíduo (PIERMATTEI \& FLO, 1997); heterólogos ou xenoenxertos, transplantados entre animais de espécies diferentes (PIERMATTEI \& FLO, 1997; MARTINEZ \& WALKER, 1999).

Os enxertos autógenos são histocompatíveis e não induzem à rejeição, diferente do observado com os homógenos e xenoenxertos. Esses últimos, para serem utilizados, devem ter a antigenicidade diminuída por irradiação, congelamento, preservação química ou autoclavagem, entre outros tratamentos propostos (JOHNSON, 1995).

O reparo de grandes defeitos ósseos continua sendo um desafio aos profissionais da cirurgia e traumatologia, onde os métodos tradicionais de tratamento utilizam o enxerto ósseo autógeno pela sua propriedade osteogênica e facilidade de 
incorporação, preferencialmente aos enxertos homógenos e xenógenos (FINKEMEIER, 2002).

Após a aplicação do enxerto autógeno, de osso esponjoso, a formação óssea se inicia a partir de osteoblastos provenientes da medula da peça, contida no interior de suas trabéculas, determinando formação osteóide direta. Segue-se migração e diferenciação de células osteblasticas, quimiotaticamente atraídas por fatores de crescimento presentes no enxerto. Todavia, a sua associação com BMP é um procedimento recente (MARX, 1994).

O enxerto esponjoso tem grande potencial osteogênico por conter células quiescentes, células mesenquimais indiferenciadas e osteoblastos ativos (MARTINEZ \& WALKER, 1999). Estima-se que apenas $10 \%$ das células deste tipo de enxerto sobrevivam à transferência (PIERMATTEI \& FLO, 1997). Este tipo de enxerto tem sido considerado um carreador ideal, atuando como arcabouço, ao promover a osteoindução e a vascularização precoce (ALLEGRINI ET AL., 2004). Também, apresenta histocompatibilidade, fornece células osteogênicas e adapta-se às falhas ósseas existentes (ELLIS E SINN, 1993).

Os enxertos autógenos são naturalmente vascularizados, contém células vitais e fatores de crescimento que facilitam a remodelação, formando uma estrutura de maior similaridade sítio receptor (TSIGKOU ET AL., 2010). Porém, existe uma importante desvantagem da utilização do osso autógeno, é a necessidade de um segundo sítio cirúrgico para a coleta do material, este enxerto apresenta tamanho e formato restrito, e além de aumentar a morbidade associada ao procedimento, aumenta significativamente o custo para o paciente (OLIVEIRA ET AL., 2011).

A incorporação do enxerto ósseo apresenta cinco estágios: 1) inflamatório, com aumento da atividade osteoclástica; 2) revascularização do enxerto; 3) 
osteocondução, na qual o enxerto tem a função de arcabouço para o crescimento de vasos e formação de osso; 4) osteoindução, na qual células mesenquimais do hospedeiro são induzidas, por proteínas (BMPs) encontradas no enxerto, a se transformarem em osteoblastos e 5) remodelação óssea, com características de formação e reabsorção contínua de osso (DUARTE DA SILVA ET AL., 2000).

Antes da aplicação do enxerto, o local receptor deve ser limpo amplamente para remover restos necróticos, fragmentos teciduais e coágulos sanguíneos, para facilitar a revascularização do enxerto e reduzir a incidência de infecção (JOHNSON, 1995; PIERMATTEI \& FLO, 1997).

Após a colheita, o enxerto esponjoso autólogo deve ser aplicado o mais rapidamente possível (PIERMATTEI \& FLO, 1997). No entanto, se for necessária a estocagem até o momento da transferência para a área receptora, pesquisas indicam que o enxerto pode ser mantido envolto em compressa de gaze umedecida com sangue ou colocado em uma cuba que deve ser coberta com gaze umedecida em solução salina $0,9 \%$ ou Ringer (JOHNSON, 1995; PIERMATTEI \& FLO, 1997).

Os enxertos homólogos são também muito utilizados e apresentam atividades osteoindutoras e osteocondutoras, além de preservar o arcabouço mineral, facilitar o preenchimento do defeito ósseo pelos osteócitos, diminuir a morbidade do paciente (pois não necessitam ser excisados do mesmo) e podem ser utilizados quando não é possível obter enxertos ósseos autólogos (ZABEU \& MERCADANTE, 2008). Porém, existem desvantagens na utilização deste tipo de enxerto ósseo, como o maior índice de reabsorção, reação imunológica exacerbada, menor capacidade osteogênica em comparação ao enxerto autólogo e possibilidade de transmissão de doenças entre o doador e o receptor (BAPTISTA ET AL., 2003). 
Os xenoenxertos teriam como uma grande vantagem a similaridade com o osso natural, embora seu componente inorgânico varie as formas cristalinas e morfologia de acordo com o método de preparo (ACCORSI-MENDONÇA ET AL., 2008). Estes enxertos poderiam, em tese, manter as características osteoindutoras em seu componente inorgânico (GIANNOUDIS ET AL., 2005), que supostamente teria maior potencial imunogênico (LANE ET AL., 1999). A matriz bovina desvitalizada forma uma hidroxiapatita natural de composição química e porosidade semelhante à humana, que quando utilizada de forma isolada ou em associação com fármacos para preencher defeitos ósseos, comporta-se como arcabouço para que as células mesenquimais do osso sadio circundante invadam e se diferenciem em novo tecido ósseo (SASSIOTO ET AL., 2004). Suas propriedades osteocondutivas podem ser melhoradas pela adição de fatores de crescimento (BERGLUNDH \& LINDHE, 1997; YOSHIKAWA ET AL., 1999).

O tecido ósseo bovino é o mais utilizado por possuir custo acessível, quantidades ilimitadas e comodidade ao paciente devido a não necessidade da operação de novo sítio (SILVEIRA, 2007). O osso bovino possui disponibilidade praticamente ilimitada além de grande similaridade físico-química e estrutural com o humano (OLIVEIRA ET AL., 1999).

\section{JUSTIFICATIVA}

O reparo ósseo exige uma via complexa de eventos que leva à formação do novo osso no local do defeito cirúrgico. Muitos são os materiais que favorecem essa neoformação do tecido e cada um deles apresenta características próprias, como 
antigenicidade, potencial inflamatório, tempo de reparo agenciado e solicitação de citocinas e proteases endógenas.

O modelo experimental utilizado destaca-se pela baixa capacidade regenerativa dos ossos do crânio, e permite avaliar alternativas reconstrutivas com agentes que estimulam a reparação, uma vez que implantes sintéticos podem provocar desconforto ao paciente e o auto-enxerto ósseo, quando usado isoladamente, corre o risco de ser reabsorvido antes que a reparação se processe por completo (BRAZ ET AL., 2003; DEL CARLO ET AL., 1994).

No modelo experimental escolhido, no momento da confecção do defeito padrão, optou-se pela não ressecção do periósteo no local de posicionamento da trefina, apesar do conhecimento da grande capacidade osteogênica que este tecido possui, e que pode ser responsabilizada pela formação óssea ectópica presente em todos os grupos de estudo. Para evitar necrose celular nas paredes do defeito padrão, utilizou-se um perfurador elétrico de baixa rotação. Este fato foi observado por Ignácio e colaboradores (IGNACIO ET AL., 1997), que relataram necrose térmica das células ósseas, na zona de transição implante/osso receptor, provocada por perfurador elétrico de alta rotação, prejudicando a possível consolidação.

A escolha do enxerto a ser utilizado é decisivamente influenciada pela estabilidade do leito receptor. Nos casos de defeitos estáveis, como os defeitos ósseos criados experimentalmente, os enxertos não necessitam oferecer nenhuma estabilidade adicional ou receber nenhum tipo de fixação interna ou externa (BERGLUNDH \& LINDHE, 1997; FIGUEIREDO ET AL., 2004).

O enxerto deve se aplicado sem compressão dentro do local recipiente e mantido pela pressão dos tecidos moles circundantes (SANTOS \& RAHAL, 2004). 
Os osteoclastos, tanto humanos como de ratos, apresentam um padrão similar de reabsorção. Com isso, o modelo animal utilizado neste trabalho seria válido para o estudo sobre reabsorção de substitutos ósseos (MONCHAU ET AL., 2002).

A hidroxiapatita, utilizada como carreador apresenta capacidade de atuar como substrato mecânico para o novo crescimento ósseo, juntamente com a propriedade de permanecer por maior tempo no sítio de ação. Segundo relatos de Helm e colaboradores (HELM ET AL., 2002), apresentam poros capazes de reter as BMPs, dificultando assim sua absorção, logo, essas propriedades associadas conferem à hidroxiapatita grande potencial osteocondutor e, por esse motivo, foi a opção utilizada neste estudo.

É importante o estudo aprofundado dos mecanismos estabelecidos pelos materiais nos diferentes tempos de reparo e sua biocompatibilidade. A aplicação clínica destes materiais é detalhadamente estudada e visa esclarecer os benefícios de cada um quanto aos diferentes tipos de lesões ósseas e regiões de implante.

O presente estudo está relacionado a uma extensa linha de pesquisa realizada sobre o reparo ósseo em calvária de ratos e a disponibilização de diversos materiais indutores para do processo. Intenciona-se definir qual o material com a melhor relação custo-benefício e qual o tempo pós-operatório favorável ao reparo, bem como as características inflamatórias e a qualidade do osso nesses diferentes tempos. Com a abordagem bioquímica de parte desses eventos podemos identificar parte das moléculas que atuam sobre o osso em reconstrução e isso nos fornece um guia para o desenvolvimento de novas técnicas e novos materiais, buscando explorar o potencial benéfico do estímulo da reação orgânica à agressão. 


\section{OBJETIVOS}

\subsection{OBJETIVO GERAL}

O estudo tem como objetivo identificar no decurso do reparo ósseo os níveis de MMP-2 e MMP-9, bem como a concentração de cálcio no osso neoformado, comparando entre os diversos grupos tratados o potencial de remodelação e mineralização nos dois diferentes tempos.

\subsection{OBJETIVOS ESPECÍFICOS}

- identificar as concentrações de MMP-2 e MMP-9, bem como as suas formas pró-ativas no tecido ósseo excisado e comparar os achados entre os grupos operados com diferentes tratamentos;

- identificar os níveis de cálcio no tecido ósseo excisado e comparar os achados entre os grupos operados com diferentes tratamentos. 


\section{MATERIAL E MÉTODO}

\subsection{OBTENÇÃO DAS FORMULAÇÕES}

A proteína osteoindutora rhBMP-2 foi dissolvida na proporção de 1:1 em uma solução neutra, representada aqui pela solução de tampão fosfato em pH 7,2. Foi aplicada na concentração de $5 \mu \mathrm{g}$ de rhBMP-2 com o auxílio de uma micropipeta previamente calibrada sobre o leito do defeito ósseo cirúrgico ou carreada pelos enxertos ósseos esponjosos.

\subsection{SELEÇÃO DOS ANIMAIS}

Neste trabalho foram utilizados 112 ratos Wistar albinos, adultos, machos pesando aproximadamente 250 gramas, oriundos do Biotério Central do Campus de Ribeirão Preto, USP. O projeto está relacionado à aprovação $n^{\circ}$ 098/2010 do Comitê de Ética em Pesquisa permitindo o uso dos animais para experimentação. Estes foram então divididos em 8 grupos, cada um deles com um período de espera de 4 e 6 semanas para o sacrifício. Foram alojados em caixas com 5 animais cada, com livre acesso a água e alimento, com temperatura controlada $\left(23 \pm 1^{\circ} \mathrm{C}\right)$ e ciclo claro/escuro de 12/12 horas, sendo o início do período de claro às 7:00 h.

Quanto à divisão dos grupos:

Grupo 1: enxerto ósseo autólogo particulado

Grupo 2: enxerto ósseo homólogo particulado

Grupo 3: enxerto ósseo heterólogo (osso bovino liofilizado) 
Grupo 4: enxerto ósseo autólogo particulado + $5 \mu \mathrm{g}$ rhBMP-2

Grupo 5: enxerto ósseo homólogo particulado + $5 \mu \mathrm{g}$ rhBMP-2

Grupo 6: enxerto ósseo heterólogo (osso bovino liofilizado) + $5 \mu \mathrm{g}$ rhBMP-2

Grupo 7: 5 нg rhBMP-2

Grupo 8: defeito ósseo cirúrgico apenas

\subsection{TÉCNICA CIRURGICA}

\subsubsection{ANESTESIA}

Os animais foram anestesiados com a solução anestésica de Coopazine (Xylazina) - sedativo, analgésico e relaxante muscular; e Dopalen (Ketamina) anestésico geral, fornecido pela Agibrands do Brasil LTDA- Campinas, SP, Brasil, na proporção de $75-100 \mathrm{mg} / \mathrm{Kg}$ de Ketamina e de $5-10 \mathrm{mg} / \mathrm{Kg}$ de Xylazina, injetada por via intraperitoneal, e quando necessário, houve uma complementação de 20-30\% da dose inicial.

\subsubsection{INCISÃO E DIVULSÃO DOS TECIDOS}

Os animais foram anestesiados e submetidos a uma incisão sagital de aproximadamente $1 \mathrm{~cm}$ de extensão na região central da calvária, com lâmina de bisturi estéril número 15 , previamente montada em cabo de bisturi número 3 , de modo a expor a região óssea desejada (Figura 1). 

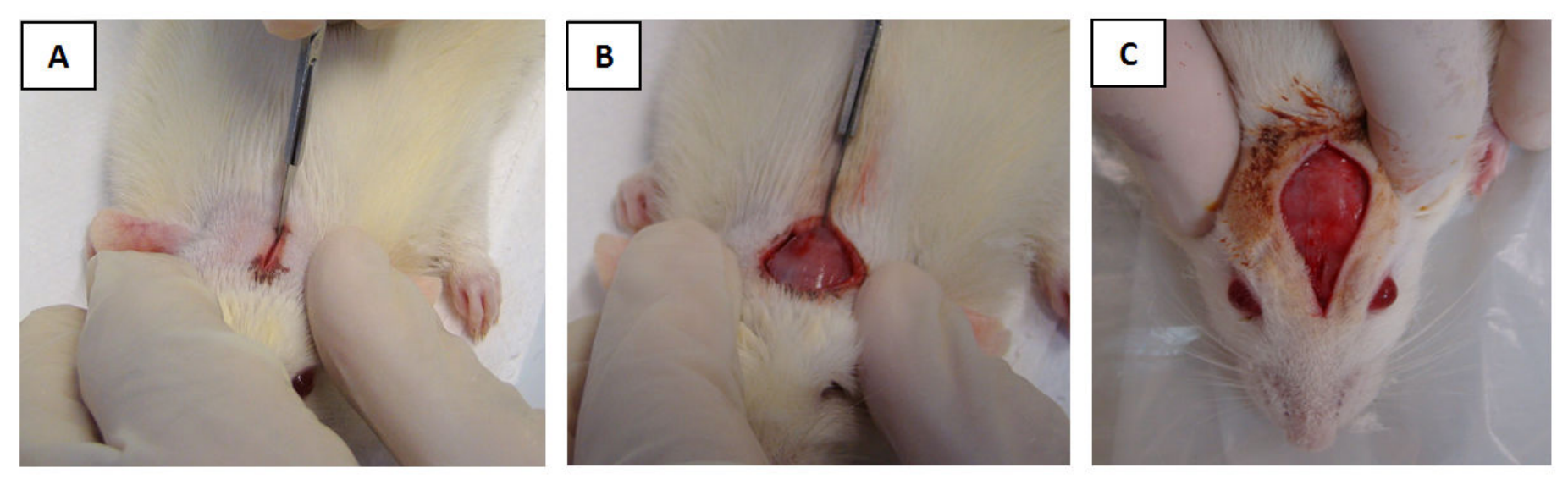

Figura 1 - Incisão e divulsão dos tecidos.

A - Início da incisão sagital na calvária do animal.

B - Fim da incisão sagital na calvária do animal.

C - Divulsão do tecido subjacente para exposição da área cirúrgica.

\subsubsection{CRIAÇÃO DO DEFEITO ÓSSEO CIRÚRGICO E INSERÇÃo dOS MATERIAIS}

Na calvária exposta, foi realizado defeito ósseo cirúrgico na região do lobo parietal esquerdo. Para isso foi utilizada uma broca do tipo trefina adaptada em contra-ângulo (Kavo, São Paulo, Brasil) e com o auxílio de um motor elétrico para implantes, ajustado em 3000rpm, com constante e abundante irrigação com soro fisiológico 0,9\%; criando um defeito ósseo cilíndrico de $6 \mathrm{~mm}$ de diâmetro externo, estando esta dimensão dentro dos padrões citados na literatura. Foram realizadas as falhas ósseas na região fronto-parietal esquerda de cada animal, transpassando toda espessura óssea, com exposição e manutenção da integridade das meninges no fundo da falha. Posteriormente se deu a inserção dos materiais (Figura 2). 

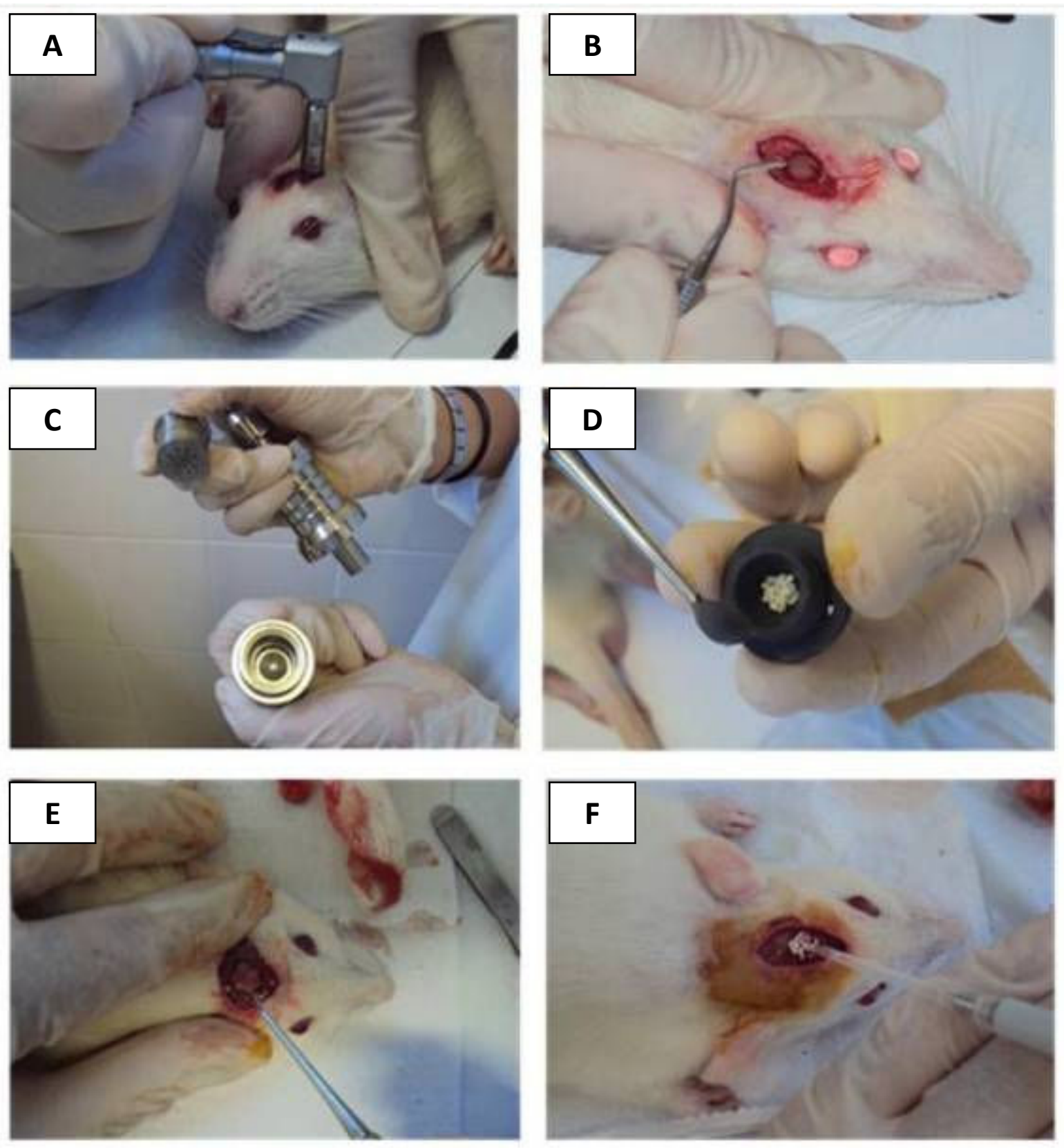

Figura 2 - Criação do defeito ósseo e aplicação do material.

A: Criação do defeito ósseo cirúrgico no lobo parietal esquerdo com broca trefina.

B: Defeito ósseo cirúrgico delimitado.

C: Aparelho confeccionado para trituração de ossos de pequenos animais.

D: Coleta do material após trituração.

E: Aplicação da enxertia óssea.

F: Aplicação da proteína rhBMP-2. 
Para a confecção do enxerto do grupo 1 (autólogo) se excisou o tecido ósseo da calota do animal com auxílio da broca trefina, se procedeu a limpeza com remoção do periósteo e sangue, e o osso foi macerado e reposicionado sobre o leito do defeito ósseo. Para o grupo 2 (homólogo) se excisou o tecido ósseo da calota de um animal aleatório do grupo 8 (animal B), se procedeu a limpeza e maceração, e este osso particulado foi posicionado sobre o leito do defeito ósseo de um outro animal do grupo 2 (animal A). Para o grupo 3 (heterólogo), se depositou osso bovino liofilizado industrial sobre o leito do defeito ósseo. O mesmo foi realizado respectivamente para os animais dos grupos 4 (autólogo + BMP), 5 (homólogo + BMP) e 6 (heterólogo + BMP), porém com adição posterior do preparado de rhBMP2. No grupo 7 (BMP) foi adicionada apenas o preparado de rhBMP-2 sobre o leito do defeito ósseo. O grupo 8 (defeito ósseo), doador do enxerto homólogo para os grupos 2 e 5, não foi tratado.

\subsubsection{SUTURA DOS TECIDOS E MEDICAÇÃO}

Após a cirurgia foi realizada a sutura dos tecidos, sendo a pele do animal, juntamente do periósteo reposicionada a sua posição original, suturada com fio de seda 4.0 (Ethicon, Johnson \& Johnson, São José dos Campos, SP, Brasil), de modo a fechar devidamente as margens do retalho. Em seguida, cada animal recebeu uma dose de $0,1 \mathrm{~mL} / 100 \mathrm{~g}$ de peso do antibiótico Pentabiotic Veterinário Pequeno Porte (Fort Dodge ${ }^{\circledR}$, Campinas, SP, Brasil). Os animais também receberam imediatamente após a cirurgia uma dose única do analgésico Banamine $(1 \mathrm{~mL} / \mathrm{kg})$ por via subcutânea (Figura 3). 

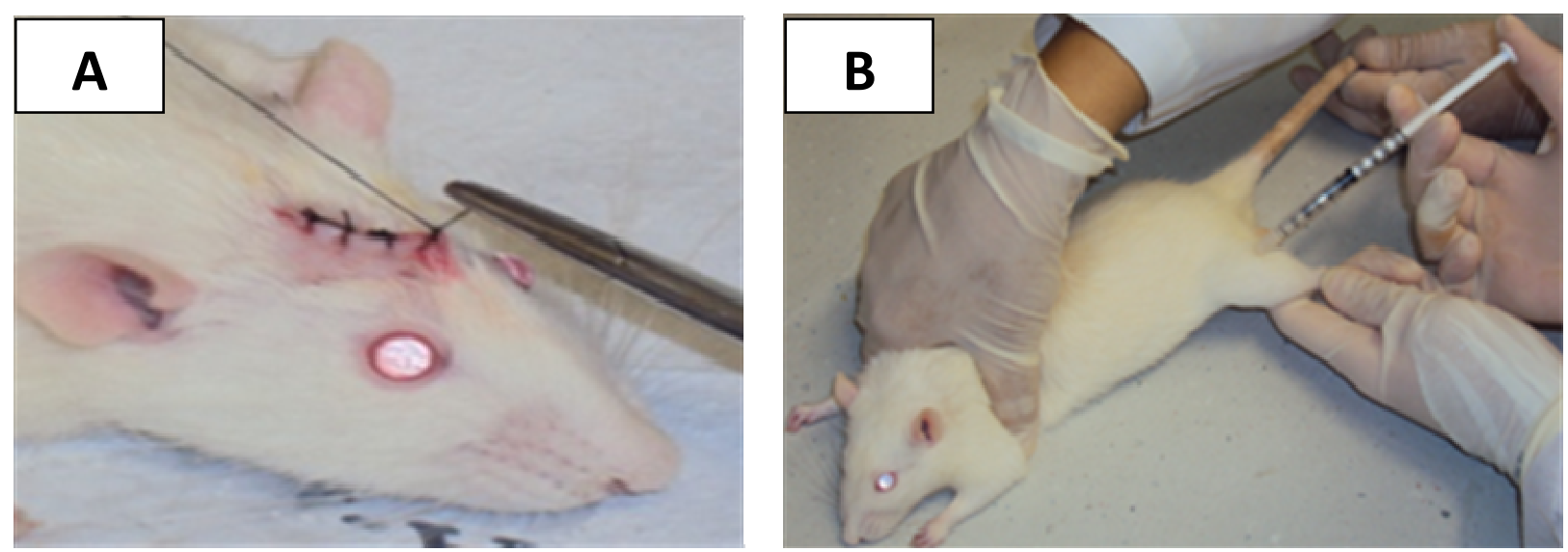

Figura 3 - Sutura e medicação.

A: Sutura dos tecidos e posterior anti-sepsia.

B: Injeção de antibiótico.

\subsection{CONTROLE PÓS-OPERATÓRIO}

Os animais operados ficaram sob observação constante e receberam ração comum para animais de pequeno porte, sendo feita a limpeza de suas caixas, com troca da maravalha diariamente.

\subsection{SACRIFÍCIO DOS ANIMAIS}

Após os períodos pré-determinado de 4 e 6 semanas de criação do defeito ósseo cirúrgico, os animais foram anestesiados com a solução anestésica de Coopazine (Xylazina) - sedativo, analgésico e relaxante muscular; e Dopalen (Ketamina) - anestésico geral, fornecido pela Agibrands do Brasil LTDA- Campinas, SP, Brasil, na proporção de $75-100 \mathrm{mg} / \mathrm{Kg}$ de Ketamina e de $5-10 \mathrm{mg} / \mathrm{Kg}$ de 
Xylazina, injetada por via intramuscular. Na sequência, a cabeça dissecada para a obtenção da amostra de interesse.

\subsection{PREPARO DAS AMOSTRAS}

Para obtenção do tecido para análise foi realizada a exposição do osso na região fronto-parietal e identificado o defeito ósseo em reparo mediante observação dos limites entre a lesão de $6 \mathrm{~mm}$ de diâmetro externo e o osso secundário sadio. Procedeu-se então a remoção da região em reparo, utilizando serra de corte sagital, com manutenção de margem de $2 \mathrm{~mm}$ em cada lado da lesão, formando um quadrado de lados de $10 \mathrm{~mm}$ com a região do defeito ósseo no centro. Este tecido excisado foi então dividido ao meio fornecendo duas peças: uma utilizada na técnica de zimografia, a outra na técnica de dosagem total de cálcio (conforme esquema representado nas figuras 4 e 5). As peças foram congeladas em nitrogênio líquido e armazenadas em freezer $-80^{\circ} \mathrm{C}$.
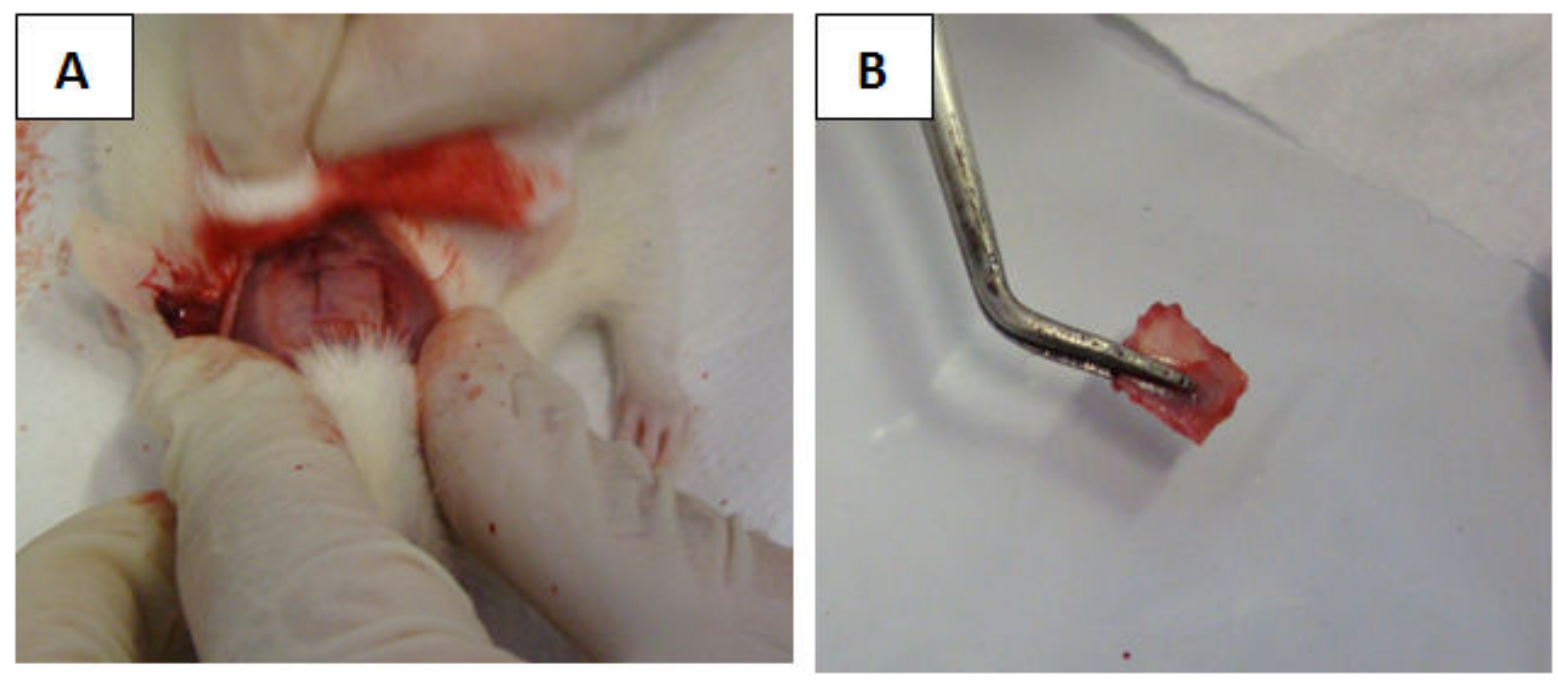

Figura 4 - Remoção da peça amostral. 

A: Confecção da excisão com margem.
B: Tecido amostral excisado.

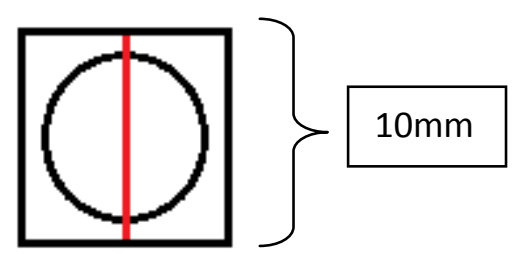

Figura 5 - Divisão do tecido amostral excisado. A metade esquerda foi pesada e utilizada na dosagem de cálcio, a metade direita foi utilizada na dosagem de proteínas.

\subsection{ANÁLISE ZIMOGRÁFICA}

Os procedimentos para verificação da atividade de MMP-2 e -9 seguiram o protocolo de Marqueti et al. (2008), que foi adaptado para este estudo. Cada grupo de animais foi analisado conjuntamente. A calota craniana em reparo foi removida, limpa e macerada com nitrogênio líquido. A amostra de osso macerado foi incubada em $2 \mathrm{~mL}$ de tampão de extração [10mM de ácido cacodílico, $\mathrm{pH} 5,0 ; 0,15 \mathrm{M} \mathrm{NaCl} ; 1 \mathrm{M}$ $\mathrm{ZnCl} 2 ; 20 \mathrm{mM} \mathrm{CaCl} 2 ; 1,5 \mathrm{mM}$ NaN3; $0,01 \%$ Triton X-100 (v/v)] em $4^{\circ} \mathrm{C}$ overnight sob agitação constante. Após este período, a solução foi centrifugada durante 10 minutos $\left(9000 \mathrm{~g}\right.$ a $\left.4^{\circ} \mathrm{C}\right)$. As proteínas presentes nas amostras foram então quantificadas pelo método de Bradford, utilizando o reagente Protein Assay (BioRad Laboratories) e aplicou-se $40 \mathrm{mg}$ do total de proteínas em cada poço de um gel de poliacrilamida SDS $10 \%$, preparado com $1 \mathrm{mg} / \mathrm{mL}$ de gelatina. Depois da eletroforese, o gel foi lavado duas vezes em 2,5\% Triton X-100 para remover o SDS. O gel foi então incubado em tampão $(50 \mathrm{mM}$ Tris-HCl, $\mathrm{pH} 8,0 ; 5 \mathrm{mM} \mathrm{CaCl} 2 ; 0,02 \%$ NaN3) a $37^{\circ} \mathrm{C}$ por $20 \mathrm{~h}$. Foi então corado com Comassie brilliant blue durante $1,5 \mathrm{~h}$ e o excesso de coloração removido com descorante à base de ácido 
acético:metanol:água (1:4:5) para a visualização das bandas com atividade enzimática. Após fotografia em comutador especial, as bandas encontradas e relacionadas ao padrão de soro fetal bovino, que apresentavam 66-62 kDa, foram consideradas ativas para MMP-2. As bandas de $82 \mathrm{kDa}$ foram consideradas ativas para MMP-9. As bandas de $72 \mathrm{kDa}$ foram consideradas ativas de proMMP-2 e as bandas de $92 \mathrm{kDa}$ foram consideradas ativas de proMMP-9. O padrão de massa molecular utilizado foi a soroalbumina bovina (BSA Sigma, EUA; 66kDa). As imagens foram analisadas no programa "Image J".
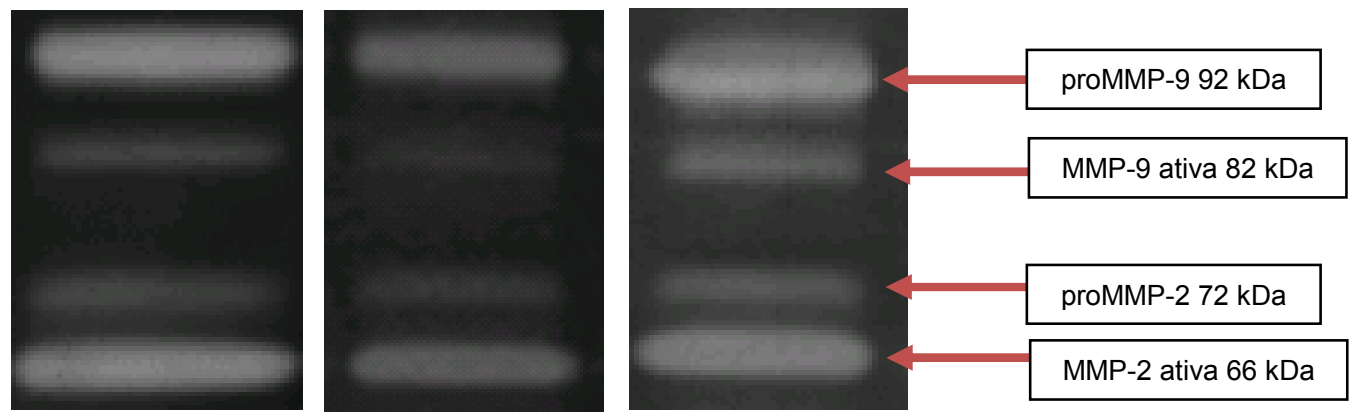

Figura 6 - Imagens zimográficas das enzimas. As figuras representam a imagem obtida no gel de poliacrilamida com gelatina, que após coloração, identifica o local onde ocorre a atividade da enzima, degradando a gelatina. À direita os pesos moleculares das respectivas isoformas das enzimas estudadas. 

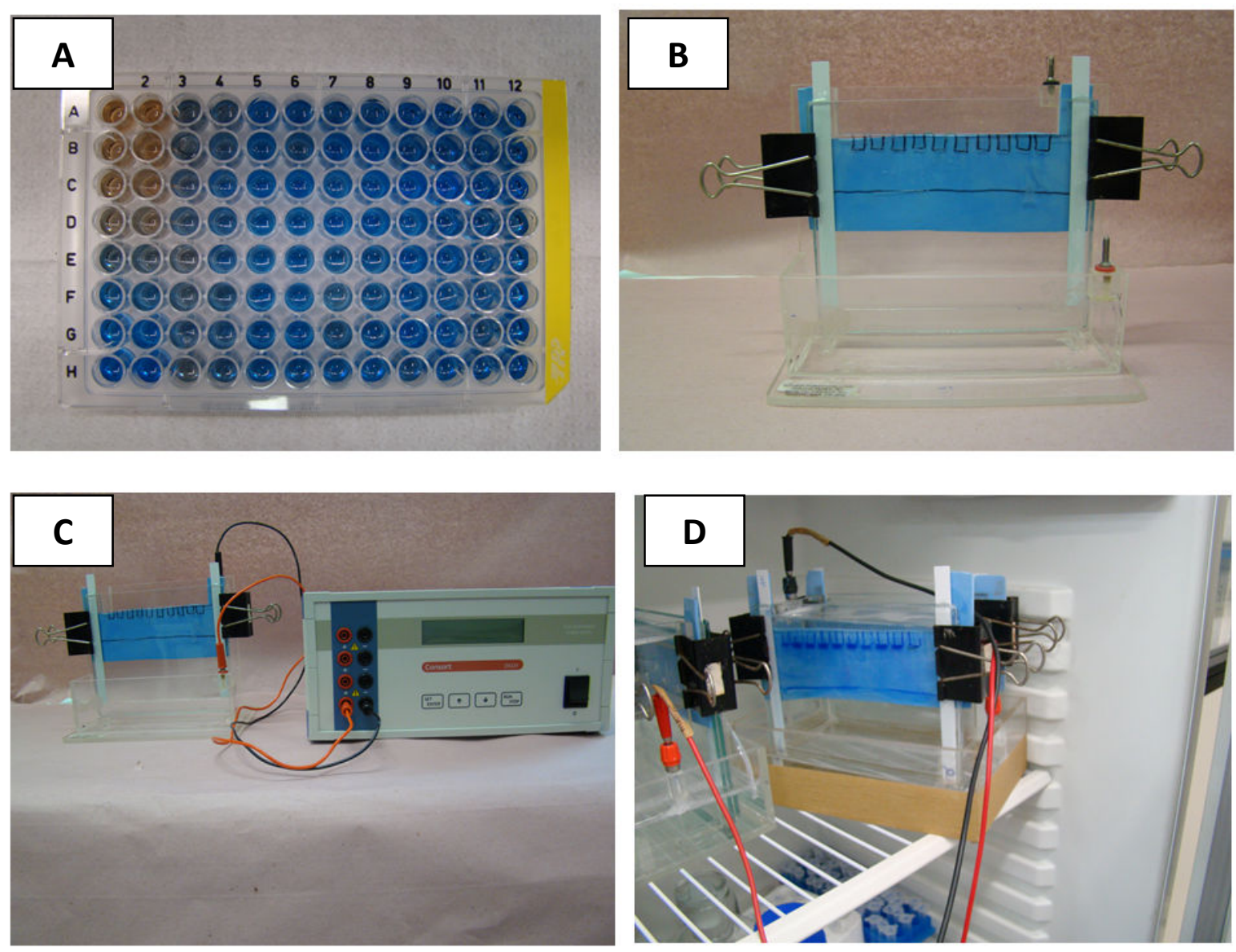

Figura7 - Dosagem de proteínas e zimografia.
A: Preparo das amostras em placa de ELISA para dosagem de proteínas
B: Preparo do gel de poliacrilamida
C: Equipamento de eletroforese
D: Eletroforese do gel de poliacrilamida

\subsection{WESTERN-BLOT}

O processo de western-blot teve por finalidade comprovar a existência das proteínas em questão no estudo e permitir uma análise segura da zimografia.

As amostras foram preparadas e submetidas à corrida em minigel de poliacrilamida $15 \%$. Depois, seguir no processo de transferência de proteínas para 
membrana de nitrocelulose (electroblotting). A membrana foi bloqueada em tampão com Tris-HCl10 mM, NaCl 150 mM, pH 7,5 (TBS) contendo BSA 5\% por duas horas à temperatura ambiente, sob agitação lenta. Após três lavagens com TBS, contendo Tween20 0,05\% (TBS-T), a membrana foi incubada overnight (aproximadamente 18 horas) com anticorpo para a MMP-2 (Millipore, MAB3308) e após processo de deblotting com anti-MMP-9 (Millipore, MAB3309) em TBS-T. O excesso de anticorpo na membrana foi removido com três lavagens de 10 minutos em TBS-T. Em seguida, a membrana foi incubada com o anticorpo secundário (anti-lgG de camundongo/fosfatase alcalina diluído 1:10000 - Sigma, EUA) por 60 minutos. Novamente a membrana foi submetida a lavagens sucessivas com tampão TBS e, então, revelada com o substrato $\mathrm{BCIP}$ 0,4 mM/ NBT 0,4 mM. Após a revelação, a membrana foi digitalizada.

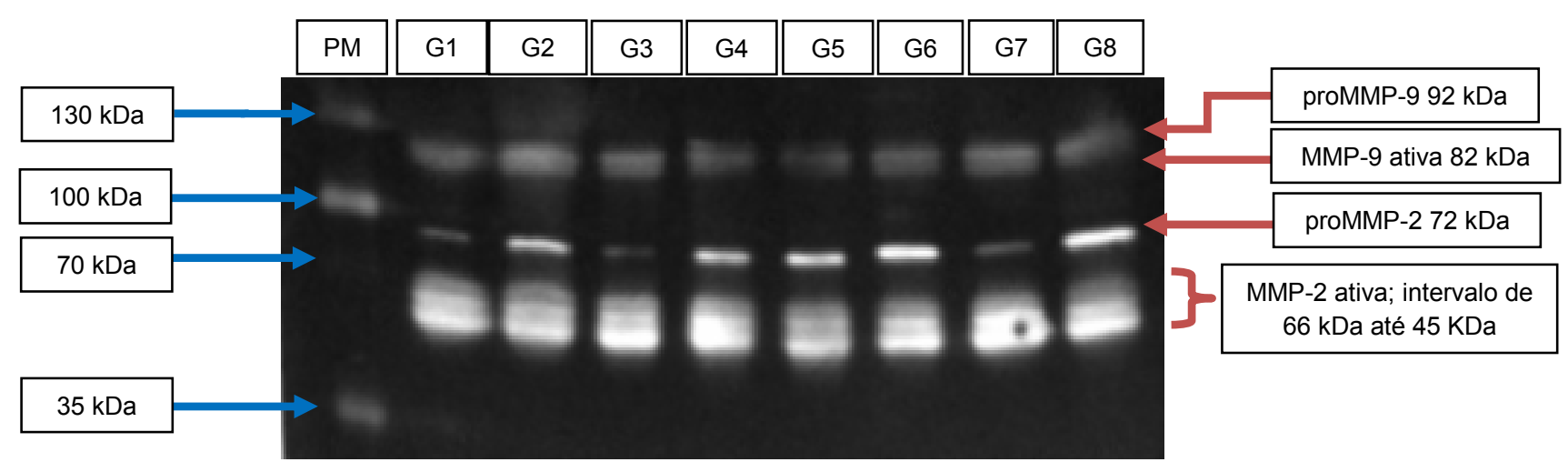

Figura 8 - Imagem do western-blot comprovando a existência das proteínas em questão. Da esquerda para a direita: a primeira coluna corresponde ao marcador de peso molecular (PM), as demais colunas representam os grupos de 1 a 8 (G1 a G8) cujas amostras foram conjugadas. À esquerda os pesos moleculares de cada escala do marcador de peso molecular. À direita os pesos moleculares das respectivas isoformas das enzimas. 


\subsection{ANÁLISE DA DOSAGEM DE CÁLCIO}

A análise da dosagem de cálcio foi executada em equipamento de absorção atômica por chama (AAS400 Perkin Elmer, Norwalk, USA), que mede a absorbância de acordo com o espectro crômico da chama. O protocolo consiste em 10L/min de oxidante misturado com $2,5 \mathrm{~L} / \mathrm{min}$ de gás acetileno, para um consistir chama ideal purificada de aproximadamente 2700 graus Celsius. Com lâmpada especial para cálcio operando a 10mA para captar a absorbância. Conforme figura 9, demonstrando a chama do aparelho durante a análise.
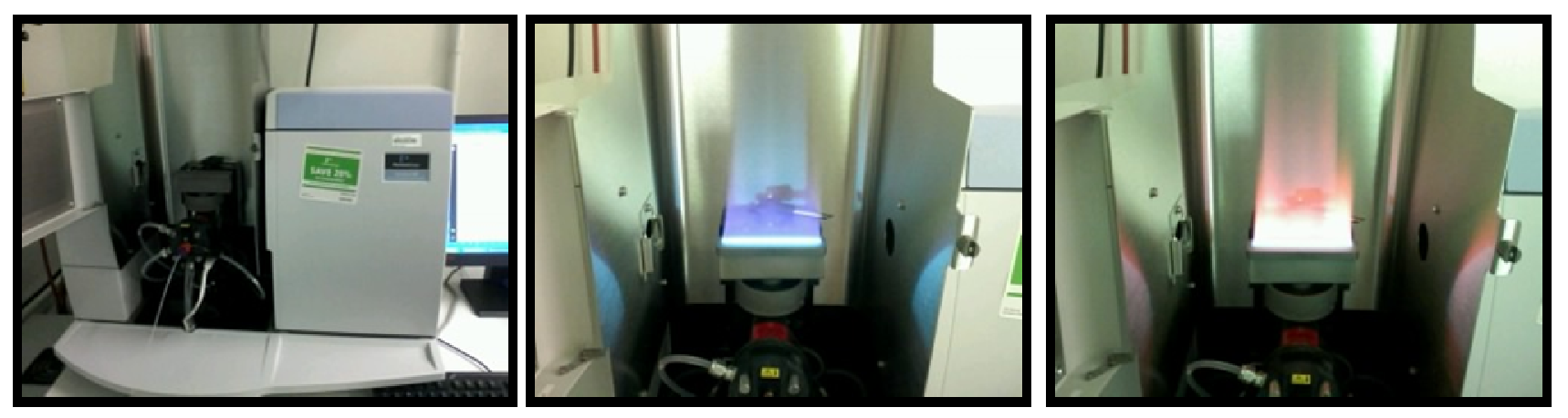

Figura 9 - Imagens do computador dosador de metais utilizado na dosagem de cálcio. Da esquerda para direita: o equipamento preparado para a dosagem; a chama azul livre de substâncias; a chama vermelha cuja densidade varia de acordo com as dosagens de cálcio na mistura.

A calibração ideal responde a um slope de 0,9995\%. O Lantânio é o catalisador necessário para a amostra, uma vez que o Fósforo é muito presente em amostras digeridas de ossos (cerca de $13,5 \%$ é fosfato) e este elemento interfere no sinal do espectrômetro quando quantificamos cálcio. Portanto o Lantânio captura o fosfato na proporção de 0,1 a $1 \%$ em solução (BEZERRA DE MENEZES ET AL., 2003). 
O comprimento de onda da lâmpada (Perkin Elmer, Norwalk, USA) para medir cálcio é de $422.67 \mathrm{~nm}$ com nível de corrente igual a $15 \mathrm{~mA}$.

Para o padrão: 150 ul de padrão concentrado $5 \mathrm{mg} / \mathrm{L}$ para $29,8 \mathrm{ml}$ de água miliQ+ 50uL de Lantânio para obter $5 \mathrm{mg} / \mathrm{L}$ de cálcio diluído.

Para as amostras foi utilizada uma diluição de 1:10.000, considerando que a solução final corresponde a $5 \mathrm{ml}$, pois a maquina realiza a sucção de $3 \mathrm{ml}$ em média. Para as análises considerou-se que o cálcio corresponde a $37,6 \%$ do total de osso (AMMERMAN ET AL., 1974).

\subsection{ANÁLISE ESTATÍSTICA}

O teste estatístico utilizado foi ONE-WAY ANOVA com o pós-teste de TURKEY. Todas as amostras foram verificadas quanto à distribuição normal e também quanto à presença de outliers mediante teste de Grubbs. Os dados foram expressos como média \pm desvio padrão. O nível de significância estatística foi $p<0,05$. 


\section{RESULTADOS}

Todos os animais do experimento sobreviveram ao procedimento cirúrgico. Apesar da exposição das meninges na confecção das falhas, durante o período pósoperatório não foram observados sinais de infecção ou complicações neurológicas e todos os animais permaneceram alertas, conscientes e deambulando normalmente.

Não foi observado crescimento ósseo na face ventral das meninges, em contato com o tecido nervoso. Independentemente do período de observação e do tratamento, o preenchimento iniciou-se a partir das bordas para o centro (centrípeto) e do fundo para a superfície das falhas, apresentando aspecto menos compacto que o tecido ósseo vizinho, típico de tecido osteóide, provavelmente pela precocidade da observação e imaturidade do tecido ósseo formado.

\subsection{PESO DOS ANIMAIS - ANÁLISE COMPARATIVA DOS GRUPOS}

1 - Peso dos animais nos grupos de 4 semanas:

\begin{tabular}{|r|rrrrr|rrrrr|} 
& Grupo 1 & Grupo 2 & Grupo 3 & Grupo 4 & Grupo 5 & Grupo 6 & Grupo 7 & Grupo 8 \\
\hline A1 & 285 & 266 & 288 & 256 & 299 & 302 & 236 & 256 \\
A2 & 274 & 278 & 304 & 275 & 301 & 278 & 299 & 298 \\
A3 & 258 & 277 & 256 & 279 & 274 & 277 & 300 & 300 \\
A4 & 277 & 296 & 289 & 306 & 273 & 256 & 288 & 288 \\
A5 & 268 & 265 & 288 & 314 & 265 & 274 & 285 & 256 \\
A6 & 289 & 277 & 275 & 288 & 266 & 266 & 265 & 268 \\
A7 & 290 & 255 & 254 & 265 & 286 & 289 & 274 & 269 \\
\hline
\end{tabular}

Figura 10 - Tabela representando os números individuais de peso em gramas dos animais pertencentes aos grupos de 4 semanas. 


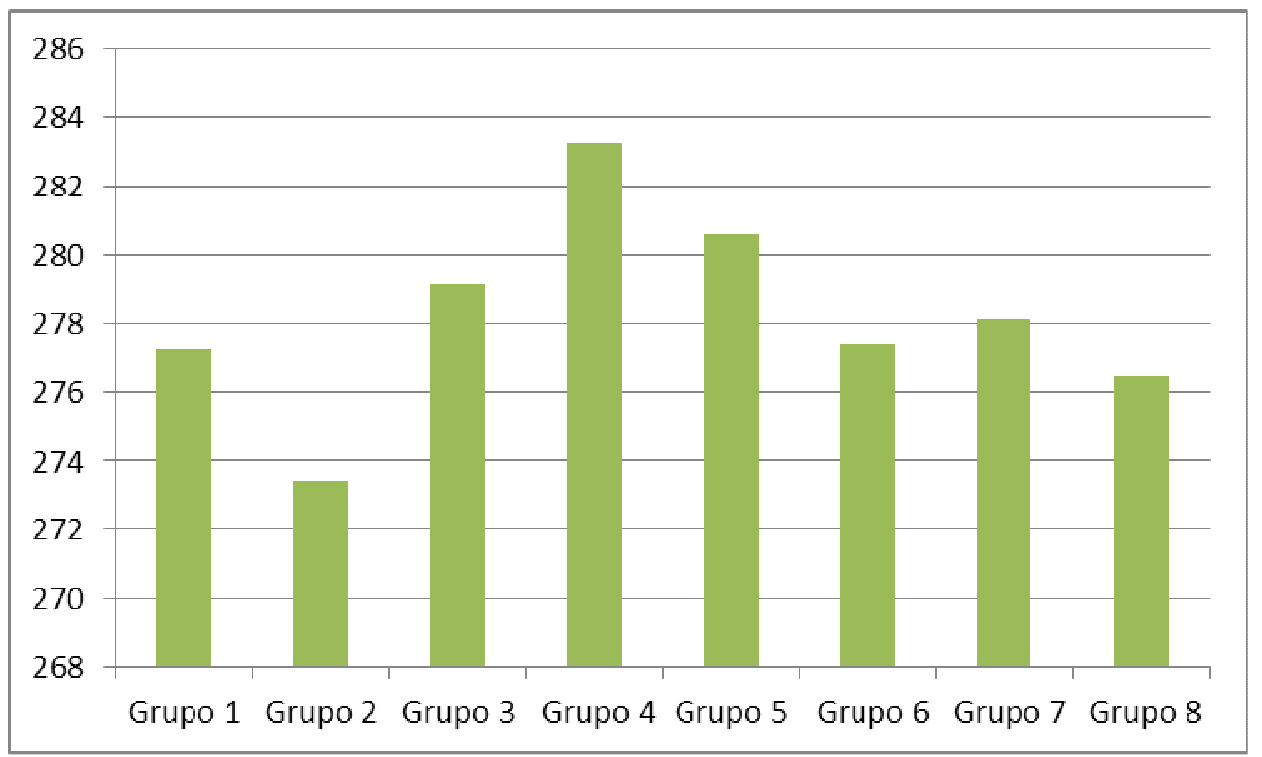

Figura 11 - Gráfico das médias de peso em gramas dos animais nos grupos de 4 semanas.

2 - Peso dos animais nos grupos de 6 semanas:

\begin{tabular}{|l|r|r|r|r|r|r|r|r|}
\cline { 3 - 9 } \multicolumn{1}{l|}{} & Grupo 1 & Grupo 2 & Grupo 3 & Grupo 4 & Grupo 5 & Grupo 6 & Grupo 7 & Grupo 8 \\
\hline A1 & 354 & 288 & 289 & 322 & 306 & 338 & 288 & 278 \\
\hline A2 & 336 & 301 & 308 & 300 & 312 & 306 & 319 & 304 \\
\hline A3 & 306 & 306 & 318 & 300 & 306 & 307 & 335 & 312 \\
\hline A4 & 282 & 298 & 306 & 312 & 299 & 322 & 306 & 300 \\
\hline A5 & 302 & 314 & 302 & 350 & 289 & 300 & 300 & 289 \\
\hline A6 & 299 & 322 & 288 & 302 & 302 & 298 & 299 & 278 \\
\hline A7 & 314 & 326 & 300 & 301 & 300 & 303 & 304 & 301 \\
\hline
\end{tabular}

Figura 12 - Tabela representando os números individuais de peso em gramas dos animais pertencentes aos grupos de 6 semanas. 


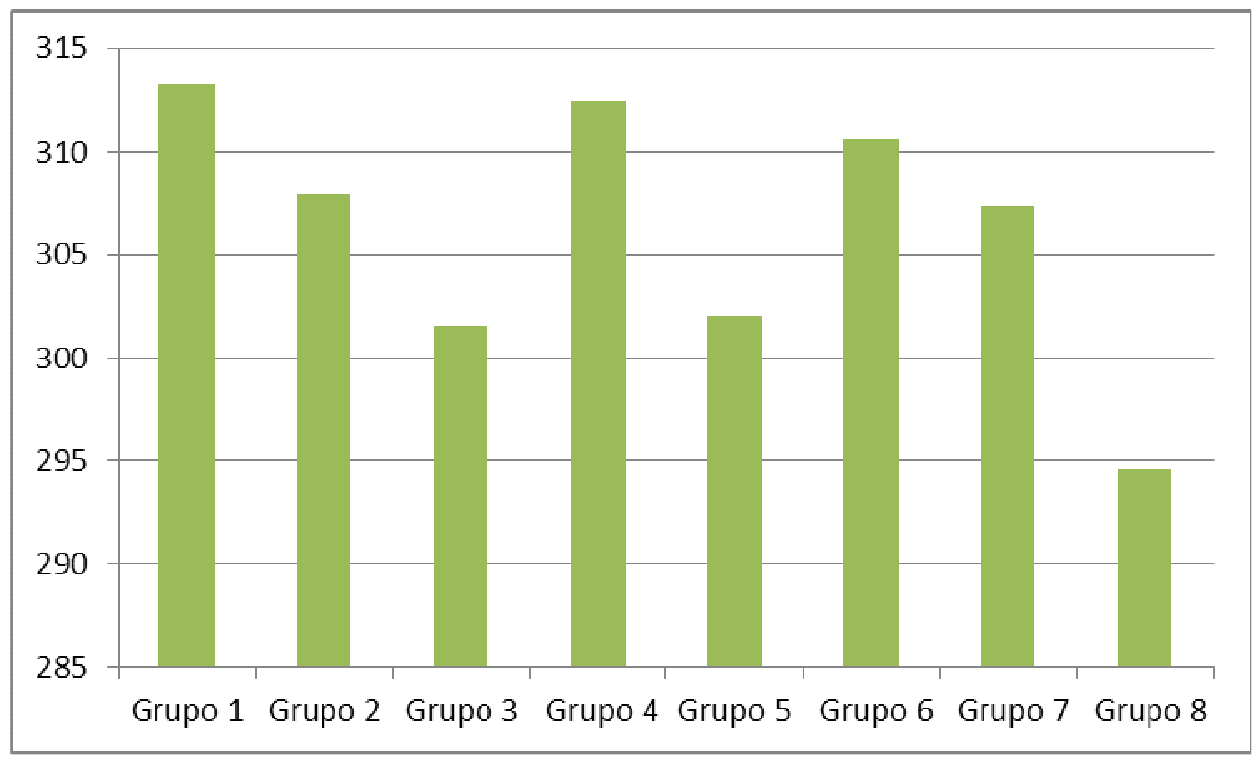

Figura 13 - Gráfico das médias de peso em gramas dos animais nos grupos de 6 semanas.

\subsection{MMP-2 e PrOMMP-2 - ANÁLISE COMPARATIVA DOS GRUPOS}

$\mathrm{Na}$ análise de MMP-2 no tempo de 4 semanas todos os grupos passaram no teste de normalidade "Shapiro-Wilk normality test" e "Kolmogorov-Smirnovtest", com intervalo de confiança de 95\%,mostrando distribuição normal. A figura 15 mostra a comparação entre os grupos mediante One-way ANOVA com pós-teste de Turkey.

\begin{tabular}{|l|r|r|r|r|r|r|r|r|}
\cline { 2 - 9 } & Grupo 1 & Grupo 2 & Grupo 3 & Grupo 4 & Grupo 5 & Grupo 6 & Grupo 7 & Grupo 8 \\
\hline A1 & 1,133775 & 0,718581 & 1,044545 & 1,348934 & 0,963543 & 0,823862 & 0,58695 & 0,900454 \\
A2 & 1,416748 & 1,064593 & 1,092748 & 1,397755 & 1,534177 & 0,941419 & 1,670892 & 1,051777 \\
\hline A3 & 1,077569 & 1,147327 & 1,687791 & 1,236669 & 1,094779 & 1,500175 & 1,343827 & 1,130842 \\
\hline A4 & 1,291217 & 1,266707 & 1,28114 & 0,968165 & 1,01616 & 1,536621 & 1,76328 & 1,13916 \\
\hline A5 & 0,96759 & 1,415944 & 1,459639 & 0,968165 & 1,225189 & 1,238343 & 1,325543 & 1,074681 \\
A6 & 1,192743 & 1,469417 & 1,034531 & 1,111153 & 1,657549 & 1,425312 & 0,931492 & 1,253725 \\
A7 & 0,80615 & 1,005936 & 1,02373 & 1,129636 & 0,928758 & 1,020405 & 1,082247 & 1,115151 \\
\hline Média & 1,126542 & 1,155501 & 1,232018 & 1,165783 & 1,202879 & 1,212305 & 1,243461 & 1,095113 \\
\hline
\end{tabular}

Figura 14 - Resultados individuais de cada grupo mostrando a relação de acordo com os níveis de MMP-2 identificados no tempo de 4 semanas. Unidades Arbitrárias. 


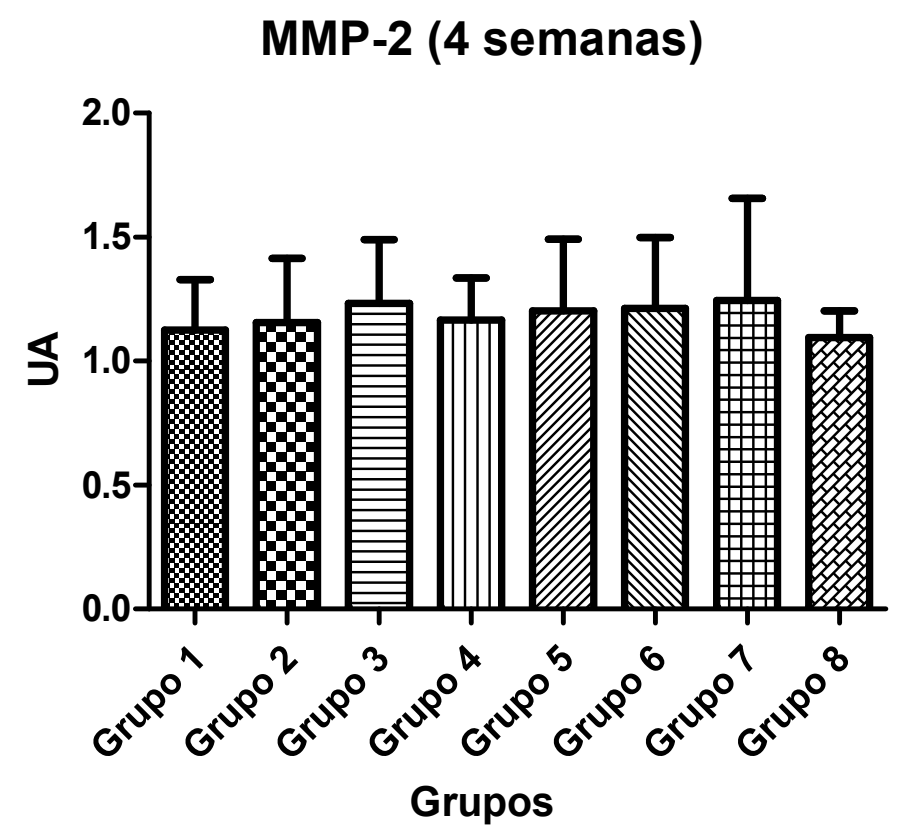

Figura 15 - Gráfico de comparação dos níveis de MMP-2 entre os grupos no tempo de 4 semanas. Valor de $P=0,9594$. Unidades Arbitrárias.

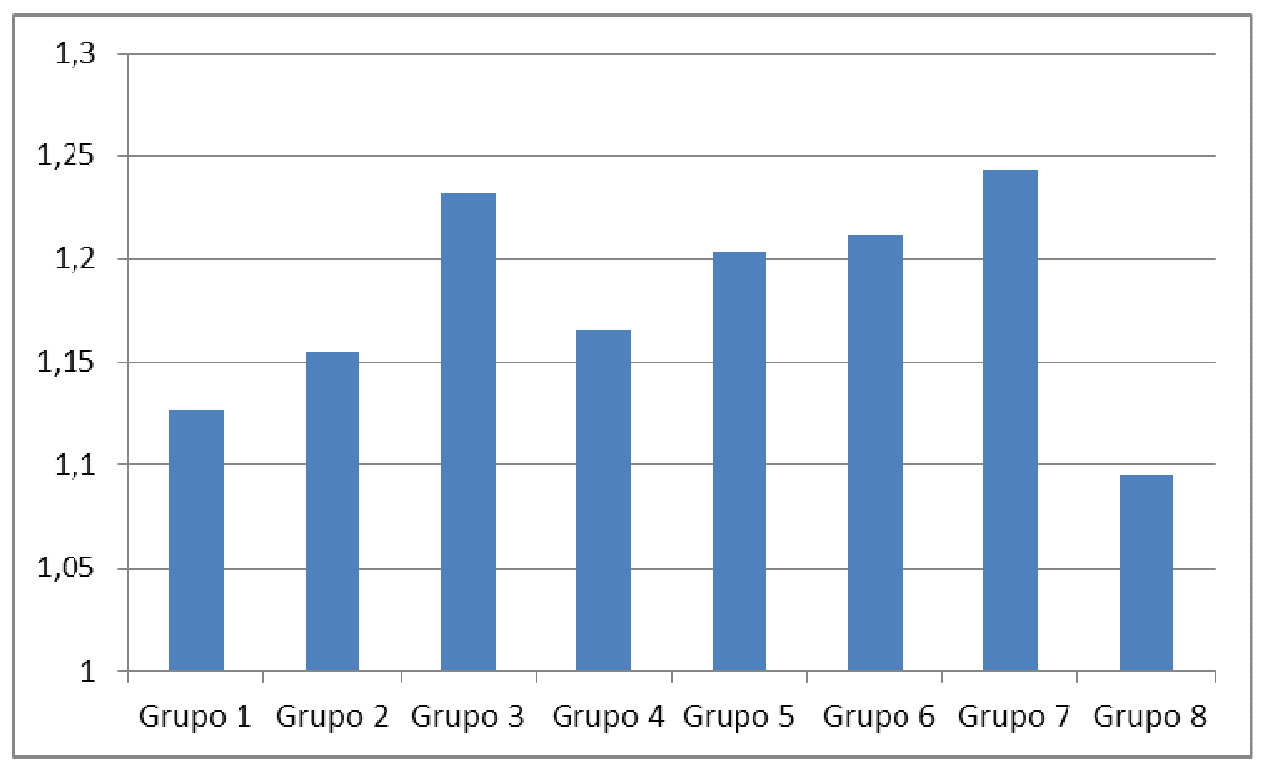

Figura 16 - Gráfico representando as médias de cada grupo para MMP-2 no tempo de 4 semanas. Unidades Arbitrárias.

A análise estatística não identificou diferença significante entre os grupos para MMP-2 no tempo de quatro semanas quando comparados entre si. 
Na análise de proMMP-2 no tempo de 4 semanas todos os grupos passaram no teste de normalidade "Shapiro-Wilk normality test", com intervalo de confiança de 95\%, mostrando distribuição normal. A figura 18 mostra a comparação entre os grupos mediante One-way ANOVA com pós-teste de Turkey.

\begin{tabular}{|l|r|r|r|r|r|r|r|r|}
\cline { 2 - 9 } & Grupo 1 & Grupo 2 & Grupo 3 & Grupo 4 & Grupo 5 & Grupo 6 & Grupo 7 & Grupo 8 \\
\hline A1 & 0,995458 & 1,04502 & 1,868518 & 1,07221 & 1,552778 & 1,582563 & 0,997066 & 1,061572 \\
\hline A2 & 0,917815 & 1,124236 & 1,620918 & 1,133453 & 1,310995 & 1,288769 & 1,352279 & 1,057173 \\
\hline A3 & 1,029878 & 0,975058 & 1,682785 & 1,207619 & 0,765613 & 1,205152 & 1,041883 & 0,9398 \\
A4 & 1,214525 & 1,408953 & 1,124163 & 1,156677 & 1,06307 & 1,190873 & 1,822999 & 1,054621 \\
A5 & 1,276609 & 1,399657 & 1,29362 & 0,958451 & 1,16007 & 1,35015 & 1,754482 & 1,084493 \\
A6 & 0,896214 & 1,313091 & 0,917671 & 1,275406 & 1,505491 & 0,927049 & 1,567394 & 1,12508 \\
A7 & 0,711938 & 1,186299 & 1,006592 & 1,174463 & 1,587896 & 0,935268 & 0,937933 & 1,071264 \\
\hline Média & 1,006062 & 1,207473 & 1,359181 & 1,139754 & 1,277988 & 1,211404 & 1,353434 & 1,056286 \\
\hline
\end{tabular}

Figura 17 - Resultados individuais de cada grupo mostrando a relação de acordo com os níveis de proMMP-2 identificados no tempo de 4 semanas. Unidades Arbitrárias.

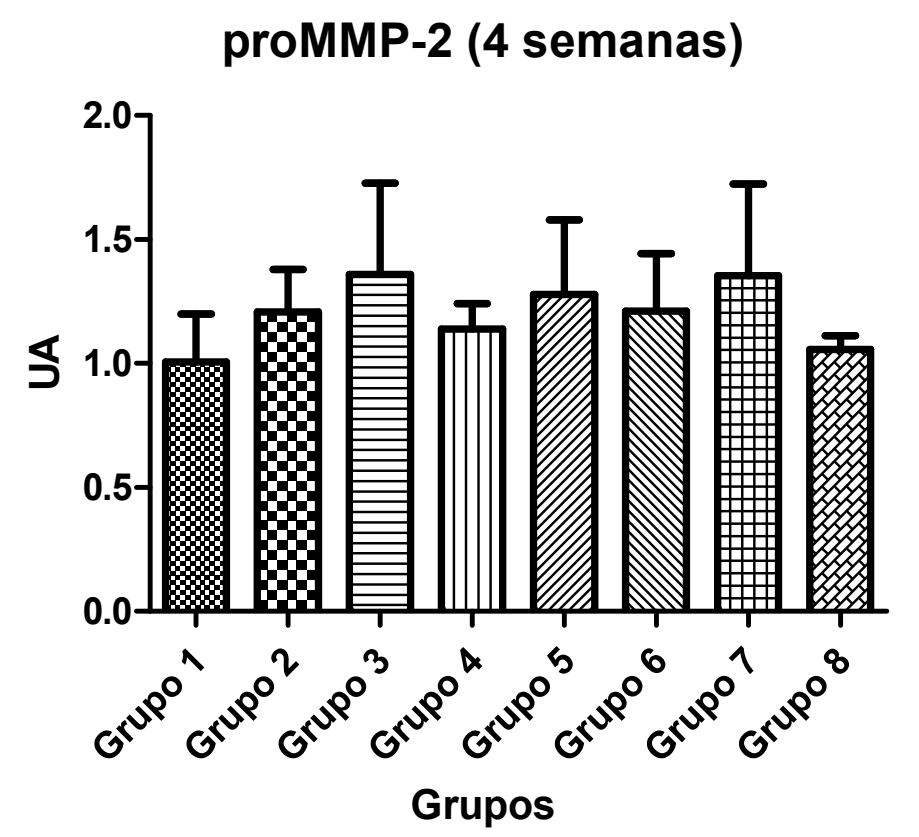

Figura 18 - Gráfico de comparação dos níveis de proMMP-2 entre os grupos no tempo de 4 semanas. Valor de $\mathrm{P}=0,0933$. Unidades Arbitrárias. 


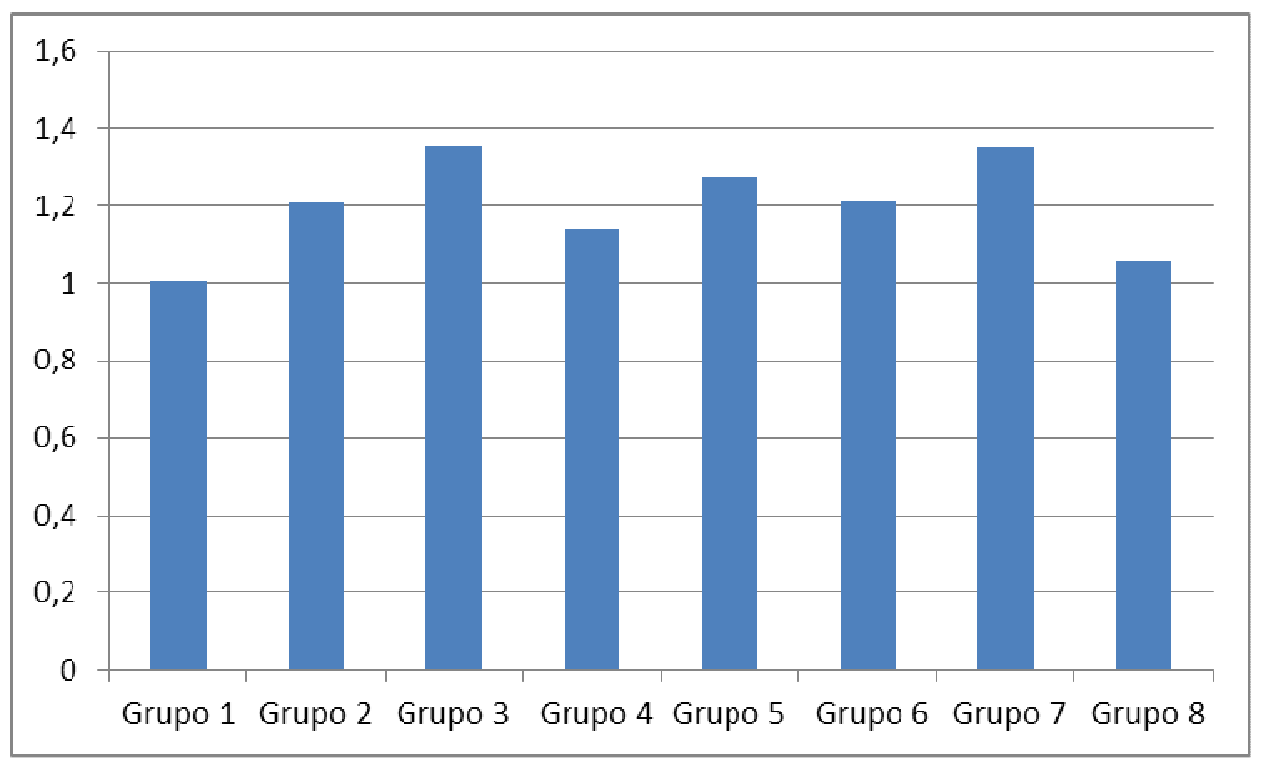

Figura 19 - Gráfico representando as médias de cada grupo para proMMP-2 no tempo de 4 semanas. Unidades Arbitrárias.

A análise estatística não identificou diferença significante entre os grupos para proMMP-2 no tempo de quatro semanas quando comparados entre si $(p=0,0933)$.

Na análise de MMP-2 no tempo de 6 semanas todos os grupos passaram no teste de normalidade "Shapiro-Wilk normality test" e "Kolmogorov-Smirnov test", com intervalo de confiança de 95\%, mostrando distribuição normal. A figura 21 mostra a comparação entre os grupos mediante One-way ANOVA com pós-teste de Turkey.

\begin{tabular}{|l|r|r|r|r|r|r|r|r|}
\cline { 2 - 9 } & Grupo 1 & Grupo 2 & Grupo 3 & Grupo 4 & Grupo 5 & Grupo 6 & Grupo 7 & Grupo 8 \\
\hline A1 & 0,817956 & 0,860883 & 1,620895 & 1,000915 & 1,100976 & 1,186894 & 1,66107 & 0,921635 \\
\hline A2 & 1,092439 & 0,663222 & 1,576833 & 0,855148 & 0,986847 & 1,36955 & 1,594576 & 0,796803 \\
\hline A3 & 0,922817 & 0,712683 & 1,652315 & 1,151578 & 1,0088 & 1,65513 & 1,536871 & 1,12722 \\
\hline A4 & 1,182707 & 1,007188 & 1,53552 & 1,078852 & 0,927464 & 1,628801 & 1,167715 & 0,982508 \\
\hline A5 & 0,816128 & 0,949269 & 1,307931 & 1,130738 & 1,543805 & 1,032508 & 1,542899 & 1,298354 \\
\hline A6 & 1,141397 & 1,285858 & 1,117169 & 1,138647 & 1,458997 & 1,404996 & 1,061129 & 1,402405 \\
\hline A7 & 1,332937 & 1,236183 & 1,153935 & 1,178299 & 1,042262 & 1,10568 & 1,17558 & 1,171297 \\
\hline Média & 1,043769 & 0,959327 & 1,423514 & 1,076311 & 1,152736 & 1,340508 & 1,391406 & 1,100032 \\
\hline
\end{tabular}

Figura 20 - Resultados individuais de cada grupo mostrando a relação de acordo com os níveis de MMP-2 identificados no tempo de 6 semanas. Unidades Arbitrárias. 


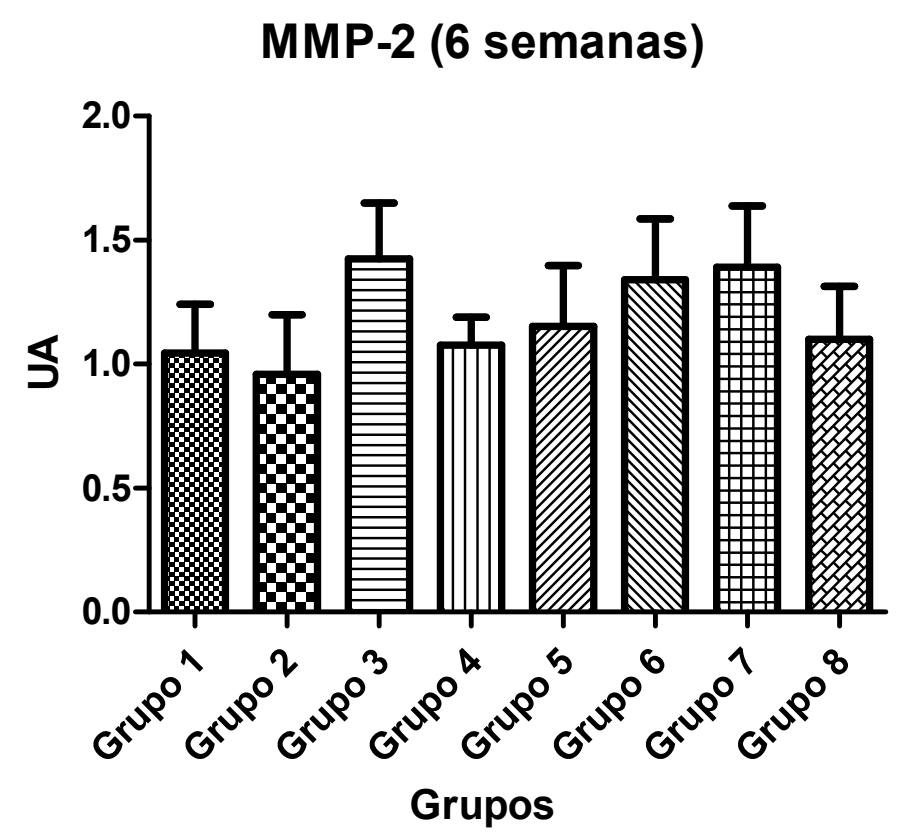

Figura 21 - Gráfico de comparação dos níveis de MMP-2 entre os grupos no tempo de 6 semanas. Valor de $\mathrm{P}=0,0007$. Unidades Arbitrárias.

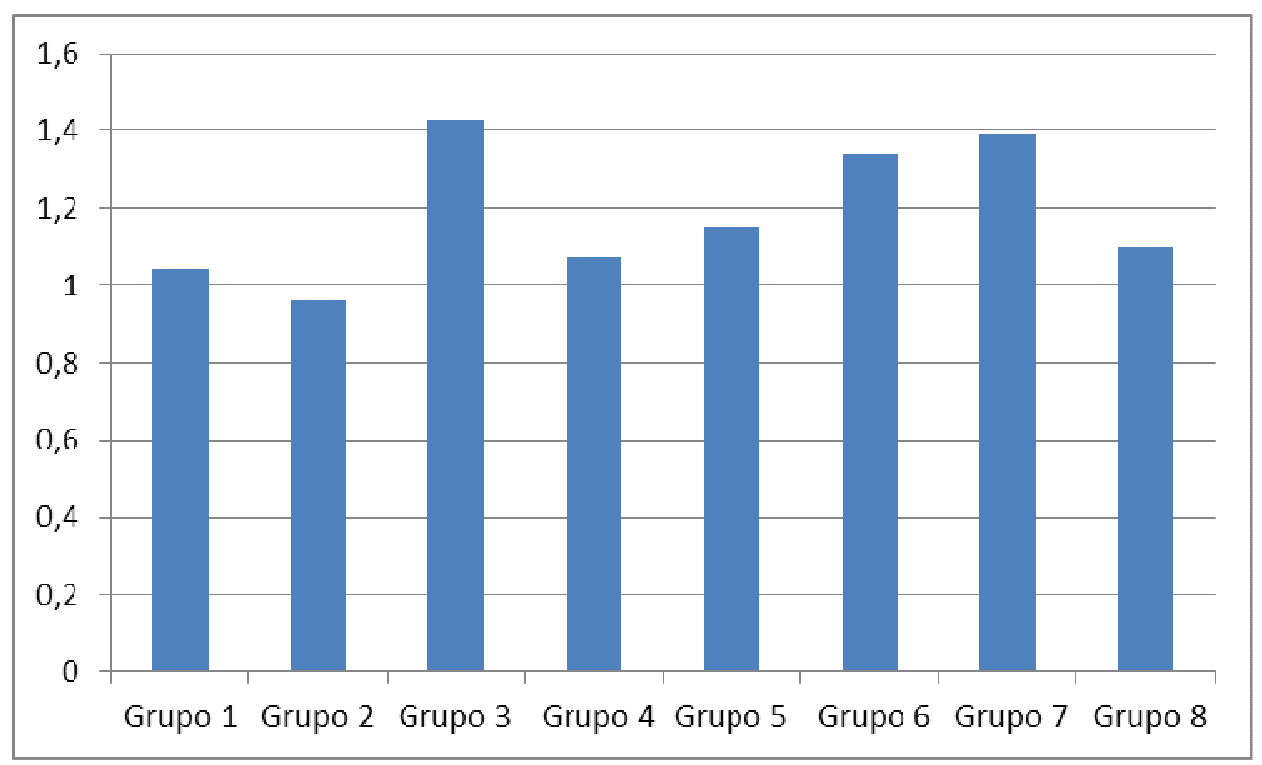

Figura 22 - Gráfico representando as médias de cada grupo para MMP-2 no tempo de 6 semanas. Unidades Arbitrárias.

A análise estatística identificou diferença significante entre os grupos 1 e $3(P$ $<0,05)$, entre os grupos 2 e 3 , entre os grupos 2 e $6(P<0,05)$, e entre os grupos 2 e $7(P<0,05)$, para MMP-2 no tempo de seis semanas quando comparados entre si. 
$\mathrm{Na}$ análise de proMMP-2 no tempo de 6 semanas todos os grupos passaram no teste de normalidade "Shapiro-Wilk normality test" e "Kolmogorov-Smirnov test", com intervalo de confiança de 95\%, mostrando distribuição normal. A figura 24 mostra a comparação entre os grupos mediante One-way ANOVA com pós-teste de Turkey.

\begin{tabular}{|l|r|r|r|r|r|r|r|r|}
\cline { 2 - 9 } & Grupo 1 & Grupo 2 & Grupo 3 & Grupo 4 & Grupo 5 & Grupo 6 & Grupo 7 & Grupo 8 \\
\hline A1 & 0,880157 & 0,835341 & 1,947903 & 0,867641 & 0,968711 & 1,533525 & 1,882433 & 0,994201 \\
\hline A2 & 1,100638 & 0,730077 & 1,857557 & 0,761258 & 0,800872 & 1,707031 & 1,639693 & 0,827449 \\
\hline A3 & 0,843307 & 0,662418 & 1,614371 & 0,873291 & 0,961601 & 1,629055 & 1,780346 & 1,139082 \\
\hline A4 & 1,007532 & 0,811102 & 1,954542 & 0,864049 & 0,803684 & 1,382656 & 1,196264 & 1,091391 \\
\hline A5 & 0,866004 & 1,0805 & 1,303301 & 1,216885 & 1,231432 & 0,915396 & 1,465969 & 1,426988 \\
\hline A6 & 1,330295 & 1,447733 & 1,096275 & 1,065103 & 1,085776 & 1,398401 & 1,024823 & 1,579939 \\
\hline A7 & 1,340466 & 1,174972 & 1,099291 & 1,13939 & 0,954678 & 0,947239 & 1,1776 & 1,083548 \\
\hline Média & 1,052629 & 0,963163 & 1,55332 & 0,96966 & 0,972393 & 1,359043 & 1,452447 & 1,163228 \\
\hline
\end{tabular}

Figura 23 - Resultados individuais de cada grupo mostrando a relação de acordo com os níveis de proMMP-2 identificados no tempo de 6 semanas. Unidades Arbitrárias.

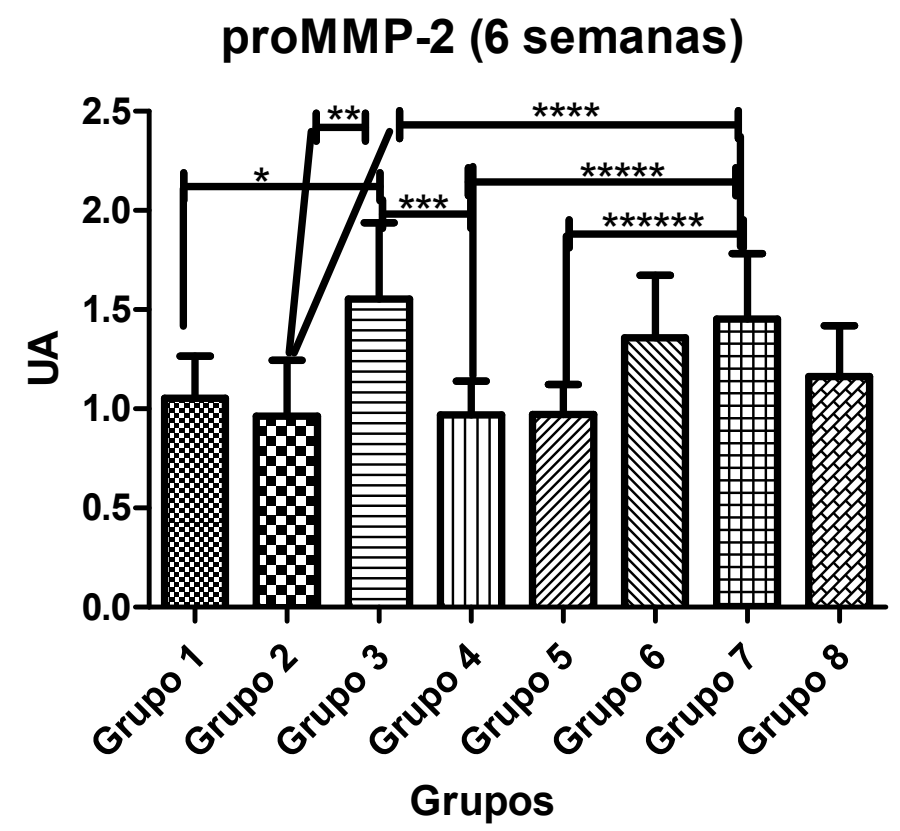

Figura 24 - Gráfico de comparação dos níveis de proMMP-2 entre os grupos no tempo de 6 semanas. Valor de $\mathrm{P}=0,0002$. Unidades Arbitrárias. 


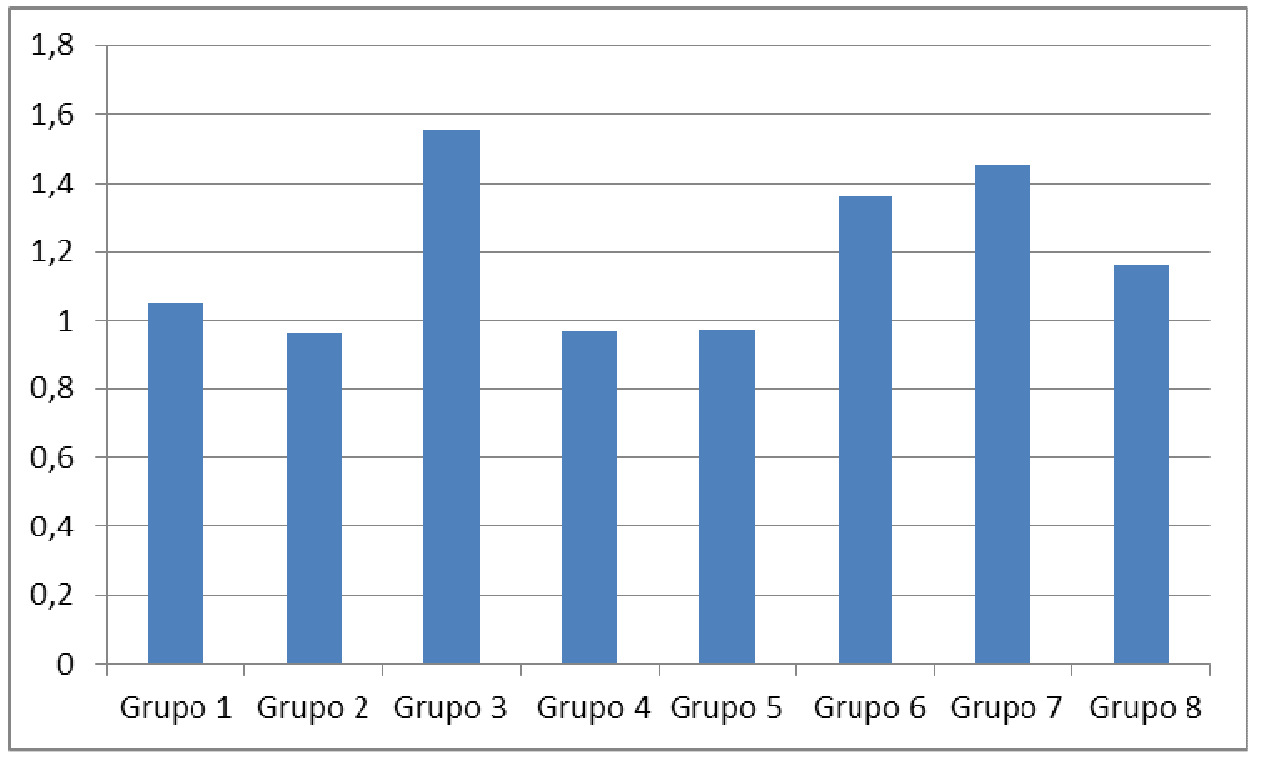

Figura 25 - Gráfico representando as médias de cada grupo para proMMP-2 no tempo de 6 semanas. Unidades Arbitrárias.

A análise estatística identificou diferença significante entre os grupos 2 e 3 , entre os grupos 1 e 3 identificado em gráfico com um asterisco $(P<0,05)$, entre os grupos 2 e 7 identificado em gráfico com dois asteriscos $(P<0,05)$, entre os grupos 3 e 4 identificado em gráfico com três asteriscos $(P<0,05)$, entre os grupos 3 e 5 identificado em gráfico com quatro asteriscos $(P<0,05)$, entre os grupos 4 e 7 identificado em gráfico com cinco asteriscos $(P<0,05)$, e entre os grupos 5 e 7 identificado em gráfico com seis asteriscos $(P<0,05)$ para proMMP-2 no tempo de seis semanas quando comparados entre si.

\subsection{MMP-9 e proMMP-9 - ANÁLISE COMPARATIVA DOS GRUPOS}

Na análise de MMP-9 no tempo de 4 semanas todos os grupos passaram no teste de normalidade "Shapiro-Wilk normality test", com intervalo de confiança de 95\%, mostrando distribuição normal. A figura 27 mostra a comparação entre os grupos mediante One-way ANOVA com pós-teste de Turkey. 


\begin{tabular}{|l|r|r|r|r|r|r|r|r|}
\cline { 2 - 9 } & Grupo 1 & Grupo 2 & Grupo 3 & Grupo 4 & Grupo 5 & Grupo 6 & Grupo 7 & Grupo 8 \\
\hline A1 & 0,941634 & 1,140155 & 1,424977 & 1,029906 & 1,287321 & 1,469974 & 1,568176 & 1,050193 \\
A2 & 1,19407 & 1,172747 & 1,944059 & 1,088741 & 0,93494 & 1,306505 & 0,978754 & 1,049345 \\
A3 & 1,270611 & 1,069012 & 1,093522 & 0,922003 & 0,837007 & 1,175823 & 0,882941 & 0,929653 \\
A4 & 1,106463 & 1,195032 & 0,917555 & 1,521125 & 1,091084 & 1,009823 & 1,669731 & 1,055062 \\
A5 & 0,682291 & 1,148851 & 1,214373 & 1,330416 & 0,956444 & 1,026823 & 1,549098 & 0,948166 \\
\hline A6 & 0,810853 & 1,320391 & 1,241855 & 1,396779 & 1,471002 & 1,098206 & 1,199446 & 1,084477 \\
A7 & 1,696976 & 1,467134 & 0,811606 & 1,027911 & 0,656083 & 1,48906 & 0,789033 & 0,906107 \\
\hline Média & 1,100414 & 1,216189 & 1,235421 & 1,188126 & 1,033412 & 1,225174 & 1,233883 & 1,003286 \\
\hline
\end{tabular}

Figura 26 - Resultados individuais de cada grupo mostrando a relação de acordo com os níveis de MMP-9 identificados no tempo de 4 semanas. Unidades Arbitrárias.

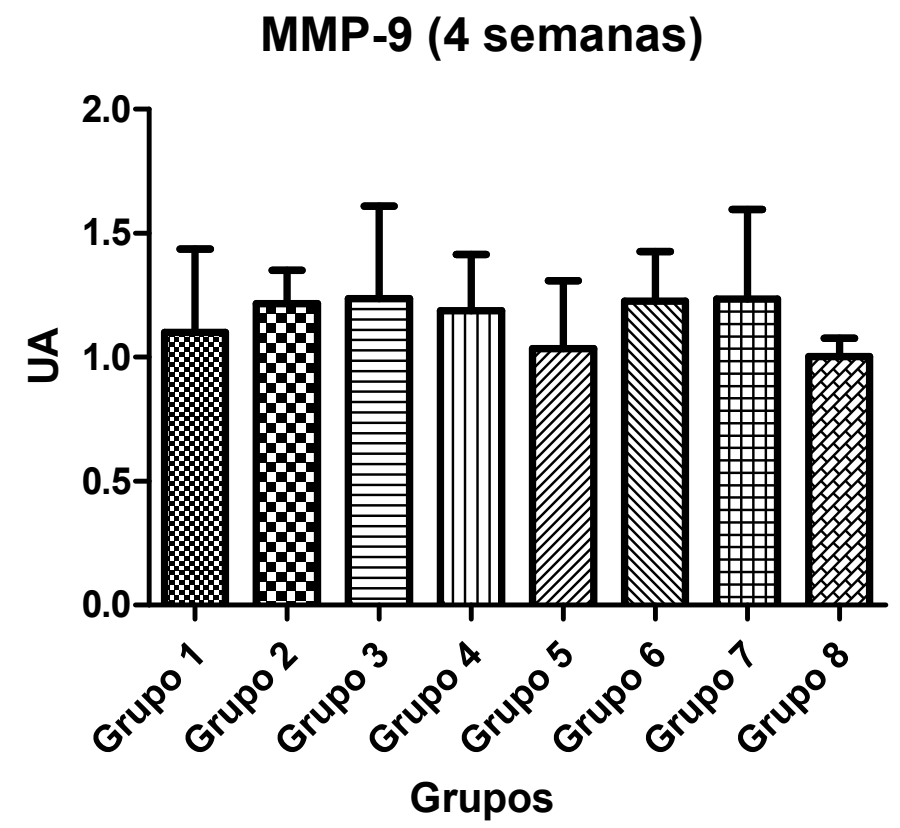

Figura 27 - Gráfico de comparação dos níveis de MMP-9 entre os grupos no tempo de 4 semanas. Valor de $\mathrm{P}=0,5289$. Unidades Arbitrárias. 


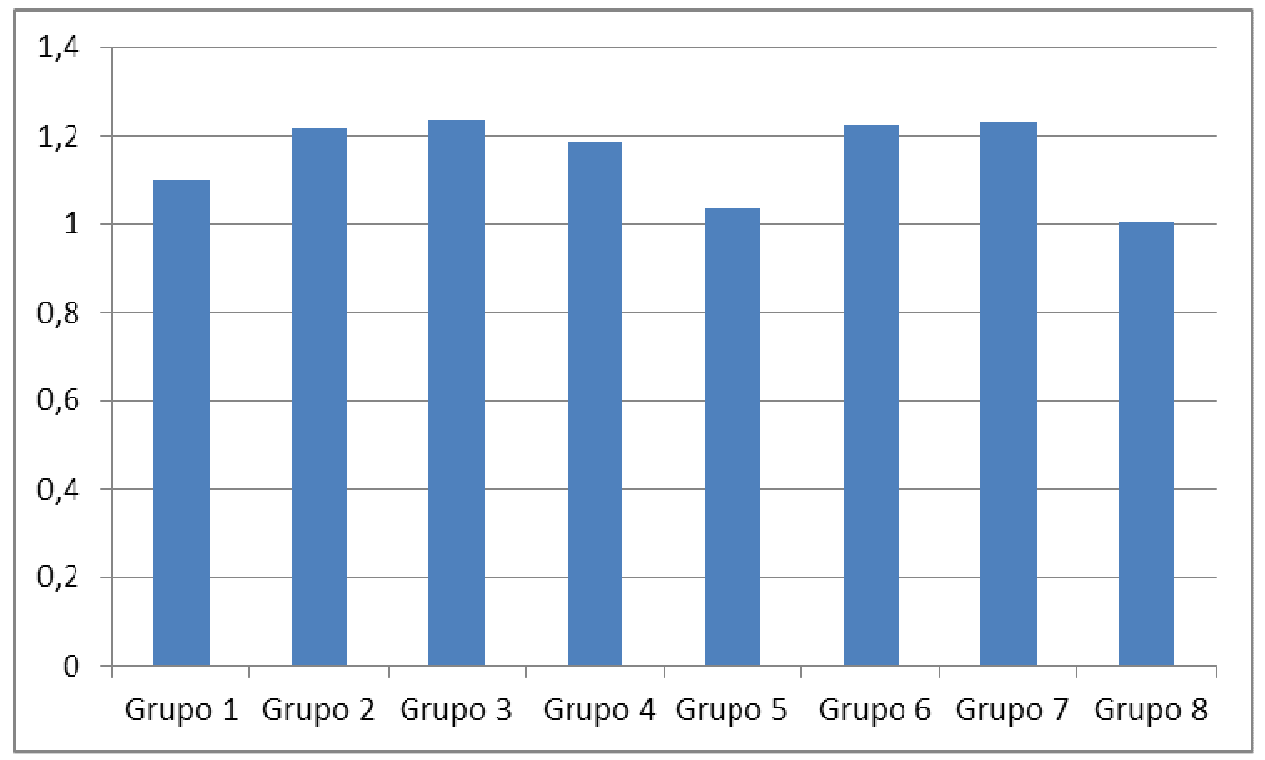

Figura 28 - Gráfico representando as médias de cada grupo para MMP-9 no tempo de 4 semanas. Unidades Arbitrárias.

A análise estatística não identificou diferença significante entre os grupos para MMP-9 no tempo de quatro semanas quando comparados entre si.

Na análise de proMMP-9 no tempo de 4 semanas todos os grupos passaram no teste de normalidade "Shapiro-Wilk normality test" e "Kolmogorov-Smirnov test", com intervalo de confiança de 95\%, mostrando distribuição normal. A figura 30mostra a comparação entre os grupos mediante One-way ANOVA com pós-teste de Turkey.

\begin{tabular}{|l|r|r|r|r|r|r|r|r|}
\cline { 2 - 9 } & Grupo 1 & Grupo 2 & Grupo 3 & Grupo 4 & Grupo 5 & Grupo 6 & Grupo 7 & Grupo 8 \\
\hline A1 & 1,067694 & 1,38637 & 1,171018 & 1,19578 & 1,285502 & 1,359893 & 1,293372 & 0,97335 \\
\hline A2 & 1,004572 & 0,81202 & 1,657139 & 1,185 & 1,387331 & 1,586335 & 0,789789 & 0,96671 \\
\hline A3 & 0,999275 & 1,342437 & 1,432833 & 0,957769 & 0,932716 & 1,282928 & 1,326721 & 1,059844 \\
\hline A4 & 1,384665 & 1,225589 & 1,087292 & 1,073831 & 0,878226 & 1,041816 & 1,800962 & 1,015232 \\
\hline A5 & 0,689108 & 1,323793 & 1,260118 & 1,326911 & 1,000595 & 0,960291 & 0,88793 & 0,92608 \\
\hline A6 & 0,652746 & 0,524668 & 1,356789 & 1,331801 & 1,317595 & 1,180307 & 1,440119 & 1,057355 \\
\hline A7 & 1,157783 & 0,97244 & 1,230451 & 1,092861 & 0,973105 & 1,228472 & 0,989063 & 1,049839 \\
\hline Média & 0,993692 & 1,083902 & 1,313663 & 1,166279 & 1,110724 & 1,234292 & 1,21828 & 1,006916 \\
\hline
\end{tabular}

Figura 29 - Resultados individuais de cada grupo mostrando a relação de acordo com os níveis de proMMP-9 identificados no tempo de 4 semanas. Unidades Arbitrárias. 


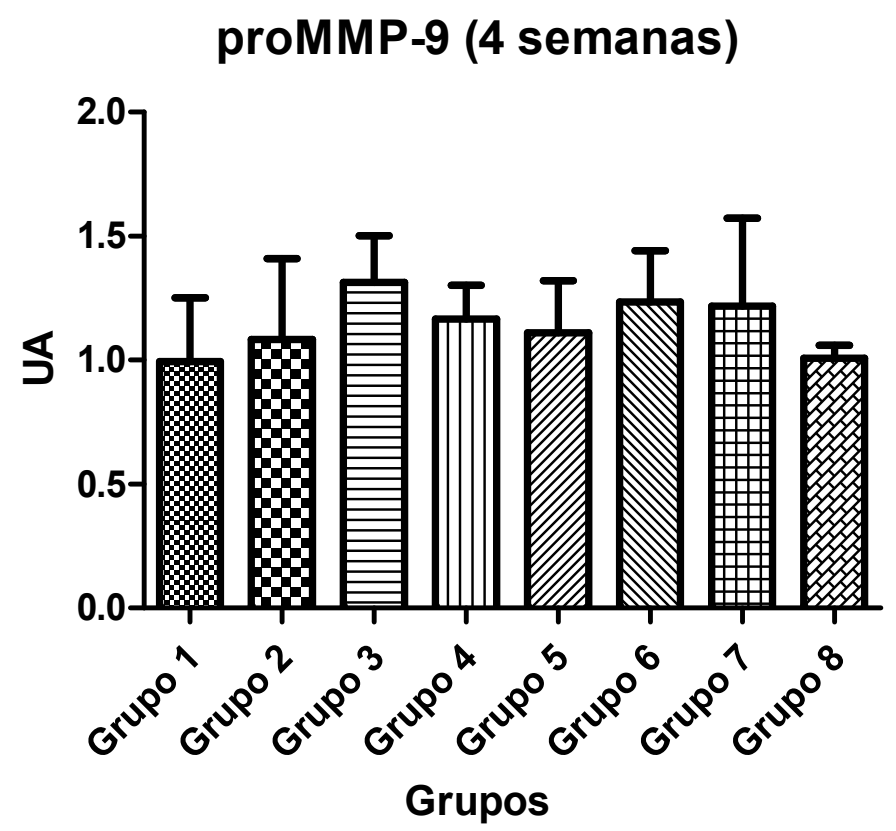

Figura 30 - Gráfico de comparação dos níveis de proMMP-9 entre os grupos no tempo de 4 semanas. Valor de $\mathrm{P}=0,1547$. Unidades Arbitrárias.

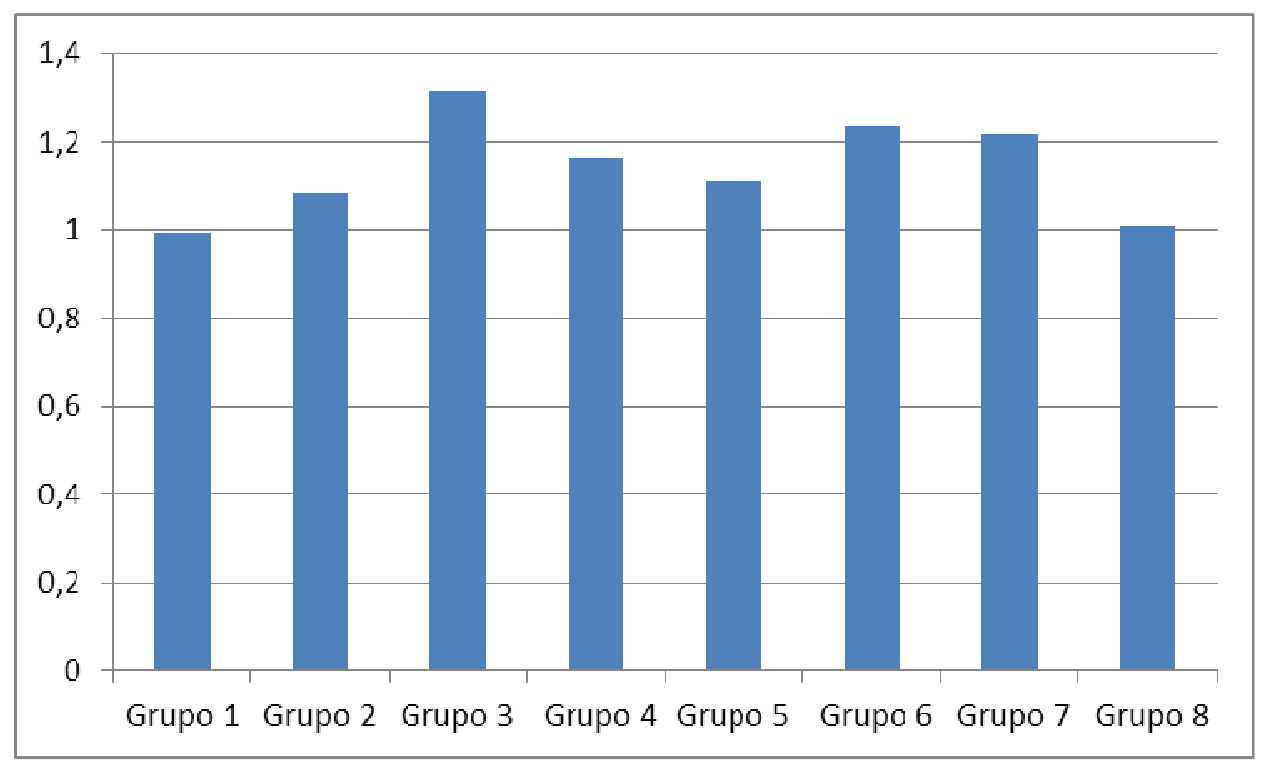

Figura 31 - Gráfico representando as médias de cada grupo para proMMP-9 no tempo de 4 semanas. Unidades Arbitrárias.

A análise estatística não identificou diferença significante entre os grupos para proMMP-9 no tempo de quatro semanas quando comparados entre si. 
$\mathrm{Na}$ análise de MMP-9 no tempo de 6 semanas todos os grupos passaram no teste de normalidade "Shapiro-Wilk normality test" e "Kolmogorov-Smirnov test", com intervalo de confiança de 95\%, mostrando distribuição normal. A figura 33 mostra a comparação entre os grupos mediante One-way ANOVA com pós-teste de Turkey.

\begin{tabular}{|l|r|r|r|r|r|r|r|r|}
\cline { 2 - 9 } & Grupo 1 & Grupo 2 & Grupo 3 & Grupo 4 & Grupo 5 & Grupo 6 & Grupo 7 & Grupo 8 \\
\hline A1 & 0,692522 & 0,84292 & 1,300895 & 0,821098 & 1,206241 & 1,178029 & 1,376063 & 0,893659 \\
A2 & 0,919719 & 0,802076 & 1,179721 & 0,755587 & 0,801806 & 1,296452 & 1,102501 & 0,658144 \\
A3 & 0,602599 & 0,658831 & 1,794721 & 0,80506 & 0,84088 & 1,406808 & 1,218286 & 1,157547 \\
A4 & 0,849817 & 0,793066 & 1,509864 & 0,988681 & 0,892654 & 1,331121 & 0,911547 & 0,953051 \\
A5 & 0,815594 & 1,078934 & 1,167845 & 1,237803 & 1,010007 & 0,776113 & 1,243686 & 1,058501 \\
A6 & 1,074362 & 1,191442 & 0,967596 & 0,84381 & 1,214078 & 1,223116 & 0,880408 & 1,216471 \\
A7 & 1,174086 & 1,222179 & 0,935281 & 1,19052 & 0,816457 & 0,868689 & 1,044324 & 0,885992 \\
Média & 0,875528 & 0,94135 & 1,265132 & 0,948937 & 0,968875 & 1,154333 & 1,110974 & 0,974767 \\
\hline
\end{tabular}

Figura 32 - Resultados individuais de cada grupo mostrando a relação de acordo com os níveis de MMP-9 identificados no tempo de 6 semanas. Unidades Arbitrárias.

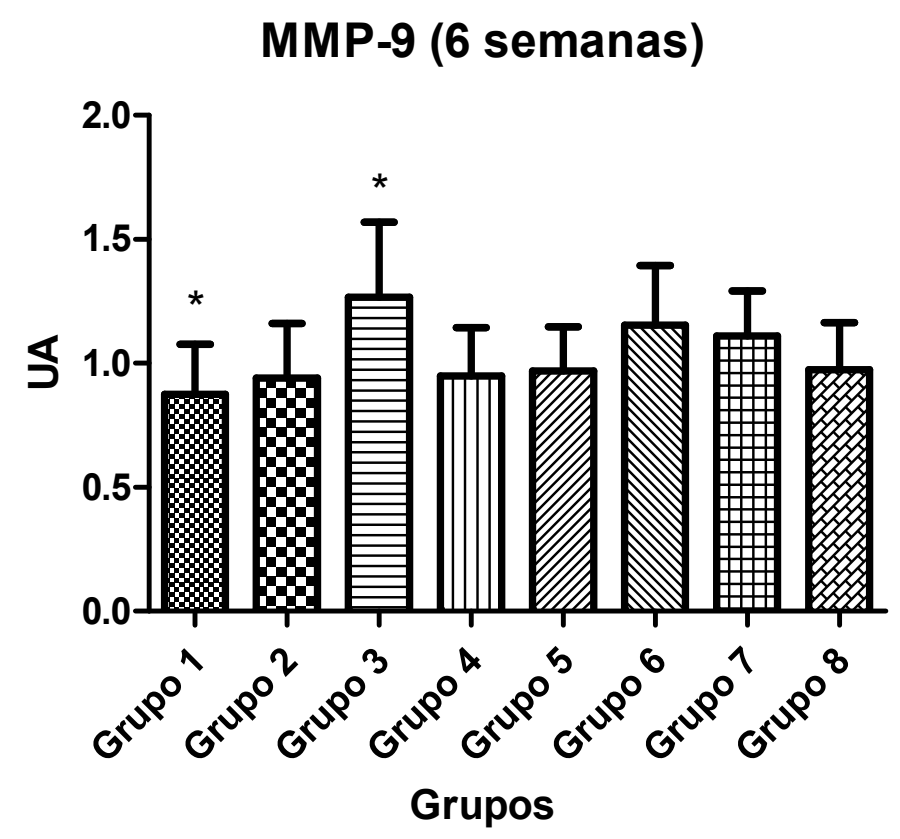

Figura 33 - Gráfico de comparação dos níveis de MMP-9 entre os grupos no tempo de 6 semanas. Valor de $\mathrm{P}=0,0237$. Unidades Arbitrárias. 


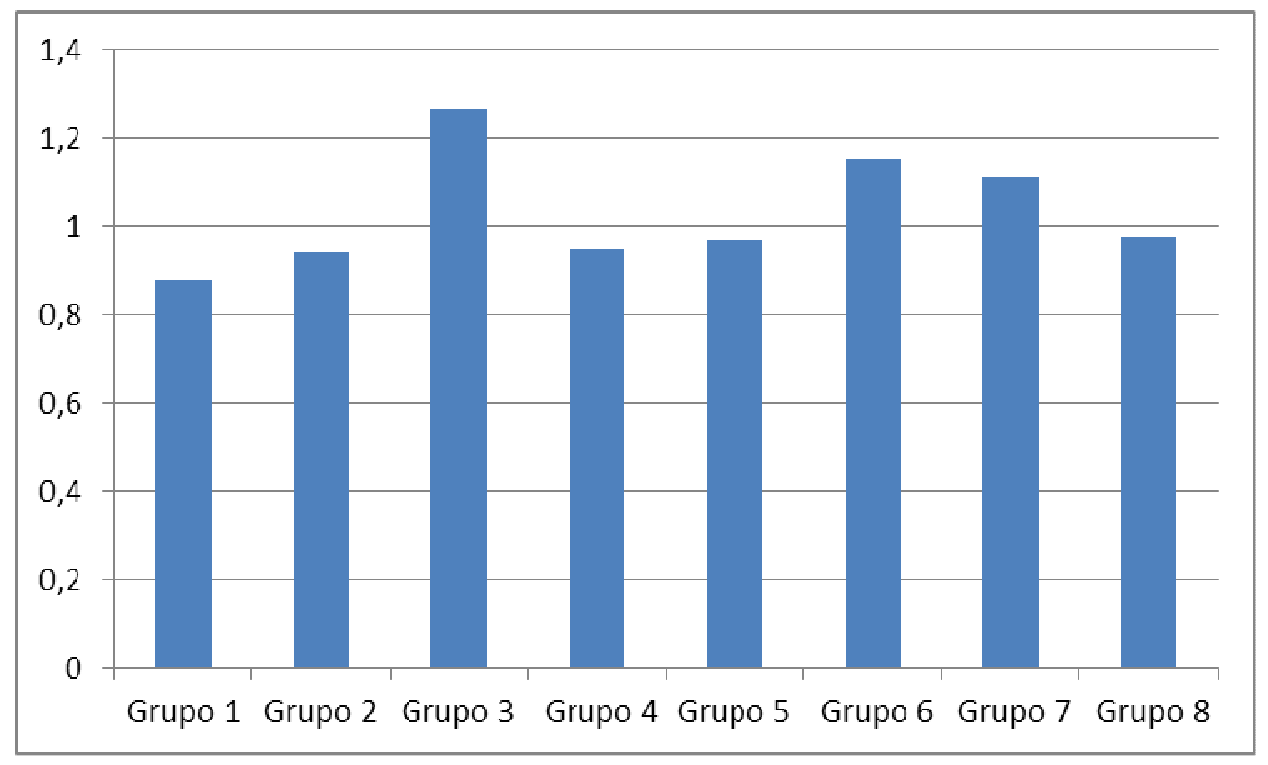

Figura 34 - Gráfico representando as médias de cada grupo para MMP-9 no tempo de 6 semanas. Unidades Arbitrárias.

A análise estatística identificou diferença significante apenas entre os grupos 1 e 3, identificado no gráfico com um asterisco $(P<0,05)$ para MMP-9 no tempo de seis semanas quando comparados entre si.

Na análise de proMMP-9 no tempo de 6 semanas todos os grupos passaram no teste de normalidade "Shapiro-Wilk normality test" e "Kolmogorov-Smirnov test", com intervalo de confiança de 95\%, mostrando distribuição normal. A figura 36 mostra a comparação entre os grupos mediante One-way ANOVA com pós-teste de Turkey.

\begin{tabular}{|l|r|r|r|r|r|r|r|r|}
\cline { 2 - 9 } & Grupo 1 & Grupo 2 & Grupo 3 & Grupo 4 & Grupo 5 & Grupo 6 & Grupo 7 & Grupo 8 \\
\hline A1 & 0,929984 & 1,067295 & 1,134473 & 1,113414 & 1,249717 & 0,747872 & 1,157881 & 1,016477 \\
A2 & 0,997821 & 0,765904 & 0,982073 & 0,946083 & 0,775154 & 0,862825 & 1,074563 & 0,773598 \\
\hline A3 & 0,96252 & 0,614181 & 1,783898 & 0,800614 & 0,989136 & 1,191985 & 1,074025 & 1,450296 \\
\hline A4 & 1,05044 & 0,902965 & 1,403844 & 0,942028 & 0,979918 & 1,338729 & 0,934677 & 1,248238 \\
A5 & 1,112062 & 1,569342 & 1,01817 & 1,401871 & 1,218131 & 1,066245 & 1,25591 & 0,942166 \\
\hline A6 & 1,259744 & 1,082297 & 1,242812 & 1,474863 & 1,482856 & 1,49763 & 1,113261 & 1,257893 \\
\hline A7 & 1,285617 & 1,65582 & 1,296192 & 1,556809 & 1,107114 & 1,120755 & 1,414912 & 1,199441 \\
\hline Média & 1,085455 & 1,093972 & 1,265923 & 1,176526 & 1,114575 & 1,118006 & 1,146461 & 1,126873 \\
\hline
\end{tabular}

Figura 35 - Resultados individuais de cada grupo mostrando a relação de acordo com os níveis de proMMP-9 identificados no tempo de 6 semanas. Unidades Arbitrárias. 


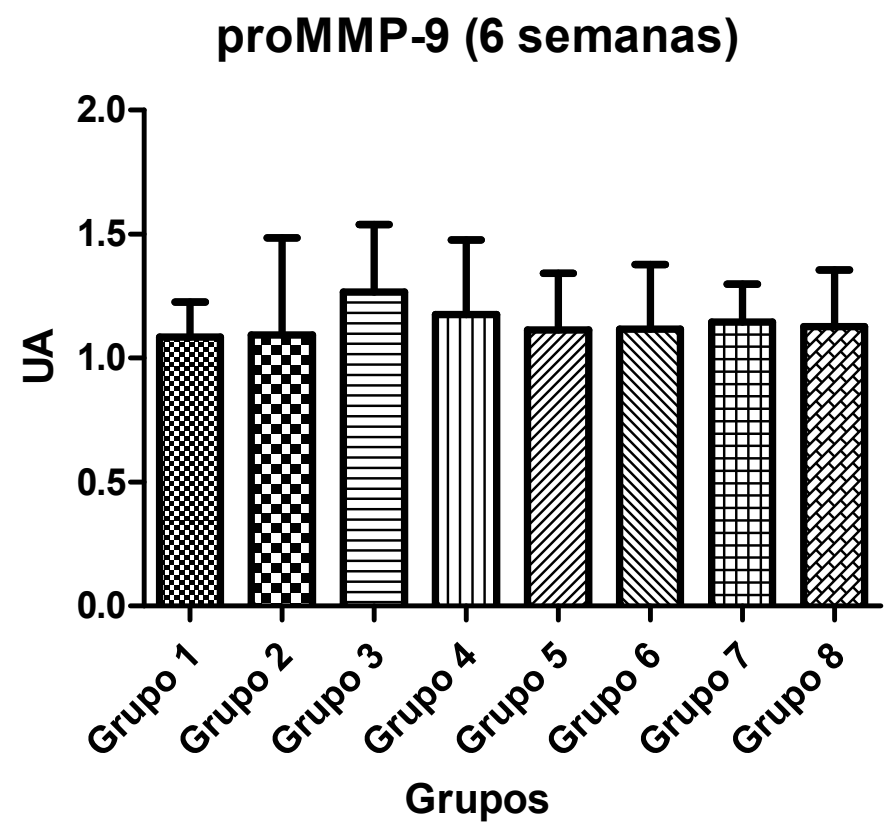

Figura 36 - Gráfico de comparação dos níveis de proMMP-9 entre os grupos no tempo de 6 semanas. Valor de $\mathrm{P}=0,9235$. Unidades Arbitrárias.

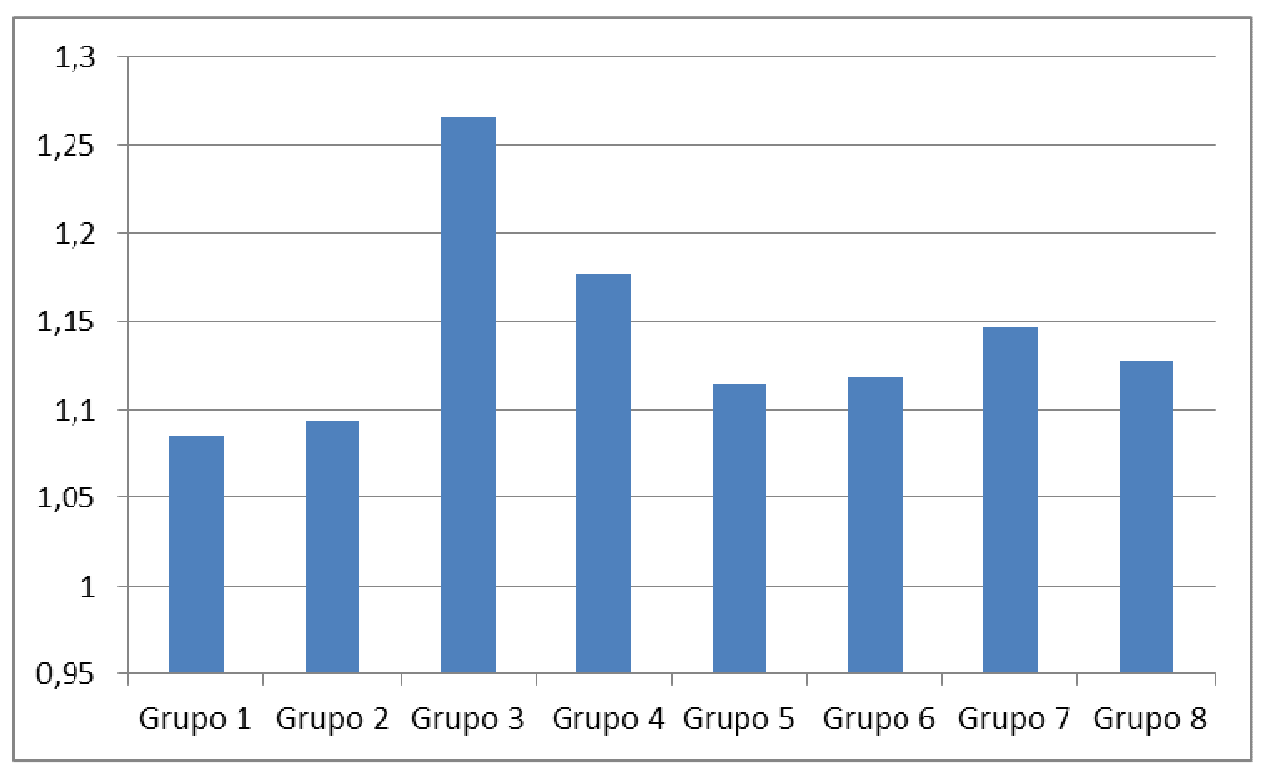

Figura 37 - Gráfico representando as médias de cada grupo para proMMP-9 no tempo de 6 semanas. Unidades Arbitrárias.

A análise estatística não identificou diferença significante entre os grupos para proMMP-9 no tempo de seis semanas quando comparados entre si. 


\subsection{MMP-2 e proMMP-2 - ANÁLISE DE CADA GRUPO ISOLADO}

A análise do grupo 1 passou no teste de normalidade "Shapiro-Wilk normality test" e "Kolmogorov-Smirnov test", com intervalo de confiança de 95\%, mostrando distribuição normal. A figura 38 mostra a comparação entre MMP-2 e proMMP-2 nos diferentes tempos mediante One-way ANOVA com pós-teste de Turkey.

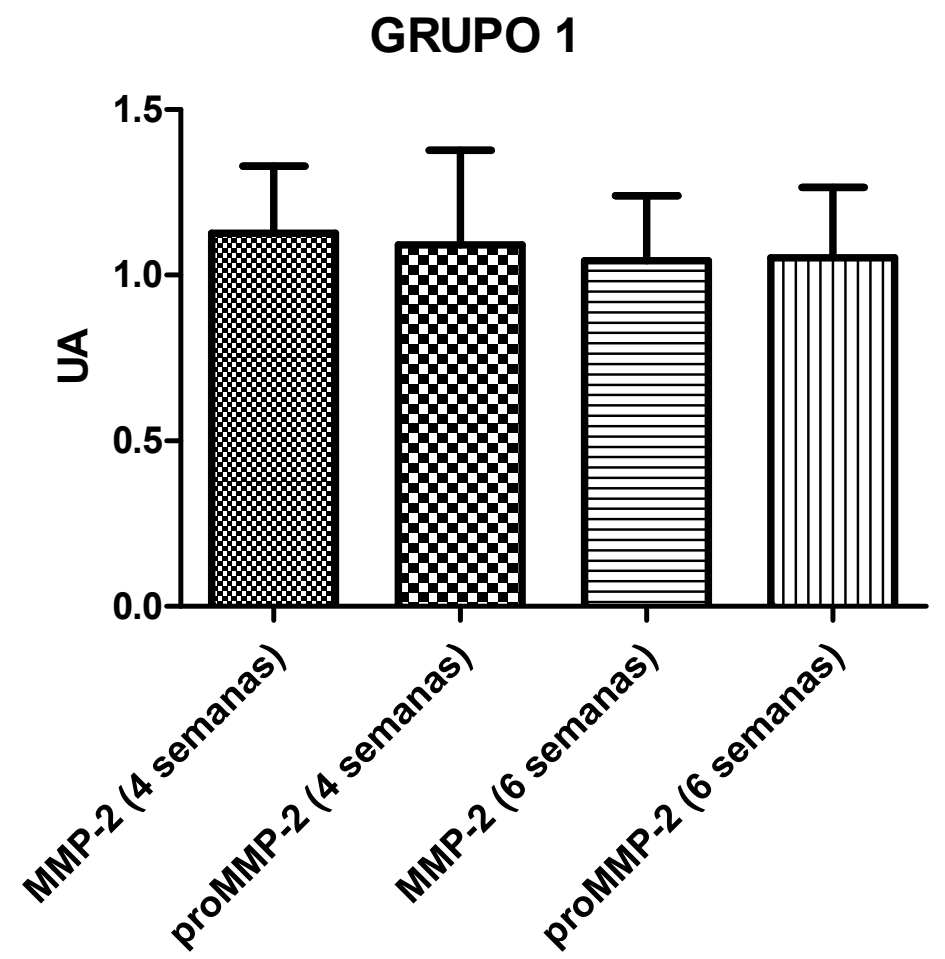

Figura 38 - Gráfico de comparação dos níveis de MMP-2 e proMMP-2 entre os diferentes tempos do grupo 1. Valor de $P=0,8978$. Unidades Arbitrárias.

A análise estatística não identificou diferença significante entre os tempos quanto à concentração das enzimas. 
A análise do grupo 2 passou no teste de normalidade "Shapiro-Wilk normality test" e "Kolmogorov-Smirnov test", com intervalo de confiança de $95 \%$, mostrando distribuição normal. A figura 39 mostra a comparação entre MMP-2 e proMMP-2 nos diferentes tempos mediante One-way ANOVA com pós-teste de Turkey.

\section{GRUPO 2}

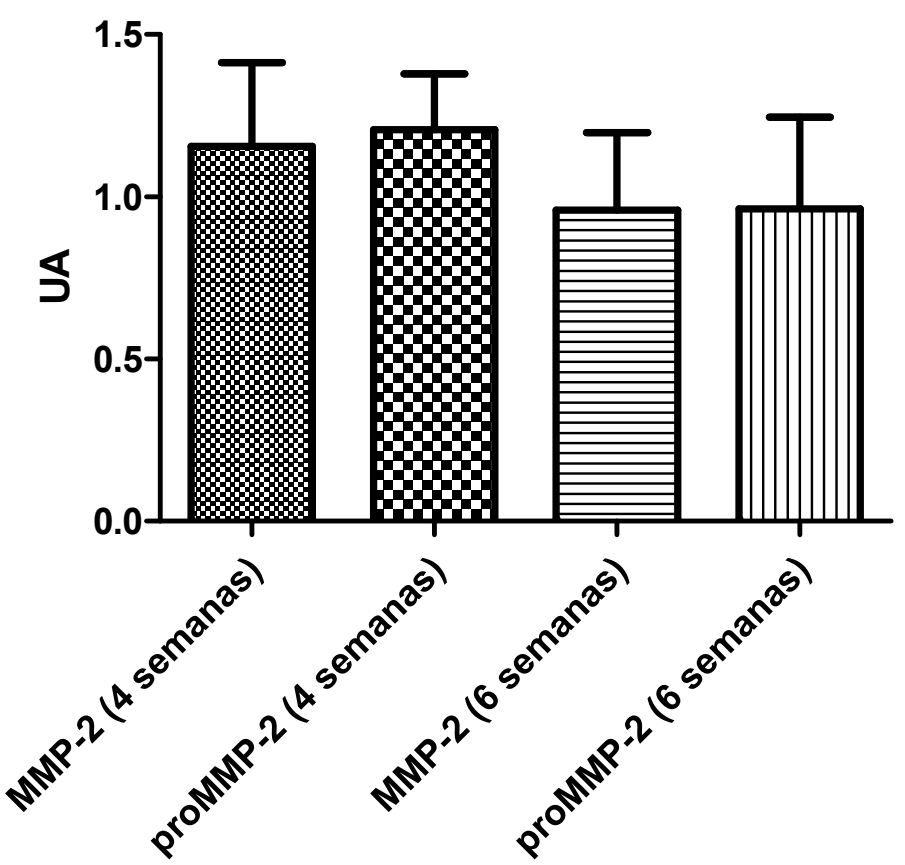

Figura 39 - Gráfico de comparação dos níveis de MMP-2 e proMMP-2 entre os diferentes tempos do grupo 2. Valor de $P=0,1413$. Unidades Arbitrárias.

A análise estatística não identificou diferença significante entre os tempos quanto à concentração das enzimas. 
A análise do grupo 3 passou no teste de normalidade "Shapiro-Wilk normality test" e "Kolmogorov-Smirnov test", com intervalo de confiança de 95\%, mostrando distribuição normal. A figura 40 mostra a comparação entre MMP-2 e proMMP-2 nos diferentes tempos mediante One-way ANOVA com pós-teste de Turkey.

\section{GRUPO 3}

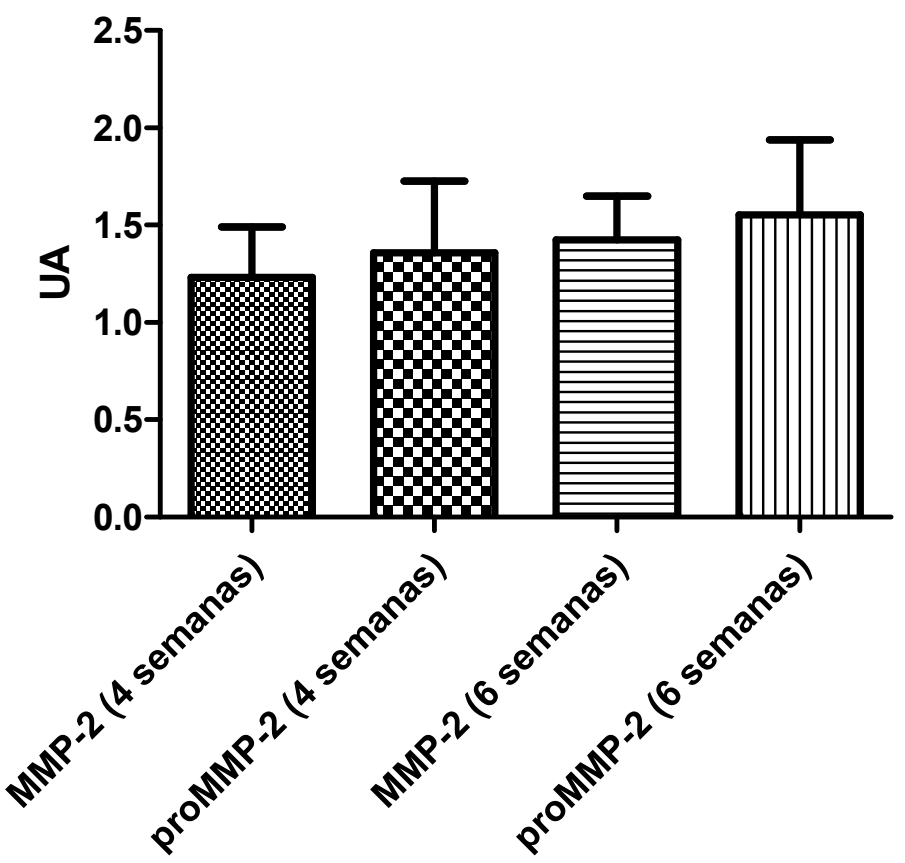

Figura 40 - Gráfico de comparação dos níveis de MMP-2 e proMMP-2 entre os diferentes tempos do grupo 3. Valor de $P=0,3142$. Unidades Arbitrárias.

A análise estatística não identificou diferença significante entre os tempos quanto à concentração das enzimas. 
A análise do grupo 4 passou no teste de normalidade "Shapiro-Wilk normality test" e "Kolmogorov-Smirnov test", com intervalo de confiança de 95\%, mostrando distribuição normal. A figura 41 mostra a comparação entre MMP-2 e proMMP-2 nos diferentes tempos mediante One-way ANOVA com pós-teste de Turkey.

\section{GRUPO 4}

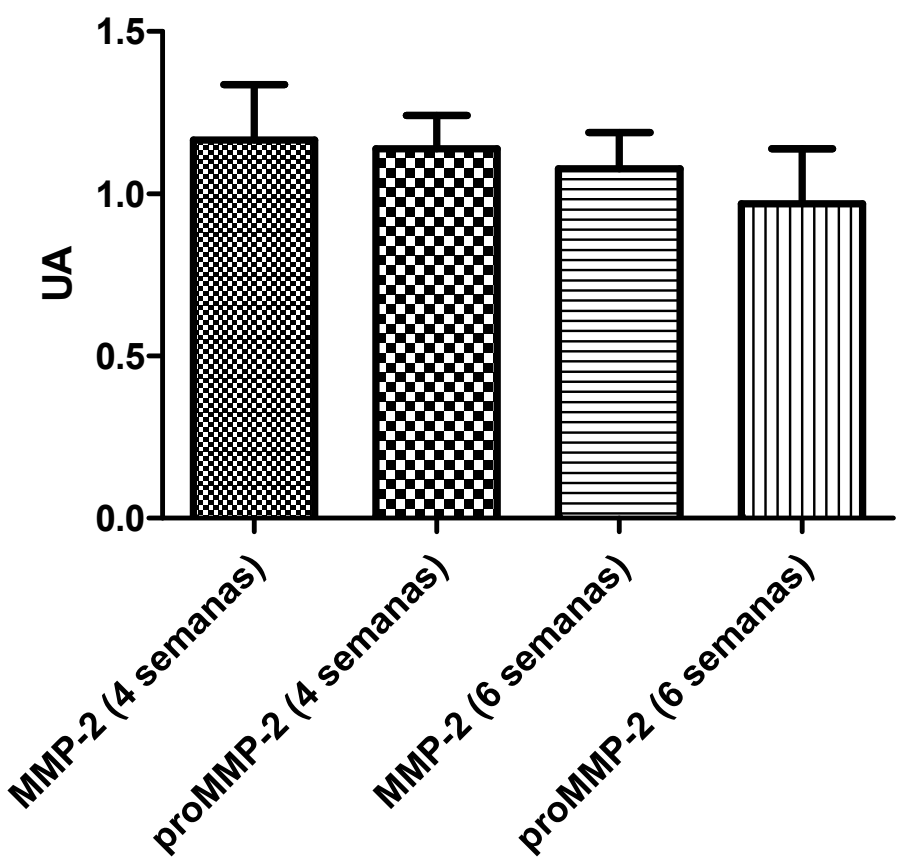

Figura 41 - Gráfico de comparação dos níveis de MMP-2 e proMMP-2 entre os diferentes tempos do grupo 4. Valor de $P=0,0735$. Unidades Arbitrárias.

A análise estatística não identificou diferença significante entre os tempos quanto à concentração das enzimas. 
A análise do grupo 5 passou no teste de normalidade "Shapiro-Wilk normality test" e "Kolmogorov-Smirnov test", com intervalo de confiança de 95\%, mostrando distribuição normal. A figura 42 mostra a comparação entre MMP-2 e proMMP-2 nos diferentes tempos mediante One-way ANOVA com pós-teste de Turkey.

\section{GRUPO 5}

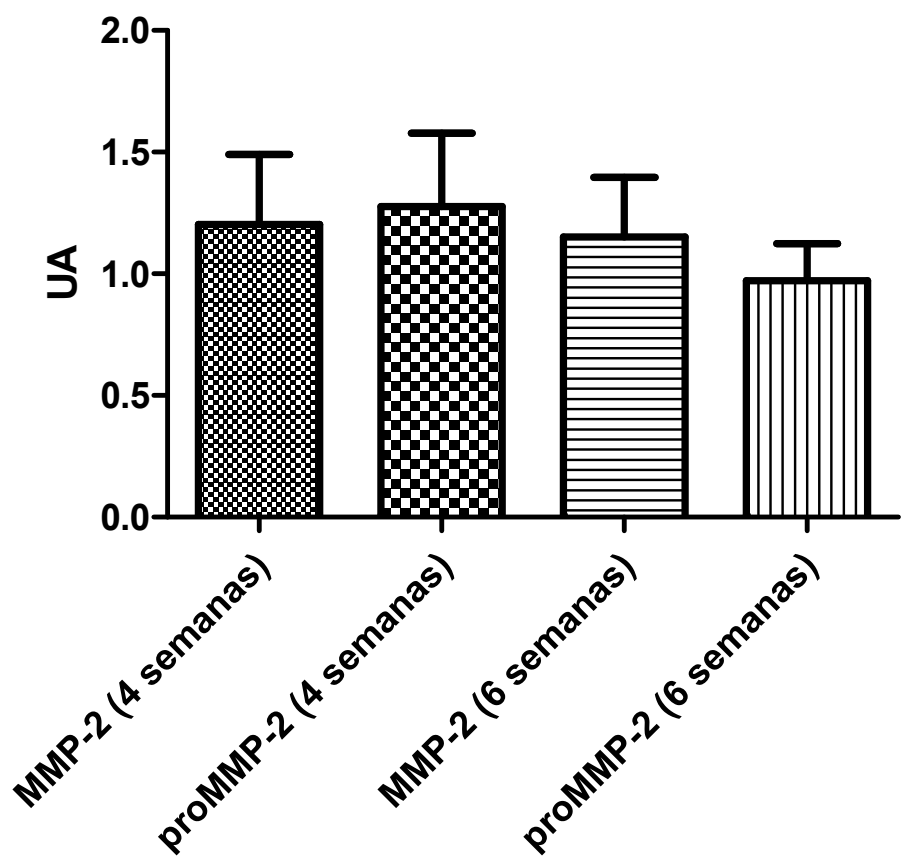

Figura 42 - Gráfico de comparação dos níveis de MMP-2 e proMMP-2 entre os diferentes tempos do grupo 5. Valor de $P=0,1665$. Unidades Arbitrárias.

A análise estatística não identificou diferença significante entre os tempos quanto à concentração das enzimas. 
A análise do grupo 6 passou no teste de normalidade "Shapiro-Wilk normality test" e "Kolmogorov-Smirnov test", com intervalo de confiança de 95\%, mostrando distribuição normal. A figura 43 mostra a comparação entre MMP-2 e proMMP-2 nos diferentes tempos mediante One-way ANOVA com pós-teste de Turkey.

\section{GRUPO 6}

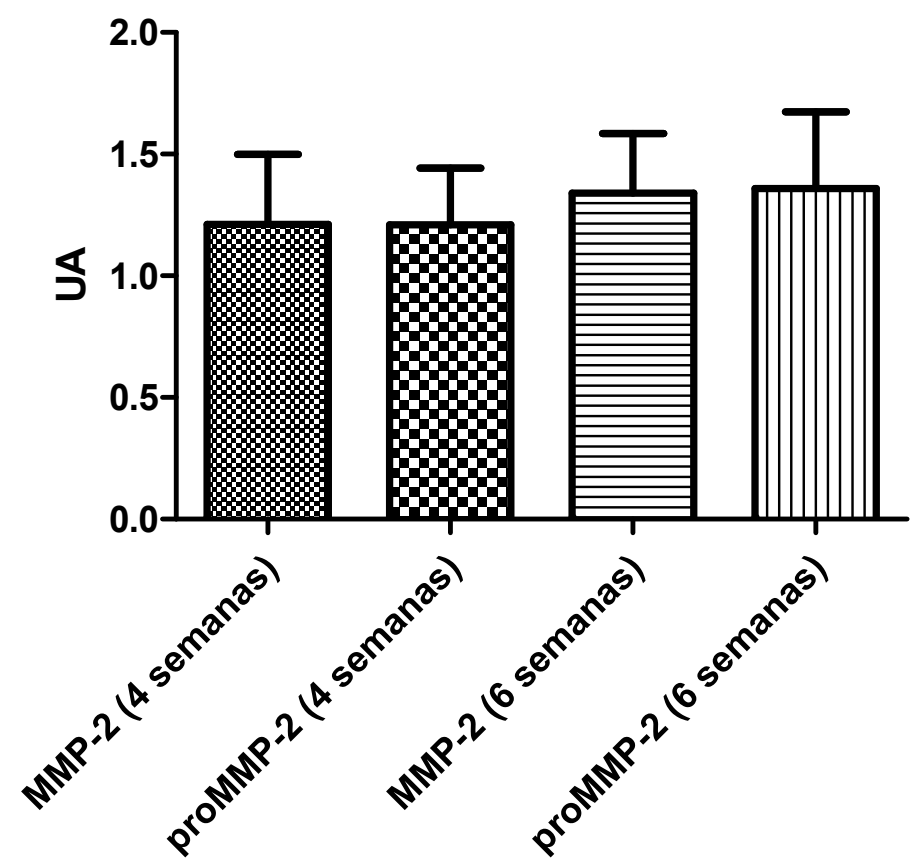

Figura 43 - Gráfico de comparação dos níveis de MMP-2 e proMMP-2 entre os diferentes tempos do grupo 6 . Não houve diferenças significantes, $P=0,6166$. Unidades Arbitrárias.

A análise estatística não identificou diferença significante entre os tempos quanto à concentração das enzimas. 
A análise do grupo 7 passou no teste de normalidade "Shapiro-Wilk normality test" e "Kolmogorov-Smirnov test", com intervalo de confiança de 95\%, mostrando distribuição normal. A figura 44 mostra a comparação entre MMP-2 e proMMP-2 nos diferentes tempos mediante One-way ANOVA com pós-teste de Turkey.

\section{GRUPO 7}

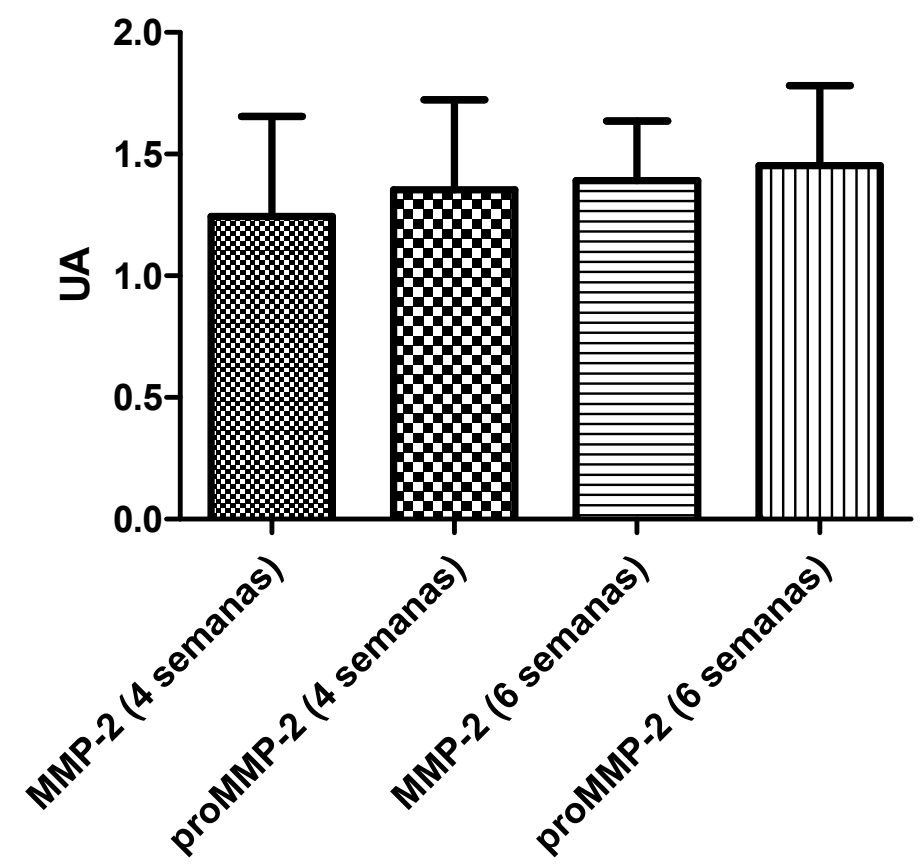

Figura 44 - Gráfico de comparação dos níveis de MMP-2 e proMMP-2 entre os diferentes tempos do grupo 7. Não houve diferenças significantes, $P=0,7176$. Unidades Arbitrárias.

A análise estatística não identificou diferença significante entre os tempos quanto à concentração das enzimas. 
A análise do grupo 8 passou no teste de normalidade "Shapiro-Wilk normality test”, com intervalo de confiança de 95\%, mostrando distribuição normal. A figura 45 mostra a comparação entre MMP-2 e proMMP-2 nos diferentes tempos mediante One-way ANOVA com pós-teste de Turkey.

\section{GRUPO 8}

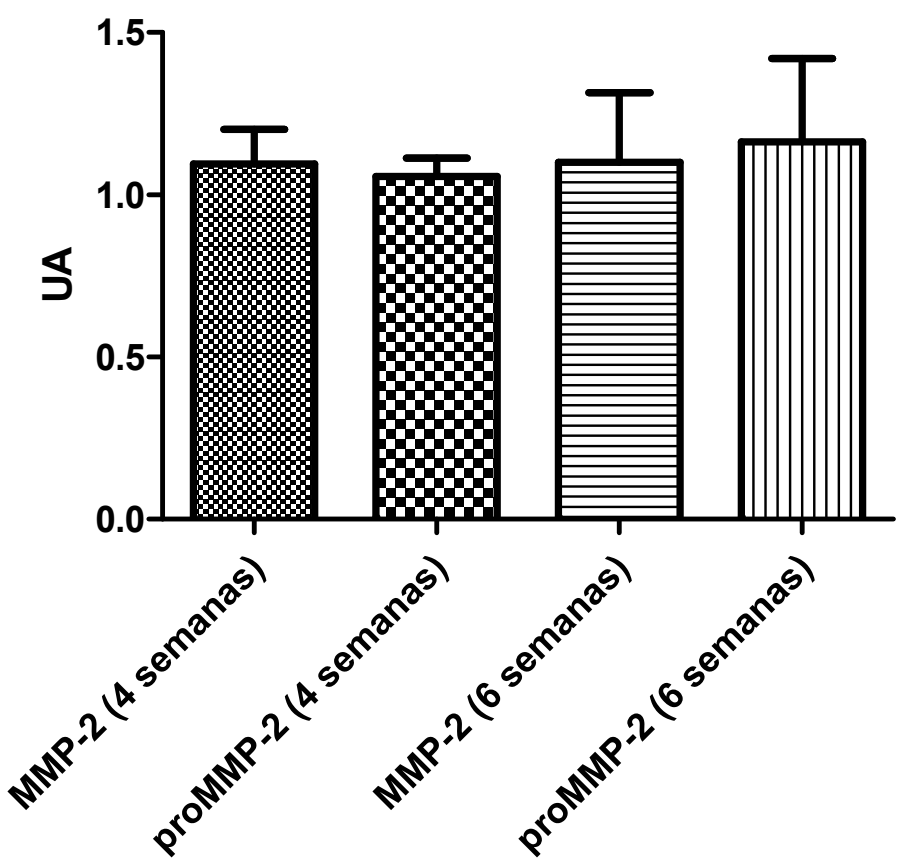

Figura 45 - Gráfico de comparação dos níveis de MMP-2 e proMMP-2 entre os diferentes tempos do grupo 8. Não houve diferenças significantes, $P=0,7308$. Unidades Arbitrárias.

A análise estatística não identificou diferença significante entre os tempos quanto à concentração das enzimas.

Quando comparados os valores absolutos de MMP-2 e proMMP-2 de cada grupo, representados pelas médias dos grupos, obtém-se a expressão da tendência de cada grupo nos diferentes tempos (Figura 46). 


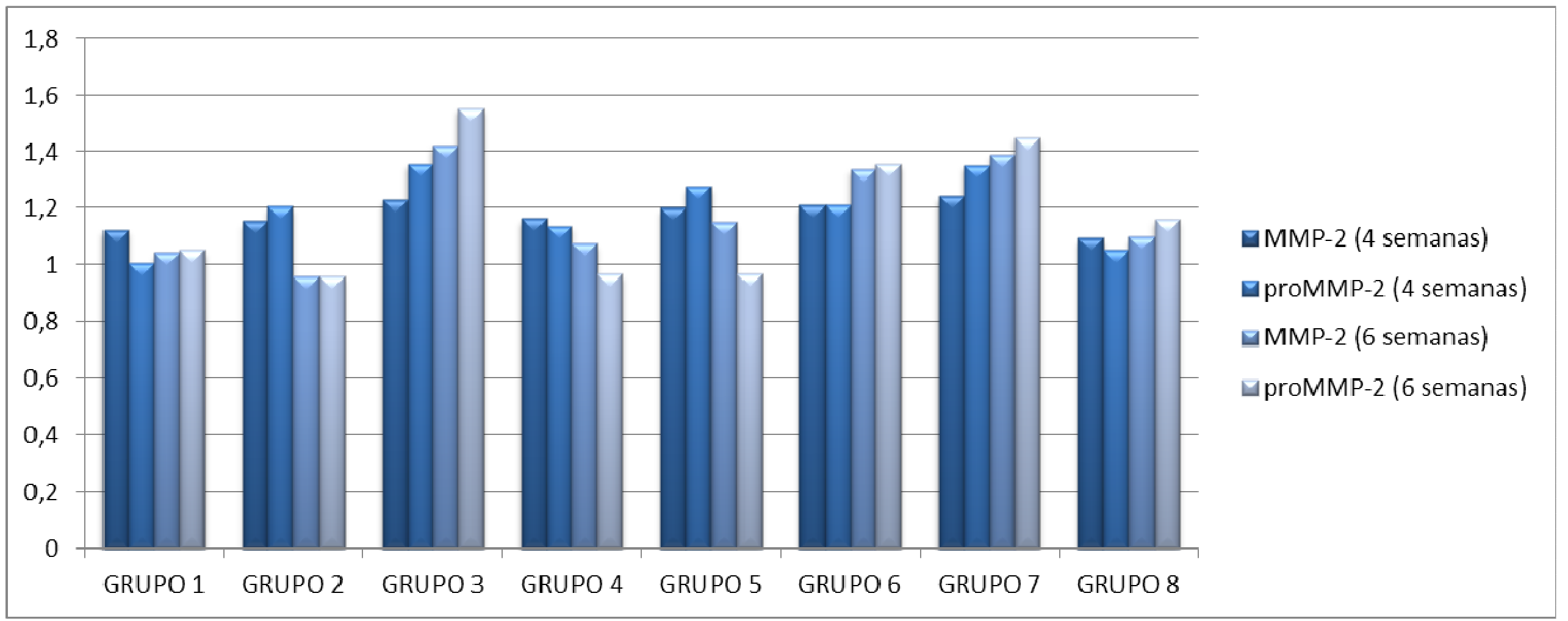

Figura 46 - Comparação das médias dos grupos em relação aos níveis de MMP-2 e proMMP-2 identificados. 


\subsection{MMP-9 e proMMP-9 - ANÁLISE DE CADA GRUPO ISOLADO}

A análise do grupo 1 passou no teste de normalidade "Shapiro-Wilk normality test" e "Kolmogorov-Smirnov test", com intervalo de confiança de 95\%, mostrando distribuição normal. A figura 47 mostra a comparação entre MMP-9 e proMMP-9 nos diferentes tempos mediante One-way ANOVA com pós-teste de Turkey.

\section{GRUPO 1}

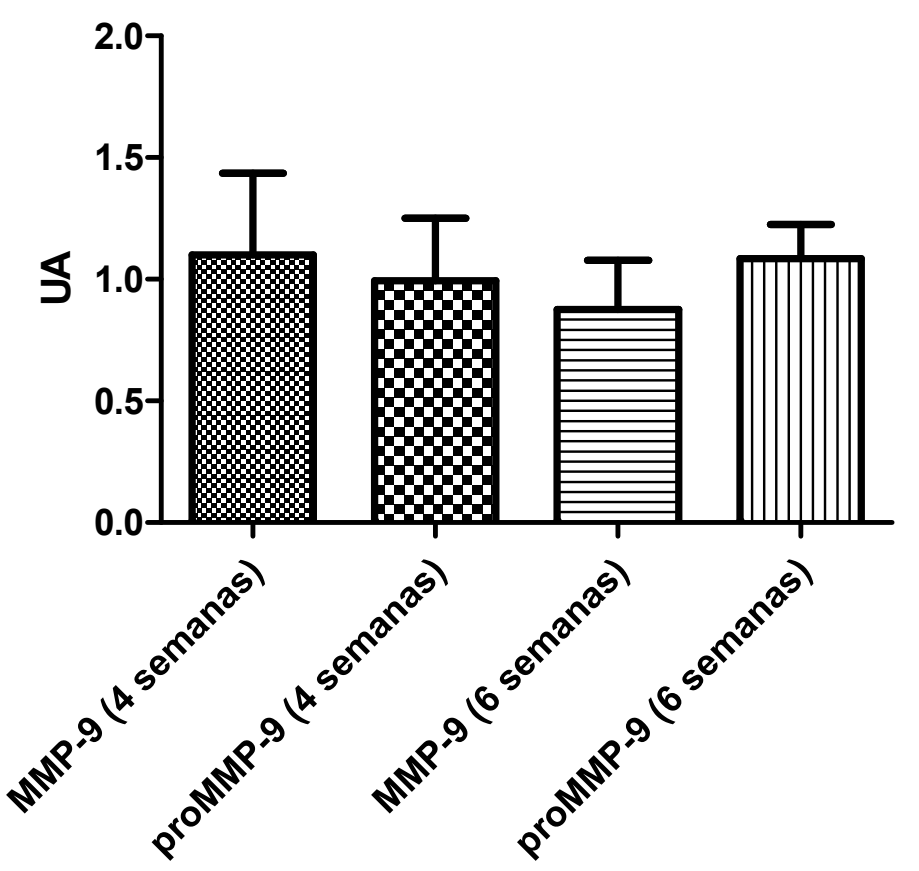

Figura 47 - Gráfico de comparação dos níveis de MMP-9 e proMMP-9 entre os diferentes tempos do grupo 1. Não houve diferenças significantes, $P=0,3118$. Unidades Arbitrárias.

A análise estatística não identificou diferença significante entre os tempos quanto à concentração das enzimas. 
A análise do grupo 2 passou no teste de normalidade "Shapiro-Wilk normality test"e "Kolmogorov-Smirnov test", com intervalo de confiança de 95\%, mostrando distribuição normal. A figura 48 mostra a comparação entre MMP-9 e proMMP-9 nos diferentes tempos mediante One-way ANOVA com pós-teste de Turkey.

\section{GRUPO 2}

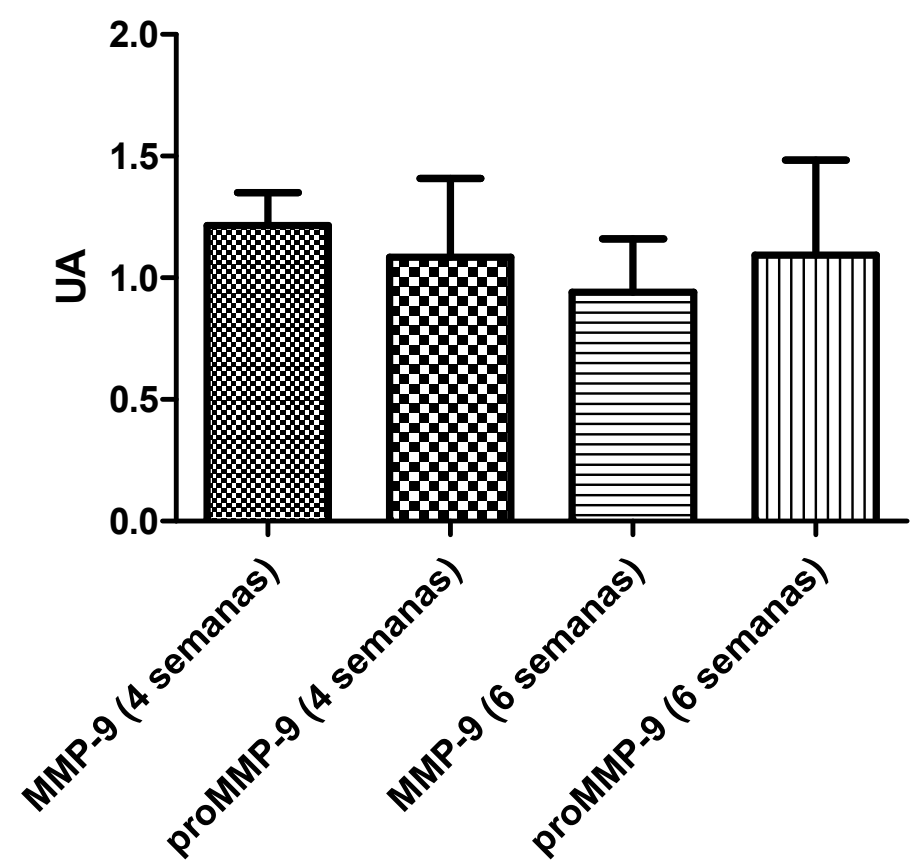

Figura 48 - Gráfico de comparação dos níveis de MMP-9 e proMMP-9 entre os diferentes tempos do grupo 2. Valor de $P=0,3730$. Unidades Arbitrárias.

A análise estatística não identificou diferença significante entre os tempos quanto à concentração das enzimas. 
A análise do grupo 3 passou no teste de normalidade "Shapiro-Wilk normality test"e "Kolmogorov-Smirnov test", com intervalo de confiança de 95\%, mostrando distribuição normal. A figura 49 mostra a comparação entre MMP-9 e proMMP-9 nos diferentes tempos mediante One-way ANOVA com pós-teste de Turkey.

\section{GRUPO 3}

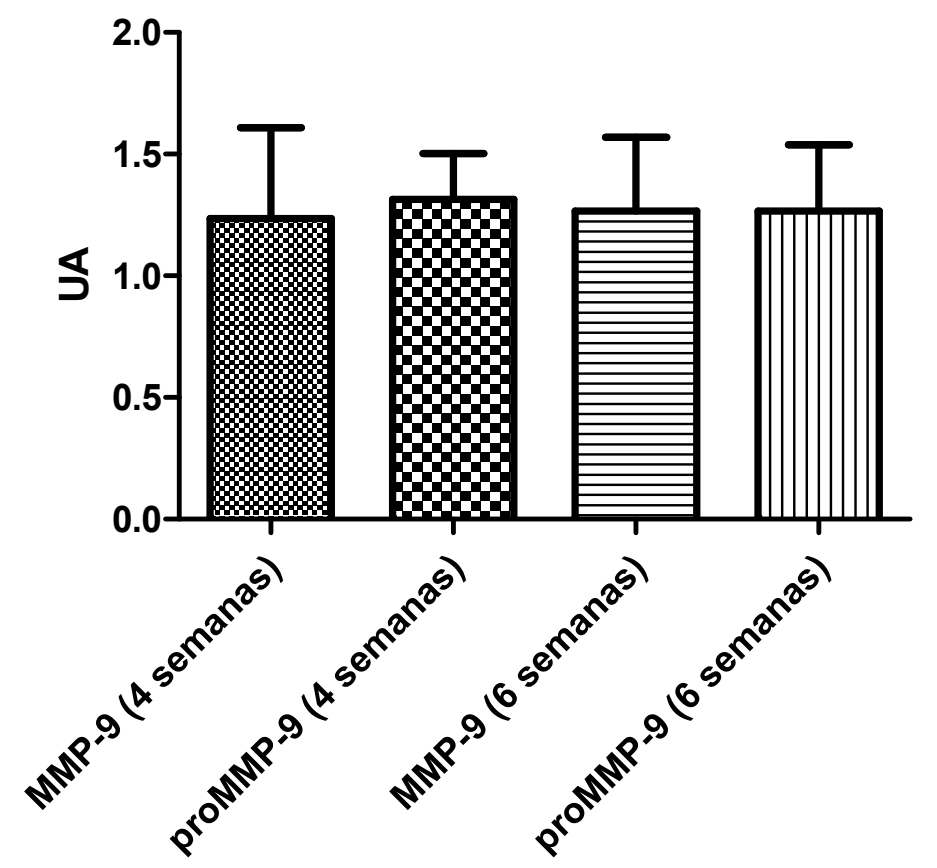

Figura 49 - Gráfico de comparação dos níveis de MMP-9 e proMMP-9 entre os diferentes tempos do grupo 3. Valor de $P=0,9673$. Unidades Arbitrárias.

A análise estatística não identificou diferença significante entre os tempos quanto à concentração das enzimas. 
A análise do grupo 4 passou no teste de normalidade "Shapiro-Wilk normality test" e "Kolmogorov-Smirnov test", com intervalo de confiança de 95\%, mostrando distribuição normal. A figura 50 mostra a comparação entre MMP-9 e proMMP-9 nos diferentes tempos mediante One-way ANOVA com pós-teste de Turkey.

\section{GRUPO 4}

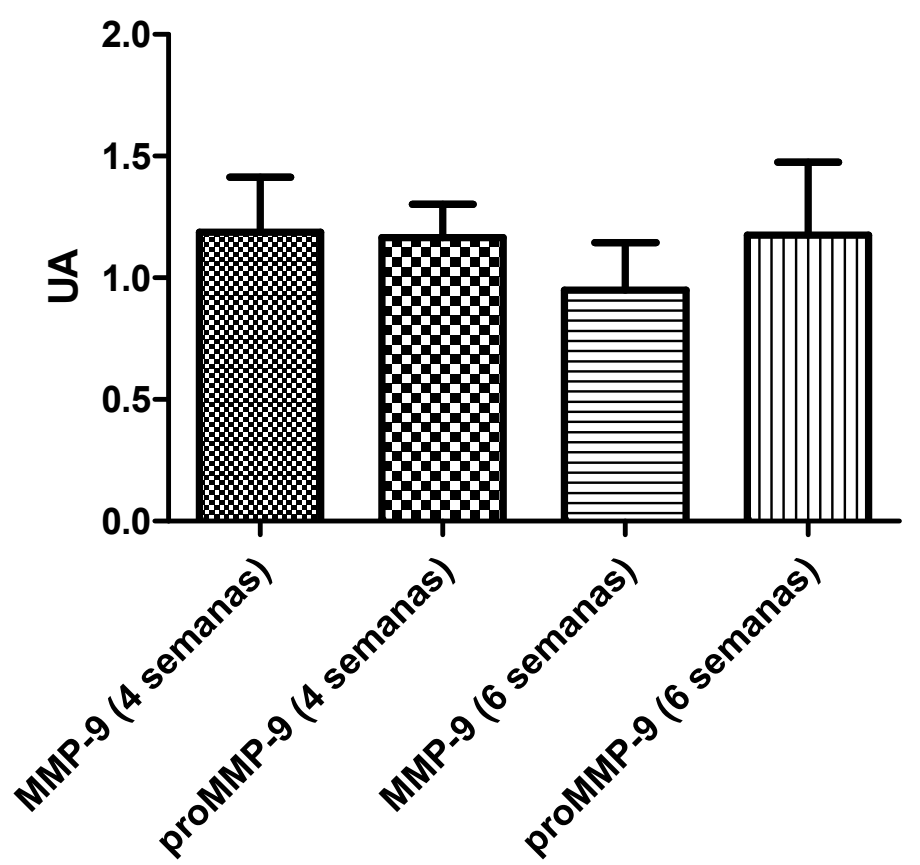

Figura 50 - Gráfico de comparação dos níveis de MMP-9 e proMMP-9 entre os diferentes tempos do grupo 4. Valor de $P=0,1642$. Unidades Arbitrárias.

A análise estatística não identificou diferença significante entre os tempos quanto à concentração das enzimas. 
A análise do grupo 5 passou no teste de normalidade "Shapiro-Wilk normality test"e "Kolmogorov-Smirnov test", com intervalo de confiança de 95\%, mostrando distribuição normal. A figura 51 mostra a comparação entre MMP-9 e proMMP-9 nos diferentes tempos mediante One-way ANOVA com pós-teste de Turkey.

\section{GRUPO 5}

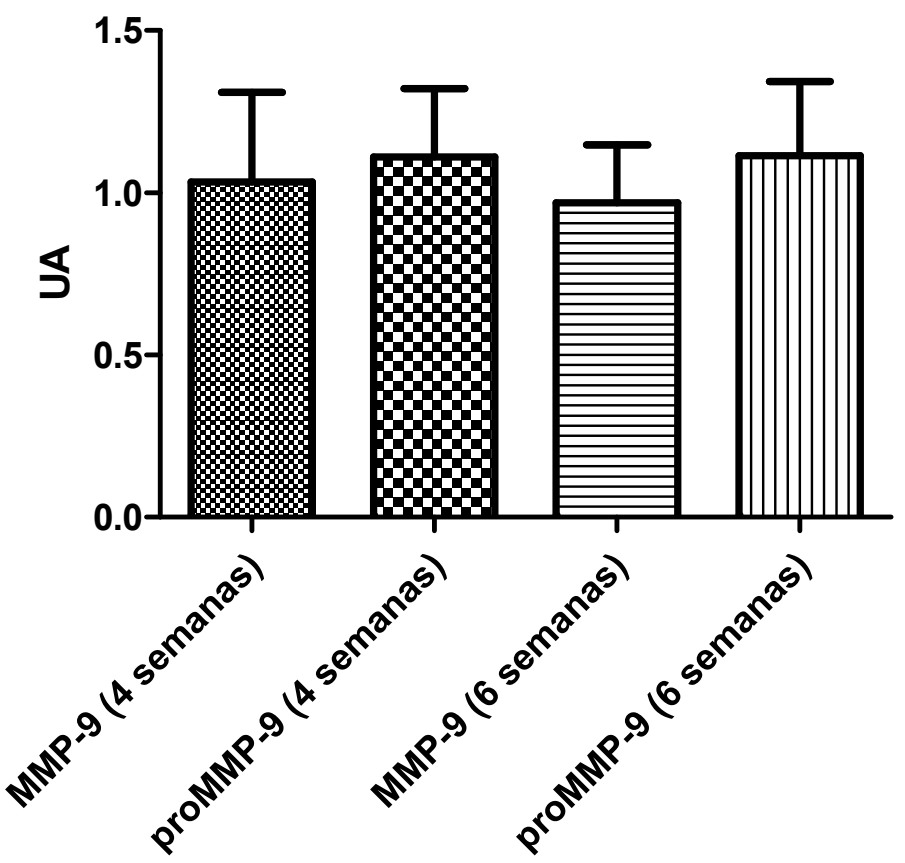

Figura 51 - Gráfico de comparação dos níveis de MMP-9 e proMMP-9 entre os diferentes tempos do grupo 5. Valor de $P=0,5832$. Unidades Arbitrárias.

A análise estatística não identificou diferença significante entre os tempos quanto à concentração das enzimas. 
A análise do grupo 6 passou no teste de normalidade "Shapiro-Wilk normality test" e "Kolmogorov-Smirnov test", com intervalo de confiança de 95\%, mostrando distribuição normal. A figura 52 mostra a comparação entre MMP-9 e proMMP-9 nos diferentes tempos mediante One-way ANOVA com pós-teste de Turkey.

\section{GRUPO 6}

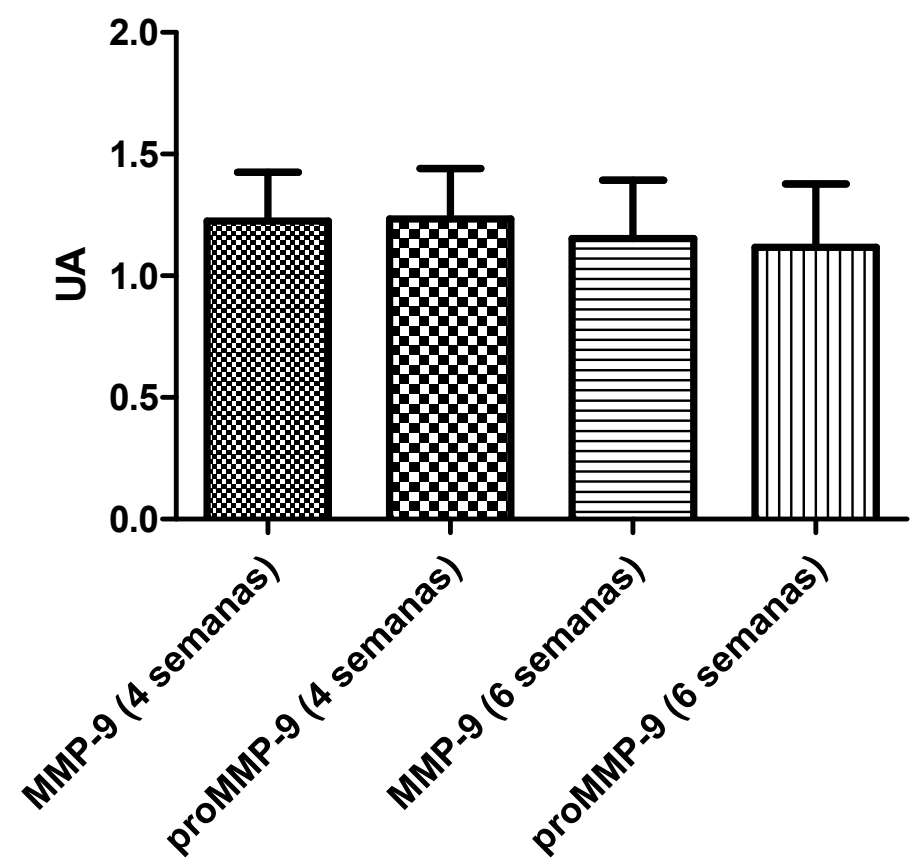

Figura 52 - Gráfico de comparação dos níveis de MMP-9 e proMMP-9 entre os diferentes tempos do grupo 6 . Valor de $P=0,7368$. Unidades Arbitrárias.

A análise estatística não identificou diferença significante entre os tempos quanto à concentração das enzimas. 
A análise do grupo 7 passou no teste de normalidade "Shapiro-Wilk normality test" e "Kolmogorov-Smirnov test", com intervalo de confiança de 95\%, mostrando distribuição normal. A figura 53 mostra a comparação entre MMP-9 e proMMP-9 nos diferentes tempos mediante One-way ANOVA com pós-teste de Turkey.

\section{GRUPO 7}

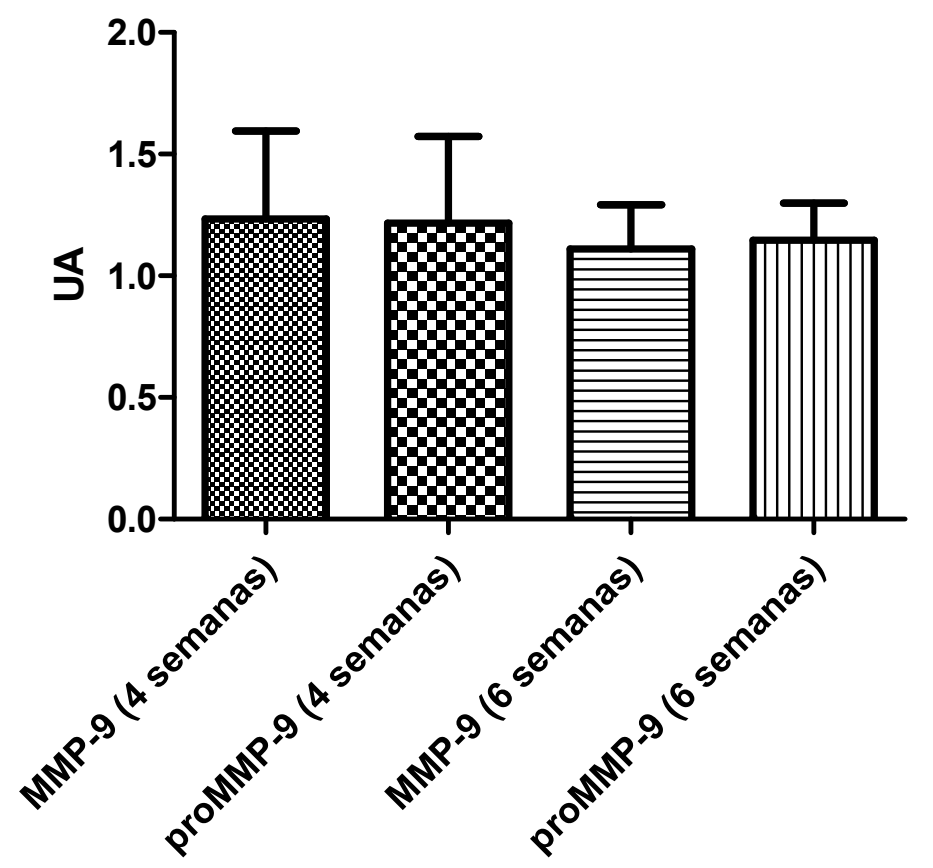

Figura 53 - Gráfico de comparação dos níveis de MMP-9 e proMMP-9 entre os diferentes tempos do grupo 7. Valor de $\mathrm{P}=0,8213$. Unidades Arbitrárias.

A análise estatística não identificou diferença significante entre os tempos quanto à concentração das enzimas. 
A análise do grupo 8 passou no teste de normalidade "Shapiro-Wilk normality test" e "Kolmogorov-Smirnov test", com intervalo de confiança de 95\%, mostrando distribuição normal. A figura 54 mostra a comparação entre MMP-9 e proMMP-9 nos diferentes tempos mediante One-way ANOVA com pós-teste de Turkey.

\section{GRUPO 8}

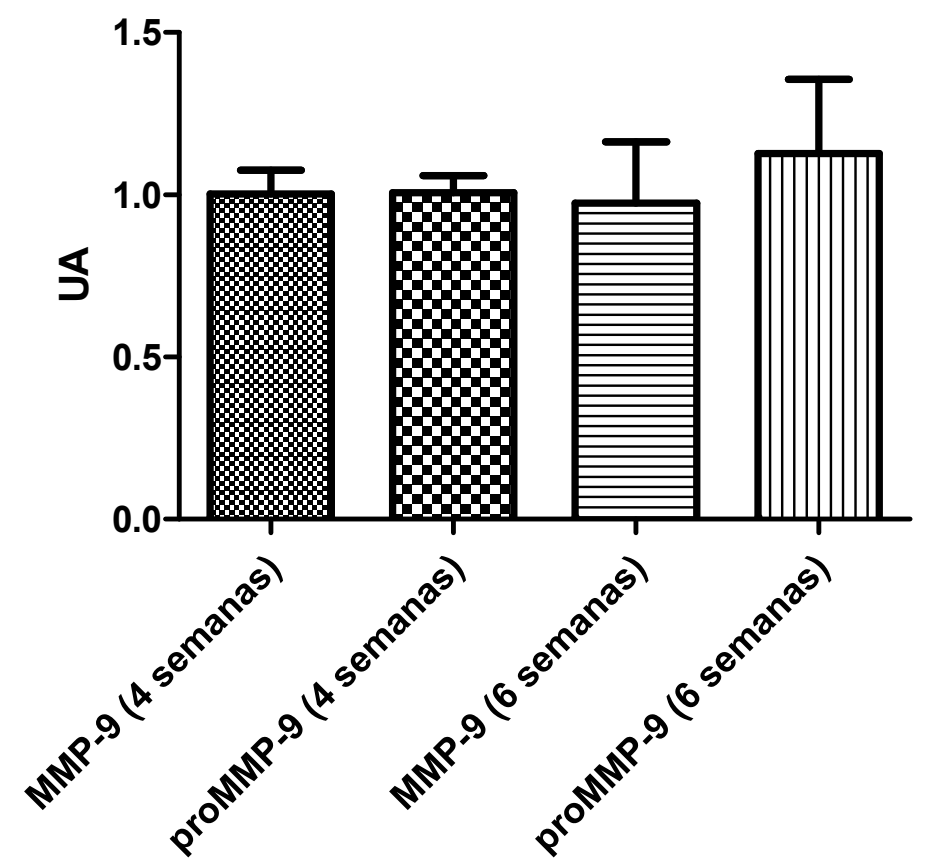

Figura 54 - Gráfico de comparação dos níveis de MMP-9 e proMMP-9 entre os diferentes tempos do grupo 8 . Valor de $P=0,2876$. Unidades Arbitrárias.

A análise estatística não identificou diferença significante entre os tempos quanto à concentração das enzimas.

Quando comparados os valores absolutos de MMP-9 e proMMP-9 de cada grupo, representados pelas médias dos grupos, obtém-se a expressão da tendência de cada grupo nos diferentes tempos (Figura 55). 


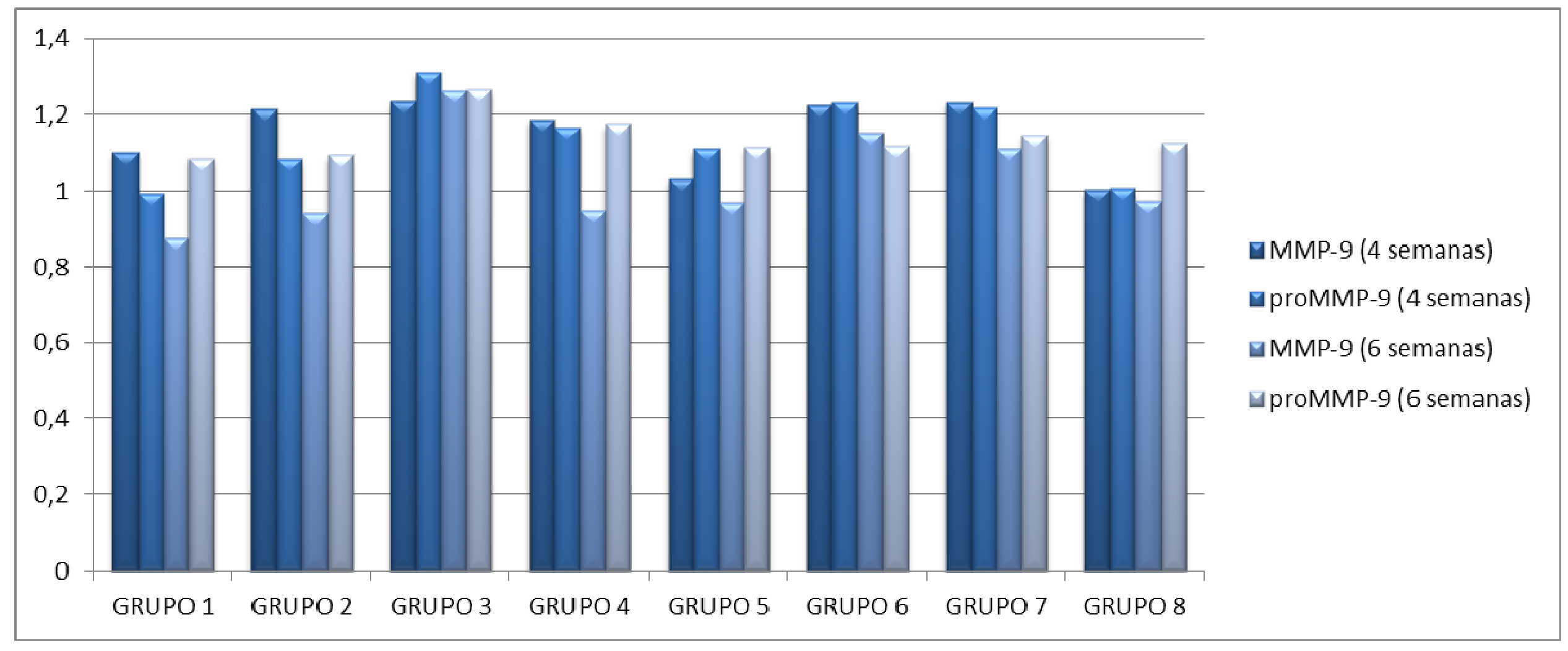

Figura 55 - Comparação das médias dos grupos em relação aos níveis de MMP-9 e proMMP-9 identificados 


\subsection{COMPARAÇÃO DOS GRUPOS DE ENXERTO}

A análise procedeu-se com a média de cada grupo, somando-se as concentrações de MMP-2 e proMMP-2, e as concentrações de MMP-9 e proMMP-9, fornecendo um quadro geral de cada grupo afim de comparação dos tipos de enxerto quanto aos níveis das enzimas (Figura 56).

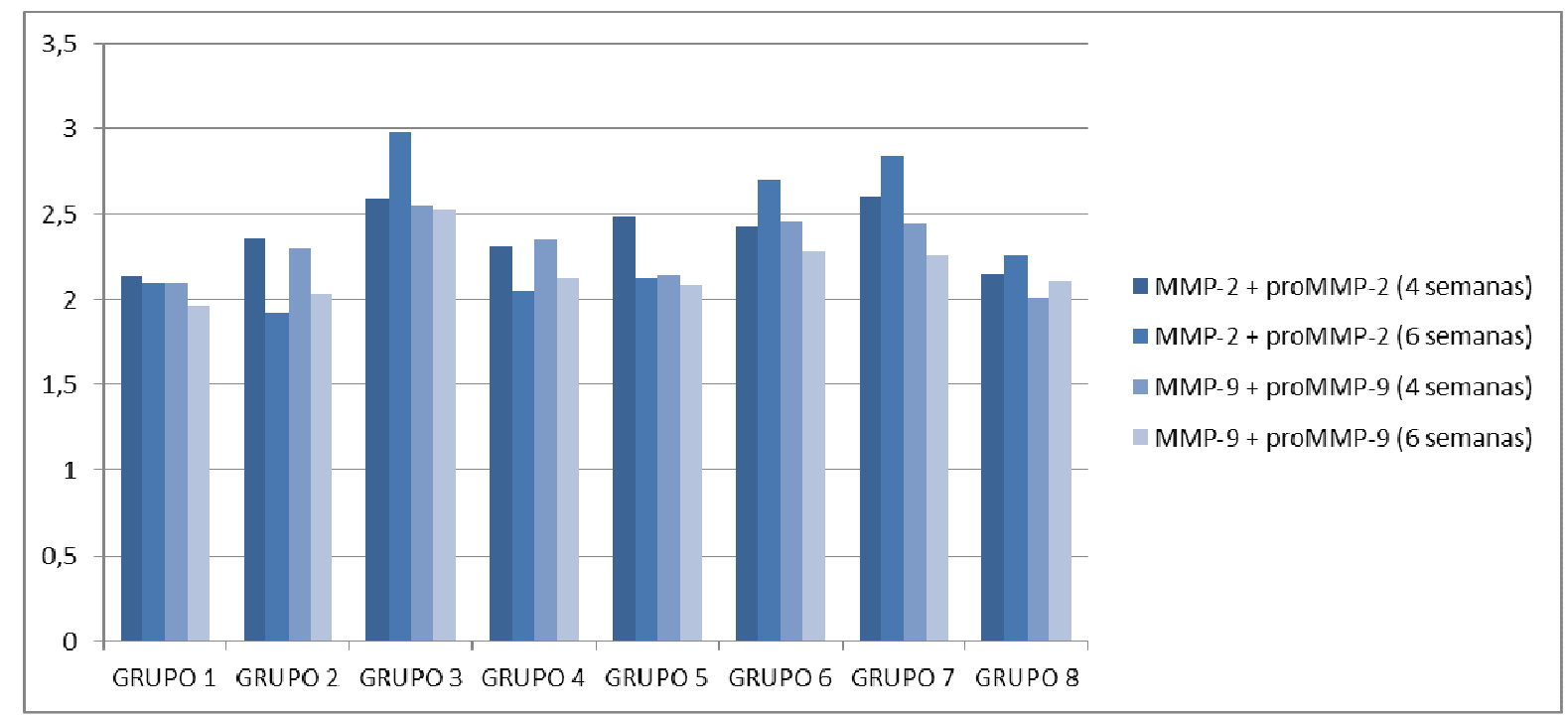

Figura 56 - Gráfico das médias de cada grupo quanto aos níveis totais de cada enzima (soma da enzima ativa com a proenzima) nos diferentes tempos. Unidades Arbitrárias.

\subsection{COMPARAÇÃO DOS GRUPOS QUANTO À DOSAGEM DE CÁLCIO}

A análise da dosagem de cálcio em miligramas por grama de amostra colhida, para o tempo de 4 semanas, mostrou que todos os grupos passaram no teste de normalidade "Shapiro-Wilk normality test" e "Kolmogorov-Smirnov test", com intervalo de confiança de $95 \%$, mostrando distribuição normal. A figura 58 mostra a comparação entre os grupos mediante One-way ANOVA com pós-teste de Turkey. 


\begin{tabular}{|c|c|c|c|c|c|c|c|}
\hline \multicolumn{7}{|c|}{ GRUPOS DE 4 SEMANAS } \\
\hline GRUPO 1 & GRUPO 2 & GRUPO 3 & GRUPO 4 & GRUPO 5 & GRUPO 6 & GRUPO 7 & GRUPO 8 \\
\hline 6,500606 & 7,197554 & 5,842786 & 6,372996 & 5,813115 & 5,467451 & 7,182417 & 4,269091 \\
\hline 5,978333 & 5,161404 & 7,009167 & 5,690535 & 6,427861 & 7,171717 & 7,69622 & 3,877949 \\
\hline 9,962318 & 6,950175 & 5,795833 & 6,129524 & 7,268065 & 7,744984 & 5,449433 & 5,12116 \\
\hline 7,266667 & 8,352592 & 6,100813 & 8,208889 & 6,52657 & 4,412445 & 7,798907 & 6,361728 \\
\hline 9,672072 & 9,727273 & 4,926061 & 5,612121 & 5,997867 & 5,265185 & 6,752174 & 6,197701 \\
\hline 7,671111 & 6,191489 & 6,943478 & 9,222222 & 6,281481 & 5,885252 & 6,462585 & 6,84386 \\
\hline 5,717284 & 5,710303 & 7,339683 & 7,178711 & 6,915013 & 8,088372 & 6,130159 & 6,920635 \\
\hline
\end{tabular}

Figura 57 - Tabela com os resultados individuais de cada dosagem de cálcio em miligramas por grama de amostra no tempo de quatro semanas.

\section{Grupos de 4 semanas}

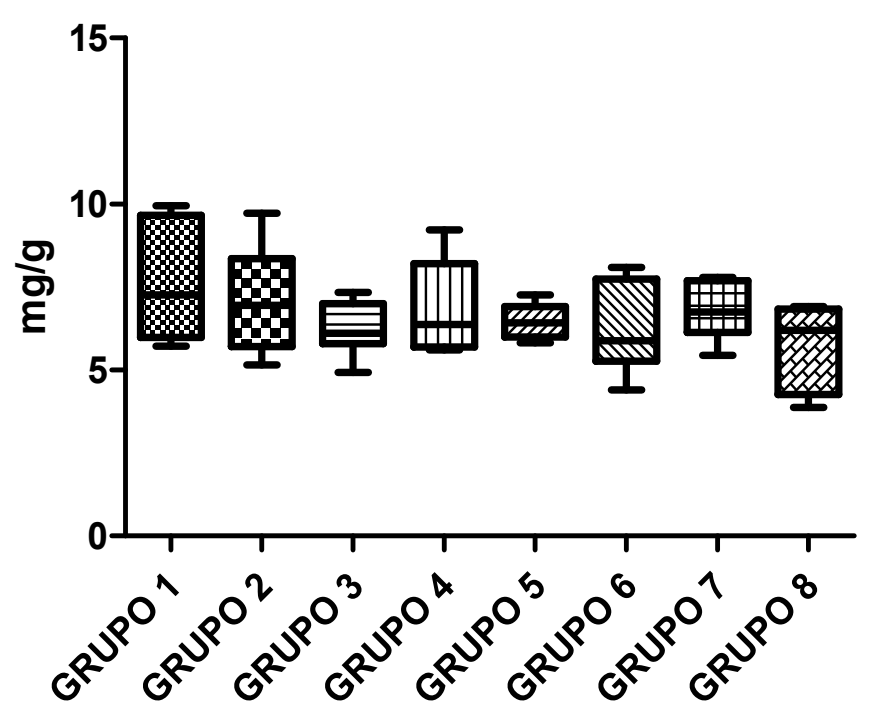

Figura 58 - Gráfico comparativo dos grupos de quatro semanas quanto aos níveis de cálcio em miligramas por grama de osso da amostra. $P=0,1931$.

A análise estatística não identificou diferença significante entre os grupos comparados para a dosagem de cálcio no tempo de quatro semanas.

Na dosagem de cálcio em miligramas por grama de amostra colhida, para o tempo de 6 semanas, todos os grupos passaram no teste de normalidade "ShapiroWilk normality test" e "Kolmogorov-Smirnov test", com intervalo de confiança de 95\%, mostrando distribuição normal. A figura 60 mostra a comparação entre os grupos mediante One-way ANOVA com pós-teste de Turkey. 


\begin{tabular}{|c|c|c|c|c|c|c|c|}
\hline \multicolumn{7}{|c|}{ GRUPOS DE 6 SEMANAS } \\
\hline GRUPO 1 & GRUPO 2 & GRUPO 3 & GRUPO 4 & GRUPO 5 & GRUPO 6 & GRUPO 7 & GRUPO 8 \\
\hline 8,767901 & 9,013333 & 6,030409 & 6,027619 & 5,182222 & 4,605608 & 4,701667 & 5,320741 \\
\hline 9,47451 & 7,736054 & 5,736092 & 7,088333 & 6,125397 & 4,368992 & 6,706011 & 5,847901 \\
\hline 7,0784 & 6,660417 & 5,62193 & 6,825532 & 5,802105 & 4,77193 & 4,410884 & 6,622933 \\
\hline 5,173333 & 6,531519 & 5,81017 & 4,795959 & 5,260215 & 4,751282 & 5,579487 & 7,953459 \\
\hline 9,639025 & 7,823611 & 5,524242 & 4,281778 & 4,15679 & 4,422716 & 6,757806 & 7,207576 \\
\hline 6,170667 & 7,578022 & 6,894118 & 4,907802 & 5,179205 & 5,506306 & 5,489157 & 5,651282 \\
\hline 8,502857 & 7,3483 & 4,848628 & 5,372754 & 4,979894 & 5,357303 & 5,172222 & 3,938298 \\
\hline
\end{tabular}

Figura 59 - Tabela com os resultados individuais de cada dosagem de cálcio em miligramas por grama de amostra no tempo de seis semanas.

\section{Grupos de 6 semanas}

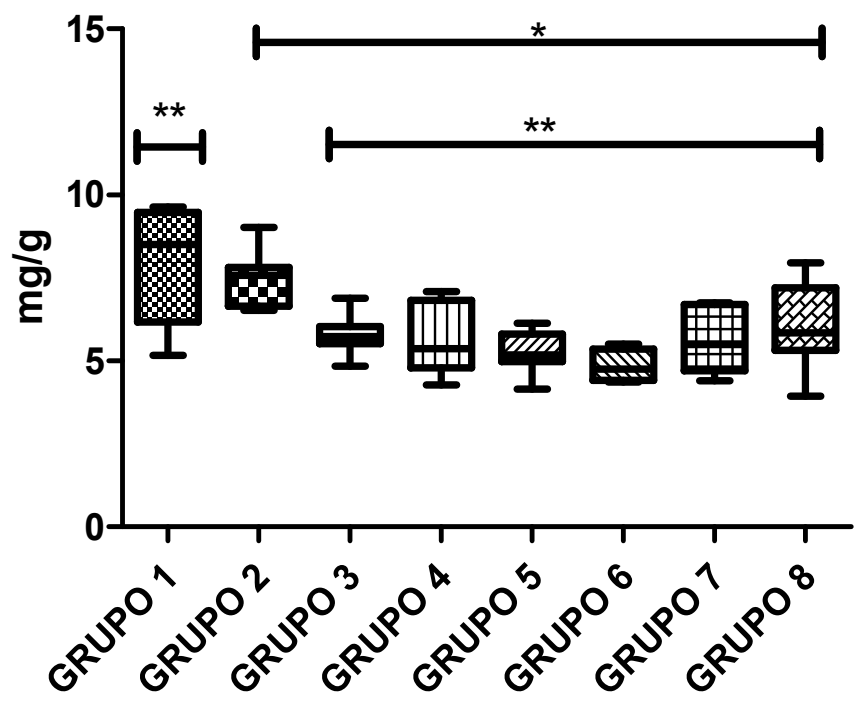

Figura 60 - Gráfico comparativo dos grupos de seis semanas quanto aos níveis de cálcio em miligramas por grama de osso da amostra. $\mathrm{P}<0,0001$.

A análise estatística identificou diferença significante entre o grupo 1 e todos os grupos exceto o grupo 2, identificado com um asterisco $(P<0,05)$ e entre o grupo 2 e todos os grupos exceto o grupo 8 , identificado com dois asteriscos $(P<0,05)$. 
A tabela da figura 61 representa as médias de cada grupo nos dois tempos e o gráfico da figura 62 representa a comparação destas médias.

\begin{tabular}{|c|c|c|c|c|c|c|c|c|}
\hline Médias & GRUPO 1 & GRUPO 2 & GRUPO 3 & GRUPO 4 & GRUPO 5 & GRUPO 6 & GRUPO 7 & GRUPO 8 \\
\hline 4 Semanas & 7,538342 & 7,041541 & 6,279689 & 6,916428 & 6,461425 & 6,290772 & 6,781699 & 5,656018 \\
\hline 6 Semanas & 7,829528 & 7,527322 & 5,780798 & 5,614254 & 5,240833 & 4,826305 & 5,545319 & 6,077456 \\
\hline
\end{tabular}

Figura 61 - Tabela das médias de cada grupo representando as concentrações obtidas de cálcio em miligramas para cada grama de osso da amostra.

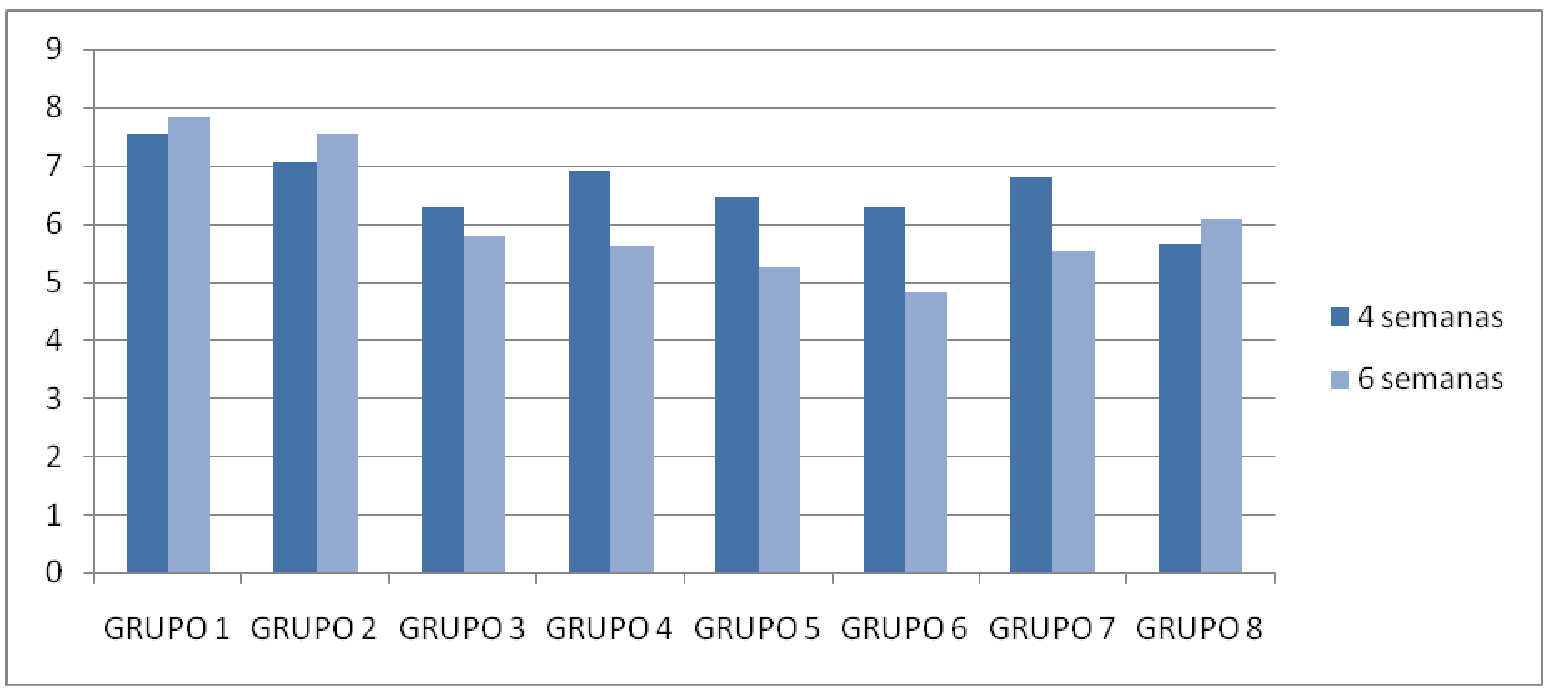

Figura 62 - Gráfico das médias de cada grupo representando as concentrações obtidas de cálcio em miligramas para cada grama de osso da amostra. 


\section{DISCUSSÃO}

Os animais do experimento apresentaram padrão de normalidade no crescimento e ganho de peso durante o experimento. Todos sobreviveram à cirurgia e se desenvolveram adequadamente no decurso. As figuras 10 e 12 mostram as tabelas onde se afere o peso individual dos animais no momento do sacrifício nos diferentes tempos, e a relação entre os pesos se dá nos gráficos das figuras 11 e 13 . Como não foi o enfoque principal da pesquisa não se fez a relação do peso do animal com o reparo ósseo e os índices bioquímicos obtidos na análise das concentrações enzimáticas das peças obtidas. Também, a relação entre a densidade óssea e a dosagem de cálcio foi obtida mediante o peso das peças recolhidas, este foi inserido em fórmula matemática.

Em relação à expressão de MMP-2 e proMMP-2 no tempo de quatro semanas, a análise estatística não foi capaz de identificar diferença na comparação entre os grupos (Figuras 15 e 18). Porém, quando transpomos os resultados absolutos destes grupos, representados pelas médias obtidas de cada grupo, podemos observar que os grupos seguem uma tendência tanto na expressão da enzima ativa como na proenzima (Figuras 16 e 19). Verifica-se que em ambos os casos o grupo 1, que recebeu enxerto autólogo particulado, apresenta níveis menores de expressão que o grupo 2, cujo enxerto foi de osso homólogo, e este se apresenta menor que o grupo 3, de osso heterólogo. Padrão parecido ocorre com os grupos 4,5 e 6 , que seguem os enxertos respectivos dos grupos 1, 2 e 3, mas apresentam a adição de rhBMP-2. O grupo 4 mostra menor concentração das enzimas em relação ao grupo 5 , e o grupo 5 se apresenta semelhante ao grupo 6 . Apenas na expressão da proenzima que ocorre uma alteração, o grupo 4 permanece 
menor que os outros dois, porém o grupo 5 apresenta maior expressão de proMMP2 que o grupo 6 (Figura 19). Tanto na expressão da enzima, quanto na expressão da proenzima o grupo 7, cujo tratamento se deu apenas com a deposição de rhBMP-2 no leito de defeito cirúrgico, apresenta níveis elevados, compatíveis aos maiores níveis alcançados pelos outros grupos. O grupo 8, grupo controle sem tratamento, apresenta um padrão de expressão semelhante aos grupo 1 e 4 .

No tempo de recuperação de seis semanas, analisando os índices de MMP-2 e proMMP-2, constatamos na Figura 21 que houve uma diferença significante entre o grupo 2 e os grupos 3, 6 e 7. A figura 24 nos indica que há diferença estatística entre os grupos. Ao analisarmos as médias de cada grupo (Figuras 22 e 25) podemos observar que o grupo 1 apresentou maior expressão que o grupo 2 em ambos os casos, porém com pequena margem relativa, mas o grupo 3 , como ocorrido no tempo de quatro semanas apresentou uma maior expressão em relação a esses grupos. Tanto na expressão de MMP-2 quanto na expressão de proMMP-2 foi o grupo que mais expressou. O padrão também se seguiu quando comparamos os grupos 4, 5 e 6 nesse tempo, pois quanto à expressão de MMP-2 os níveis foram crescentes do grupo 4 ao 6 e quanto à expressão de proMMP-2, o grupo 4 apresentou semelhança ao grupo 5, mas ambos foram muito menos expressivos que o grupo 6. O grupo 7 novamente apresentou alta expressão das duas proteínas e, nestas duas concentrações o grupo 8 apresentou maior expressão que os grupos 1 e 4 . O grupo 2 apresentou a menor expressão de todos.

Os grupos dos enxertos ósseos autólogos e homólogos se mostraram muito próximos aos obtidos no grupo controle, e com menor índice quando comparados ao tempo de quatro semanas. Os menores índices pertencem ao grupo 2 seguido dos grupos 1, 4, 8 e 5 para a enzima ativa. Interessantemente os índices dos grupos 3, 6 
e 7 se mostraram maiores que os do tempo de quatro semanas. Lieu e colaboradores (2011) em seu trabalho verificaram que a expressão de MMP-2 é baixa no osso normal, mas perceberam que há uma alta produção de MMP-2 nas fases precoces do reparo, principalmente na formação do calo mole e essa concentração se torna menor e difusa em estágios tardios. Eles também observaram que um mutante nocaute para o gene de MMP-2, ou seja, que não expressa essa proteína, tem um atraso significante no processo de reparo e remodelação óssea, mostrando que essa requisição da protease se faz necessária para o correto desenvolvimento da cicatrização. Itagaki e colaboradores (2008) de mesma maneira noticiaram que os índices de MMP-2 rapidamente se elevam nas fases precoces do reparo e vão diminuindo gradativamente conforme se estende o tempo, mostrando pico máximo de expressão em torno das terceira e quarta semanas pós-operatório. Eles sugerem no final que a inflamação promove a diferenciação de osteoblastos e aumenta a sua atividade de produção e degradação de matriz extracelular, essa atividade diminui quando a inflamação diminui. Isso condiz com a expressão da proteína MMP-2 no presente estudo. Dada sua importância no processo de reparo, pode ser evidenciada desde as fases mais precoces do reparo se estendendo entre os tempos de quatro e seis semanas.

A concentração elevada de MMP-2 e proMMP-2 pode estar relacionada a uma persistência no período inflamatório, sendo essas enzimas recrutadas para reabsorção de tecido de granulação e reconstrução tardia da matriz extracelular. Os grupos 3 e 6 mostraram os maiores índices de atuação dessa enzima no quadro geral, o que pode ser devido ao tipo de enxerto, de osso heterólogo, que pode necessitar de maior tempo para ser reabsorvido e integrado. Os melhores índices deram-se ao osso autólogo, cuja concentração de MMP-2 ficou bastante próxima à 
concentração apresentada pelo grupo controle. Corry e colaboradores em 2004, além de Greenlee e colaboradores em 2006 observaram características similares, dizendo que embora a MMP-2 participe na regulação inflamatória de outros tecidos ela pode estar envolvida na resposta inflamatória associada ao reparo de fraturas ósseas.

Quanto aos níveis de MMP-9 e proMMP-9 no tempo de quatro semanas, não houve uma diferença estatística entre os grupos, como observado nas figuras 27 e 30. Quando analisamos os números médios dos grupos, vimos na figura 28 que o grupo 1 mostra menor expressão que os grupos 2 e 3 , sendo a expressão do grupo 2 menor que a expressão do grupo 3. O grupo 3 apresentou a maior expressão de MMP-9, seguido do grupo 6. A menor expressão ocorreu no grupo 8. 0 grupo 7 também obteve alta expressão de MMP-9. A expressão de proenzima seguiu o padrão analisado (Figura 31). O grupo 1 com expressão menor que o grupo 2 e este menor que o 3. O grupo 3 ainda com expressão elevada também da proenzima, muito parecida com as concentrações obtidas pelo grupo 6. Novamente o grupo 7 obtém alto índice de expressão e o grupo controle menor índice, compatível com o grupo 1, apesar deste aparecer um pouco elevado.

No tempo de seis semanas houve diferença estatística somente entre o grupo 1 e 3 quanto à expressão de MMP-9 (Figura 33). Entretanto, analisando-se o gráfico das médias e a tendência seguida por estes grupos notamos que novamente o grupo 1 apresenta baixos índices de enzima MMP (Figura 34) e de novo seguido pelos grupos 2 e 3 (este com altos índices). 0 mesmo ocorre entre os grupos $4,5 \mathrm{e}$ 6 e mais uma vez o grupo 7 mostra alta expressão e o grupo controle expressão compatível com as menores apresentadas. Já na apresentação da proenzima, estatisticamente todos os grupos se apresentaram com muita semelhança (Figura 
36), mas as maiores médias pertencem aos grupos 3, 4, 7 e 6 . O grupo 4 mostrou alta expressão em relação ao 5 e 6 (Figura 37).

Colnot e colaboradores, em 2003, verificaram abundante expressão de MMP9 nas células inflamatórias e mesenquimais que envolviam o tecido em reparo nas fases precoces e que a concentração de MMP-9 se manteve constante nas fases tardias devido à ativação dos osteoclastos para a remodelação do osso neoformado. Esses dados condizem com os obtidos no presente estudo, dado que os níveis de MMP-9 obtidos, ao contrário do ocorrido com os níveis de MMP-2, se mantiveram com características semelhantes nos dois tempos operatórios, pois embora ocorresse pequena diminuição na presença da enzima ativa no tempo de seis semanas, os níveis de proenzima se mantiveram em patamares elevados mostrando que esta protease estava sendo requisitada no sítio de reparo.

Wang (2012) em seu trabalho diz ser a MMP-9 expressada tanto por células mielóides derivadas da medula-óssea quanto por osteoclastos, todas envolvidas na resposta inflamatória e remodelação da matriz extracelular durante o reparo ósseo. Na ausência de MMP-9, verificada em animais sem o gene que expressa a proteína, o recrutamento de osteoclastos fica prejudicado, além disso, prejudica-se também o recrutamento de linfócitos T e macrófagos. Ele conclui então que a manutenção dos níveis de expressão da MMP-9 é necessário para a modulação da resposta inflamatória e para o correto desenvolvimento da remodelação de tecido de reparo. Em nosso trabalho, vimos mantidos estes níveis nos vários tempos operatórios.

Lu e Rabie (2006) observaram em seu trabalho que os níveis de MMP-9 se mantêm em fases tardias do reparo ósseo e puderam supor que isso se deve à expressão dos osteoclastos com o propósito de integrar o osso enxertado com o osso neoformado, o que depende de um processo continuo até que o osso 
enxertado seja completamente substituído por novo tecido ósseo. Em nosso trabalho também pudemos observar a manutenção desses níveis de MMP-9 nas fases tardias de reparo, e percebemos que quanto mais diferente o enxerto utilizado em relação ao leito receptor, maior a expressão das formas enzimáticas.

Nas figuras 46 e 55 temos a representação gráfica de todo o quadro baseada na relação das médias, pois como apresentado anteriormente os grupos seguem uma tendência de expressão das proteínas e há necessidade da análise dessas proteínas em relação aos dois tempos operatórios. Verificamos então, na figura 46 que o grupo 1 apresenta baixos índices de MMP-2 e proMMP-2, muito semelhantes ao grupo 4 e ao grupo controle. No grupo 1 as concentrações da enzima e proenzima se mantêm relativamente constantes nos dois tempos, como no controle. Os grupos 2 e 3 apresentaram em maior quantidade a forma ativa da enzima em relação ao grupo 1, assim como os grupos 5 e 6 em relação ao grupo 4, isso ocorrendo nos dois tempos cirúrgicos. Entretanto o interessante é que enquanto nos outros grupos houve convergência à diminuição na concentração dessas enzimas, nos grupos 3 e 6 elas aumentaram na fase mais tardia de reparo. O mesmo ocorreu com o grupo 7, um dos grupos que mais expressou as proteases em ambos os tempos.

A figura 55 trata dos níveis de MMP-9 e proMMP-9 nos dois tempos analisados. Neste quadro notamos que o padrão de expressão dos grupos que receberam o enxerto de mesma espécie animal mostrou características bastante semelhantes. Nestes grupos (grupos 1, 2, 4 e 5), percebemos que houve um pico nos níveis enzimáticos no período de quatro semanas e que no tempo de seis semanas esses níveis decaíram muito na forma ativa, predominando a forma de proenzima. Quadro muito semelhante ao que ocorreu no grupo controle. 
Interessante notar também que novamente se destacam os grupos 3 e 6 , que receberam osso bovino liofilizado, pois nestes grupos os níveis de MMP-9 e proMMP-9 se mantiveram constantes em seis semanas. Este quadro se assemelhou ao ocorrido no grupo 7. O enxerto de osso heterólogo apresentou alta expressão nos dois tempos, sugerindo que este tecido tenha necessidade de maior ação osteoclástica para integração. Como esperado, o enxerto de osso autólogo apresentou índices próximos aos obtidos no grupo controle, mostrando uma modulação próxima à normalidade.

Assim, a figura 56 resume o que aconteceu de maneira geral nos grupos em relação às quantidades totais de enzimas nos dois tempos operatórios. Notamos que a expressão mais equilibrada se deu ao grupo 1 e que este é o que mais se aproxima à características de reparo do grupo controle. Observamos também que a adição de rhBMP-2 não pareceu influenciar significativamente a expressão das MMPs neste estudo. Somente o grupo 7, que recebeu a deposição da rhBMP-2 diretamente sobre o leito do defeito, apresentou um quadro interessante em que ocorreu intensa produção das duas proteínas durante os dois tempos, possivelmente por uma rápida resposta antigênica causada por esta proteína diretamente no local. A literatura costuma indicar o uso de carreadores para a BMP, para que esta seja liberada em pequenas doses num longo espaço de tempo (LA ET AL., 2012; ROHANIZADEH \& CHUNG, 2011).

Dessa situação podemos supor que a modulação da inflamação e o manejo do processo de reparo apresentam características mais lineares no grupo controle, pois expressou altas doses de MMP-2 no período inicial e baixas doses de MMP-9 no mesmo período, condizente, pois ainda há uma fase inflamatória instalada e pequeno recrutamento de osteoclastos, maiores produtores de MMP-9. Supõe-se 
que este mesmo grupo controle inverteu o padrão de expressão, liberando relativamente uma soma maior de MMP-9 e proMMP-9 na fase tardia de reparo, concomitante ao maior recrutamento de osteoclastos para remodelação do osso neoformado. A alta expressão da soma MMP-2 e proMMP-2 no tempo de seis semanas por ser devida à amplitude do defeito ósseo nesse grupo, com a formação de um calo ósseo maior e mais persistente. Nos grupos onde houve enxertia a produção total das formas de MMP-9 sempre diminuiu no tempo de seis semanas.

Van der Kraan e colaboradores em 2010 identificaram em seu estudo que a proteína BMP pode apresentar uma ação dúbia; por um lado apresenta efeito de proteção restaurando tecido ósseo e cartilaginoso, por outro, também aumenta as concentrações de MMPs, o que em determinados quadros clínicos pode causar degradação e levar a quadros patológicos como osteoartrite. Assim, um manejo da concentração de BMP no local de reparo é necessário para coordenar os efeitos benéficos. No presente estudo houve uma relação positiva entre a aplicação de BMP e as concentrações de MMPs.

$\mathrm{Na}$ comparação dos materiais o enxerto autólogo apresentou os melhores resultados, como era esperado, muito semelhante ao que ocorreu no grupo controle, seguido dos grupos de enxerto homólogo, que apresentou índices das enzimas um pouco mais elevados e isso pode ser devido à presença de antígenos no material que leva a uma reação imunológica mais exacerbada que no enxerto do próprio animal. Por fim os grupos de enxerto heterólogo apresentaram relativamente maior expressão das enzimas, podendo-se dizer que o material industrializado necessita de maior reação de adaptação do organismo para ser manejado e remodelado. Stein e colaboradores em 2009 também verificaram características semelhantes, mostrando-se o enxerto autólogo com melhor neoformação óssea. Segundo 
Kawachi e colaboradores (2000), a hidroxiapatita é degradada lentamente in vivo e começa a ser reabsorvida em ensaios clínicos após quatro a cinco anos de sua implantação em humanos. Essa é uma das razões de sua limitação, pois a absorção é uma propriedade importante do biomaterial, necessária a neoformação óssea. Anderson e colaboradores (2008) também noticiaram que a implantação de microesferas de hidroxiapatita desenvolve uma reação granulomatosa, com presença de macrófagos e células gigantes multinucleadas circundando as microesferas que foi reduzida progressivamente ao longo do tempo, caracterizando uma reação de corpo estranho. Assim, o biomaterial tem características de osteoindução e serve de arcabouço para a neoformação óssea, porém necessita de maior atividade do organismo para sua substituição.

O grupo que recebeu apenas rhBMP-2 nos deu a impressão que esta proteína, quando lançada isoladamente sobre o leito sem um carreador que a entregue em pequenas doses por maior tempo, causa uma maior reação do organismo, podendo essa não ser a ideal e levar a danos teciduais secundários. Laflamme e Rouabhia (2008) em seus estudos noticiaram que a adição de BMP-2 em cultura de células da linhagem osteoblástica diminuiu os níveis de expressão de MMP-2 e permitiu um maior crescimento da matriz extracelular. A mesma razão foi identificada por Hu e seus colaboradores em 2008. No presente estudo não houve uma diferença expressiva nos índices enzimáticos entre os grupos que receberam rhBMP-2 e os grupos que utilizaram-se de enxertos isoladamente. Possivelmente um aumento na dose administrada ou um número amostral maior poderia diferenciar esses grupos.

Devido ao efeito dual das MMPs, podendo ser benéficas nas reações fisiológicas, regulando as defesas do hospedeiro sob intensa modulação de sua 
expressão e ativação, mas também podendo ser prejudiciais em expressões elevadas e desreguladas, como ocorre nos processos inflamatórios patológicos, é essencial que se definam mecanismos moleculares específicos que decifrem qual a função individual de cada uma das MMPs e suas formas de apresentação nos processos inflamatórios normais e anormais. Manicone e McGuire (2008) levam essa discussão adiante dizendo que essa dualidade de efeitos se estende às diferenças dos tipos celulares que estão expressando a MMP, os substratos onde elas irão atuar e a presença de processos patológicos. Assim, dependendo do caso, a inibição da produção de MMPs, bem como o aumento de sua expressão, pode levar a benefícios limitados ou mesmo ser prejudicial. Deste modo, é necessário que se estude cada vez mais o papel e o comportamento dessas enzimas em diferentes situações e sobre diferentes substratos e, com isso, em casos específicos poder-seia indicar estratégias terapêuticas explorando os benefícios e eliminando os possíveis malefícios da modulação de MMP.

A análise das dosagens de cálcio nas amostras colhidas mostrou, no tempo de quatro semanas, que não houve diferença significante entre os grupos, como verificado na figura 58. Porém, na comparação dos grupos do tempo de seis semanas houve diferença significativa entre o grupo 1 e os demais grupos exceto 0 grupo 2, e entre este mesmo grupo 2 e os grupos 3, 4, 5, 6 e 7, como apresentado pela figura 60. Pode-se, no entanto reconhecer a tendência destes grupos na análise comparativa entre as médias, representada pela figura 62. Nesta, vê-se que os grupos 1 e 2 apresentam as maiores médias nos dois tempos, havendo ainda um aumento nesta concentração no segundo período. O mesmo ocorreu com o grupo 8 . Como esperado, neste mesmo grupo 8 as dosagens de cálcio foram baixas, pois se trata de um grupo onde se realizou um defeito cirúrgico e não se inseriu nenhum 
material, supondo então que realmente o osso neste local levaria maior tempo para se regenerar e se mineralizar. Isso corrobora com o aspecto visual da peça obtida, que no momento da colheita da amostra se apresentou com menor volume ósseo que todas as demais.

Seguindo esse princípio, os resultados foram favoráveis também aos grupos de enxertia autóloga e homóloga (grupos 1 e 2) que no momento da recuperação da amostra apresentavam sólido bloco ósseo em todos os tempos. Quanto ao grupo 3, no momento da coleta do material para análise, notou-se que havia ainda grande quantidade de material particulado sobre o reparo, indicando que a integração do material mineralizado foi menor que nos grupos 1 e 2 nos dois tempos cirúrgicos e isto também pode ser visto no gráfico da figura 62 , pois nos dois tempos este grupo apresentou menor média na dosagem de cálcio. Já no que diz respeito aos grupos que receberam a rhBMP-2, todos mostraram características semelhantes, tanto nas peças recolhidas, onde se observava a olho nu que o reparo havia se concretizado, mas com densidade menor que nos outros grupos onde não foi inserida a proteína, quanto nas dosagens de cálcio, que representaram que o reparo formado sobre o defeito ósseo nestes grupos ainda consistia de material menos mineralizado. Neste ponto pareceu haver maior deposição de material colágeno e menor mineralização quando em comparação aos demais grupos. E ainda mais interessante, exceto nos grupos 1, 2 e 8, pareceu haver redução na densidade de cálcio da amostra no segundo tempo analisado. Assim, mais estudos se mostram necessários acerca da qualidade deste material reparador e seu aspecto na progressão da cicatrização do defeito. Os dados corroboram com o estudo de Yan e colaboradores, de 2010, onde o tratamento com rhBMP-2 mostrou um significante aumento na quantidade de 
tecido cicatricial, porém a qualidade deste osso neoformado poderia ser inferior ao osso sem indução.

\section{CONCLUSÃO}

Em relação às concentrações obtidas das enzimas e das proenzimas não houve uma diferença estatística dos grupos comparados entre si, porém podemos notar uma tendência seguida por estes grupos nos diferentes tempos de tratamento. No período inicial, de quatro semanas, houve relativamente uma maior expressão de MMP-2, que diminui no período tardio (seis semanas). A expressão de MMP-9 foi maior nos grupos enxertados em comparação ao grupo controle e também diminuiu no período de seis semanas. Os enxertos autólogos apresentaram índices compatíveis aos obtidos no grupo controle, seguidos dos enxertos homólogos e por fim do enxerto heterólogo. A aplicação direta de rhBMP-2 mostrou desencadear uma maior expressão das enzimas, comparável às maiores expressões de todos os grupos nos diferentes tempos.

Quanto à densidade de cálcio nas amostras, observou-se que está se apresentou maior nos grupos de enxerto autólogo e homólogo, que no grupo controle, assim como nos dois anteriores, o nível de cálcio aumentou no tempo de seis semanas, mas em todos os outros grupos houve redução nos índices no segundo período. 


\section{REFERÊNCIAS}

ACCORSI-MENDONCA T, CONZ MB, BARROS TC, DE SENA LA, SOARES GDE A, GRANJEIRO JM. Physicochemical characterization of two deproteinized bovine xenografts. Braz Oral Res, 2008; 22(1):5-10.

AICHELMANN-REIDY ME, YUKNA RA. Bone replacement grafts: the bone substitutes. Dent Clin North Am, 1998; 42(3):491-503.

AI-AQL ZS, ALAGL AS, GRAVES DT, GERSTENFELD LC, EINHORN TA. Molecular mechanisms controlling bone formation during fracture healing and distraction osteogenesis. J Dent Res, 2008; 87:107-118.

ALLEGRINI Jr. S, YOSHIMOTO M, SALLES MB, ET AL. Bone regeneration in rabbit sinus lifting associated with bovine BMP. J Biomed Mater Res, 2004; 15:127-131.

AMMERMAN CB, LOAIZA JM, BLUE WG, GAMBLE JF, MARTIN FG. Mineral composition of tissues from beef cattle under grazing conditions in Panama. J Anim Sci, 1974; 38(1):158-162.

ANDERSON JM, RODRIGUEZ A, CHANG DT. Foreign body reaction to biomaterials. Semin Immunol, 2008; (20)2:86-100.

AUBIN JE. Regulation of osteoblast formation and function. Rev Endocr Metab Disord, 2001; 2:81-94. 
BAPTISTA AD. ET AL. Estudo Histológico dos Enxertos Ósseos Homólogos Humanos. Acta Ortop Bras, 2003; 4:221-225.

BEHONICK DJ, XING Z, LIEU S, ET AL. Role of matrix metalloproteinase 13 in both endochondral and intramembranous ossification during skeletal regeneration. PLoS One, 2007; 2(11):e1150.

BESSA PC, CASAL M, REIS RL. Bone morphogenetic proteins in tissue engineering: the road from the laboratory to the clinic, part I (basic concepts) J Tissue Eng Regen Med, 2008; 2:1-13.

BERGLUNDH T, LINDHE J. Healing around implants placed in bone defects treated with Bio-Oss: an experimental study in the dog. Clin Oral Impl Res, 1997; 8:117124.

BEZERRA DE MENEZES LM. ET AL. Bone as a biomarker of acute fluoride toxicity. Forensic Sci Int, 2003; 137(2-3):209-214.

BIRKEDAL-HANSEN H, MOORE WGI, BODDEN MK, WINDSOR LJ, BIRKEDALHANSEN B, DECARLO A, ENGLER JA. Matrix metalloproteinases: a review. Crit Rev Oral Bio and Med, 1993; 4:197-250.

BRANDI ML, COLLIN-OSDOBY P. Vascular biology and the skeleton. J Bone Miner Res, 2006; 21:183-192. 
BRAZ F, RAHAL SC, ROCHA NS. ET AL. Emprego de matriz óssea orgânica bovina e hidroxiapatita no reparo de defeito induzido em crânio de ratos. Acta Cir Bras, 2003; 18:19-24.

CENNI E, PERUT F, BALDINI N. In vitro medels for the evaluation of angiogenic potential in bone engineering. Acta Pharm Sinica, 2011; 32:21-30.

CIANI RB, RAHAL SC, VOLPI RS,ET AL. Mistura de proteínas morfogenéticas ósseas, hidroxiapatita, osso inorgânico e colágeno envolta por membrana de pericárdio no preenchimento de defeito ósseo segmentar em coelhos. Arq Bras Med Vet Zootec, 2006; 58:59-67.

COLNOT C,THOMPSON Z, MICLAU T, WERB Z, HELMS JA. Altered fracture repair in the absence of MMP9. Development, 2003; 130(17):4123-4133.

CORBEL M, BOICHOT E, LAGENTE V. Role of gelatinases MMP-2 and MMP-9 in tissue remodeling following acute lung injury. Braz J Med Biol Res, 2000; (33)7:749754.

CORRY DB, KISS A, SONG LZ, SONG L, XU J, LEE SH, WERB Z, KHERADMAND F. Overlapping and independent contributions of MMP2 and MMP9 to lung allergic inflammatory cell egression through decreased CC chemokines. FASEB J, 2004; 18: 995-997. 
DEL CARLO RJ, IAMAGUTI P, BRANCO MDL. ET AL. Cranioplastia por interposição de auto-enxerto costal. III. Aspectos da enxertia óssea. Arq Bras Med Vet Zootec, 1994; 46:244-252.

DIMITRIOU R, TSIRIDIS E, GIANNOUDIS PV. Current concepts of molecular aspects of bone healing. Injury, 2005; 36:1392-1404.

DIMITRIOU R, JONES E, MCGONAGLE D, GIANNOUDIS PV. Bone regeneration: current concepts and future directions. BMC Med, 2011; 9:66.

DUARTE DA SILVA AB, RODRIGUES L, JORGETTI W, BESTEIRO JM, FERREIRA MC, GONÇALVES CG, DOS REIS LM. Histological alterations in homogenous bone graft with two techniques of preparation and storage. Acta Cir Bras, 2000; 15 (supl 3): 74-77.

ELLIS E, SINN DP. Use of homologous bone in maxillofacial surgery. J Oral Maxillof Surg, 1993; 51:181-193.

ERIKSEN EF, GUNDERSEN HJ, MELSEN F, MOSEKILDE L. Reconstruction of the formative site in iliac trabecular bone in 20 normal individuals employing a kinetic model for matrix and mineral apposition. Metab Bone Dis Relat Res, 1984a; 5:243252. 
ERIKSEN EF, MELSEN F, MOSEKILDE L. Reconstruction of the resorptive site in iliac trabecular bone: a kinetic model for bone resorption in 20 normal individuals. Metab Bone Dis Relat Res,1984b; 5:235-242.

ERIKSEN EF. Cellular mechanisms of bone remodeling. Rev Endocr Metab Disord, $2010 ; 11(4): 219-227$.

$\mathrm{ETOH}$ T, ET AL. Angiopoietin-2 is related to tumor angiogenesis in gastric carcinoma: possible in vivo regulation via induction of proteases. Cancer Res, 2001; 61:2145-2153.

FAZZALARI NL. Bone fracture and bone fracture repair. Osteoporos Int, 2011; 22:2003-2006.

FINKEMEIER CG. Bone-grafting and bone-graft substitutes. J Bone Joint Surg, 2002; 84(3):454-465.

GALASSO O, FAMILIARI F, DE GORI M, GASPARINI G. Recent findings on the role of gelatinases (matrix metalloproteinase-2 and -9) in osteoarthritis. Adv Orthop, 2012; vol. 2012, Article ID 834208, 7 pages

GERSTENFELD LC, CULLINANE DM, BARNES GL, GRAVES DT, EINHORN TA. Fracture healing as a post-natal developmental process: molecular, spatial, and temporal aspects of its regulation. J Cell Biochem, 2003; 88:873-884. 
GERSTENFELD LC, ALKHIARY YM, KRALL EA, NICHOLLS FH, STAPLETON SN, FITCH JL.ET AL. Three-dimensional reconstruction of fracture callus morphogenesis. J Histo Chem Cyto Chem, 2006; 54:1215-1228.

GHAJAR CM, GEORGE SC, PUTNAM AJ. Matrix Metalloproteinase Control of Capillary Morphogenesis Crit Rev Eukaryot Gene Expr, 2008; 18(3):251-278.

GIANNOUDIS PV, DINOPOULOS H, TSIRIDIS E. Bone substitutes: an update. Injury, 2005; 36(Suppl 3):20-27.

GREENLEE KJ, CORRY DB, ENGLER DA, MATSUNAMI RK, TESSIER P, COOK RG, WERB Z, KHERADMAND F. Proteomic identification of in vivo substrates for matrix metalloproteinases 2 and 9 reveals a mechanism for resolution of inflammation. J Immunol, 2006; 177:7312-7321.

GUO Z M, XIA SZ, LIN LB. The mechanical and biological properties of desmineralized cortical bone allografts in animals. J Bone Joint Surg, 1991; 73-B: 791-794.

HANEMAAIJER R, KOOLWIJK P, LE CLERCQ L, DE VREE WJ, VAN HINSBERGH VW. Regulation of matrix metalloproteinase expression in human vein and microvascular endothelial cells. Effects of tumour necrosis factor alpha, interleukin 1 and phorbol ester. Biochem J, 1993; 296:803-809. 
HELM G, ANDERSON DG, ANDERSSON GB ET AL. Bone morphogenetic proteins: basic science. Spine, 2002; 27:9-14.

HERFORD AS, STOFFELLA E, TANDON R. Reconstruction of mandibular defects using bone Morphogenic protein: can growth factors replace the need for autologous bone grafts? A systematic review of the literature. Plast Surg Int, 2011; vol. 2011, Article ID 165824, 7 pages.

HOYHTYA M, HUJANEN E, TURPEENNIEMI-HUJANEN T, THORGEIRSSON U, LIOTTA LA, TRYGGVASON K. "Modulation of type-IV collagenase activity and invasive behavior of metastatic human melanoma (A2058) cells in vitro by monoclonal antibodies to type-IV collagenase," Int J of Cancer, 1990; (46)2:282286.

HU J, CUI D, YANG X, WANG S, HU S, LI C, ZENG J.Bone morphogenetic protein2: a potential regulator in scleral remodeling. Mol Vis, 2008; 14:2373-2380.

IGNÁCIO H, MAZZER N, BARBIERI CH, CHIERICI G. Uso da poliuretana derivada do óleo de mamona para preencher defeitos ósseos diafisários segmentares do rádio. Estudo experimental em coelhos. Rev Bras Ortop, 1997; 32:815-821.

INODA H, YAMAMOTO G, HATTORI T. Histological investigation of osteoinductive properties of rhBMP-2 in a rat calvarial bone defect model. J Cranio Maxillofac Surg, 2004; 32:365-369. 
ISRAEL DI, NOVE J, KERNS KM, MOUTSATSOS IK, KAUFMAN RJ. Expression and characterization of bone morphogenetic protein-2 in Chinese hamster ovary cells. Growth Fact, 1992; 7:139-150.

ITAGAKI T, HONMA T, TAKAHASHI I, ECHIGO S, SASANO Y. Quantitative analysis and localization of mRNA transcripts of type I collagen, osteocalcin, MMP 2, MMP 8, and MMP 13 during bone healing in a rat calvarial experimental defect model. Anat Rec (Hoboken), 2008; 291(8):1038-1046.

JAIN RK. Molecular regulation of vessel maturation. Nat Med, 2003; 9:685-693.

JOHNSON AL. Bone grafting. In: OLMSTEAD ML. Small animal orthopedics. St. Louis: Mosby, 1995; 146-151.

JUNQUEIRA LC, CARNEIRO J. Histologia básica. 11a.ed. Rio de Janeiro: Guanabara; 2008.

KAMAKURA S, NAKAJO S, SUZUKI O, SASANO Y. New scaffold for recombinanthumanbonemorphogenetic protein-2. J Biomed Mater Res A, 2004; 71:299-307.

KAWACHI EY ET AL. Biocerâmicas: tendências e perspectivas de uma área interdisciplinar. Quim Nova, São Paulo, 2000; (23)1:518-522. 
KHOSLA S. Minireview: the OPG/RANKL/RANK system. Endocrinology, 2001; 142:5050-5055.

KIM KJ, ITOH T, KOTAKE S. Effects of recombinant human bone morphogenetic protein-2 on human bone marrow cells cultured with various biomaterials. J Biomed Mater Res, 1997; 35(3):279-285.

KLEIN-NULEND J, NIJWEIDE PJ, BURGER EH. Osteocyte and bone structure. Curr Osteoporos Rep, 2003; 1:5-10.

KNOTHE TATE ML, ADAMSON JR, TAMI AE, BAUER TW. The osteocyte. Int J Biochem Cell Biol, 2004; 36:1-8.

LA WG, KWON SH, LEE TJ, YANG HS, PARK J, KIM BS. The effect of the delivery carrier on the quality of bone formed via bone morphogenetic protein-2. Artif Organs, 2012; 36(7):642-647.

LAFLAMME C, ROUABHIA M. Effect of BMP-2 and BMP-7 homodimers and a mixture of BMP-2/BMP-7 homodimers on osteoblast adhesion and growth following culture on a collagen scaffold. Biomed Mater, 2008; vol.3(1):015008. doi: 10.1088/1748-6041/3/1/015008.

LANE JM, YASKO AW, TOMIN E, COLE BJ, WALLER S, BROWNE M, ET AL. Bone marrow and recombinant human bone morphogenetic protein-2 in osseous repair. Clin Orthop Relat Res, 1999; 361:216-227. 
LEE KS, KIM HJ, LI QL. ET AL. "Runx2 is a common target of transforming growth factor $\beta 1$ and bone morphogenetic protein 2, and cooperation between Runx2 and Smad5 induces osteoblast-specific gene expression in the pluripotent mesenchymal precursor cell line C2C12," Mol Cel Bio, 2000; (20)23:8783-8792.

LI A, DUBEY S, VARNEY ML, DAVE BJ, SINGH RK. IL-8 directly enhanced endothelial cell survival, proliferation, and matrix metalloproteinases production and regulated angiogenesis. J Immunol, 2003; 170:3369-3376.

LI G, CUI Y, MCILMURRAY L, ALLEN WE, WANG H. rhBMP-2, rhVEGF(165), rhPTN and thrombin-related peptide, TP508 induce chemotaxis of human osteoblasts and microvascular endothelial cells. J Orthop Res, 2005; 23:680-685.

LIAN JB, STEIN GS, JAVED A, VAN WIJNEN AJ, STEIN JL, MONTECINO M, ET AL. Networks and hubs for the transcriptional control of osteoblastogenesis. Rev Endocr Metab Disord, 2006; 7:1-16.

LIEBERMAN JR, DALUISKI A., EINHORN TA. The role of growth factors in the repair of bone.Biology and clinical applications. J Bon Joint Surg, American Volume 2002; 84-A:1032-1044.

LIEU S, HANSEN E, DEDINI R, BEHONICK D, WERB Z, MICLAU T, MARCUCIO R, COLNOT C.Impaired remodeling phase of fracture repair in the absence of matrix metalloproteinase-2. Dis Model Mech, 2011; 4(2):203-211. 
LOGAR DB, KOMADINA R, PREZELJ J, OSTANEK B, TROST Z, MARC J. "Expression of bone resorption genes in osteoarthritis and in osteoporosis," $\mathbf{J}$ Bon Min Meta, 2007; (25)4:219-225.

LORENZO J, HOROWITZ M, CHOI Y. Osteoimmunology: interactions of the bone and immune system. Endocr Rev, 2008; 29(4):403-440.

LU M, RABIE AB.Matrix metalloproteinase-9 regulates graft bone resorption. Angle Orthod, 2006; 76(4):598-604.

MANICONE AM, MCGUIRE JK. Matrix metalloproteinases as modulators of inflammation. Semin Cell Dev Biol, 2008; 19(1):34-41.

MARQUETI RC.ET AL. MMP-2, jumping exercise and nandrolone in skeletal muscle. Int J Sports Med, 2008; 29:559-563.

MARTIN RM, CORREA PHS. Bone quality and osteoporosis therapy. Arq Bras Endocrino Metab, 2010; (54)2:186-199.

MARTINEZ SA, WALKER T. Bone grafts. Vet Clin North Am Small Anim Pract, Philadelphia, 1999; (29)5:207-219. 
MARUKAWA E, ASAHINA I, ODA M. ET AL. Bone regeneration using recombinant human bone morphogenetic protein-2 (rhBMP-2) in alveolar defects of primate mandibles. Br J Oral Maxill Surg, 2001; 39:452-459.

MARX RE.Clinical applications of bone biology to mandibular and maxillary reconstruction. Clin Plast Surg, 1994; 21:377-392.

MAZZIERI R, MASIERO L, ZANETTA L. ET AL., "Control of type IV collagenase activity by the urokinase-plasmin system: a regulatory mechanism with cell-bound reactants," The EMBO J, 1997; (16)9:2319-2332.

MONCHAU F, LEFEVRE A, DESCAMPS M, BELQUIN-MYRDYCZ A, LAFFARGUE P, HILDEBRAND HF. In vitro studies of human and rat osteoclast activity on hydroxyapatite, beta-tricalcium phosphate, calcium carbonate. Biomol Eng, 2002; 19(2-6):143-152.

MURPHY G \& DOCHERTY AJP. The matrix metalloproteinases and their inhibitors American. J Resp Cell Mol Biol, 1992; 7:120-125.

MURSHED M, HARMEY D, MILLAN JL, MCKEE MD, KARSENTY G. Unique coexpression in osteoblasts of broadly expressed genes accounts for the spatial restriction of ECM mineralization to bone. Genes Dev, 2005; 19:1093-1094. 
NAKASHIMA K, ZHOU X, KUNKEL G, ZHANG Z, DENG JM, BEHRINGER RR, DE CROMBRUGGHE B. The novel zinc finger-containing transcription factor osterix is required for osteoblast differentiation and bone formation. Cell, 2002; 108:17-29.

NGUYEN M, ARKELL J, JACKSON CJ. Human endothelial gelatinases and angiogenesis.Int J Biochem Cell Biol, 2001; 33:960-970.

ODA N, ABE M, SATO Y. ETS-1 converts endothelial cells to the angiogenic phenotype by inducing the expression of matrix metalloproteinases and integrin beta3. J Cell Physiol, 1999; 178:121-132.

OLIVEIRA RC, SICCA CM, SILVA TL, CESTARI TM, OLIVEIRA DT, BUZALAF MAR, ET AL. Efeito da temperatura de desproteinização no preparo de osso cortical bovino microgranular. Avaliação microscópica e bioquímica da resposta celular em subcutâneo de ratos. Revista FOB, 1999; 7(1):85-93.

ONG JL, CARDENAS HL, CAVIN R, CARNES DL JR. Osteoblast responses to BMP2 treated titanium in vitro. Int $\mathbf{J}$ Oral Maxillofac Implants, 1997; 12(5):649-654.

PIERMATTEI DL, FLO GL. Bone grafting. Small animal orthopedics and fracture repair. 3.ed. Philadelphia : Saunders, 1997; 3:147-153.

PUYRAIMOND A, WEITZMAN JB, BABIOLE E, MENASHI S. Examining the relationship between the gelatinolytic balance and the invasive capacity of endothelial cells. J Cell Sci, 1999; 112:1283-1290. 
QIN L, QIU P, WANG L, LI X, SWARTHOUT JT, SOTEROPOULOS P, ET AL. Gene expression profiles and transcription factors involved in parathyroid hormone signaling in osteoblasts revealed by microarray and bioinformatics. J Biol Chem, $2003 ; 278: 723-731$.

RAISZ LG, KREAM BE, LORENZO JA, LARSEN PR, KRONENBERG HM, MELMED S, POLONSKY KS. 2002 Metabolic bone disease. In: DAVIES TF, LARSEN PR, KRONENBERG HM, eds. Williams textb of endo,. Philadelphia: W.B. Saunders; 1373.

RAMOS-DE SIMONE N, HAHN-DANTONA E, SIPLEY J, NAGASE H, FRENCH DL, QUIGLEY JP. "Activation of matrix metalloproteinase-9 (MMP-9) via a converging plasmin/stromelysin-1 cascade enhances tumor cell invasion," The J Bio Chem, 1999; (274)19:13066-13076.

REPONEN PC, SAHLBERG C, MUNAUT I, THESLEFF K, TRYGGVASON.High expression of $92-k D$ type IV collagenase (gelatinase B) in the osteoclast lineage during mouse development. J Cell Biol, 1994; 124:1091-1102.

RIGGS BL, O'FALLON WM, LANE A, HODGSON SF, WAHNER HW, MUHS J, ET AL. Clinical trial of fluoride therapy in postmenopausal osteoporotic women: extended observations and additional analysis. J Bone Miner Res, 1994; 9(2):265-275. 
RILEY EH, LANE JM, URIST MR, LYONS KM, LIEBERMAN JR. Bone morphogenetic protein-2: biology and applications. Clin Orthop, 1996; 334:39-46.

ROBERTSON WG. Plasma Phosphatase Homeostasis. In: calcium, phosphate and magnesium metabolism. B.E.C. Nordin, ed, Churchill- Livingstone, edit, Edimburg, 1976; 3:113-161.

ROHANIZADEH R, CHUNG K.Hydroxyapatite as a carrier for bone morphogenetic protein. J Oral Implantol, 2011; 37(6):659-672.

ROSS C, CLEMMESEN KM, SVENSON M, SORENSEN PS, KOCH-HENRIKSEN N, SKOVGAARD GL, ET AL: Immunogenicity of interferon beta in multiple sclerosis patients: influence of preparation, dosage, dose frequency, and route of administration. Danish Multiple Sclerosis Study Group. Ann Neurol, 2000; 48:706712.

ROSSI JUNIOR, W.C., BARBOSA L.C.O., ESTEVES A. Evaluation of osteogenic capacity of the periosteum in combination with collagen membrane. Acta Ortop Bras, 2010; (18)6:327-330.

SALO T, LIOTTA LA, TRYGGVASON K. "Purification and characterization of a murine basement membrane collagendegrading enzyme secreted by metastatic tumor cells," The J Bio Chem, 1983; (258)5:3058-3063. 
SANTOS FC, RAHAL SC. Enxerto ósseo esponjoso autólogo em pequenos animais. Cienc Rural, 2004; (34)6:1969-1975.

SASSIOTO MCP. ET AL. Efeito da Casearia sylvestris no reparo ósseo com matriz óssea bovina desvitalizada em ratos. Acta Cir Bras, 2004; (19)6:637-641.

SCHELLEKENS $\mathrm{H}$ : Immunogenicity of therapeutic proteins. Nephrol Dial Transplant, 2003; 18:1257-1259.

SCHELLEKENS H: Immunogenicity of therapeutic proteins: clinical implications and future prospects. Clin Ther, 2002; 24:1720-1740.

SHEN B, BHARGAV D, WEI A, WILLIAMS LA, TAO H, MA DD, DIWAN AD. BMP-13 emerges as a potential inhibitor of bone formation. Int J Biol Sci, 2009; 5:192-200.

SIEBER C, KOPF J, HIEPEN C, KNAUS P. Recent advances in BMP receptor signaling. Cyto Gr Fact Rev, 2009; 20:343-355.

SILVEIRA RJ. Reparo Ósseo Utilizando Enxerto de Matriz Orgânica Bovina. Análise Histológica em Calvária de Coelhos. Dissertação para obtenção do título de mestre apresentada na Universidade Federal de Uberlândia - MG, Programa de PósGraduação em Odontologia, 2007. 
STEIN RS, SILVA, Braga J, SILVA VD. Estudo comparativo da neoformação óssea utilizando-se o enxerto autógeno e três substitutos: defeitos ósseos em ratos. Rev Bras Ortop, 2009; (44)4:330-335.

STERNLICHT MD, WERB Z. "How matrix metalloproteinases regulate cell behavior," Ann Rev Cell and Dev Bio, 2001; 17:463-516.

STRONGIN AY, COLLIER I, BANNIKOV G, MARMER BL, GRANT GA \& GOLDBERG GI. Mechanism of cell surface activation of $72 \mathrm{kDa}$ type IV collagenase. J Bio Chem, 1995; 270: 5331-5338.

SUDA T, TAKAHASHI N, UDAGAWA N, JIMI E, GILLESPIE MT, MARTIN TJ.Modulation of osteoclast differentiation and function by the new members of the tumor necrosis factor receptor and ligand families. Endocr Rev, 1999; 20:345-357.

TARABOLETTI G, ET AL. Shedding of the matrix metalloproteinases MMP-2, MMP9, and MT1-MMP as membrane vesicle-associated components by endothelial cells. Am J Pathol, 2002; 160:673-680.

THIES RS, BAUDUY M, ASHTON BA, KURTZBERG L, WOZNEY JM, ROSEN V. Recombinant human bone morphogenetic protein-2 induces osteoblastic differentiation in W-20-17 stromal cells. Endocrinology, 1992; 130:1318-1324.

TOMBRAN-TINK J, BARNSTABLE CJ. Osteoblasts and osteoclasts express PEDF, VEGF-A isoforms, and VEGF receptors: possible mediators of angiogenesis and 
matrix remodeling in the bone. Biochem Biophys Res Commun, 2004; 316:573579.

TOWLER DA. Angiogenesis and marrow stromal cell fates: roles in bone strength. Osteoporos Int, 2003; 14(5):546-553.

TREMAIN N, KORKKO J, IBBERSON D, KOPEN GC, DIGIROLAMO C, PHINNEY DG, "MicroSAGE analysis of 2,353 expressed genes in a single cell-derived colony of undifferentiated human mesenchymal stem cells reveals mRNAS of multiple cell lineages," Stem Cells, 2001;(19)5:408-418.

TSIGKOU O, POMERANTSEVA I, SPENCER JA, REDONDO PA, HART AR, O'DOHERTY E, LIN Y, FRIEDRICH CC, DAHERON L, LIN CP, SUNDBACK CA, VACANTI JP, NEVILLE C. Engineered vascularized bone grafts. Proc Natl Acad Sci, 2010; (107)8:3311-3316.

TSIRIDIS E, UPADHYAY N, GIANNOUDIS P. Molecular aspects of fracture healing: which are the important molecules? Injury, 2007; 38:11-25.

TSUMAKI N, YOSHIKAWA H.The role of bone morphogenetic proteins in endochondral bone formation.Cytok. Growth Factor Rev, 2005; 16:279-285.

TSURUKAI T, TAKAHASHI N, JIMI E, NAKAMURA I, UDAGAWA N, NOGIMORI K, TAMURA M, SUDA T. Isolation and characterization of osteoclast precursors that 
differentiate into osteoclasts on calvarial cells within a short period of time. $\mathbf{J}$ Cell Physiol, 1998; 177:26-35.

URIST MR. The search for and the discovery of bone morphogenetic protein (BMP). In: Urist MR, O'Conner BT, Burwell RG, editors. Bone grafts, derivates and substitutes. London: Butterworth Heinemann, 1994; 315-362.

VAN DER KRAAN PM, BLANEY DAVIDSON EN, VAN DEN BERG WB.Bone morphogenetic proteins and articular cartilage: To serve and protect or a wolf in sheep clothing's? Osteoarth Cartil, 2010, 18(6): 735-741.

VAN WART HE \& BIRKEDAL-HANSEN H. The cysteine switch: A principle of regulation of metalloproteinase activity with potential applicability to the entire matrix metalloproteinase gene family. Proc Nat Aca Sci USA, 1990; 87:5578-5582.

VAN HINSBERGH VW, ENGELSE MA, QUAX PH. Pericellular proteolysis in angiogenesis and vasculogenesis. Arterioscler Thromb Vasc Biol. 2006; 26:716728.

VARTIO T, HOVI T, VAHERI A. "Human macrophages synthesize and secrete a major 95,000-dalton gelatin-binding protein distinct from fibronectin," The $\mathbf{J}$ Bio Chem, 1982; (257)15:8862-8866.

WANG H, KEISER JA. Hepatocyte growth factor enhances MMP activity in human endothelial cells. Biochem Biophys Res Commun, 2000; 272:900-905. 
WANG X, YU YY, LIEU S, YANG F, LANG J, LU C, WERB Z, HU D, MICLAU T, MARCUCIO R, Colnot C.MMP9 regulates the cellular response to inflammation after skeletal injury. Bone, 2012; 52(1):111-119.

WANG EA, ROSEN V, D'ALESSANDRO JS, BAUDUY M, CORDES P, HARADA T, ET AL. Recombinant human bone morphogenetic protein induce bone formation. Proc Natl Acad Sci USA, 1990;87(6):2220-2224.

WEIGEL J, BOJRAB M. Enxerto ósseo. BOJRAB, MJ Mecanismos da moléstia na cirurgia dos pequenos animais. São Paulo: Manole 1996; 791-798.

YAMAGUCHI A, KATAGIRI T, IKEDA T, WOZNEY JM, ROSEN V, WANG EA, ET AL. Recombinant human bone morphogenetic protein-2 stimulates osteoblastic maturation and inhibits myogenic differentation in vitro. J Cell Biol, 1991; 113(3):681-687.

YAN XZ, GE SH, SUN QF, GUO HM, YANG PS.A pilot study evaluating the effect of recombinant human bone morphogenetic protein-2 and recombinant human betanerve growth factor on the healing of Class III furcation defects in dogs. $\mathbf{J}$ Periodontol, 2010; 81(9):1289-1298.

YAO JS, ZHAI W, YOUNG WL, YANG GY. Interleukin-6 triggers human cerebral endothelial cells proliferation and migration: the role for KDR and MMP-9. Biochem Biophys Res Commun, 2006; 342:1396-1404. 
YILDIRIM M. ET AL. Maxillary sinus augmentation using xenogenic bone substitute material Bio Oss $®$ in combination with venous blood. Clin Oral Impl Res, 2000; (11)3:217-229.

YOSHIKAWA T, OHGUSHI H, NAKAJIMA H, YAMADA E, ICHIJIMA K, TAMAI S, OHTA T. In vivo osteogenic durability of cultured bone in porous ceramics: a novel method for autogenous bone graft substitution. Transplantation, 2000; 69(1):128134.

ZABEU JLA, MERCADANTE MT. Substitutos ósseos comparados ao enxerto ósseo autólogo em cirurgia ortopédica-Revisão sistemática da literatura. Rev Bras Ortop, 2008; (43)3:59-68. 
ANEXO

\begin{tabular}{|c|c|c|c|c|c|c|c|c|c|}
\hline & Grupo 1 & Grupo 2 & Grupo 3 & Grupo 4 & Grupo 5 & Grupo 6 & Grupo 7 & Grupo 8 & \\
\hline Number of values & 7 & 7 & 7 & 7 & 7 & 7 & 7 & 7 & 7 \\
\hline Minimum & 0,8061 & 0,7186 & 1,024 & 0,9682 & 0,9288 & 0,8239 & 0,5869 & 0,9005 & \\
\hline 25\% Percentile & 0,9676 & 1,006 & 1,035 & 0,9682 & 0,9635 & 0,9414 & 0,9315 & 1,052 & \\
\hline Median & 1,134 & 1,147 & 1,093 & 1,130 & 1,095 & 1,238 & 1,326 & 1,115 & \\
\hline $75 \%$ Percentile & 1,291 & 1,416 & 1,460 & 1,349 & 1,534 & 1,500 & 1,671 & 1,139 & \\
\hline Maximum & 1,417 & 1,469 & 1,688 & 1,398 & 1,658 & 1,537 & 1,763 & 1,254 & \\
\hline Mean & 1,127 & 1,156 & 1,232 & 1,166 & 1,203 & 1,212 & 1,243 & 1,095 & \\
\hline Std. Deviation & 0,2025 & 0,2583 & 0,2578 & 0,1707 & 0,2875 & 0,2873 & 0,4131 & 0,1072 & \\
\hline Std. Error & 0,07655 & 0,09763 & 0,09745 & 0,06451 & 0,1087 & 0,1086 & 0,1561 & 0,04052 & \\
\hline Lower $95 \% \mathrm{Cl}$ of mean & 0,9392 & 0,9166 & 0,9936 & 1,008 & 0,9370 & 0,9466 & 0,8614 & 0,9960 & \\
\hline Upper $95 \% \mathrm{Cl}$ of mean & 1,314 & 1,394 & 1,470 & 1,324 & 1,469 & 1,478 & 1,626 & 1,194 & \\
\hline \multicolumn{10}{|l|}{ KS normality test } \\
\hline KS distance & 0,1188 & 0,1384 & 0,2769 & 0,1622 & 0,2180 & 0,1993 & 0,1502 & 0,2002 & \\
\hline$P$ value & $P>0.10$ & $P>0.10$ & $P>0.10$ & $P>0.10$ & $P>0.10$ & $P>0.10$ & $P>0.10$ & $P>0.10$ & \\
\hline Passed normality test (alpha $=0.05) ?$ & Yes & Yes & Yes & Yes & Yes & Yes & Yes & Yes & \\
\hline$P$ value summary & ns & ns & ns & ns & ns & ns & ns & ns & \\
\hline \multicolumn{10}{|l|}{ Shapiro-Wilk normality test } \\
\hline W & 0,9948 & 0,9621 & 0,8317 & 0,9190 & 0,8691 & 0,9081 & 0,9647 & 0,9394 & \\
\hline$P$ value & 0,9990 & 0,8365 & 0,0831 & 0,4617 & 0,1823 & 0,3828 & 0,8582 & 0,6335 & \\
\hline Passed normality test (alpha $=0.05) ?$ & Yes & Yes & Yes & Yes & Yes & Yes & Yes & Yes & \\
\hline$P$ value summary & ns & ns & ns & ns & ns & ns & ns & ns & \\
\hline Sum & 7,886 & 8,089 & 8,624 & 8,160 & 8,420 & 8,486 & 8,704 & 7,666 & \\
\hline
\end{tabular}

MMP-2 (4 semanas), teste de normalidade 


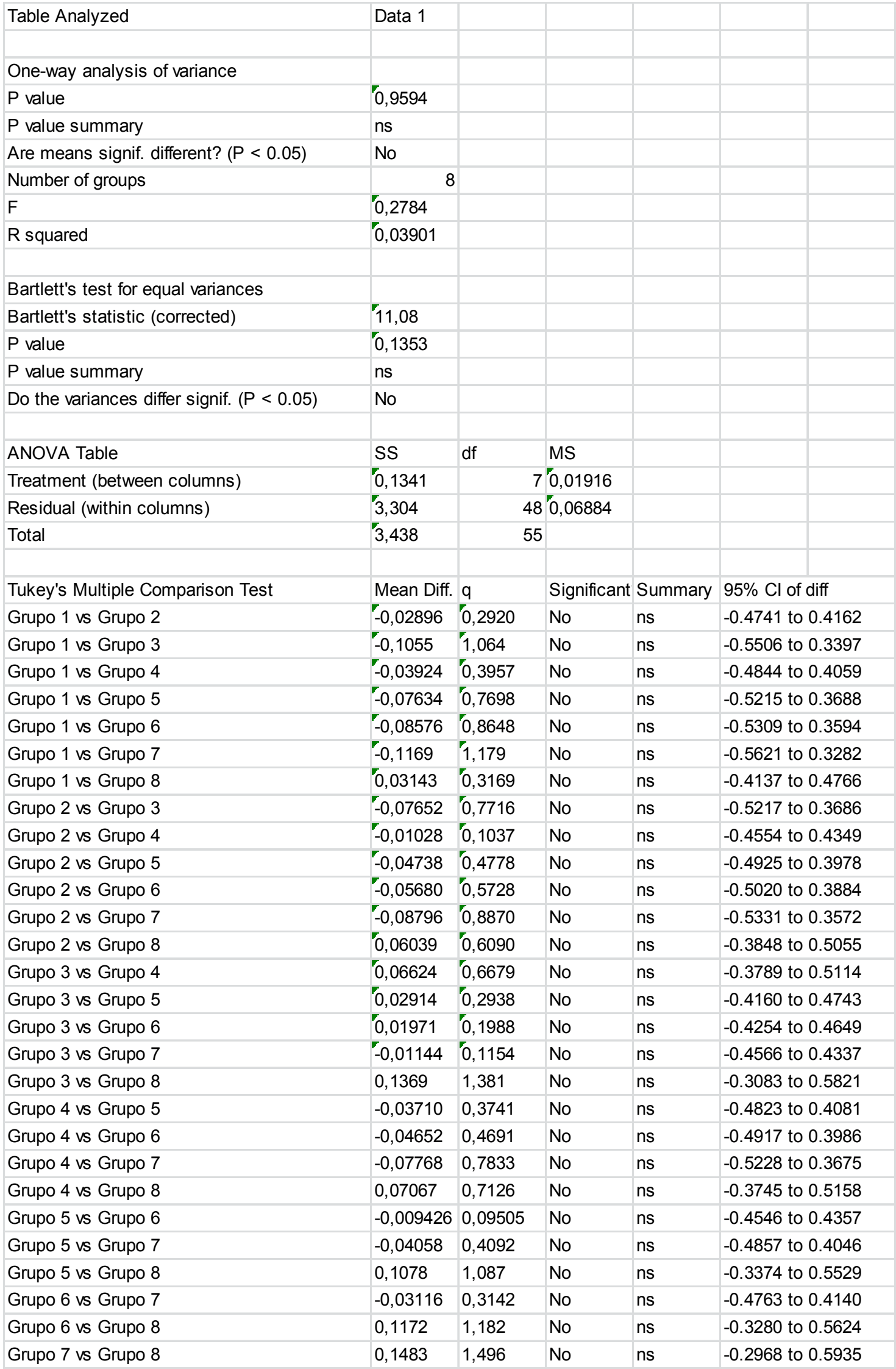

MMP-2 (4 semanas), análise dos grupos 


\begin{tabular}{|c|c|c|c|c|c|c|c|c|c|}
\hline & Grupo 1 & Grupo 2 & Grupo 3 & Grupo 4 & Grupo 5 & Grupo 6 & Grupo 7 & Grupo 8 & \\
\hline Number of values & 7 & 7 & 7 & 7 & 7 & 7 & 7 & 7 & 7 \\
\hline Minimum & 0,7119 & 0,9751 & 0,9177 & 0,9585 & 0,7656 & 0,9270 & 0,9379 & 0,9398 & \\
\hline 25\% Percentile & 0,8962 & 1,045 & 1,007 & 1,072 & 1,063 & 0,9353 & 0,9971 & 1,055 & \\
\hline Median & 0,9955 & 1,186 & 1,294 & 1,157 & 1,311 & 1,205 & 1,352 & 1,062 & \\
\hline 75\% Percentile & 1,215 & 1,400 & 1,683 & 1,208 & 1,553 & 1,350 & 1,754 & 1,084 & \\
\hline Maximum & 1,277 & 1,409 & 1,869 & 1,275 & 1,588 & 1,583 & 1,823 & 1,125 & \\
\hline Mean & 1,006 & 1,207 & 1,359 & 1,140 & 1,278 & 1,211 & 1,353 & 1,056 & \\
\hline Std. Deviation & 0,1931 & 0,1715 & 0,3677 & 0,1016 & 0,3019 & 0,2311 & 0,3705 & 0,05679 & \\
\hline Std. Error & 0,07298 & 0,06482 & 0,1390 & 0,03841 & 0,1141 & 0,08736 & 0,1401 & 0,02147 & \\
\hline Lower $95 \% \mathrm{Cl}$ of mean & 0,8275 & 1,049 & 1,019 & 1,046 & 0,9987 & 0,9976 & 1,011 & 1,004 & \\
\hline Upper $95 \% \mathrm{Cl}$ of mean & 1,185 & 1,366 & 1,699 & 1,234 & 1,557 & 1,425 & 1,696 & 1,109 & \\
\hline \multicolumn{10}{|l|}{ KS normality test } \\
\hline KS distance & 0,1652 & 0,1596 & 0,1902 & 0,1896 & 0,2030 & 0,1789 & 0,2283 & 0,3454 & \\
\hline$P$ value & $P>0.10$ & $P>0.10$ & $P>0.10$ & $P>0.10$ & $P>0.10$ & $P>0.10$ & $P>0.10$ & 0,0115 & \\
\hline Passed normality test (alpha $=0.05) ?$ & Yes & Yes & Yes & Yes & Yes & Yes & Yes & No & \\
\hline$P$ value summary & ns & ns & ns & ns & ns & ns & ns & * & \\
\hline \multicolumn{10}{|l|}{ Shapiro-Wilk normality test } \\
\hline W & 0,9630 & 0,9271 & 0,9274 & 0,9632 & 0,9203 & 0,9368 & 0,8877 & 0,8267 & \\
\hline$P$ value & 0,8436 & 0,5264 & 0,5291 & 0,8457 & 0,4714 & 0,6097 & 0,2629 & 0,0745 & \\
\hline Passed normality test (alpha $=0.05) ?$ & Yes & Yes & Yes & Yes & Yes & Yes & Yes & Yes & \\
\hline$P$ value summary & ns & ns & ns & ns & ns & ns & ns & ns & \\
\hline Sum & 7,042 & 8,452 & 9,514 & 7,978 & 8,946 & 8,480 & 9,474 & 7,394 & \\
\hline
\end{tabular}

proMMP-2 (4 semanas), teste de normalidade 


\begin{tabular}{|c|c|c|c|c|c|}
\hline Table Analyzed & Data 1 & & & & \\
\hline \multicolumn{6}{|l|}{ One-way analysis of variance } \\
\hline$P$ value & 0,0933 & & & & \\
\hline$P$ value summary & ns & & & & \\
\hline Are means signif. different? $(P<0.05)$ & No & & & & \\
\hline Number of groups & 8 & & & & \\
\hline $\mathrm{F}$ & 1,882 & & & & \\
\hline R squared & 0,2154 & & & & \\
\hline \multicolumn{6}{|l|}{ Bartlett's test for equal variances } \\
\hline Bartlett's statistic (corrected) & 23,79 & & & & \\
\hline$P$ value & 0,0012 & & & & \\
\hline$P$ value summary & ** & & & & \\
\hline Do the variances differ signif. $(P<0.05)$ & Yes & & & & \\
\hline ANOVA Table & SS & df & MS & & \\
\hline Treatment (between columns) & 0,8192 & 7 & 0,1170 & & \\
\hline Residual (within columns) & 2,984 & 48 & 0,06217 & & \\
\hline Total & 3,804 & 55 & & & \\
\hline Tukey's Multiple Comparison Test & Mean Diff. & q & Significant & Summary & $95 \% \mathrm{Cl}$ of diff \\
\hline Grupo 1 vs Grupo 2 & $-0,2014$ & 2,137 & No & ns & -0.6245 to 0.2216 \\
\hline Grupo 1 vs Grupo 3 & $-0,3531$ & 3,747 & No & ns & -0.7762 to 0.06994 \\
\hline Grupo 1 vs Grupo 4 & $-0,1337$ & 1,419 & No & ns & -0.5568 to 0.2894 \\
\hline Grupo 1 vs Grupo 5 & $-0,2719$ & 2,885 & No & ns & -0.6950 to 0.1511 \\
\hline Grupo 1 vs Grupo 6 & $-0,2053$ & 2,179 & No & ns & -0.6284 to 0.2177 \\
\hline Grupo 1 vs Grupo 7 & $-0,3474$ & 3,686 & No & ns & -0.7704 to 0.07569 \\
\hline Grupo 1 vs Grupo 8 & $-0,05022$ & 0,5329 & No & ns & -0.4733 to 0.3728 \\
\hline Grupo 2 vs Grupo 3 & $-0,1517$ & 1,610 & No & ns & -0.5748 to 0.2714 \\
\hline Grupo 2 vs Grupo 4 & 0,06772 & 0,7186 & No & ns & -0.3553 to 0.4908 \\
\hline Grupo 2 vs Grupo 5 & $-0,07051$ & 0,7482 & No & ns & -0.4936 to 0.3525 \\
\hline Grupo 2 vs Grupo 6 & $-0,003930$ & 0,04170 & No & ns & -0.4270 to 0.4191 \\
\hline Grupo 2 vs Grupo 7 & $-0,1460$ & 1,549 & No & ns & -0.5690 to 0.2771 \\
\hline Grupo 2 vs Grupo 8 & 0,1512 & 1,604 & No & ns & -0.2719 to 0.5742 \\
\hline Grupo 3 vs Grupo 4 & 0,2194 & 2,328 & No & ns & -0.2036 to 0.6425 \\
\hline Grupo 3 vs Grupo 5 & 0,08119 & 0,8615 & No & ns & -0.3419 to 0.5043 \\
\hline Grupo 3 vs Grupo 6 & 0,1478 & 1,568 & No & ns & -0.2753 to 0.5708 \\
\hline Grupo 3 vs Grupo 7 & 0,005747 & 0,06098 & No & ns & -0.4173 to 0.4288 \\
\hline Grupo 3 vs Grupo 8 & 0,3029 & 3,214 & No & ns & -0.1202 to 0.7260 \\
\hline Grupo 4 vs Grupo 5 & $-0,1382$ & 1,467 & No & ns & -0.5613 to 0.2848 \\
\hline Grupo 4 vs Grupo 6 & $-0,07165$ & 0,7603 & No & ns & -0.4947 to 0.3514 \\
\hline Grupo 4 vs Grupo 7 & $-0,2137$ & 2,267 & No & ns & -0.6367 to 0.2094 \\
\hline Grupo 4 vs Grupo 8 & 0,08347 & 0,8857 & No & ns & -0.3396 to 0.5065 \\
\hline Grupo 5 vs Grupo 6 & 0,06658 & 0,7065 & No & ns & -0.3565 to 0.4896 \\
\hline Grupo 5 vs Grupo 7 & $-0,07545$ & 0,8005 & No & ns & -0.4985 to 0.3476 \\
\hline Grupo 5 vs Grupo 8 & 0,2217 & 2,352 & No & ns & -0.2014 to 0.6448 \\
\hline Grupo 6 vs Grupo 7 & $-0,1420$ & 1,507 & No & ns & -0.5651 to 0.2810 \\
\hline Grupo 6 vs Grupo 8 & 0,1551 & 1,646 & No & ns & -0.2679 to 0.5782 \\
\hline Grupo 7 vs Grupo 8 & 0,2971 & 3,153 & No & ns & -0.1259 to 0.7202 \\
\hline
\end{tabular}

proMMP-2 (4 semanas), análise dos grupos 


\begin{tabular}{|c|c|c|c|c|c|c|c|c|c|}
\hline & Grupo 1 & Grupo 2 & Grupo 3 & Grupo 4 & Grupo 5 & Grupo 6 & Grupo 7 & Grupo 8 & \\
\hline Number of values & 7 & 7 & 7 & 7 & 7 & 7 & 7 & & 7 \\
\hline Minimum & 0,8161 & 0,6632 & 1,117 & 0,8551 & 0,9275 & 1,033 & 1,061 & 0,7968 & \\
\hline 25\% Percentile & 0,8180 & 0,7127 & 1,154 & 1,001 & 0,9868 & 1,106 & 1,168 & 0,9216 & \\
\hline Median & 1,092 & 0,9493 & 1,536 & 1,131 & 1,042 & 1,370 & 1,537 & 1,127 & \\
\hline 75\% Percentile & 1,183 & 1,236 & 1,621 & 1,152 & 1,459 & 1,629 & 1,595 & 1,298 & \\
\hline Maximum & 1,333 & 1,286 & 1,652 & 1,178 & 1,544 & 1,655 & 1,661 & 1,402 & \\
\hline Mean & 1,044 & 0,9593 & 1,424 & 1,076 & 1,153 & 1,341 & 1,391 & 1,100 & \\
\hline Std. Deviation & 0,1968 & 0,2394 & 0,2263 & 0,1137 & 0,2452 & 0,2452 & 0,2462 & 0,2138 & \\
\hline Std. Error & 0,07436 & 0,09048 & 0,08553 & 0,04296 & 0,09266 & 0,09267 & 0,09307 & 0,08079 & \\
\hline Lower $95 \% \mathrm{Cl}$ of mean & 0,8618 & 0,7379 & 1,214 & 0,9712 & 0,9260 & 1,114 & 1,164 & 0,9023 & \\
\hline Upper $95 \% \mathrm{Cl}$ of mean & 1,226 & 1,181 & 1,633 & 1,181 & 1,379 & 1,567 & 1,619 & 1,298 & \\
\hline \multicolumn{9}{|l|}{ KS normality test } & \\
\hline KS distance & 0,1691 & 0,1619 & 0,2611 & 0,2554 & 0,2979 & 0,1658 & 0,2941 & 0,1373 & \\
\hline$P$ value & $P>0.10$ & $P>0.10$ & $P>0.10$ & $P>0.10$ & 0,0603 & $P>0.10$ & 0,0679 & $P>0.10$ & \\
\hline Passed normality test (alpha $=0.05) ?$ & Yes & Yes & Yes & Yes & Yes & Yes & Yes & Yes & \\
\hline$P$ value summary & ns & ns & ns & ns & ns & ns & ns & ns & \\
\hline \multicolumn{9}{|l|}{ Shapiro-Wilk normality test } & \\
\hline W & 0,9246 & 0,9357 & 0,8562 & 0,8418 & 0,8090 & 0,9238 & 0,8467 & 0,9793 & \\
\hline$P$ value & 0,5056 & 0,6007 & 0,1400 & 0,1033 & 0,0503 & 0,4996 & 0,1146 & 0,9559 & \\
\hline Passed normality test (alpha $=0.05) ?$ & Yes & Yes & Yes & Yes & Yes & Yes & Yes & Yes & \\
\hline$P$ value summary & ns & ns & ns & ns & ns & ns & ns & ns & \\
\hline Sum & 7,306 & 6,715 & 9,965 & 7,534 & 8,069 & 9,384 & 9,740 & 7,700 & \\
\hline
\end{tabular}

MMP-2 (6 semanas), teste de normalidade 


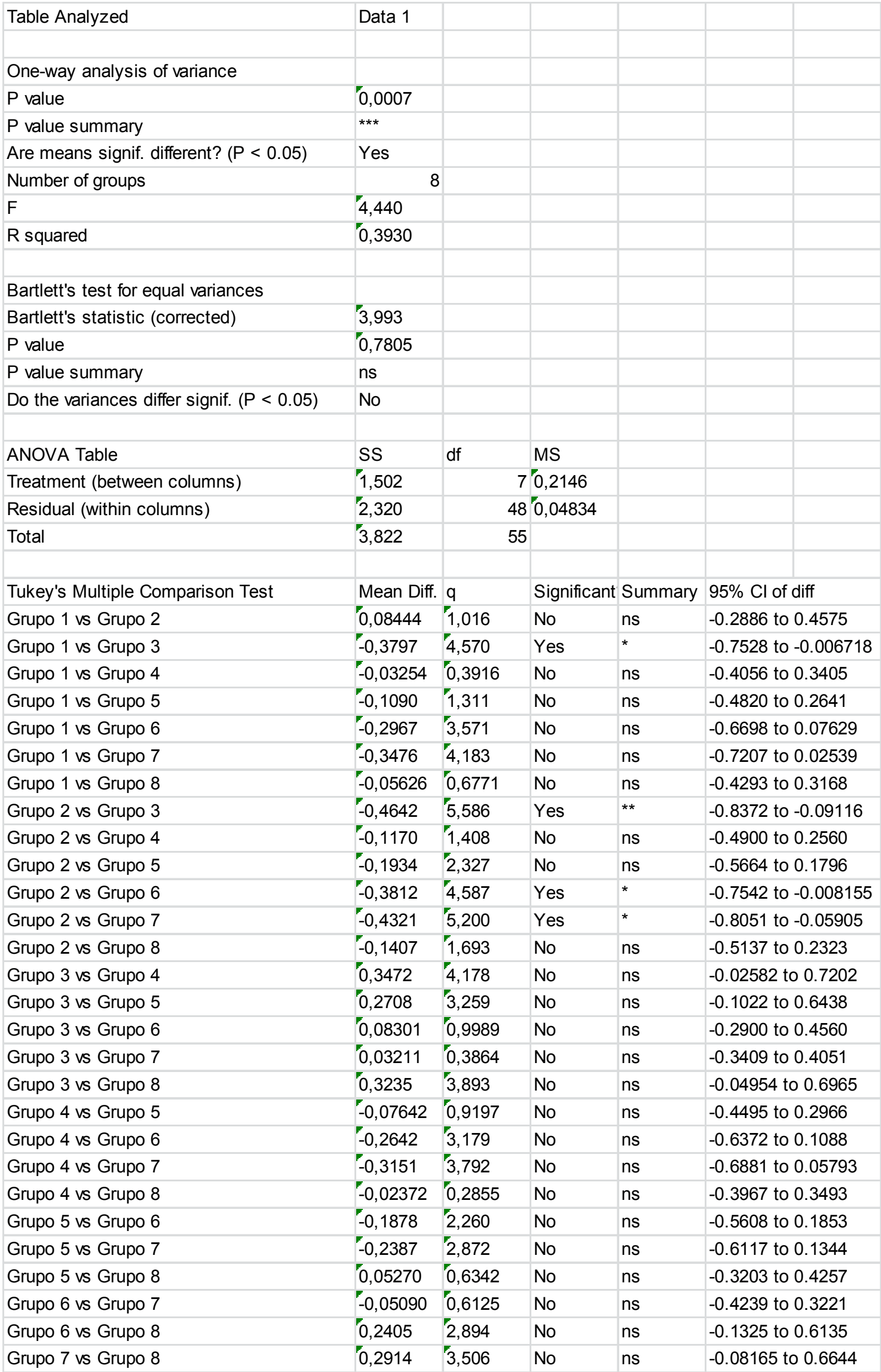

MMP-2 (6 semanas), análise dos grupos 


\begin{tabular}{|c|c|c|c|c|c|c|c|c|c|}
\hline & Grupo 1 & Grupo 2 & Grupo 3 & Grupo 4 & Grupo 5 & Grupo 6 & Grupo 7 & Grupo 8 & \\
\hline Number of values & 7 & 7 & 7 & 7 & 7 & 7 & 7 & 7 & 7 \\
\hline Minimum & 0,8433 & 0,6624 & 1,096 & 0,7613 & 0,8009 & 0,9154 & 1,025 & 0,8274 & \\
\hline 25\% Percentile & 0,8660 & 0,7301 & 1,099 & 0,8640 & 0,8037 & 0,9472 & 1,178 & 0,9942 & \\
\hline Median & 1,008 & 0,8353 & 1,614 & 0,8733 & 0,9616 & 1,398 & 1,466 & 1,091 & \\
\hline 75\% Percentile & 1,330 & 1,175 & 1,948 & 1,139 & 1,086 & 1,629 & 1,780 & 1,427 & \\
\hline Maximum & 1,340 & 1,448 & 1,955 & 1,217 & 1,231 & 1,707 & 1,882 & 1,580 & \\
\hline Mean & 1,053 & 0,9632 & 1,553 & 0,9697 & 0,9724 & 1,359 & 1,452 & 1,163 & \\
\hline Std. Deviation & 0,2132 & 0,2822 & 0,3852 & 0,1700 & 0,1518 & 0,3144 & 0,3296 & 0,2571 & \\
\hline Std. Error & 0,08058 & 0,1066 & 0,1456 & 0,06424 & 0,05738 & 0,1188 & 0,1246 & 0,09718 & \\
\hline Lower $95 \% \mathrm{Cl}$ of mean & 0,8555 & 0,7022 & 1,197 & 0,8125 & 0,8320 & 1,068 & 1,148 & 0,9254 & \\
\hline Upper $95 \% \mathrm{Cl}$ of mean & 1,250 & 1,224 & 1,910 & 1,127 & 1,113 & 1,650 & 1,757 & 1,401 & \\
\hline \multicolumn{9}{|l|}{ KS normality test } & \\
\hline KS distance & 0,2193 & 0,2462 & 0,2137 & 0,2861 & 0,2240 & 0,2442 & 0,2101 & 0,2517 & \\
\hline$P$ value & $P>0.10$ & $P>0.10$ & $P>0.10$ & 0,0866 & $P>0.10$ & $P>0.10$ & $P>0.10$ & $P>0.10$ & \\
\hline Passed normality test (alpha $=0.05) ?$ & Yes & Yes & Yes & Yes & Yes & Yes & Yes & Yes & \\
\hline$P$ value summary & ns & ns & ns & ns & ns & ns & ns & ns & \\
\hline \multicolumn{9}{|l|}{ Shapiro-Wilk normality test } & \\
\hline W & 0,8506 & 0,9179 & 0,8503 & 0,9012 & 0,9152 & 0,8771 & 0,9326 & 0,9316 & \\
\hline$P$ value & 0,1243 & 0,4533 & 0,1236 & 0,3381 & 0,4329 & 0,2139 & 0,5736 & 0,5646 & \\
\hline Passed normality test (alpha $=0.05) ?$ & Yes & Yes & Yes & Yes & Yes & Yes & Yes & Yes & \\
\hline$P$ value summary & ns & ns & ns & ns & ns & ns & ns & ns & \\
\hline Sum & 7,368 & 6,742 & 10,87 & 6,788 & 6,807 & 9,513 & 10,17 & 8,143 & \\
\hline
\end{tabular}

proMMP-2 (6 semanas), teste de normalidade 


\begin{tabular}{|c|c|c|c|c|c|}
\hline Table Analyzed & Data 1 & & & & \\
\hline \multicolumn{6}{|l|}{ One-way analysis of variance } \\
\hline$P$ value & 0,0002 & & & & \\
\hline$P$ value summary & *** & & & & \\
\hline Are means signif. different? $(P<0.05)$ & Yes & & & & \\
\hline Number of groups & 8 & & & & \\
\hline $\mathrm{F}$ & 5,293 & & & & \\
\hline R squared & 0,4356 & & & & \\
\hline \multicolumn{6}{|l|}{ Bartlett's test for equal variances } \\
\hline Bartlett's statistic (corrected) & 7,674 & & & & \\
\hline$P$ value & 0,3622 & & & & \\
\hline$P$ value summary & ns & & & & \\
\hline Do the variances differ signif. $(P<0.05)$ & No & & & & \\
\hline ANOVA Table & SS & df & MS & & \\
\hline Treatment (between columns) & 2,774 & 7 & 0,3963 & & \\
\hline Residual (within columns) & 3,594 & 48 & 0,07487 & & \\
\hline Total & 6,368 & 55 & & & \\
\hline Tukey's Multiple Comparison Test & Mean Diff. & $q$ & Significant & Summary & $95 \% \mathrm{Cl}$ of diff \\
\hline Grupo 1 vs Grupo 2 & 0,08947 & 0,8651 & No & ns & -0.3748 to 0.5537 \\
\hline Grupo 1 vs Grupo 3 & $-0,5007$ & 4,841 & Yes & * & -0.9649 to -0.03644 \\
\hline Grupo 1 vs Grupo 4 & 0,08297 & 0,8023 & No & ns & -0.3813 to 0.5472 \\
\hline Grupo 1 vs Grupo 5 & 0,08024 & 0,7758 & No & ns & -0.3840 to 0.5445 \\
\hline Grupo 1 vs Grupo 6 & $-0,3064$ & 2,963 & No & ns & -0.7707 to 0.1578 \\
\hline Grupo 1 vs Grupo 7 & $-0,3998$ & 3,866 & No & ns & -0.8641 to 0.06443 \\
\hline Grupo 1 vs Grupo 8 & $-0,1106$ & 1,069 & No & ns & -0.5749 to 0.3537 \\
\hline Grupo 2 vs Grupo 3 & $-0,5902$ & 5,706 & Yes & ** & -1.054 to -0.1259 \\
\hline Grupo 2 vs Grupo 4 & $-0,006496$ & 0,06282 & No & ns & -0.4707 to 0.4578 \\
\hline Grupo 2 vs Grupo 5 & $-0,009230$ & 0,08925 & No & ns & -0.4735 to 0.4550 \\
\hline Grupo 2 vs Grupo 6 & $-0,3959$ & 3,828 & No & ns & -0.8601 to 0.06837 \\
\hline Grupo 2 vs Grupo 7 & $-0,4893$ & 4,731 & Yes & * & -0.9535 to -0.02503 \\
\hline Grupo 2 vs Grupo 8 & $-0,2001$ & 1,934 & No & ns & -0.6643 to 0.2642 \\
\hline Grupo 3 vs Grupo 4 & 0,5837 & 5,644 & Yes & ** & 0.1194 to 1.048 \\
\hline Grupo 3 vs Grupo 5 & 0,5809 & 5,617 & Yes & ** & 0.1167 to 1.045 \\
\hline Grupo 3 vs Grupo 6 & 0,1943 & 1,879 & No & ns & -0.2700 to 0.6585 \\
\hline Grupo 3 vs Grupo 7 & 0,1009 & 0,9754 & No & ns & -0.3634 to 0.5651 \\
\hline Grupo 3 vs Grupo 8 & 0,3901 & 3,772 & No & ns & -0.07416 to 0.8543 \\
\hline Grupo 4 vs Grupo 5 & $-0,002734$ & 0,02643 & No & ns & -0.4670 to 0.4615 \\
\hline Grupo 4 vs Grupo 6 & $-0,3894$ & 3,765 & No & ns & -0.8536 to 0.07487 \\
\hline Grupo 4 vs Grupo 7 & $-0,4828$ & 4,668 & Yes & * & -0.9470 to -0.01854 \\
\hline Grupo 4 vs Grupo 8 & $-0,1936$ & 1,872 & No & ns & -0.6578 to 0.2707 \\
\hline Grupo 5 vs Grupo 6 & $-0,3867$ & 3,739 & No & ns & -0.8509 to 0.07760 \\
\hline Grupo 5 vs Grupo 7 & $-0,4801$ & 4,642 & Yes & * & -0.9443 to -0.01580 \\
\hline Grupo 5 vs Grupo 8 & $-0,1908$ & 1,845 & No & ns & -0.6551 to 0.2734 \\
\hline Grupo 6 vs Grupo 7 & $-0,09340$ & 0,9032 & No & ns & -0.5577 to 0.3708 \\
\hline Grupo 6 vs Grupo 8 & 0,1958 & 1,893 & No & ns & -0.2684 to 0.6601 \\
\hline Grupo 7 vs Grupo 8 & 0,2892 & 2,797 & No & ns & -0.1750 to 0.7535 \\
\hline
\end{tabular}

proMMP-2 (6 semanas), análise dos grupos 


\begin{tabular}{|c|c|c|c|c|c|c|c|c|c|}
\hline & Grupo 1 & Grupo 2 & Grupo 3 & Grupo 4 & Grupo 5 & Grupo 6 & Grupo 7 & Grupo 8 & \\
\hline Number of values & 7 & 7 & 7 & 7 & 7 & 7 & 7 & 7 & 7 \\
\hline Minimum & 0,6823 & 1,069 & 0,8116 & 0,9220 & 0,6561 & 1,010 & 0,7890 & 0,9061 & \\
\hline 25\% Percentile & 0,8109 & 1,140 & 0,9176 & 1,028 & 0,8370 & 1,027 & 0,8829 & 0,9297 & \\
\hline Median & 1,106 & 1,173 & 1,214 & 1,089 & 0,9564 & 1,176 & 1,199 & 1,049 & \\
\hline 75\% Percentile & 1,271 & 1,320 & 1,425 & 1,397 & 1,287 & 1,470 & 1,568 & 1,055 & \\
\hline Maximum & 1,697 & 1,467 & 1,944 & 1,521 & 1,471 & 1,489 & 1,670 & 1,084 & \\
\hline Mean & 1,100 & 1,216 & 1,235 & 1,188 & 1,033 & 1,225 & 1,234 & 1,003 & \\
\hline Std. Deviation & 0,3360 & 0,1343 & 0,3740 & 0,2259 & 0,2756 & 0,2002 & 0,3625 & 0,07245 & \\
\hline Std. Error & 0,1270 & 0,05074 & 0,1414 & 0,08537 & 0,1042 & 0,07566 & 0,1370 & 0,02739 & \\
\hline Lower $95 \% \mathrm{Cl}$ of mean & 0,7896 & 1,092 & 0,8895 & 0,9792 & 0,7785 & 1,040 & 0,8986 & 0,9363 & \\
\hline Upper $95 \% \mathrm{Cl}$ of mean & 1,411 & 1,340 & 1,581 & 1,397 & 1,288 & 1,410 & 1,569 & 1,070 & \\
\hline \multicolumn{10}{|l|}{ KS normality test } \\
\hline KS distance & 0,1634 & 0,2769 & 0,2074 & 0,2415 & 0,1814 & 0,1750 & 0,2363 & 0,3089 & \\
\hline$P$ value & $P>0.10$ & $P>0.10$ & $P>0.10$ & $P>0.10$ & $P>0.10$ & $P>0.10$ & $P>0.10$ & 0,0422 & \\
\hline Passed normality test (alpha $=0.05) ?$ & Yes & Yes & Yes & Yes & Yes & Yes & Yes & No & \\
\hline$P$ value summary & ns & ns & ns & ns & ns & ns & ns & * & \\
\hline \multicolumn{10}{|l|}{ Shapiro-Wilk normality test } \\
\hline W & 0,9617 & 0,8841 & 0,9233 & 0,9091 & 0,9738 & 0,8888 & 0,8884 & 0,8491 & \\
\hline$P$ value & 0,8329 & 0,2452 & 0,4953 & 0,3899 & 0,9245 & 0,2685 & 0,2663 & 0,1207 & \\
\hline Passed normality test (alpha $=0.05) ?$ & Yes & Yes & Yes & Yes & Yes & Yes & Yes & Yes & \\
\hline$P$ value summary & ns & ns & ns & ns & ns & ns & ns & ns & \\
\hline Sum & 7,703 & 8,513 & 8,648 & 8,317 & 7,234 & 8,576 & 8,637 & 7,023 & \\
\hline
\end{tabular}

MMP-9 (4 semanas), teste de normalidade 


\begin{tabular}{|c|c|c|c|c|c|}
\hline Table Analyzed & Data 1 & & & & \\
\hline \multicolumn{6}{|l|}{ One-way analysis of variance } \\
\hline$P$ value & 0,5289 & & & & \\
\hline$P$ value summary & ns & & & & \\
\hline Are means signif. different? $(P<0.05)$ & No & & & & \\
\hline Number of groups & 8 & & & & \\
\hline $\mathrm{F}$ & 0,8805 & & & & \\
\hline R squared & 0,1138 & & & & \\
\hline \multicolumn{6}{|l|}{ Bartlett's test for equal variances } \\
\hline Bartlett's statistic (corrected) & 17,76 & & & & \\
\hline$P$ value & 0,0131 & & & & \\
\hline$P$ value summary & * & & & & \\
\hline Do the variances differ signif. $(P<0.05)$ & Yes & & & & \\
\hline ANOVA Table & SS & df & MS & & \\
\hline Treatment (between columns) & 0,4426 & 7 & 0,06323 & & \\
\hline Residual (within columns) & 3,447 & 48 & 0,07182 & & \\
\hline Total & 3,890 & 55 & & & \\
\hline Tukey's Multiple Comparison Test & Mean Diff. & q & Significant & Summary & $95 \% \mathrm{Cl}$ of diff \\
\hline Grupo 1 vs Grupo 2 & $-0,1158$ & 1,143 & No & ns & -0.5705 to 0.3389 \\
\hline Grupo 1 vs Grupo 3 & $-0,1350$ & 1,333 & No & ns & -0.5897 to 0.3197 \\
\hline Grupo 1 vs Grupo 4 & $-0,08771$ & 0,8659 & No & ns & -0.5424 to 0.3670 \\
\hline Grupo 1 vs Grupo 5 & 0,06700 & 0,6615 & No & ns & -0.3877 to 0.5217 \\
\hline Grupo 1 vs Grupo 6 & $-0,1248$ & 1,232 & No & ns & -0.5795 to 0.3299 \\
\hline Grupo 1 vs Grupo 7 & $-0,1335$ & 1,318 & No & ns & -0.5882 to 0.3212 \\
\hline Grupo 1 vs Grupo 8 & 0,09713 & 0,9589 & No & ns & -0.3576 to 0.5518 \\
\hline Grupo 2 vs Grupo 3 & $-0,01923$ & 0,1899 & No & ns & -0.4739 to 0.4355 \\
\hline Grupo 2 vs Grupo 4 & 0,02806 & 0,2771 & No & ns & -0.4266 to 0.4828 \\
\hline Grupo 2 vs Grupo 5 & 0,1828 & 1,804 & No & ns & -0.2719 to 0.6375 \\
\hline Grupo 2 vs Grupo 6 & $-0,008985$ & 0,08870 & No & ns & -0.4637 to 0.4457 \\
\hline Grupo 2 vs Grupo 7 & $-0,01769$ & 0,1747 & No & ns & -0.4724 to 0.4370 \\
\hline Grupo 2 vs Grupo 8 & 0,2129 & 2,102 & No & ns & -0.2418 to 0.6676 \\
\hline Grupo 3 vs Grupo 4 & 0,04730 & 0,4669 & No & ns & -0.4074 to 0.5020 \\
\hline Grupo 3 vs Grupo 5 & 0,2020 & 1,994 & No & ns & -0.2527 to 0.6567 \\
\hline Grupo 3 vs Grupo 6 & 0,01025 & 0,1012 & No & ns & -0.4444 to 0.4649 \\
\hline Grupo 3 vs Grupo 7 & 0,001538 & 0,01519 & No & ns & -0.4532 to 0.4562 \\
\hline Grupo 3 vs Grupo 8 & 0,2321 & 2,292 & No & ns & -0.2226 to 0.6868 \\
\hline Grupo 4 vs Grupo 5 & 0,1547 & 1,527 & No & ns & -0.3000 to 0.6094 \\
\hline Grupo 4 vs Grupo 6 & $-0,03705$ & 0,3658 & No & ns & -0.4917 to 0.4176 \\
\hline Grupo 4 vs Grupo 7 & $-0,04576$ & 0,4517 & No & ns & -0.5005 to 0.4089 \\
\hline Grupo 4 vs Grupo 8 & 0,1848 & 1,825 & No & ns & -0.2699 to 0.6395 \\
\hline Grupo 5 vs Grupo 6 & $-0,1918$ & 1,893 & No & ns & -0.6465 to 0.2629 \\
\hline Grupo 5 vs Grupo 7 & $-0,2005$ & 1,979 & No & ns & -0.6552 to 0.2542 \\
\hline Grupo 5 vs Grupo 8 & 0,03013 & 0,2974 & No & ns & -0.4246 to 0.4848 \\
\hline Grupo 6 vs Grupo 7 & $-0,008709$ & 0,08598 & No & ns & -0.4634 to 0.4460 \\
\hline Grupo 6 vs Grupo 8 & 0,2219 & 2,191 & No & ns & -0.2328 to 0.6766 \\
\hline Grupo 7 vs Grupo 8 & 0,2306 & 2,277 & No & ns & -0.2241 to 0.6853 \\
\hline
\end{tabular}

MMP-9 (4 semanas), análise dos grupos 


\begin{tabular}{|c|c|c|c|c|c|c|c|c|c|}
\hline & Grupo 1 & Grupo 2 & Grupo 3 & Grupo 4 & Grupo 5 & Grupo 6 & Grupo 7 & Grupo 8 & \\
\hline Number of values & 7 & 7 & 7 & 7 & 7 & 7 & 7 & 7 & 7 \\
\hline Minimum & 0,6527 & 0,5247 & 1,087 & 0,9578 & 0,8782 & 0,9603 & 0,7898 & 0,9261 & \\
\hline 25\% Percentile & 0,6891 & 0,8120 & 1,171 & 1,074 & 0,9327 & 1,042 & 0,8879 & 0,9667 & \\
\hline Median & 1,005 & 1,226 & 1,260 & 1,185 & 1,001 & 1,228 & 1,293 & 1,015 & \\
\hline 75\% Percentile & 1,158 & 1,342 & 1,433 & 1,327 & 1,318 & 1,360 & 1,440 & 1,057 & \\
\hline Maximum & 1,385 & 1,386 & 1,657 & 1,332 & 1,387 & 1,586 & 1,801 & 1,060 & \\
\hline Mean & 0,9937 & 1,084 & 1,314 & 1,166 & 1,111 & 1,234 & 1,218 & 1,007 & \\
\hline Std. Deviation & 0,2564 & 0,3253 & 0,1895 & 0,1365 & 0,2108 & 0,2070 & 0,3539 & 0,05250 & \\
\hline Std. Error & 0,09691 & 0,1230 & 0,07162 & 0,05160 & 0,07968 & 0,07825 & 0,1338 & 0,01984 & \\
\hline Lower $95 \% \mathrm{Cl}$ of mean & 0,7566 & 0,7830 & 1,138 & 1,040 & 0,9157 & 1,043 & 0,8910 & 0,9584 & \\
\hline Upper $95 \% \mathrm{Cl}$ of mean & 1,231 & 1,385 & 1,489 & 1,293 & 1,306 & 1,426 & 1,546 & 1,055 & \\
\hline \multicolumn{10}{|l|}{ KS normality test } \\
\hline KS distance & 0,2230 & 0,2398 & 0,1827 & 0,1660 & 0,2707 & 0,1292 & 0,1700 & 0,2218 & \\
\hline$P$ value & $P>0.10$ & $P>0.10$ & $P>0.10$ & $P>0.10$ & $P>0.10$ & $P>0.10$ & $P>0.10$ & $P>0.10$ & \\
\hline Passed normality test (alpha $=0.05) ?$ & Yes & Yes & Yes & Yes & Yes & Yes & Yes & Yes & \\
\hline$P$ value summary & ns & ns & ns & ns & ns & ns & ns & ns & \\
\hline \multicolumn{10}{|l|}{ Shapiro-Wilk normality test } \\
\hline W & 0,9364 & 0,8793 & 0,9494 & 0,9403 & 0,8566 & 0,9759 & 0,9504 & 0,8944 & \\
\hline$P$ value & 0,6066 & 0,2233 & 0,7243 & 0,6411 & 0,1411 & 0,9376 & 0,7329 & 0,2986 & \\
\hline Passed normality test (alpha $=0.05) ?$ & Yes & Yes & Yes & Yes & Yes & Yes & Yes & Yes & \\
\hline$P$ value summary & ns & ns & ns & ns & ns & ns & ns & ns & \\
\hline Sum & 6,956 & 7,587 & 9,196 & 8,164 & 7,775 & 8,640 & 8,528 & 7,048 & \\
\hline
\end{tabular}

proMMP-9 (4 semanas), teste de normalidade 


\begin{tabular}{|c|c|c|c|c|c|}
\hline Table Analyzed & Data 1 & & & & \\
\hline \multicolumn{6}{|l|}{ One-way analysis of variance } \\
\hline$P$ value & 0,1547 & & & & \\
\hline$P$ value summary & ns & & & & \\
\hline Are means signif. different? $(P<0.05)$ & No & & & & \\
\hline Number of groups & 8 & & & & \\
\hline $\mathrm{F}$ & 1,613 & & & & \\
\hline R squared & 0,1904 & & & & \\
\hline \multicolumn{6}{|l|}{ Bartlett's test for equal variances } \\
\hline Bartlett's statistic (corrected) & 18,83 & & & & \\
\hline$P$ value & 0,0087 & & & & \\
\hline$P$ value summary & ** & & & & \\
\hline Do the variances differ signif. $(P<0.05)$ & Yes & & & & \\
\hline ANOVA Table & SS & df & MS & & \\
\hline Treatment (between columns) & 0,6229 & 7 & 0,08898 & & \\
\hline Residual (within columns) & 2,648 & 48 & 0,05518 & & \\
\hline Total & 3,271 & 55 & & & \\
\hline Tukey's Multiple Comparison Test & Mean Diff. & q & Significant & Summary & $95 \% \mathrm{Cl}$ of diff \\
\hline Grupo 1 vs Grupo 2 & $-0,09021$ & 1,016 & No & ns & -0.4888 to 0.3083 \\
\hline Grupo 1 vs Grupo 3 & $-0,3200$ & 3,604 & No & ns & -0.7185 to 0.07857 \\
\hline Grupo 1 vs Grupo 4 & $-0,1726$ & 1,944 & No & ns & -0.5711 to 0.2260 \\
\hline Grupo 1 vs Grupo 5 & $-0,1170$ & 1,318 & No & ns & -0.5156 to 0.2815 \\
\hline Grupo 1 vs Grupo 6 & $-0,2406$ & 2,710 & No & ns & -0.6391 to 0.1579 \\
\hline Grupo 1 vs Grupo 7 & $-0,2246$ & 2,530 & No & ns & -0.6231 to 0.1740 \\
\hline Grupo 1 vs Grupo 8 & $-0,01322$ & 0,1489 & No & ns & -0.4118 to 0.3853 \\
\hline Grupo 2 vs Grupo 3 & $-0,2298$ & 2,588 & No & ns & -0.6283 to 0.1688 \\
\hline Grupo 2 vs Grupo 4 & $-0,08238$ & 0,9278 & No & ns & -0.4809 to 0.3162 \\
\hline Grupo 2 vs Grupo 5 & $-0,02682$ & 0,3021 & No & ns & -0.4254 to 0.3717 \\
\hline Grupo 2 vs Grupo 6 & $-0,1504$ & 1,694 & No & ns & -0.5489 to 0.2482 \\
\hline Grupo 2 vs Grupo 7 & $-0,1344$ & 1,514 & No & ns & -0.5329 to 0.2642 \\
\hline Grupo 2 vs Grupo 8 & 0,07699 & 0,8671 & No & ns & -0.3216 to 0.4755 \\
\hline Grupo 3 vs Grupo 4 & 0,1474 & 1,660 & No & ns & -0.2512 to 0.5459 \\
\hline Grupo 3 vs Grupo 5 & 0,2029 & 2,286 & No & ns & -0.1956 to 0.6015 \\
\hline Grupo 3 vs Grupo 6 & 0,07937 & 0,8940 & No & ns & -0.3192 to 0.4779 \\
\hline Grupo 3 vs Grupo 7 & 0,09538 & 1,074 & No & ns & -0.3032 to 0.4939 \\
\hline Grupo 3 vs Grupo 8 & 0,3067 & 3,455 & No & ns & -0.09180 to 0.7053 \\
\hline Grupo 4 vs Grupo 5 & 0,05555 & 0,6257 & No & ns & -0.3430 to 0.4541 \\
\hline Grupo 4 vs Grupo 6 & $-0,06801$ & 0,7661 & No & ns & -0.4666 to 0.3305 \\
\hline Grupo 4 vs Grupo 7 & $-0,05200$ & 0,5857 & No & ns & -0.4505 to 0.3465 \\
\hline Grupo 4 vs Grupo 8 & 0,1594 & 1,795 & No & ns & -0.2392 to 0.5579 \\
\hline Grupo 5 vs Grupo 6 & $-0,1236$ & 1,392 & No & ns & -0.5221 to 0.2750 \\
\hline Grupo 5 vs Grupo 7 & $-0,1076$ & 1,211 & No & ns & -0.5061 to 0.2910 \\
\hline Grupo 5 vs Grupo 8 & 0,1038 & 1,169 & No & ns & -0.2947 to 0.5024 \\
\hline Grupo 6 vs Grupo 7 & 0,01601 & 0,1804 & No & ns & -0.3825 to 0.4146 \\
\hline Grupo 6 vs Grupo 8 & 0,2274 & 2,561 & No & ns & -0.1712 to 0.6259 \\
\hline Grupo 7 vs Grupo 8 & 0,2114 & 2,381 & No & ns & -0.1872 to 0.6099 \\
\hline
\end{tabular}

proMMP-9 (4 semanas), análise dos grupos 


\begin{tabular}{|c|c|c|c|c|c|c|c|c|c|}
\hline & Grupo 1 & Grupo 2 & Grupo 3 & Grupo 4 & Grupo 5 & Grupo 6 & Grupo 7 & Grupo 8 & \\
\hline Number of values & 7 & 7 & 7 & 7 & 7 & 7 & 7 & 7 & 7 \\
\hline Minimum & 0,6026 & 0,6588 & 0,9353 & 0,7556 & 0,8018 & 0,7761 & 0,8804 & 0,6581 & \\
\hline 25\% Percentile & 0,6925 & 0,7931 & 0,9676 & 0,8051 & 0,8165 & 0,8687 & 0,9115 & 0,8860 & \\
\hline Median & 0,8498 & 0,8429 & 1,180 & 0,8438 & 0,8927 & 1,223 & 1,103 & 0,9531 & \\
\hline 75\% Percentile & 1,074 & 1,191 & 1,510 & 1,191 & 1,206 & 1,331 & 1,244 & 1,158 & \\
\hline Maximum & 1,174 & 1,222 & 1,795 & 1,238 & 1,214 & 1,407 & 1,376 & 1,216 & \\
\hline Mean & 0,8755 & 0,9413 & 1,265 & 0,9489 & 0,9689 & 1,154 & 1,111 & 0,9748 & \\
\hline Std. Deviation & 0,2012 & 0,2203 & 0,3043 & 0,1953 & 0,1786 & 0,2398 & 0,1811 & 0,1889 & \\
\hline Std. Error & 0,07604 & 0,08327 & 0,1150 & 0,07382 & 0,06752 & 0,09065 & 0,06846 & 0,07138 & \\
\hline Lower $95 \% \mathrm{Cl}$ of mean & 0,6895 & 0,7376 & 0,9837 & 0,7683 & 0,8036 & 0,9325 & 0,9435 & 0,8001 & \\
\hline Upper $95 \% \mathrm{Cl}$ of mean & 1,062 & 1,145 & 1,547 & 1,130 & 1,134 & 1,376 & 1,278 & 1,149 & \\
\hline \multicolumn{10}{|l|}{ KS normality test } \\
\hline KS distance & 0,1274 & 0,2439 & 0,1819 & 0,2762 & 0,2366 & 0,2536 & 0,1518 & 0,1763 & \\
\hline$P$ value & $P>0.10$ & $P>0.10$ & $P>0.10$ & $P>0.10$ & $P>0.10$ & $P>0.10$ & $P>0.10$ & $P>0.10$ & \\
\hline Passed normality test (alpha $=0.05) ?$ & Yes & Yes & Yes & Yes & Yes & Yes & Yes & Yes & \\
\hline$P$ value summary & ns & ns & ns & ns & ns & ns & ns & ns & \\
\hline \multicolumn{10}{|l|}{ Shapiro-Wilk normality test } \\
\hline W & 0,9746 & 0,8960 & 0,9293 & 0,8495 & 0,8308 & 0,8759 & 0,9571 & 0,9607 & \\
\hline$P$ value & 0,9292 & 0,3072 & 0,5446 & 0,1215 & 0,0815 & 0,2090 & 0,7931 & 0,8249 & \\
\hline Passed normality test (alpha $=0.05) ?$ & Yes & Yes & Yes & Yes & Yes & Yes & Yes & Yes & \\
\hline$P$ value summary & ns & ns & ns & ns & ns & ns & ns & ns & \\
\hline Sum & 6,129 & 6,589 & 8,856 & 6,643 & 6,782 & 8,080 & 7,777 & 6,823 & \\
\hline
\end{tabular}

MMP-9 (6 semanas), teste de normalidade 


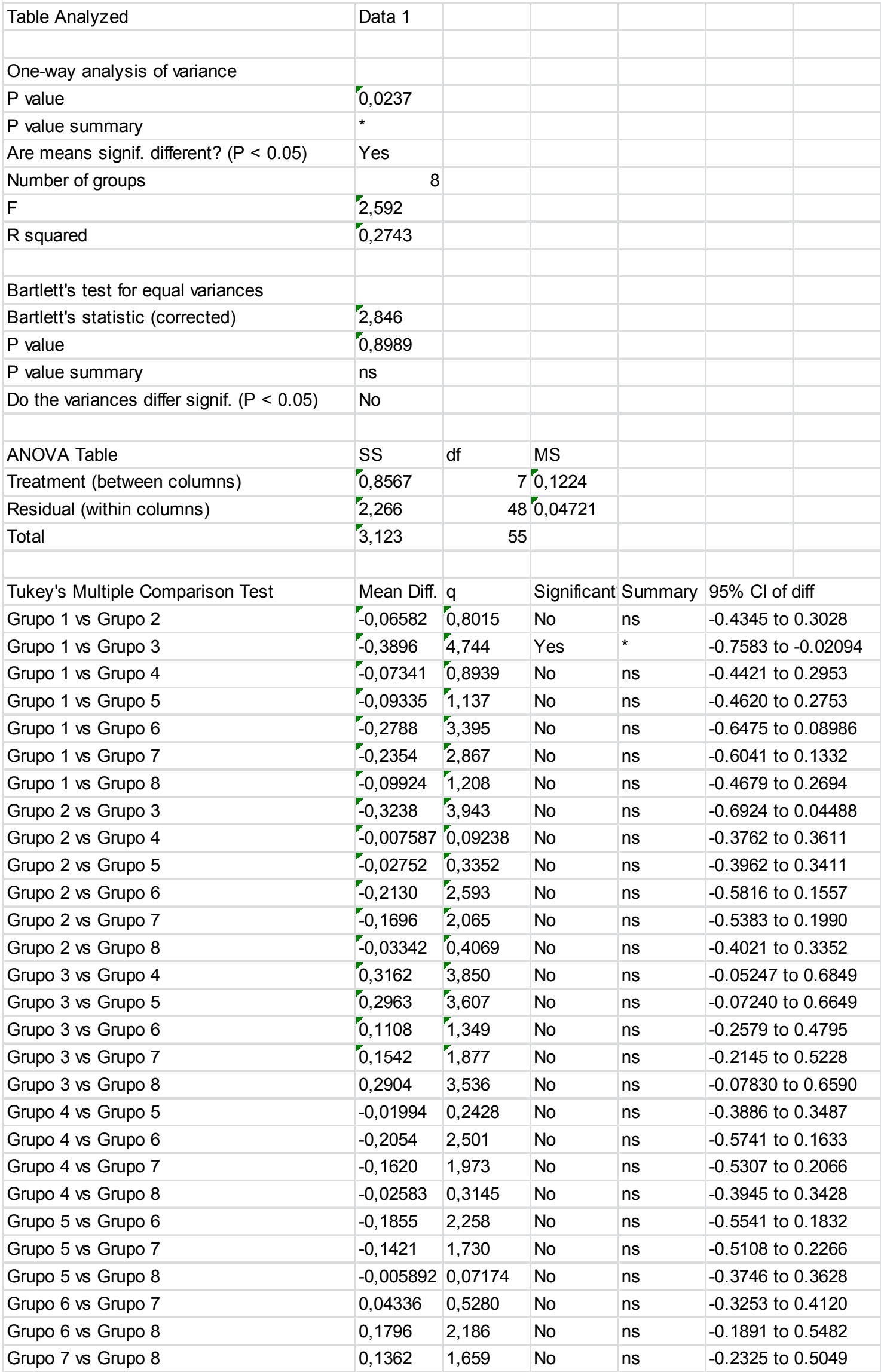

MMP-9 (6 semanas), análise dos grupos 


\begin{tabular}{|c|c|c|c|c|c|c|c|c|c|}
\hline & Grupo 1 & Grupo 2 & Grupo 3 & Grupo 4 & Grupo 5 & Grupo 6 & Grupo 7 & Grupo 8 & \\
\hline Number of values & 7 & 7 & 7 & 7 & 7 & 7 & 7 & 7 & 7 \\
\hline Minimum & 0,9300 & 0,6142 & 0,9821 & 0,8006 & 0,7752 & 0,7479 & 0,9347 & 0,7736 & \\
\hline 25\% Percentile & 0,9625 & 0,7659 & 1,018 & 0,9420 & 0,9799 & 0,8628 & 1,074 & 0,9422 & \\
\hline Median & 1,050 & 1,067 & 1,243 & 1,113 & 1,107 & 1,121 & 1,113 & 1,199 & \\
\hline 75\% Percentile & 1,260 & 1,569 & 1,404 & 1,475 & 1,250 & 1,339 & 1,256 & 1,258 & \\
\hline Maximum & 1,286 & 1,656 & 1,784 & 1,557 & 1,483 & 1,498 & 1,415 & 1,450 & \\
\hline Mean & 1,085 & 1,094 & 1,266 & 1,177 & 1,115 & 1,118 & 1,146 & 1,127 & \\
\hline Std. Deviation & 0,1410 & 0,3909 & 0,2733 & 0,2994 & 0,2287 & 0,2592 & 0,1531 & 0,2284 & \\
\hline Std. Error & 0,05330 & 0,1477 & 0,1033 & 0,1132 & 0,08643 & 0,09797 & 0,05785 & 0,08631 & \\
\hline Lower $95 \% \mathrm{Cl}$ of mean & 0,9550 & 0,7324 & 1,013 & 0,8996 & 0,9031 & 0,8783 & 1,005 & 0,9157 & \\
\hline Upper $95 \% \mathrm{Cl}$ of mean & 1,216 & 1,455 & 1,519 & 1,453 & 1,326 & 1,358 & 1,288 & 1,338 & \\
\hline \multicolumn{10}{|l|}{ KS normality test } \\
\hline KS distance & 0,1774 & 0,2262 & 0,1702 & 0,2078 & 0,1369 & 0,1352 & 0,1845 & 0,1961 & \\
\hline$P$ value & $P>0.10$ & $P>0.10$ & $P>0.10$ & $P>0.10$ & $P>0.10$ & $P>0.10$ & $P>0.10$ & $P>0.10$ & \\
\hline Passed normality test (alpha $=0.05) ?$ & Yes & Yes & Yes & Yes & Yes & Yes & Yes & Yes & \\
\hline$P$ value summary & ns & ns & ns & ns & ns & ns & ns & ns & \\
\hline \multicolumn{10}{|l|}{ Shapiro-Wilk normality test } \\
\hline W & 0,9003 & 0,9188 & 0,9123 & 0,9033 & 0,9819 & 0,9819 & 0,9537 & 0,9670 & \\
\hline$P$ value & 0,3329 & 0,4604 & 0,4122 & 0,3513 & 0,9683 & 0,9682 & 0,7631 & 0,8758 & \\
\hline Passed normality test (alpha $=0.05) ?$ & Yes & Yes & Yes & Yes & Yes & Yes & Yes & Yes & \\
\hline$P$ value summary & ns & ns & ns & ns & ns & ns & ns & ns & \\
\hline Sum & 7,598 & 7,658 & 8,861 & 8,236 & 7,802 & 7,826 & 8,025 & 7,888 & \\
\hline
\end{tabular}

proMMP-9 (6 semanas), teste de normalidade 


\begin{tabular}{|c|c|c|c|c|c|}
\hline Table Analyzed & Data 1 & & & & \\
\hline \multicolumn{6}{|l|}{ One-way analysis of variance } \\
\hline$P$ value & 0,9235 & & & & \\
\hline$P$ value summary & ns & & & & \\
\hline Are means signif. different? $(P<0.05)$ & No & & & & \\
\hline Number of groups & 8 & & & & \\
\hline $\mathrm{F}$ & 0,3552 & & & & \\
\hline R squared & 0,04925 & & & & \\
\hline \multicolumn{6}{|l|}{ Bartlett's test for equal variances } \\
\hline Bartlett's statistic (corrected) & 8,346 & & & & \\
\hline$P$ value & 0,3031 & & & & \\
\hline$P$ value summary & ns & & & & \\
\hline Do the variances differ signif. $(P<0.05)$ & No & & & & \\
\hline ANOVA Table & SS & df & MS & & \\
\hline Treatment (between columns) & 0,1653 & & 0,02362 & & \\
\hline Residual (within columns) & 3,192 & 48 & 0,06650 & & \\
\hline Total & 3,358 & 55 & & & \\
\hline Tukey's Multiple Comparison Test & Mean Diff. & q & Significant & Summary & $95 \% \mathrm{Cl}$ of diff \\
\hline Grupo 1 vs Grupo 2 & $-0,008517$ & 0,08738 & No & ns & -0.4461 to 0.4290 \\
\hline Grupo 1 vs Grupo 3 & $-0,1805$ & 1,851 & No & ns & -0.6180 to 0.2571 \\
\hline Grupo 1 vs Grupo 4 & $-0,09107$ & 0,9343 & No & ns & -0.5286 to 0.3465 \\
\hline Grupo 1 vs Grupo 5 & $-0,02912$ & 0,2988 & No & ns & -0.4667 to 0.4084 \\
\hline Grupo 1 vs Grupo 6 & $-0,03255$ & 0,3339 & No & ns & -0.4701 to 0.4050 \\
\hline Grupo 1 vs Grupo 7 & $-0,06101$ & 0,6259 & No & ns & -0.4986 to 0.3765 \\
\hline Grupo 1 vs Grupo 8 & $-0,04142$ & 0,4249 & No & ns & -0.4790 to 0.3961 \\
\hline Grupo 2 vs Grupo 3 & $-0,1720$ & 1,764 & No & ns & -0.6095 to 0.2656 \\
\hline Grupo 2 vs Grupo 4 & $-0,08255$ & 0,8470 & No & ns & -0.5201 to 0.3550 \\
\hline Grupo 2 vs Grupo 5 & $-0,02060$ & 0,2114 & No & ns & -0.4582 to 0.4169 \\
\hline Grupo 2 vs Grupo 6 & $-0,02403$ & 0,2466 & No & ns & -0.4616 to 0.4135 \\
\hline Grupo 2 vs Grupo 7 & $-0,05249$ & 0,5385 & No & ns & -0.4900 to 0.3851 \\
\hline Grupo 2 vs Grupo 8 & $-0,03290$ & 0,3375 & No & ns & -0.4704 to 0.4046 \\
\hline Grupo 3 vs Grupo 4 & 0,08940 & 0,9172 & No & ns & -0.3482 to 0.5269 \\
\hline Grupo 3 vs Grupo 5 & 0,1513 & 1,553 & No & ns & -0.2862 to 0.5889 \\
\hline Grupo 3 vs Grupo 6 & 0,1479 & 1,518 & No & ns & -0.2896 to 0.5855 \\
\hline Grupo 3 vs Grupo 7 & 0,1195 & 1,226 & No & ns & -0.3181 to 0.5570 \\
\hline Grupo 3 vs Grupo 8 & 0,1391 & 1,427 & No & ns & -0.2985 to 0.5766 \\
\hline Grupo 4 vs Grupo 5 & 0,06195 & 0,6356 & No & ns & -0.3756 to 0.4995 \\
\hline Grupo 4 vs Grupo 6 & 0,05852 & 0,6004 & No & ns & -0.3790 to 0.4961 \\
\hline Grupo 4 vs Grupo 7 & 0,03006 & 0,3084 & No & ns & -0.4075 to 0.4676 \\
\hline Grupo 4 vs Grupo 8 & 0,04965 & 0,5094 & No & ns & -0.3879 to 0.4872 \\
\hline Grupo 5 vs Grupo 6 & $-0,003431$ & 0,03520 & No & ns & -0.4410 to 0.4341 \\
\hline Grupo 5 vs Grupo 7 & $-0,03189$ & 0,3271 & No & ns & -0.4694 to 0.4057 \\
\hline Grupo 5 vs Grupo 8 & $-0,01230$ & 0,1262 & No & ns & -0.4498 to 0.4253 \\
\hline Grupo 6 vs Grupo 7 & $-0,02846$ & 0,2919 & No & ns & -0.4660 to 0.4091 \\
\hline Grupo 6 vs Grupo 8 & $-0,008867$ & 0,09097 & No & ns & -0.4464 to 0.4287 \\
\hline Grupo 7 vs Grupo 8 & 0,01959 & 0,2010 & No & ns & -0.4180 to 0.4571 \\
\hline
\end{tabular}

proMMP-9 (6 semanas), análise dos grupos 


\begin{tabular}{|c|c|c|c|c|c|}
\hline Table Analyzed & Data 1 & & & & \\
\hline \multicolumn{6}{|l|}{ One-way analysis of variance } \\
\hline$P$ value & 0,8978 & & & & \\
\hline$P$ value summary & ns & & & & \\
\hline Are means signif. different? $(P<0.05)$ & No & & & & \\
\hline Number of groups & 4 & & & & \\
\hline $\mathrm{F}$ & 0,1965 & & & & \\
\hline R squared & 0,02397 & & & & \\
\hline \multicolumn{6}{|l|}{ Bartlett's test for equal variances } \\
\hline Bartlett's statistic (corrected) & 1,096 & & & & \\
\hline$P$ value & 0,7781 & & & & \\
\hline$P$ value summary & ns & & & & \\
\hline Do the variances differ signif. $(P<0.05)$ & No & & & & \\
\hline ANOVA Table & SS & df & MS & & \\
\hline Treatment (between columns) & 0,03052 & \multicolumn{2}{|c|}{30,01017} & & \\
\hline Residual (within columns) & 1,243 & \multicolumn{2}{|c|}{240,05178} & & \\
\hline Total & 1,273 & \multicolumn{2}{|l|}{27} & & \\
\hline Tukey's Multiple Comparison Test & Mean Diff. & q & Significant & Summary & $95 \% \mathrm{Cl}$ of diff \\
\hline MMP-2 (4 semanas) vs proMMP-2 (4 semanas) & 0,03477 & 0,4042 & No & ns & -0.3007 to 0.3703 \\
\hline MMP-2 (4 semanas) vs MMP-2 (6 semanas) & 0,08277 & 0,9624 & No & ns & -0.2527 to 0.4183 \\
\hline MMP-2 (4 semanas) vs proMMP-2 (6 semanas) & 0,07391 & 0,8594 & No & ns & -0.2616 to 0.4094 \\
\hline proMMP-2 (4 semanas) vs MMP-2 (6 semanas) & 0,04801 & 0,5582 & No & ns & -0.2875 to 0.3835 \\
\hline proMMP-2 (4 semanas) vs proMMP-2 (6 semanas) & 0,03915 & 0,4552 & No & ns & -0.2964 to 0.3747 \\
\hline MMP-2 (6 semanas) vs proMMP-2 (6 semanas) & $-0,008860$ & 0,1030 & No & ns & -0.3444 to 0.3266 \\
\hline
\end{tabular}

Grupo 1 (MMP-2 e proMMP-2), análise entre os tempos 


\begin{tabular}{|c|c|c|c|c|c|}
\hline Table Analyzed & Data 1 & & & & \\
\hline \multicolumn{6}{|l|}{ One-way analysis of variance } \\
\hline$P$ value & 0,1413 & & & & \\
\hline$P$ value summary & ns & & & & \\
\hline Are means signif. different? $(\mathrm{P}<0.05)$ & No & & & & \\
\hline Number of groups & 4 & & & & \\
\hline $\mathrm{F}$ & 1,997 & & & & \\
\hline R squared & 0,1998 & & & & \\
\hline \multicolumn{6}{|l|}{ Bartlett's test for equal variances } \\
\hline Bartlett's statistic (corrected) & 1,416 & & & & \\
\hline$P$ value & 0,7018 & & & & \\
\hline$P$ value summary & ns & & & & \\
\hline Do the variances differ signif. $(P<0.05)$ & No & & & & \\
\hline ANOVA Table & SS & df & MS & & \\
\hline Treatment (between columns) & 0,3491 & \multicolumn{2}{|c|}{30,1164} & & \\
\hline Residual (within columns) & 1,398 & \multicolumn{2}{|c|}{240,05826} & & \\
\hline Total & 1,747 & 27 & & & \\
\hline Tukey's Multiple Comparison Test & Mean Diff. & q & Significant & Summary & $95 \% \mathrm{Cl}$ of diff \\
\hline MMP-2 (4 semanas) vs proMMP-2 (4 semanas) & $-0,05197$ & 0,5697 & No & ns & -0.4079 to 0.3039 \\
\hline MMP-2 (4 semanas) vs MMP-2 (6 semanas) & 0,1962 & 2,150 & No & ns & -0.1597 to 0.5521 \\
\hline MMP-2 (4 semanas) vs proMMP-2 (6 semanas) & 0,1923 & 2,108 & No & ns & -0.1636 to 0.5482 \\
\hline proMMP-2 (4 semanas) vs MMP-2 (6 semanas) & 0,2481 & 2,720 & No & ns & -0.1078 to 0.6040 \\
\hline proMMP-2 (4 semanas) vs proMMP-2 (6 semanas) & 0,2443 & 2,678 & No & ns & -0.1116 to 0.6002 \\
\hline MMP-2 (6 semanas) vs proMMP-2 (6 semanas) & \multicolumn{2}{|c|}{$-0,0038370,04205$} & No & ns & -0.3597 to 0.3521 \\
\hline
\end{tabular}

Grupo 2 (MMP-2 e proMMP-2), análise entre os tempos 


\begin{tabular}{|c|c|c|c|c|c|}
\hline Table Analyzed & Data 1 & & & & \\
\hline \multicolumn{6}{|l|}{ One-way analysis of variance } \\
\hline$P$ value & 0,3142 & & & & \\
\hline$P$ value summary & ns & & & & \\
\hline Are means signif. different? $(P<0.05)$ & No & & & & \\
\hline Number of groups & 4 & & & & \\
\hline $\mathrm{F}$ & 1,249 & & & & \\
\hline R squared & 0,1350 & & & & \\
\hline \multicolumn{6}{|l|}{ Bartlett's test for equal variances } \\
\hline Bartlett's statistic (corrected) & 2,212 & & & & \\
\hline$P$ value & 0,5296 & & & & \\
\hline$P$ value summary & ns & & & & \\
\hline Do the variances differ signif. $(P<0.05)$ & No & & & & \\
\hline ANOVA Table & SS & df & MS & & \\
\hline Treatment (between columns) & 0,3758 & \multicolumn{2}{|c|}{30,1253} & & \\
\hline Residual (within columns) & 2,408 & \multicolumn{2}{|c|}{240,1003} & & \\
\hline Total & 2,784 & 27 & & & \\
\hline Tukey's Multiple Comparison Test & Mean Diff. & q & Significant & Summary & $95 \% \mathrm{Cl}$ of diff \\
\hline MMP-2 (4 semanas) vs proMMP-2 (4 semanas) & $-0,1272$ & 1,062 & No & ns & -0.5942 to 0.3399 \\
\hline MMP-2 (4 semanas) vs MMP-2 (6 semanas) & $-0,1915$ & 1,599 & No & ns & -0.6585 to 0.2755 \\
\hline MMP-2 (4 semanas) vs proMMP-2 (6 semanas) & $-0,3213$ & 2,684 & No & ns & -0.7883 to 0.1457 \\
\hline proMMP-2 (4 semanas) vs MMP-2 (6 semanas) & $-0,06433$ & 0,5373 & No & ns & -0.5314 to 0.4027 \\
\hline proMMP-2 (4 semanas) vs proMMP-2 (6 semanas) & $-0,1941$ & 1,622 & No & ns & -0.6612 to 0.2729 \\
\hline MMP-2 (6 semanas) vs proMMP-2 (6 semanas) & $-0,1298$ & 1,084 & No & ns & -0.5968 to 0.3372 \\
\hline
\end{tabular}

Grupo 3 (MMP-2 e proMMP-2), análise entre os tempos 


\begin{tabular}{|c|c|c|c|c|c|}
\hline Table Analyzed & Data 1 & & & & \\
\hline \multicolumn{6}{|l|}{ One-way analysis of variance } \\
\hline$P$ value & 0,0735 & & & & \\
\hline$P$ value summary & ns & & & & \\
\hline Are means signif. different? $(P<0.05)$ & No & & & & \\
\hline Number of groups & 4 & & & & \\
\hline $\mathrm{F}$ & 2,627 & & & & \\
\hline R squared & 0,2472 & & & & \\
\hline \multicolumn{6}{|l|}{ Bartlett's test for equal variances } \\
\hline Bartlett's statistic (corrected) & 2,339 & & & & \\
\hline$P$ value & 0,5051 & & & & \\
\hline$P$ value summary & ns & & & & \\
\hline Do the variances differ signif. $(P<0.05)$ & No & & & & \\
\hline ANOVA Table & SS & df & MS & & \\
\hline Treatment (between columns) & 0,1601 & & 0,05336 & & \\
\hline Residual (within columns) & 0,4876 & & 0,02032 & & \\
\hline Total & 0,6477 & 27 & & & \\
\hline Tukey's Multiple Comparison Test & Mean Diff. & $q$ & Significant & Summary & $95 \% \mathrm{Cl}$ of diff \\
\hline MMP-2 (4 semanas) vs proMMP-2 (4 semanas) & 0,02603 & 0,4831 & No & ns & -0.1841 to 0.2362 \\
\hline MMP-2 (4 semanas) vs MMP-2 ( 6 semanas) & 0,08947 & 1,661 & No & ns & -0.1207 to 0.2996 \\
\hline MMP-2 (4 semanas) vs proMMP-2 (6 semanas) & 0,1961 & 3,640 & No & ns & -0.01403 to 0.4063 \\
\hline proMMP-2 (4 semanas) vs MMP-2 ( 6 semanas) & 0,06344 & 1,178 & No & ns & -0.1467 to 0.2736 \\
\hline proMMP-2 (4 semanas) vs proMMP-2 (6 semanas) & 0,1701 & 3,157 & No & ns & -0.04006 to 0.3803 \\
\hline MMP-2 (6 semanas) vs proMMP-2 (6 semanas) & 0,1067 & 1,980 & No & ns & -0.1035 to 0.3168 \\
\hline
\end{tabular}

Grupo 4 (MMP-2 e proMMP-2), análise entre os tempos 


\begin{tabular}{|c|c|c|c|c|c|}
\hline Table Analyzed & Data 1 & & & & \\
\hline \multicolumn{6}{|l|}{ One-way analysis of variance } \\
\hline$P$ value & 0,1665 & & & & \\
\hline$P$ value summary & ns & & & & \\
\hline Are means signif. different? $(P<0.05)$ & No & & & & \\
\hline Number of groups & 4 & & & & \\
\hline $\mathrm{F}$ & 1,842 & & & & \\
\hline R squared & 0,1872 & & & & \\
\hline \multicolumn{6}{|l|}{ Bartlett's test for equal variances } \\
\hline Bartlett's statistic (corrected) & 2,748 & & & & \\
\hline$P$ value & 0,4322 & & & & \\
\hline$P$ value summary & ns & & & & \\
\hline Do the variances differ signif. $(P<0.05)$ & No & & & & \\
\hline ANOVA Table & SS & df & MS & & \\
\hline Treatment (between columns) & 0,3550 & & 30,1183 & & \\
\hline Residual (within columns) & 1,542 & & 40,06424 & & \\
\hline Total & 1,897 & 27 & & & \\
\hline Tukey's Multiple Comparison Test & Mean Diff. & q & Significant & Summary & $95 \% \mathrm{Cl}$ of diff \\
\hline MMP-2 (4 semanas) vs proMMP-2 (4 semanas) & $-0,07511$ & 0,7840 & No & ns & -0.4488 to 0.2986 \\
\hline MMP-2 (4 semanas) vs MMP-2 (6 semanas) & 0,05014 & 0,5234 & No & ns & -0.3236 to 0.4239 \\
\hline MMP-2 (4 semanas) vs proMMP-2 (6 semanas) & 0,2305 & 2,406 & No & ns & -0.1432 to 0.6042 \\
\hline proMMP-2 (4 semanas) vs MMP-2 (6 semanas) & 0,1253 & 1,307 & No & ns & -0.2485 to 0.4990 \\
\hline proMMP-2 (4 semanas) vs proMMP-2 (6 semanas) & 0,3056 & 3,190 & No & ns & -0.06812 to 0.6793 \\
\hline MMP-2 (6 semanas) vs proMMP-2 (6 semanas) & 0,1803 & 1,882 & No & ns & -0.1934 to 0.5541 \\
\hline
\end{tabular}

Grupo 5 (MMP-2 e proMMP-2), análise entre tempos 


\begin{tabular}{|c|c|c|c|c|c|}
\hline Table Analyzed & Data 1 & & & & \\
\hline \multicolumn{6}{|l|}{ One-way analysis of variance } \\
\hline$P$ value & 0,6166 & & & & \\
\hline$P$ value summary & ns & & & & \\
\hline Are means signif. different? $(P<0.05)$ & No & & & & \\
\hline Number of groups & 4 & & & & \\
\hline $\mathrm{F}$ & 0,6075 & & & & \\
\hline R squared & 0,07058 & & & & \\
\hline \multicolumn{6}{|l|}{ Bartlett's test for equal variances } \\
\hline Bartlett's statistic (corrected) & 0,6746 & & & & \\
\hline$P$ value & 0,8792 & & & & \\
\hline$P$ value summary & ns & & & & \\
\hline Do the variances differ signif. $(P<0.05)$ & No & & & & \\
\hline ANOVA Table & SS & df & MS & & \\
\hline Treatment (between columns) & 0,1344 & & 30,04479 & & \\
\hline Residual (within columns) & 1,769 & & 240,07373 & & \\
\hline Total & 1,904 & & 27 & & \\
\hline Tukey's Multiple Comparison Test & Mean Diff. & q & \multicolumn{2}{|c|}{ Significant Summary } & $95 \% \mathrm{Cl}$ of diff \\
\hline MMP-2 (4 semanas) vs proMMP-2 (4 semanas) & 0,0009018 & 30,008787 & No & ns & -0.3994 to 0.4012 \\
\hline MMP-2 (4 semanas) vs MMP-2 (6 semanas) & $-0,1282$ & 1,249 & No & ns & -0.5286 to 0.2721 \\
\hline MMP-2 (4 semanas) vs proMMP-2 ( 6 semanas) & $-0,1467$ & 1,430 & No & ns & -0.5471 to 0.2536 \\
\hline proMMP-2 (4 semanas) vs MMP-2 ( 6 semanas) & $-0,1291$ & 1,258 & No & ns & -0.5295 to 0.2712 \\
\hline proMMP-2 (4 semanas) vs proMMP-2 (6 semanas) & $-0,1476$ & 1,439 & No & ns & -0.5480 to 0.2527 \\
\hline MMP-2 (6 semanas) vs proMMP-2 ( 6 semanas) & $-0,01853$ & 0,1806 & No & ns & -0.4189 to 0.3818 \\
\hline
\end{tabular}

Grupo 6 (MMP-2 e proMMP-2), análise entre tempos 


\begin{tabular}{|c|c|c|c|c|c|}
\hline Table Analyzed & Data 1 & & & & \\
\hline \multicolumn{6}{|l|}{ One-way analysis of variance } \\
\hline$P$ value & 0,7176 & & & & \\
\hline$P$ value summary & ns & & & & \\
\hline Are means signif. different? $(\mathrm{P}<0.05)$ & No & & & & \\
\hline Number of groups & 4 & & & & \\
\hline $\mathrm{F}$ & 0,4529 & & & & \\
\hline R squared & 0,05358 & & & & \\
\hline \multicolumn{6}{|l|}{ Bartlett's test for equal variances } \\
\hline Bartlett's statistic (corrected) & 1,527 & & & & \\
\hline$P$ value & 0,6761 & & & & \\
\hline$P$ value summary & ns & & & & \\
\hline Do the variances differ signif. $(P<0.05)$ & No & & & & \\
\hline ANOVA Table & SS & df & MS & & \\
\hline Treatment (between columns) & 0,1621 & \multicolumn{2}{|c|}{30,05403} & & \\
\hline Residual (within columns) & 2,863 & \multicolumn{2}{|c|}{240,1193} & & \\
\hline Total & 3,025 & 27 & & & \\
\hline Tukey's Multiple Comparison Test & Mean Diff. & q & Significant & Summary & $95 \% \mathrm{Cl}$ of diff \\
\hline MMP-2 (4 semanas) vs proMMP-2 (4 semanas) & $-0,1100$ & 0,8424 & No & ns & -0.6193 to 0.3993 \\
\hline MMP-2 (4 semanas) vs MMP-2 (6 semanas) & $-0,1479$ & 1,133 & No & ns & -0.6572 to 0.3613 \\
\hline MMP-2 (4 semanas) vs proMMP-2 (6 semanas) & $-0,2090$ & 1,601 & No & ns & -0.7183 to 0.3003 \\
\hline proMMP-2 (4 semanas) vs MMP-2 (6 semanas) & $-0,03797$ & 0,2909 & No & ns & -0.5473 to 0.4713 \\
\hline proMMP-2 (4 semanas) vs proMMP-2 (6 semanas) & $-0,09901$ & 0,7584 & No & ns & -0.6083 to 0.4103 \\
\hline MMP-2 (6 semanas) vs proMMP-2 (6 semanas) & $-0,06104$ & 0,4676 & No & ns & -0.5703 to 0.4482 \\
\hline
\end{tabular}

Grupo 7 (MMP-2 e proMMP-2), análise entre tempos 


\begin{tabular}{|c|c|c|c|c|c|}
\hline Table Analyzed & Data 1 & & & & \\
\hline \multicolumn{6}{|l|}{ One-way analysis of variance } \\
\hline$P$ value & 0,7308 & & & & \\
\hline$P$ value summary & ns & & & & \\
\hline Are means signif. different? $(P<0.05)$ & No & & & & \\
\hline Number of groups & 4 & & & & \\
\hline $\mathrm{F}$ & 0,4337 & & & & \\
\hline R squared & 0,05142 & & & & \\
\hline \multicolumn{6}{|l|}{ Bartlett's test for equal variances } \\
\hline Bartlett's statistic (corrected) & 12,29 & & & & \\
\hline$P$ value & 0,0065 & & & & \\
\hline$P$ value summary & ** & & & & \\
\hline Do the variances differ signif. $(P<0.05)$ & Yes & & & & \\
\hline ANOVA Table & SS & df & \multirow{2}{*}{30,01372} & & \\
\hline Treatment (between columns) & 0,04115 & & & & \\
\hline Residual (within columns) & 0,7591 & & 240,03163 & & \\
\hline Total & 0,8003 & & 27 & & \\
\hline Tukey's Multiple Comparison Test & Mean Diff. & $q$ & \multicolumn{2}{|c|}{ Significant Summary } & $95 \% \mathrm{Cl}$ of diff \\
\hline MMP-2 (4 semanas) vs proMMP-2 (4 semanas) & 0,03883 & 0,5776 & No & ns & -0.2234 to 0.3011 \\
\hline MMP-2 (4 semanas) vs MMP-2 (6 semanas) & $-0,004919$ & 0,07317 & No & ns & -0.2671 to 0.2573 \\
\hline MMP-2 (4 semanas) vs proMMP-2 (6 semanas) & $-0,06812$ & 1,013 & No & ns & -0.3303 to 0.1941 \\
\hline proMMP-2 (4 semanas) vs MMP-2 (6 semanas) & $-0,04375$ & 0,6508 & No & ns & -0.3060 to 0.2185 \\
\hline proMMP-2 (4 semanas) vs proMMP-2 (6 semanas) & $-0,1069$ & 1,591 & No & ns & -0.3692 to 0.1553 \\
\hline MMP-2 (6 semanas) vs proMMP-2 (6 semanas) & $-0,06320$ & 0,9402 & No & ns & -0.3254 to 0.1990 \\
\hline
\end{tabular}

Grupo 8 (MMP-2 e proMMP-2), análise entre tempos 


\begin{tabular}{|c|c|c|c|c|c|}
\hline Table Analyzed & Data 1 & & & & \\
\hline \multicolumn{6}{|l|}{ One-way analysis of variance } \\
\hline$P$ value & 0,3118 & & & & \\
\hline$P$ value summary & ns & & & & \\
\hline Are means signif. different? $(P<0.05)$ & No & & & & \\
\hline Number of groups & 4 & & & & \\
\hline $\mathrm{F}$ & 1,256 & & & & \\
\hline R squared & 0,1357 & & & & \\
\hline \multicolumn{6}{|l|}{ Bartlett's test for equal variances } \\
\hline Bartlett's statistic (corrected) & 4,252 & & & & \\
\hline$P$ value & 0,2355 & & & & \\
\hline$P$ value summary & ns & & & & \\
\hline Do the variances differ signif. $(P<0.05)$ & No & & & & \\
\hline ANOVA Table & SS & df & MS & & \\
\hline Treatment (between columns) & 0,2251 & & 0,07504 & & \\
\hline Residual (within columns) & 1,434 & 24 & 0,05976 & & \\
\hline Total & 1,659 & 27 & & & \\
\hline Tukey's Multiple Comparison Test & Mean Diff. & q & Significant & Summary & $95 \% \mathrm{Cl}$ of diff \\
\hline MMP-9 (4 semanas) vs proMMP-9 (4 semanas) & 0,1067 & 1,155 & No & ns & -0.2537 to 0.4672 \\
\hline MMP-9 (4 semanas) vs MMP-9 (6 semanas) & 0,2249 & 2,434 & No & ns & -0.1355 to 0.5853 \\
\hline MMP-9 (4 semanas) vs proMMP-9 (6 semanas) & 0,01496 & 0,1619 & No & ns & -0.3455 to 0.3754 \\
\hline proMMP-9 (4 semanas) vs MMP-9 (6 semanas) & 0,1182 & 1,279 & No & ns & -0.2423 to 0.4786 \\
\hline proMMP-9 (4 semanas) vs proMMP-9 (6 semanas) & $-0,09176$ & 0,9932 & No & ns & -0.4522 to 0.2687 \\
\hline MMP-9 (6 semanas) vs proMMP-9 (6 semanas) & $-0,2099$ & 2,272 & No & ns & -0.5704 to 0.1505 \\
\hline
\end{tabular}

Grupo 1 (MMP-9 e proMMP-9), análise entre tempos 


\begin{tabular}{|c|c|c|c|c|c|}
\hline Table Analyzed & Data 1 & & & & \\
\hline \multicolumn{6}{|l|}{ One-way analysis of variance } \\
\hline$P$ value & 0,3730 & & & & \\
\hline$P$ value summary & ns & & & & \\
\hline Are means signif. different? $(P<0.05)$ & No & & & & \\
\hline Number of groups & 4 & & & & \\
\hline $\mathrm{F}$ & 1,088 & & & & \\
\hline R squared & 0,1198 & & & & \\
\hline \multicolumn{6}{|l|}{ Bartlett's test for equal variances } \\
\hline Bartlett's statistic (corrected) & 6,326 & & & & \\
\hline$P$ value & 0,0968 & & & & \\
\hline$P$ value summary & ns & & & & \\
\hline Do the variances differ signif. $(P<0.05)$ & No & & & & \\
\hline ANOVA Table & SS & df & MS & & \\
\hline Treatment (between columns) & 0,2655 & & 0,08849 & & \\
\hline Residual (within columns) & 1,951 & 24 & 0,08130 & & \\
\hline Total & 2,217 & 27 & & & \\
\hline Tukey's Multiple Comparison Test & Mean Diff. & q & Significant & Summary & $95 \% \mathrm{Cl}$ of diff \\
\hline MMP-9 (4 semanas) vs proMMP-9 (4 semanas) & 0,1323 & 1,227 & No & ns & -0.2881 to 0.5527 \\
\hline MMP-9 (4 semanas) vs MMP-9 (6 semanas) & 0,2748 & 2,550 & No & ns & -0.1456 to 0.6953 \\
\hline MMP-9 (4 semanas) vs proMMP-9 (6 semanas) & 0,1222 & 1,134 & No & ns & -0.2982 to 0.5426 \\
\hline proMMP-9 (4 semanas) vs MMP-9 (6 semanas) & 0,1426 & 1,323 & No & ns & -0.2779 to 0.5630 \\
\hline proMMP-9 (4 semanas) vs proMMP-9 (6 semanas) & $-0,01007$ & 0,09343 & No & ns & -0.4305 to 0.4103 \\
\hline MMP-9 (6 semanas) vs proMMP-9 (6 semanas) & $-0,1526$ & 1,416 & No & ns & -0.5730 to 0.2678 \\
\hline
\end{tabular}

Grupo 2 (MMP-9 e proMMP-9), análise entre tempos 


\begin{tabular}{|c|c|c|c|c|c|}
\hline Table Analyzed & Data 1 & & & & \\
\hline \multicolumn{6}{|l|}{ One-way analysis of variance } \\
\hline$P$ value & 0,9673 & & & & \\
\hline$P$ value summary & ns & & & & \\
\hline Are means signif. different? $(P<0.05)$ & No & & & & \\
\hline Number of groups & 4 & & & & \\
\hline $\mathrm{F}$ & 0,08549 & & & & \\
\hline R squared & 0,01057 & & & & \\
\hline \multicolumn{6}{|l|}{ Bartlett's test for equal variances } \\
\hline Bartlett's statistic (corrected) & 2,488 & & & & \\
\hline$P$ value & 0,4774 & & & & \\
\hline$P$ value summary & ns & & & & \\
\hline Do the variances differ signif. $(P<0.05)$ & No & & & & \\
\hline ANOVA Table & SS & df & MS & & \\
\hline Treatment (between columns) & 0,02200 & & 0,007332 & & \\
\hline Residual (within columns) & 2,059 & & 0,08577 & & \\
\hline Total & 2,081 & 27 & & & \\
\hline Tukey's Multiple Comparison Test & Mean Diff. & $q$ & Significant & t Summary & $95 \% \mathrm{Cl}$ of diff \\
\hline MMP-9 (4 semanas) vs proMMP-9 (4 semanas) & $-0,07824$ & 0,7068 & No & ns & -0.5101 to 0.3536 \\
\hline MMP-9 (4 semanas) vs MMP-9 (6 semanas) & $-0,02971$ & 0,2684 & No & ns & -0.4615 to 0.4021 \\
\hline MMP-9 (4 semanas) vs proMMP-9 (6 semanas) & $-0,03050$ & 0,2756 & No & ns & -0.4623 to 0.4013 \\
\hline proMMP-9 (4 semanas) vs MMP-9 (6 semanas) & 0,04853 & 0,4384 & No & ns & -0.3833 to 0.4803 \\
\hline proMMP-9 (4 semanas) vs proMMP-9 (6 semanas) & 0,04774 & 0,4313 & No & ns & -0.3841 to 0.4796 \\
\hline MMP-9 (6 semanas) vs proMMP-9 ( 6 semanas) & $-0,000791$ & :0,007149 & No & ns & -0.4326 to 0.4310 \\
\hline
\end{tabular}

Grupo 3 (MMP-9 e proMMP-9), análise entre tempos 


\begin{tabular}{|c|c|c|c|c|c|}
\hline Table Analyzed & Data 1 & & & & \\
\hline \multicolumn{6}{|l|}{ One-way analysis of variance } \\
\hline$P$ value & 0,1642 & & & & \\
\hline$P$ value summary & ns & & & & \\
\hline Are means signif. different? $(P<0.05)$ & No & & & & \\
\hline Number of groups & 4 & & & & \\
\hline $\mathrm{F}$ & 1,855 & & & & \\
\hline R squared & 0,1882 & & & & \\
\hline \multicolumn{6}{|l|}{ Bartlett's test for equal variances } \\
\hline Bartlett's statistic (corrected) & 3,377 & & & & \\
\hline$P$ value & 0,3371 & & & & \\
\hline$P$ value summary & ns & & & & \\
\hline Do the variances differ signif. $(P<0.05)$ & No & & & & \\
\hline ANOVA Table & SS & df & MS & & \\
\hline Treatment (between columns) & 0,2747 & & 0,09156 & & \\
\hline Residual (within columns) & 1,185 & 24 & 0,04936 & & \\
\hline Total & 1,459 & 27 & & & \\
\hline Tukey's Multiple Comparison Test & Mean Diff. & q & Significant & Summary & $95 \% \mathrm{Cl}$ of diff \\
\hline MMP-9 (4 semanas) vs proMMP-9 (4 semanas) & 0,02185 & 0,2602 & No & ns & -0.3057 to 0.3494 \\
\hline MMP-9 (4 semanas) vs MMP-9 (6 semanas) & 0,2392 & 2,849 & No & ns & -0.08838 to 0.5668 \\
\hline MMP-9 (4 semanas) vs proMMP-9 (6 semanas) & 0,01160 & 0,1381 & No & ns & -0.3160 to 0.3392 \\
\hline proMMP-9 (4 semanas) vs MMP-9 (6 semanas) & 0,2173 & 2,588 & No & ns & -0.1102 to 0.5449 \\
\hline proMMP-9 (4 semanas) vs proMMP-9 (6 semanas) & $-0,01025$ & 0,1220 & No & ns & -0.3378 to 0.3173 \\
\hline MMP-9 (6 semanas) vs proMMP-9 (6 semanas) & $-0,2276$ & 2,710 & No & ns & -0.5552 to 0.09998 \\
\hline
\end{tabular}

Grupo 4 (MMP-9 e proMMP-9), análise entre tempos 


\begin{tabular}{|c|c|c|c|c|c|}
\hline Table Analyzed & Data 1 & & & & \\
\hline \multicolumn{6}{|l|}{ One-way analysis of variance } \\
\hline$P$ value & 0,5832 & & & & \\
\hline$P$ value summary & ns & & & & \\
\hline Are means signif. different? $(P<0.05)$ & No & & & & \\
\hline Number of groups & 4 & & & & \\
\hline $\mathrm{F}$ & 0,6624 & & & & \\
\hline R squared & 0,07647 & & & & \\
\hline \multicolumn{6}{|l|}{ Bartlett's test for equal variances } \\
\hline Bartlett's statistic (corrected) & 1,094 & & & & \\
\hline$P$ value & 0,7785 & & & & \\
\hline$P$ value summary & ns & & & & \\
\hline Do the variances differ signif. $(P<0.05)$ & No & & & & \\
\hline ANOVA Table & SS & df & MS & & \\
\hline Treatment (between columns) & 0,1017 & & 0,03389 & & \\
\hline Residual (within columns) & 1,228 & 24 & 0,05116 & & \\
\hline Total & 1,329 & 27 & & & \\
\hline Tukey's Multiple Comparison Test & Mean Diff. & q & Significant & Summary & $95 \% \mathrm{Cl}$ of diff \\
\hline MMP-9 (4 semanas) vs proMMP-9 (4 semanas) & $-0,07731$ & 0,9044 & No & ns & -0.4108 to 0.2562 \\
\hline MMP-9 (4 semanas) vs MMP-9 (6 semanas) & 0,06454 & 0,7549 & No & ns & -0.2689 to 0.3980 \\
\hline MMP-9 (4 semanas) vs proMMP-9 (6 semanas) & $-0,08116$ & 0,9494 & No & ns & -0.4147 to 0.2523 \\
\hline proMMP-9 (4 semanas) vs MMP-9 (6 semanas) & 0,1418 & 1,659 & No & ns & -0.1916 to 0.4753 \\
\hline proMMP-9 (4 semanas) vs proMMP-9 (6 semanas) & $-0,003851$ & 0,04504 & No & ns & -0.3373 to 0.3296 \\
\hline MMP-9 (6 semanas) vs proMMP-9 (6 semanas) & $-0,1457$ & 1,704 & No & ns & -0.4792 to 0.1878 \\
\hline
\end{tabular}

Grupo 5 (MMP-9 e proMMP-9), análise entre tempos 


\begin{tabular}{|c|c|c|c|c|c|}
\hline Table Analyzed & Data 1 & & & & \\
\hline \multicolumn{6}{|l|}{ One-way analysis of variance } \\
\hline$P$ value & 0,7368 & & & & \\
\hline$P$ value summary & ns & & & & \\
\hline Are means signif. different? $(P<0.05)$ & No & & & & \\
\hline Number of groups & 4 & & & & \\
\hline $\mathrm{F}$ & 0,4250 & & & & \\
\hline R squared & 0,05045 & & & & \\
\hline \multicolumn{6}{|l|}{ Bartlett's test for equal variances } \\
\hline Bartlett's statistic (corrected) & 0,5037 & & & & \\
\hline$P$ value & 0,9181 & & & & \\
\hline$P$ value summary & ns & & & & \\
\hline Do the variances differ signif. $(P<0.05)$ & No & & & & \\
\hline ANOVA Table & SS & df & MS & & \\
\hline Treatment (between columns) & 0,06619 & & 0,02206 & & \\
\hline Residual (within columns) & 1,246 & 24 & 0,05191 & & \\
\hline Total & 1,312 & 27 & & & \\
\hline Tukey's Multiple Comparison Test & Mean Diff. & q & Significant & Summary & $95 \% \mathrm{Cl}$ of diff \\
\hline MMP-9 (4 semanas) vs proMMP-9 (4 semanas) & $-0,009118$ & 0,1059 & No & ns & -0.3451 to 0.3268 \\
\hline MMP-9 (4 semanas) vs MMP-9 (6 semanas) & 0,07084 & 0,8226 & No & ns & -0.2651 to 0.4068 \\
\hline MMP-9 (4 semanas) vs proMMP-9 (6 semanas) & 0,1072 & 1,244 & No & ns & -0.2288 to 0.4431 \\
\hline proMMP-9 (4 semanas) vs MMP-9 (6 semanas) & 0,07996 & 0,9285 & No & ns & -0.2560 to 0.4159 \\
\hline proMMP-9 (4 semanas) vs proMMP-9 (6 semanas) & 0,1163 & 1,350 & No & ns & -0.2196 to 0.4522 \\
\hline MMP-9 (6 semanas) vs proMMP-9 (6 semanas) & 0,03633 & 0,4218 & No & ns & -0.2996 to 0.3723 \\
\hline
\end{tabular}

Grupo 6 (MMP-9 e proMMP-9), análise entre tempos 


\begin{tabular}{|c|c|c|c|c|c|}
\hline Table Analyzed & Data 1 & & & & \\
\hline \multicolumn{6}{|l|}{ One-way analysis of variance } \\
\hline$P$ value & 0,8213 & & & & \\
\hline$P$ value summary & ns & & & & \\
\hline Are means signif. different? $(P<0.05)$ & No & & & & \\
\hline Number of groups & 4 & & & & \\
\hline $\mathrm{F}$ & 0,3052 & & & & \\
\hline R squared & 0,03675 & & & & \\
\hline \multicolumn{6}{|l|}{ Bartlett's test for equal variances } \\
\hline Bartlett's statistic (corrected) & 6,088 & & & & \\
\hline$P$ value & 0,1074 & & & & \\
\hline$P$ value summary & ns & & & & \\
\hline Do the variances differ signif. $(P<0.05)$ & No & & & & \\
\hline ANOVA Table & SS & df & MS & & \\
\hline Treatment (between columns) & 0,07162 & & 0,02387 & & \\
\hline Residual (within columns) & 1,877 & 24 & 0,07822 & & \\
\hline Total & 1,949 & 27 & & & \\
\hline Tukey's Multiple Comparison Test & Mean Diff. & q & Significant & Summary & $95 \% \mathrm{Cl}$ of diff \\
\hline MMP-9 (4 semanas) vs proMMP-9 (4 semanas) & 0,01560 & 0,1476 & No & ns & -0.3968 to 0.4280 \\
\hline MMP-9 (4 semanas) vs MMP-9 (6 semanas) & 0,1229 & 1,163 & No & ns & -0.2895 to 0.5353 \\
\hline MMP-9 (4 semanas) vs proMMP-9 (6 semanas) & 0,08742 & 0,8270 & No & ns & -0.3249 to 0.4998 \\
\hline proMMP-9 (4 semanas) vs MMP-9 (6 semanas) & 0,1073 & 1,015 & No & ns & -0.3051 to 0.5197 \\
\hline proMMP-9 (4 semanas) vs proMMP-9 (6 semanas) & 0,07182 & 0,6794 & No & ns & -0.3405 to 0.4842 \\
\hline MMP-9 (6 semanas) vs proMMP-9 (6 semanas) & $-0,03549$ & 0,3357 & No & ns & -0.4478 to 0.3769 \\
\hline
\end{tabular}

Grupo 7 (MMP-9 e proMMP-9), análise entre tempos 


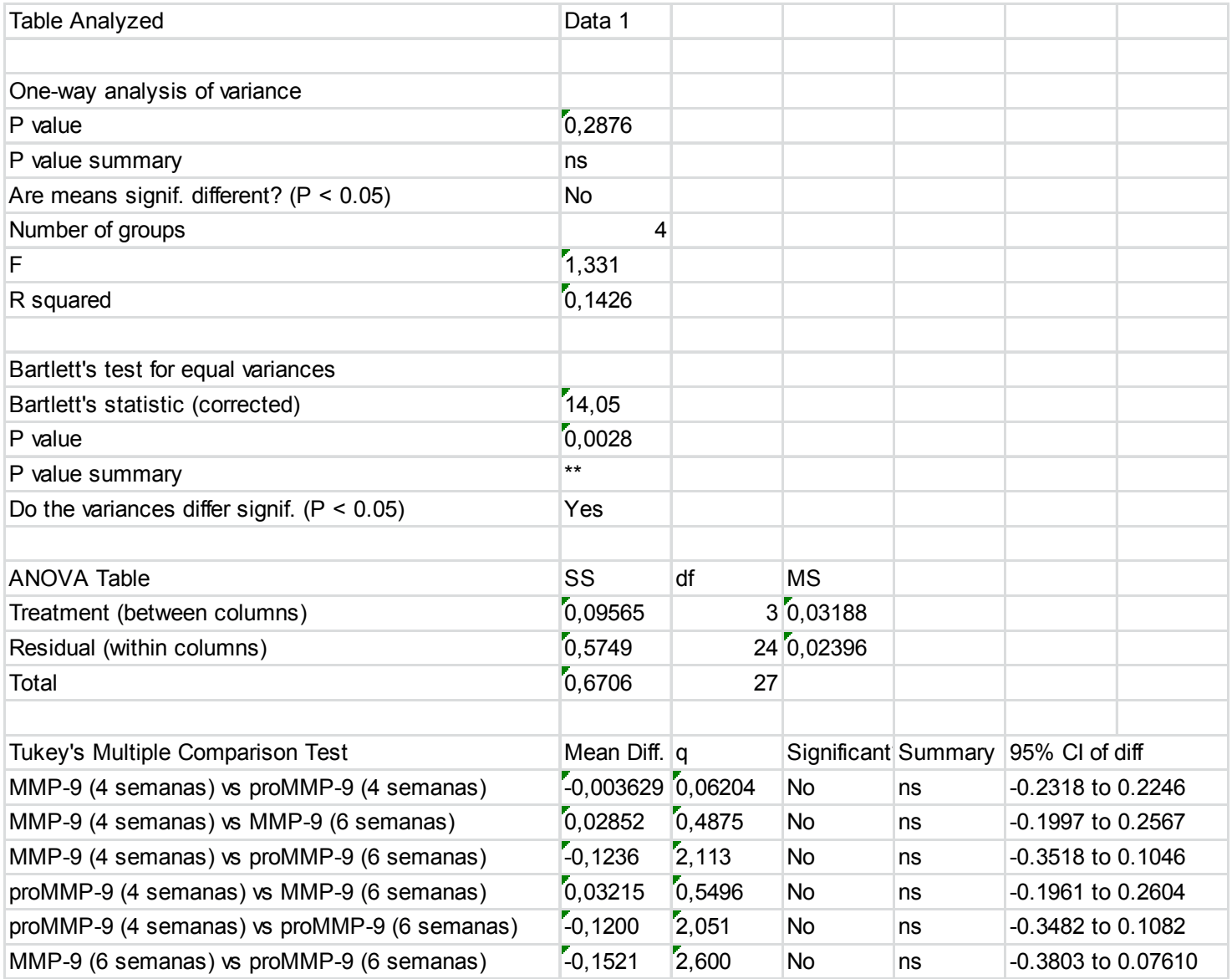

\section{Grupo 8 (MMP-9 e proMMP-9), análise entre tempos}




\begin{tabular}{|c|c|c|c|c|c|c|c|c|}
\hline & GRUPO 1 & GRUPO 2 & GRUPO 3 & GRUPO 4 & GRUPO 5 & GRUPO 6 & GRUPO 7 & GRUPO 8 \\
\hline Number of values & 7 & $\begin{array}{ll}7 & 7\end{array}$ & 7 & 7 & 7 & 7 & 7 & 7 \\
\hline Minimum & 5,717 & 5,161 & 4,926 & 5,612 & 5,813 & 4,412 & 5,449 & 3,878 \\
\hline 25\% Percentile & 5,978 & 5,710 & 5,796 & 5,691 & 5,998 & 5,265 & 6,130 & 4,269 \\
\hline Median & 7,267 & 6,950 & 6,101 & 6,373 & 6,428 & 5,885 & 6,752 & 6,198 \\
\hline 75\% Percentile & 9,672 & 8,353 & 7,009 & 8,209 & 6,915 & 7,745 & 7,696 & 6,844 \\
\hline Maximum & 9,962 & 9,727 & 7,340 & 9,222 & 7,268 & 8,088 & 7,799 & 6,921 \\
\hline Mean & 7,538 & 7,042 & 6,280 & 6,916 & 6,461 & 6,291 & 6,782 & 5,656 \\
\hline Std. Deviation & 1,700 & 1,581 & 0,8550 & 1,365 & 0,5049 & 1,387 & 0,8499 & 1,236 \\
\hline Std. Error & 0,6427 & 0,5975 & 0,3231 & 0,5158 & 0,1908 & 0,5243 & 0,3212 & 0,4673 \\
\hline Lower $95 \% \mathrm{Cl}$ of mean & 5,966 & 5,579 & 5,489 & 5,654 & 5,994 & 5,008 & 5,996 & 4,512 \\
\hline Upper $95 \% \mathrm{Cl}$ of mean & 9,111 & 8,504 & 7,070 & 8,179 & 6,928 & 7,574 & 7,568 & 6,800 \\
\hline \multicolumn{9}{|l|}{ KS normality test } \\
\hline KS distance & 0,1832 & 0,1750 & 0,2098 & 0,2262 & 0,1630 & 0,1864 & 0,1447 & 0,2408 \\
\hline$P$ value & $P>0.10$ & $P>0.10$ & $P>0.10$ & $P>0.10$ & $P>0.10$ & $P>0.10$ & $P>0.10$ & $P>0.10$ \\
\hline Passed normality test (alpha $=0.05) ?$ & Yes & Yes & Yes & Yes & Yes & Yes & Yes & Yes \\
\hline$P$ value summary & ns & ns & ns & ns & ns & ns & ns & ns \\
\hline \multicolumn{9}{|l|}{ Shapiro-Wilk normality test } \\
\hline W & 0,8902 & 0,9568 & 0,9368 & 0,8940 & 0,9718 & 0,9333 & 0,9604 & 0,8862 \\
\hline$P$ value & 0,2756 & 0,7908 & 0,6102 & 0,2961 & 0,9109 & 0,5793 & 0,8219 & 0,2556 \\
\hline Passed normality test (alpha $=0.05) ?$ & Yes & Yes & Yes & Yes & Yes & Yes & Yes & Yes \\
\hline$P$ value summary & ns & ns & ns & ns & ns & ns & ns & ns \\
\hline Sum & 52,77 & 49,29 & 43,96 & 48,42 & 45,23 & 44,04 & 47,47 & 39,59 \\
\hline
\end{tabular}

Teste de normalidade da dosagem de cálcio dos grupos de 4 semanas 


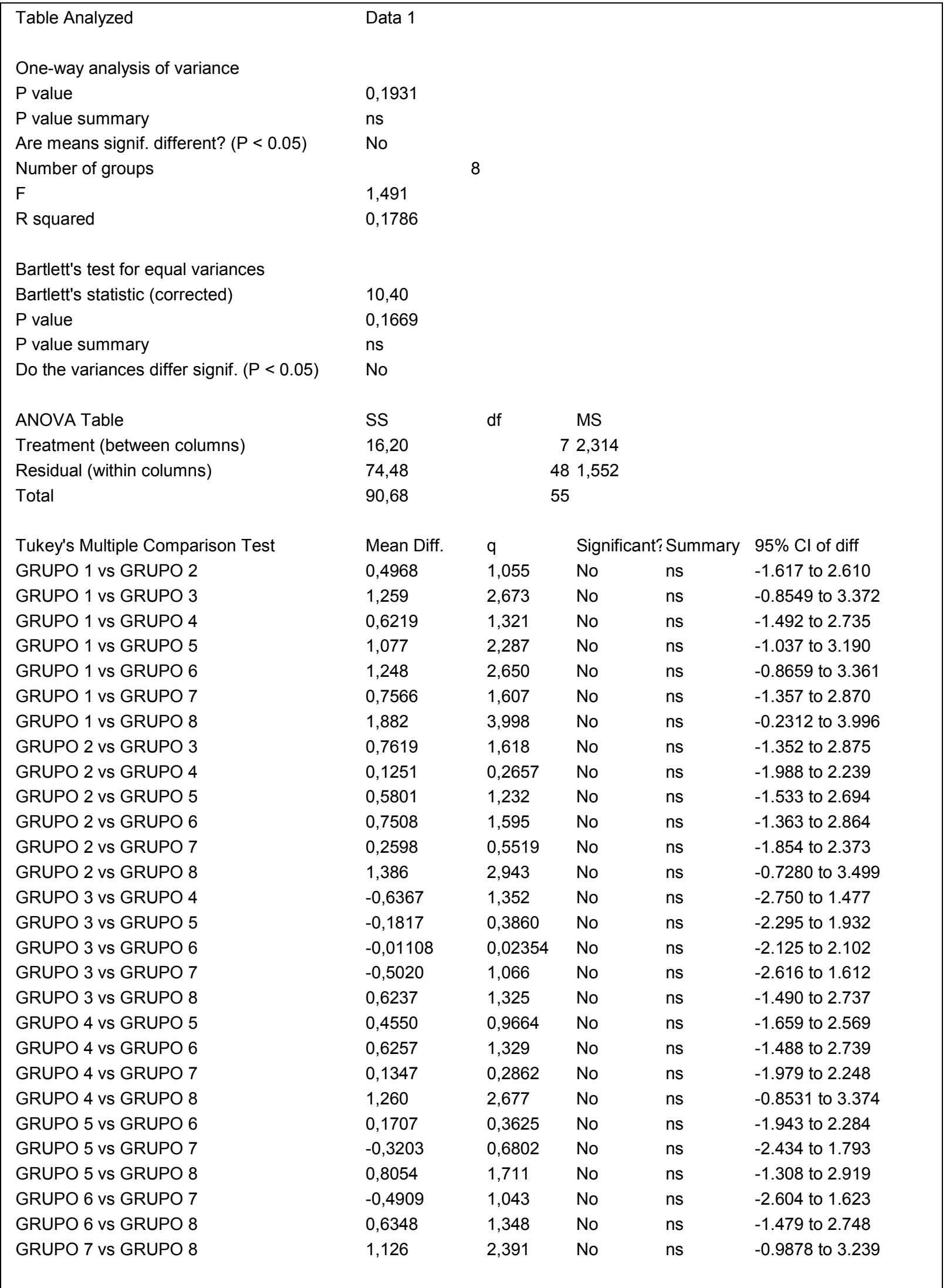

Dosagem de cálcio, tempo de 4 semanas, análise entre os grupos 


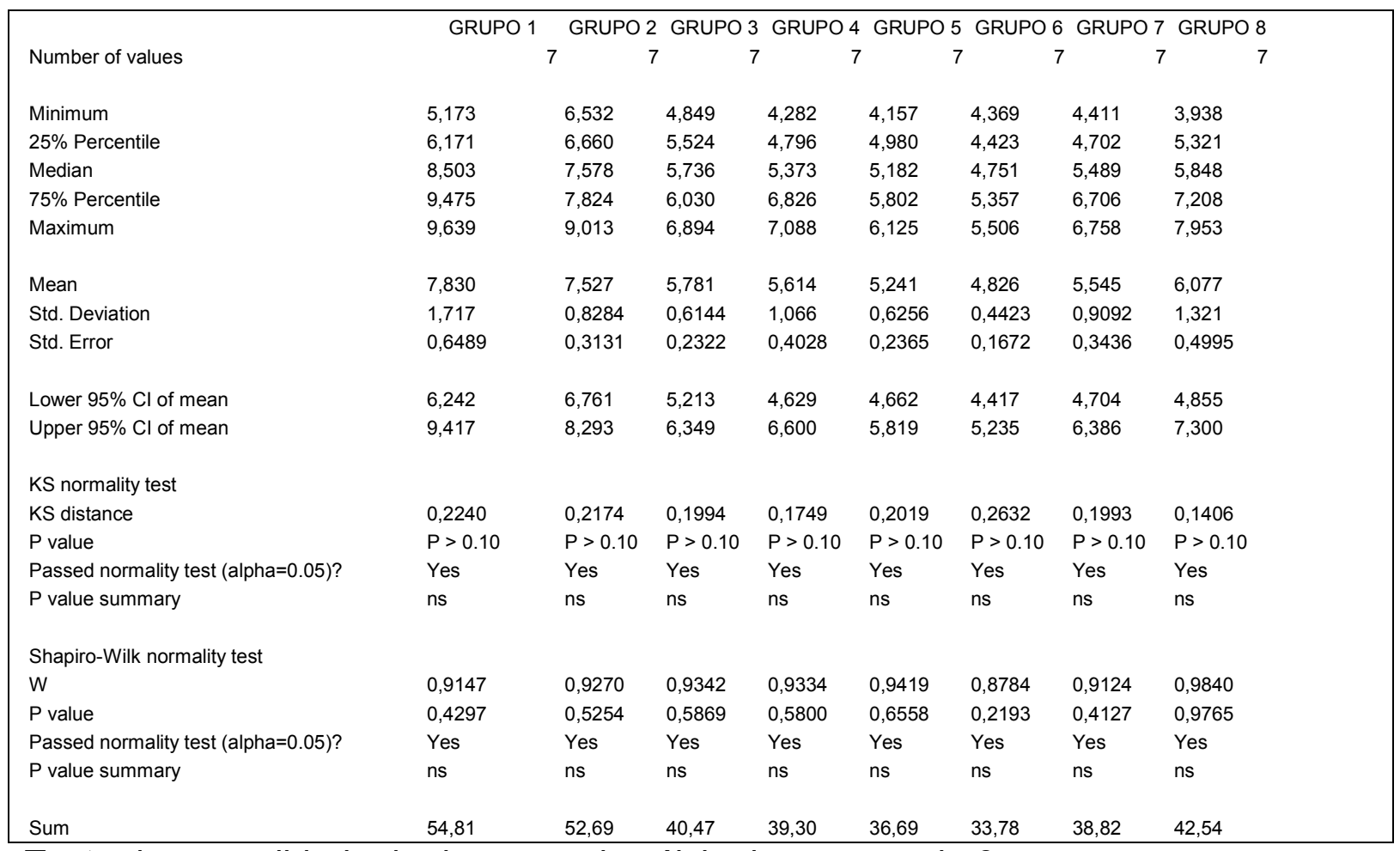

Teste de normalidade da dosagem de cálcio dos grupos de 6 semanas 


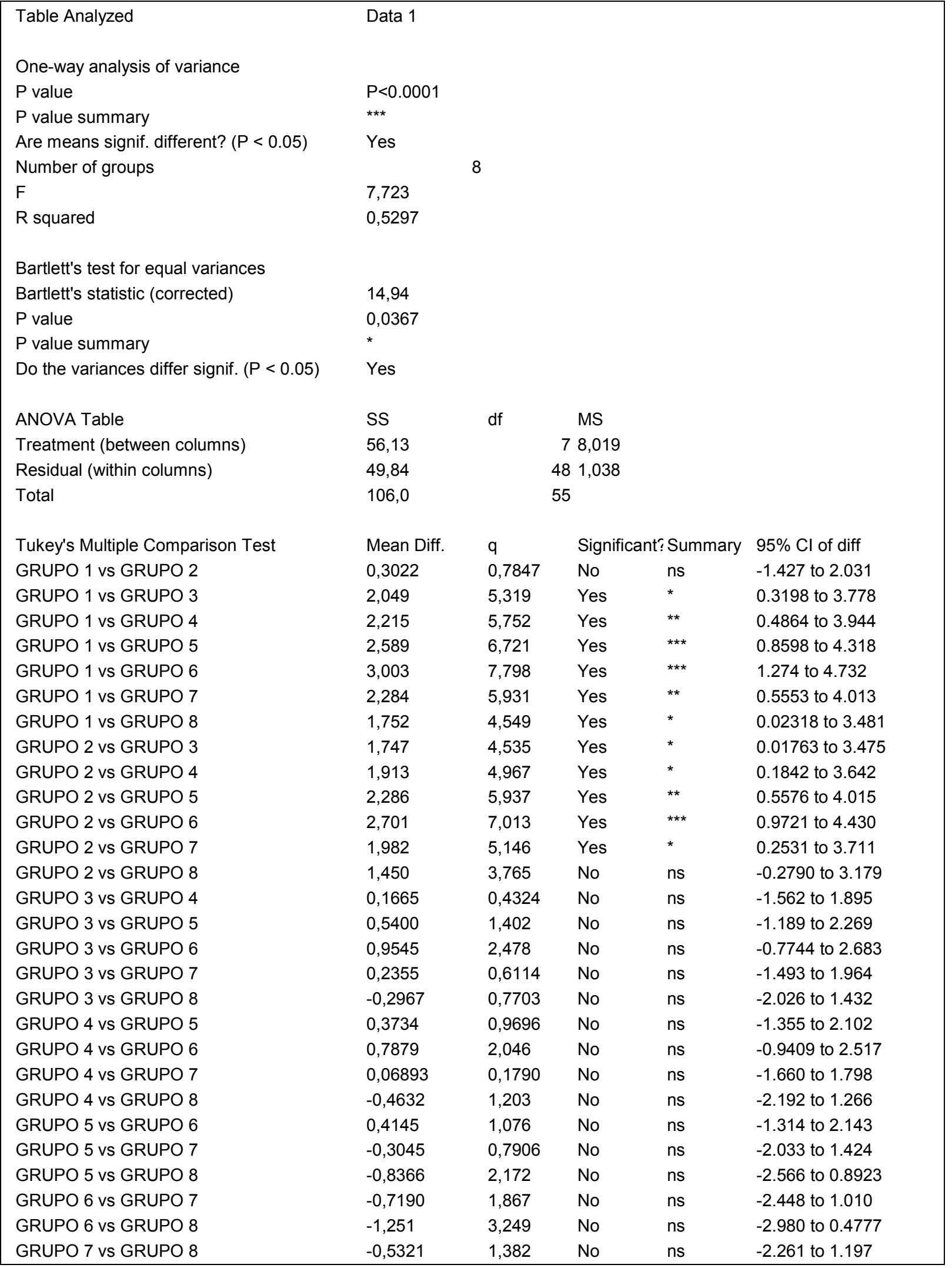

Dosagem de cálcio, tempo de 6 semanas, análise entre os grupos 